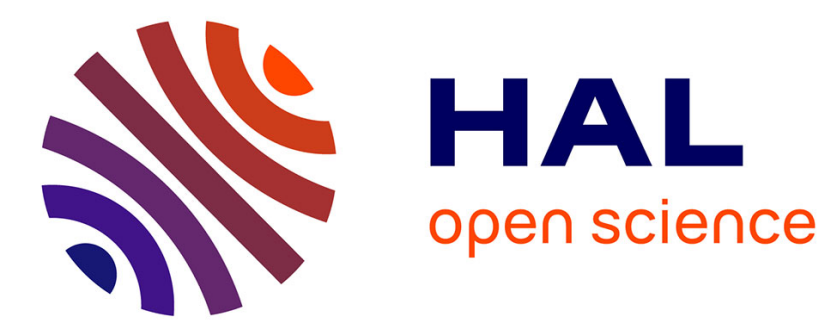

\title{
Silicate Glasses
}

Charles Le Losq, Maria Rita R Cicconi, G. Neville Neville Greaves, Daniel R. Neuville

\section{To cite this version:}

Charles Le Losq, Maria Rita R Cicconi, G. Neville Neville Greaves, Daniel R. Neuville. Silicate Glasses. Springer Handbook of Glass,, pp.441-503, 2019, 10.1007/978-3-319-93728-1_13 . hal-02989604

\section{HAL Id: hal-02989604 https://hal.science/hal-02989604}

Submitted on 24 Nov 2020

HAL is a multi-disciplinary open access archive for the deposit and dissemination of scientific research documents, whether they are published or not. The documents may come from teaching and research institutions in France or abroad, or from public or private research centers.
L'archive ouverte pluridisciplinaire HAL, est destinée au dépôt et à la diffusion de documents scientifiques de niveau recherche, publiés ou non, émanant des établissements d'enseignement et de recherche français ou étrangers, des laboratoires publics ou privés. 
Le Losq, Cicconi, Greaves, Neuville. Silicate Glasses. In: Springer Handbook of Glass.

\section{Springer Hanbook of Glass}

\section{Silicate glasses}

\section{Authors:}

\section{Dr. C. Le Losq ${ }^{1, *}$, Dr. M. R. Cicconi ${ }^{2}$, Prof. G. N. Greaves ${ }^{3,4}$, Dr. D. R. Neuville ${ }^{5}$}

${ }^{1}$ Research School of Earth Sciences, The Australian National University, Building 142, Mills Road, Acton ACT 2601, Australia.*Corresponding author, charles.lelosq@anu.edu.au

${ }^{2}$ Department Werkstoffwissenschaften, Lehrstuhl für Glas und Keramik, Universität Erlangen-Nürnberg, Martensstrasse 5, D-91058 Erlangen, Germany

${ }^{3}$ Department of Mathematics and Physics, Aberystwyth University, Physical Sciences Building, Aberystwyth, Ceredigion, SY23 3BZ, United Kingdom.

${ }^{4}$ University of Cambridge, Department of Materials Science \& Metallurgy, Cambridge CB3 0FS, United Kingdom.

${ }^{5}$ Laboratoire Géomatériaux, CNRS-IPGP UMR 7154, PRES Paris-Sorbonne Cité, 1 rue Jussieu, 75005 Paris, France.

\section{Summary:}

Silicate glasses are important cultural, societal and geological materials. Geologic glasses testify for the igneous activity of the Earth and, for instance, represented important source of tools and ornamental objects during the Paleolithic. Nowadays, silicate glasses are used to build technical materials, such as smartphone screens or glass matrix for stabilizing hazardous radioactive wastes. Therefore, silicate glasses are central to the history of the Earth and of the humanity. The compositional landscape of natural and industrial silicate glasses is vast, with various elements that all influence differently the glass properties and structure. The $\mathrm{SiO}_{4}$ tetrahedral framework, backbone of silicate glasses, is variously influenced by the introduction of network modifier metal cations or network former aluminium cations. Industrial and geologic silicate glasses further contain multivalent elements (e.g., $\left.\mathrm{Fe}^{2+/ 3+}\right)$, rare-earth elements, and volatile elements $(H, C, S, C l, F, I)$ that play different roles on the glass structure and properties. This chapter proposes to review the link between the structure, the properties and the chemical composition of silicate glasses. 
Le Losq, Cicconi, Greaves, Neuville. Silicate Glasses. In: Springer Handbook of Glass.

\section{$\underline{\text { 1.1 Silicate glasses: Historical and industrial importance }}$}

The origin of the first silicate glass is a vast question. The first glass tools actually were manufactured by breakage and date approximately of $10000 \mathrm{BCE}$, as shown by obsidian arrow heads of this age found in Turkey for example. Manufacture of silicate glasses dates back to the earliest antiquity; it follows the control of fire, and is synchronous with the Bronze Age which itself varies geographically. The first objects made by melting date of $\sim 6000$ BCE. Hazard was probably the first factor in this melting manufacturing. Henrivaux [1] proposed that the appearance of glass should be contemporary with the manufacture of bricks cooked by fire and of certain ceramics. Indeed, a plausible hypothesis is that brick and ceramic manufacturers were the first glass manufacturers because various materials subjected to the action of an intense fire may present the first symptoms of vitrification in the form of a veneer or surface glaze. This hypothesis may explain the Mesopotamian glazes observed on several ceramics and located at Suse between 7000 and 5000 BCE. However, this hypothesis contradicts with the story reported by Pline the Elder (23-79 BC). Indeed, in his Natural History [2], Pline reported that it would be Phoenician merchants who, cooking their food on the banks of the river Belus in pots supported by blocks of Natron, would have seen an unknown substance flow:

"The story is, that a ship, laden with nitre, being moored upon this spot, the merchants, while preparing their repast upon the sea-shore, finding no stones at hand for supporting their cauldrons, employed for the purpose some lumps of nitre which they had taken from the vessel. Upon its being subjected to the action of the fire, in combination with the sand of the sea-shore, they beheld transparent streams flowing forth of a liquid hitherto unknown: this, it is said, was the origin of glass"

This observation is unlikely when one knows that temperatures close to $\sim 1000^{\circ} \mathrm{C}$ are necessary to observe the flow of silicate melts, conditions difficult to achieve using campfires. Pliny's account thus probably is a legend, and current historical knowledges suggest that the formation of glass as a byproduct of mettalurgic and ceramic activities is more plausible [e.g., see the review of 3]].

Regardless of the origin of its discovery, glass was considered as precious during the antiquity. This is shown, for instance, by the Hebrew term that designates glass, "כִכִִִית" (pronounced "zkhourhit"), which comes from the Hebrew word "זכך" that means pure. Glass thus remained an expensive material during antiquity. As such, it was reserved for noble objects as jewelry and amulets (Fig. 1), competing with precious metals such as gold or silver for such uses. 
Le Losq, Cicconi, Greaves, Neuville. Silicate Glasses. In: Springer Handbook of Glass.

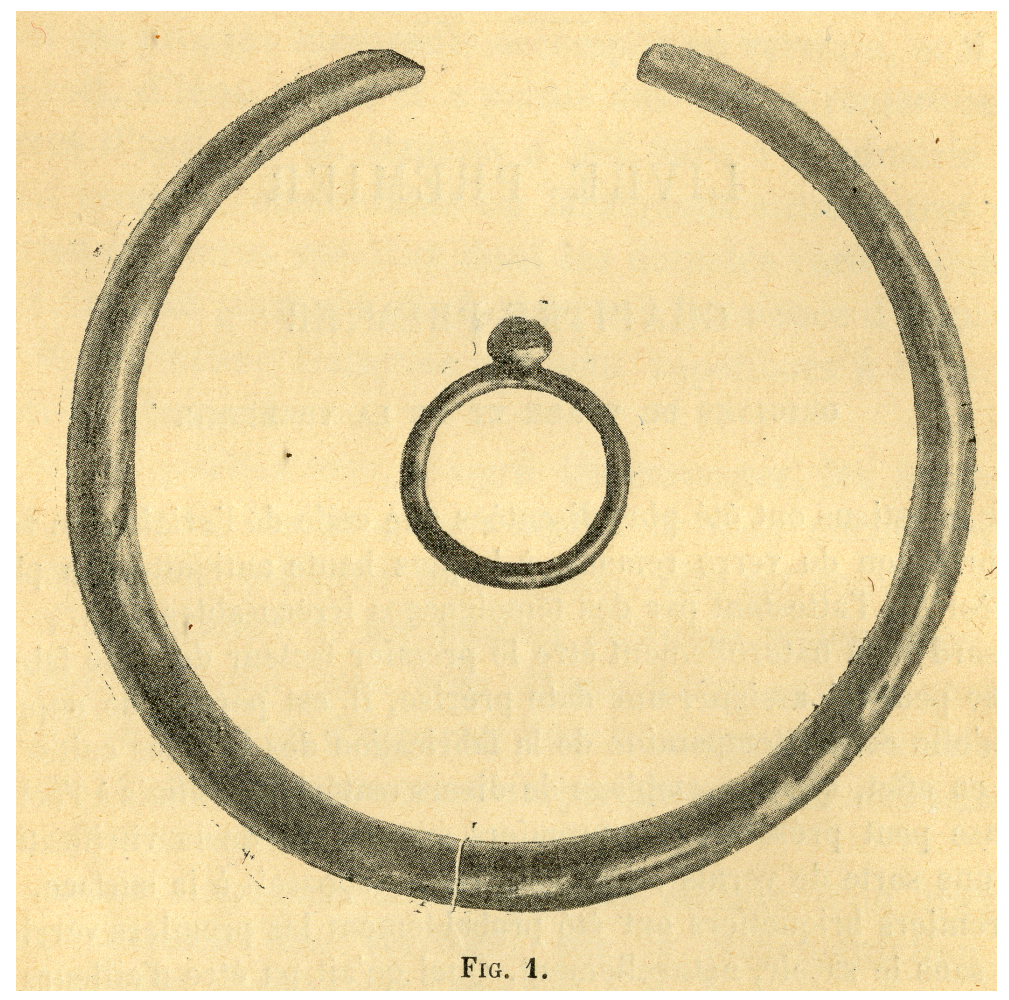

Figure 1: Ring and earring reproduction. Image reproduced from Henrivaux, 1897, "Le Verre et le cristal" Vicq-Dunaud Editors, Paris [1].

From 5000 to $3000 \mathrm{BC}$, objects partly made of glass are characterized by a faience coating placed on the surface of a ceramic material. Then, as the furnaces of the age of bronze and copper appeared, the work of the glass became easier, allowing the manufacture of colored glass bead for instance. Core-molding and cast glass methods, using molds for shaping glass objects, were subsequently developed in the 1500-500 BCE period in Mesopotamia and Egypt. Some sources attribute the invention of glass-blowing to Syrian glassmakers around 300 BCE [e.g., 4], but this disagrees with the representation of glassblowing in Egyptian tombs [5], as for instance in a tomb from the fifth dynasty at Sakkarah or the painting at Beni-Hassan (Fig. 2) that dates from the reign of Usertessen I. (2758-2714 BCE). 
Le Losq, Cicconi, Greaves, Neuville. Silicate Glasses. In: Springer Handbook of Glass.

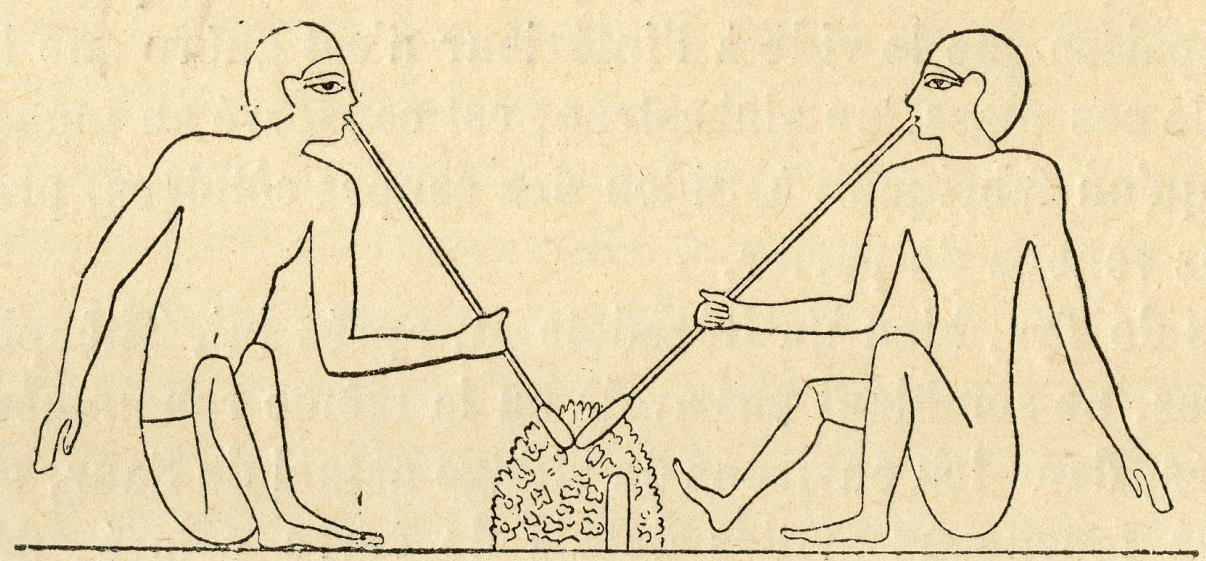

FiG。2.

Figure 2: Representation of Egyptian glassworkers blowing glasses on brazier at Beni-Hassan. Reproduced from Henrivaux (1897) "Le Verre et le cristal” Vicq-Dunaud Editors, Paris [1].

Historical glass compositions are based on the use of silica, lime and soda. The compositions of historical glasses remain in a tight chemical domain. They are still close to those of present glasses (Fig. 3), illustrating that the optimization of glassmaking processes was achieved early in the history of human glass manufacture. An interesting fact is that early glass makers already aimed at controlling the color of translucent or slightly opaque glasses through the addition of metals such as copper (red and blue-red), iron (black, brown and green), antimony (yellow), cobalt (blue) or tin (white). Such coloring substances were already identified and known before the age of glass manufacturing, as several of them were used as pigments [6]. Early glass manufacturers probably had access to raw materials presenting variable quality. Production was therefore subject to many hazards, against which they could only contrast empirical knowledge. 
Le Losq, Cicconi, Greaves, Neuville. Silicate Glasses. In: Springer Handbook of Glass.

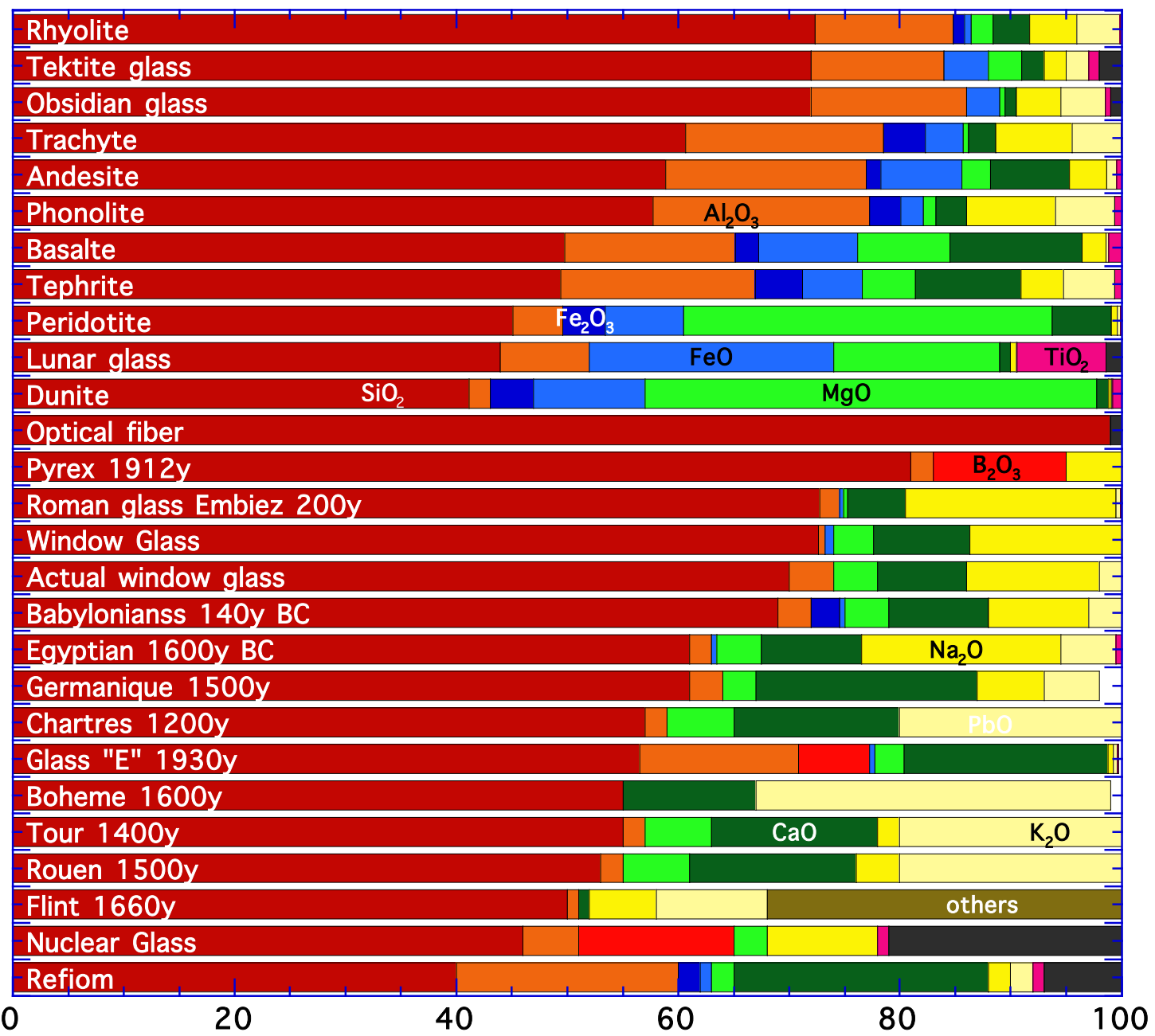

Figure 3: Examples of chemical composition of various geologic (lunar glass, dunite, peridotite, tephrite, basalt, phonolite, andesite, trachyte, rhyolite, tektite, obsidian), industrial (Optical fiber, Window glass, Glass E, Nuclear Glass, Refiom, Pyrex 1912, Actual window glass) and historic (Roman glass Embiez 200y, Flint, Egyptian, Babylonians, Tour, Chartres, Rouen, Germanique, Boheme) glasses [7-10].

Around the $15^{\text {th }}$ century BCE, improvements of the furnaces allowed higher working temperatures. As a result, fusion quality improved, leading to a technological transformation as the first translucent glasses were produced. Glass objects presenting a large variety of shape appeared, such as bottles and containers used to preserve ointments, perfumes, food or beverages, for instance. For instance, to form small containers, core-molding technics were used: a rather viscous silicate melt was spread on a core, made for example of a mixture of clay and manure; the core was then removed from the inside of the new piece. Other shaping methods were developed, and, from that time, glasses were decorated. In addition, technological glasses appeared, as for instance millefiori glasses (Fig. 4a) composed of many glass filaments embedded in a transparent glass, forming a unique piece. Thin glaze films covering various 
Le Losq, Cicconi, Greaves, Neuville. Silicate Glasses. In: Springer Handbook of Glass.

objects were also formed using silicate melts rich in lead oxide and, hence, presenting low viscosity at working temperature. Towards the $4^{\text {th }}$ century BCE, this new process improved greatly potteries, making them waterproof. From its Mesopotamian-Egyptian origin, the art of glass spread to neighboring countries. Pearls made at the end of the second millennium were found from Italy to Central Asia and China (Fig. 4b). Glass containers were found in Greece, Italy and China, respectively dating from the 13th, 8th and 5th centuries BCE. The availability and quality of the raw materials may have determined the abundance and interest in producing glass at such time. Indeed, glass transparency requires using raw materials with high purity during the glass-forming process. In particular, the starting materials should be very poor in iron oxide, one of the main glass colorant that is abundant on Earth surface. As such pure raw materials were easily found in Palestina and Egypt, for instance, this may explain the abundance of glasses made in these areas.

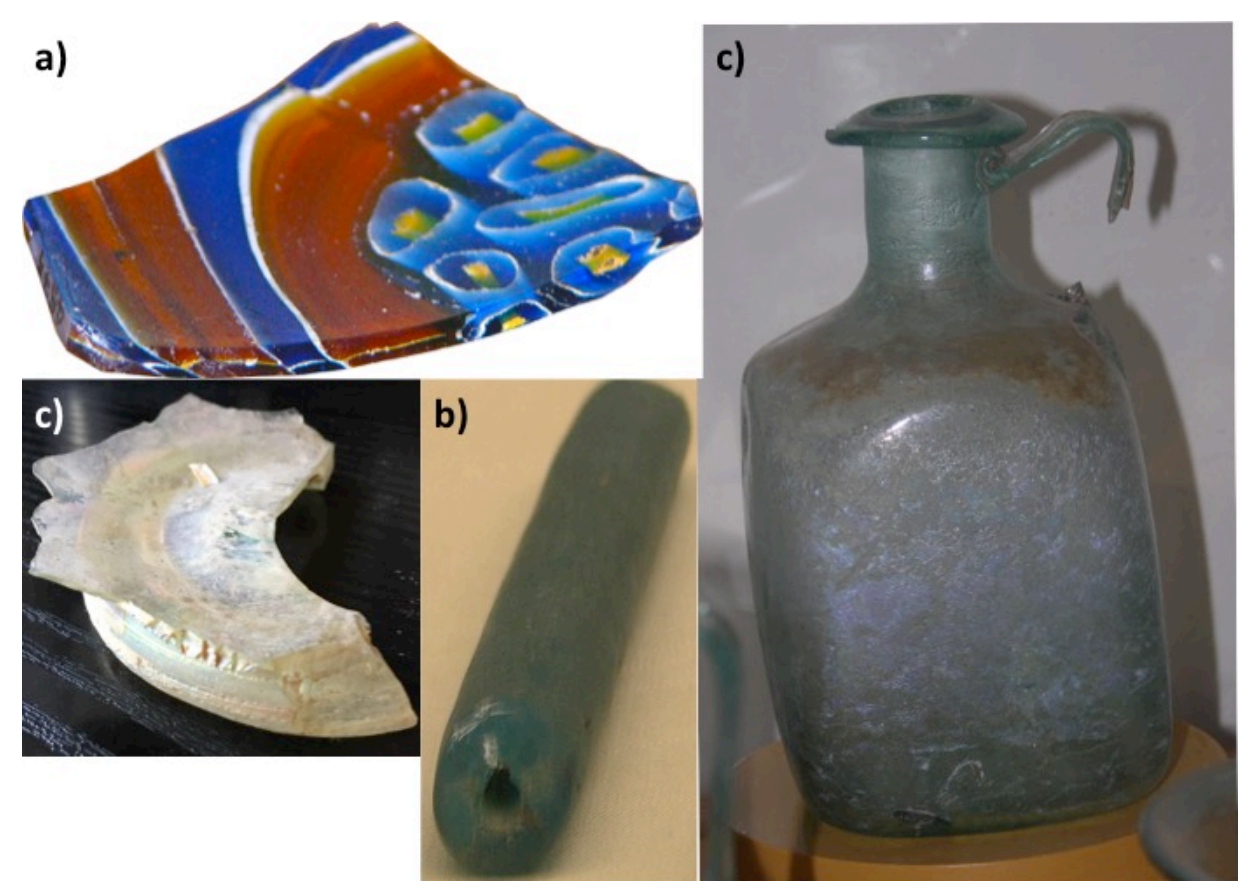

Figure 4: a) millefiori glasses, b) pearls, c) fragment of Roman glass and d) bottle from the Roman empire. Pictures Daniel R. Neuville.

The use of glass blowing during the Roman empire (Fig. 2) gave birth to a veritable industrial revolution. This process allowed fast, easy and thus cheap shaping of the glass. The size and shape of the pieces were also less limited than with previous methods. Whether intended for utilitarian or decorative 
Le Losq, Cicconi, Greaves, Neuville. Silicate Glasses. In: Springer Handbook of Glass.

purposes, glass was able to find its place in all homes under the Roman empire. Even the deceased benefited of such technological evolution as their ashes were preserved in glass urns. Glasses dating from the Roman empire cover a small chemical composition domain. This suggests a form of globalization of the glass market at that time, with the production of glass concentrated in various factories located along the syro-palestinian costline [11]. This concentration probably resulted from the abundance of local deposits of pure sand and natron, giving this region a great competitive advantage. From there, glass was exported in the form either of finished products or of glass ingots, which could be re-melted in small furnaces at their destination to shape the final objects. For instance, the Ouest-Embiez ship wreck found in the Mediterranean Sea testifies for the occurrence of this trade [11].

The decline of the Roman Empire followed by the Arab conquests probably led glass trading routes to be cut off [12]. As a result, starting at the beginning of the Middle Ages $\left(5^{\text {th }}-15^{\text {th }}\right.$ century BCE), glasses had to be produced locally in Western Europe, with the available resources on the spot. The local cullet was used together with ashes to help melting local sands in order to produce glass. Using ashes helped compensating the absence of natron. Figure 5 represents the composition of ashes obtained from different plant and tree species. In Europe, ash from beech, oak and fern were mostly used in glass making processes. Such ashes are rich in potassium (Fig. 5), such that potash-lime glasses were produced in northern Europe. Unfortunately, potassium is not an element ensuring the stability of the glass in regards of alteration, explaining why potash-lime glasses from the early Middle Ages are not well preserved. Soda-lime glasses were also produced in regions were the local availability of saltwort was good (Fig. 5). This induced a typical geographic repartition of soda-lime and potash-lime compositions in Western and North-Eastern Europe at this time. This changed during the $11^{\text {th }}$ century, as saltwort becomes to be imported from Spain for producing glass.

In parallel to the events in Europe, the development of glass in the East took a totally different path after the fall of the Roman empire. In the Byzantine empire, glassmaking processes used during the Roman period survived, such that the glass production that characterized the Roman glasses was conserved. The rise of the Muslim Arabs see the development of new glasses. The Islamic glassmakers used their knowledge of the Roman and Byzantine glassmaking technics and their own experience to produce high quality glasses. In particular, this lead to the introduction of the Islamic soda-lime glass, introduced between the $8^{\text {th }}$ and $10^{\text {th }}$ century CE. After the first crusades in the $11^{\text {th }}$ century, glassmaking centers progressively shifted from the Islamic glassmakers to the Venice (Italy) center. 
Le Losq, Cicconi, Greaves, Neuville. Silicate Glasses. In: Springer Handbook of Glass.

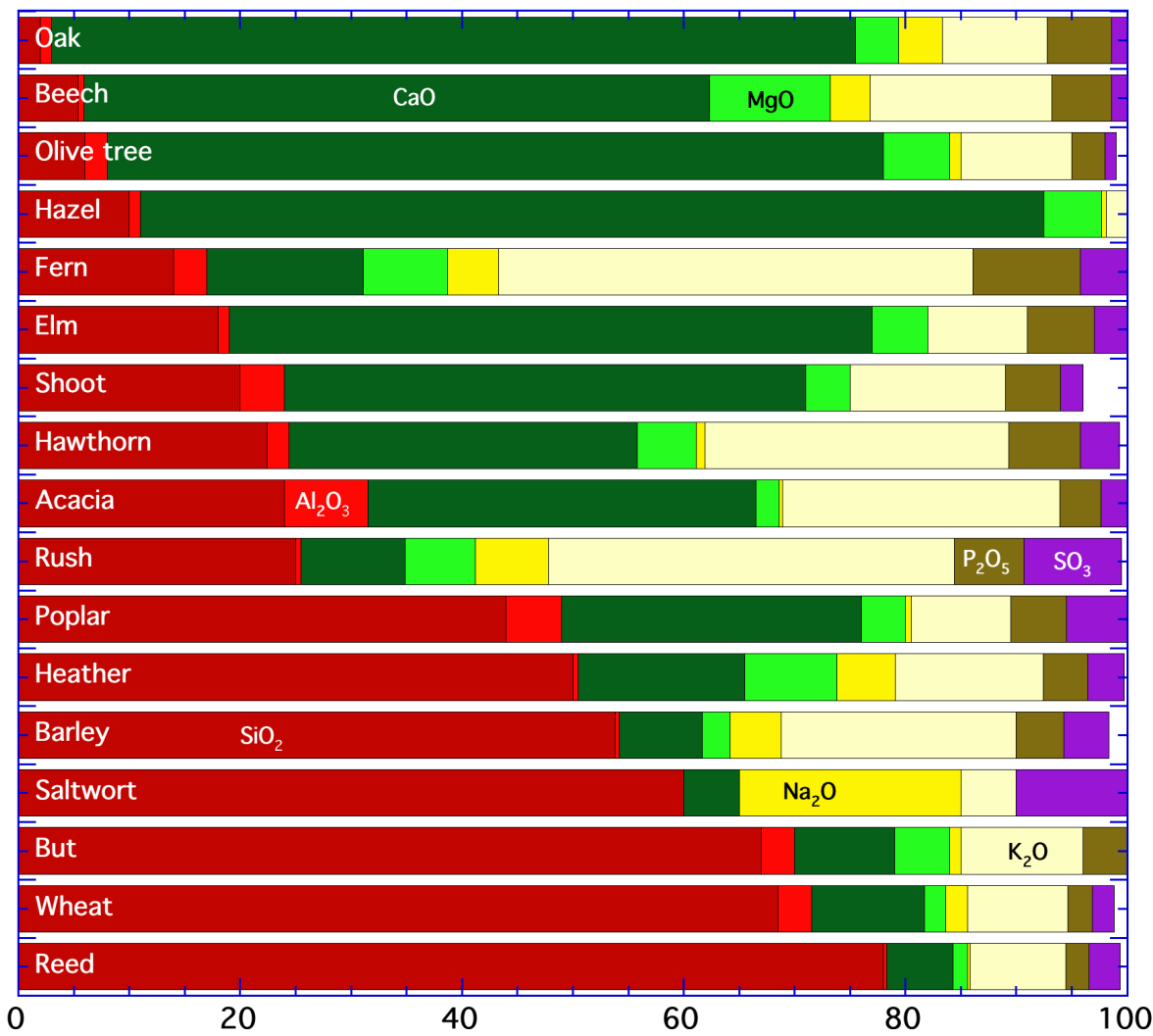

Figure 5: Chemical composition of ashes generated by burning different plant and trees. Data from Vernioles [13].

Indeed, the glassmaking knowledges acquired during the prosperous periods of the Roman empire never really died, and new contacts with the Byzantine empire following the first crusades allowed the transmission of new knowledges from the Islamic to the Venetian glassmakers. In addition, starting from the $11^{\text {th }}$ century, Venice was becoming one of the most important center of trade, commerce and arts in the Europe and Mediterranean regions. As a result of the combination of those factors, the Italian glassmaking industry started to flourish again from around $1200 \mathrm{CE}$. In 1291, the glassmaking factories moved to the Island of Murano, to keep the Venice city safe from fires. This further helped keeping the secrets of the Venetian glassmaking processes safe. By the $15^{\text {th }}$ century, Murano became one of the most important glassmaker in Europe. Venetian glassmakers continued to improve the quality of the glasses they produced, this leading to the production of the cristallo for instance, a transparent, shiny glass prepared from soda ash and quartz pebbles from Ticino (Italy). Using this glass composition that is characterized by a long working time, the Murano glassmakers manufactured thin and relatively light glass windows and mirrors that were exported all other Europe. 
Le Losq, Cicconi, Greaves, Neuville. Silicate Glasses. In: Springer Handbook of Glass.

While the Venetian glasses were of high quality, they also were expansive. This actually pushed the birth of a French glassmaking company that is nowadays one of the largest glass and material producer in the world. Indeed, when the French king Louis XIV decided to build the Versailles castle, the price asked by the Murano glassmakers for the required large quantities of glasses was particularly depressing. This pushed Louis XIV to grant a royal privilege in 1665 to a new glass factory, which finally settled in 1693 in the village of Saint-Gobain. In 1695, it became the French Royal Glass Factory, famous for the production of flat glass through cooling and flattening the melt directly on a wood table of several meters. This process was notably depicted in the painting "The visit of the duchess of Berry at Saint-Gobain in $1822 ”$.

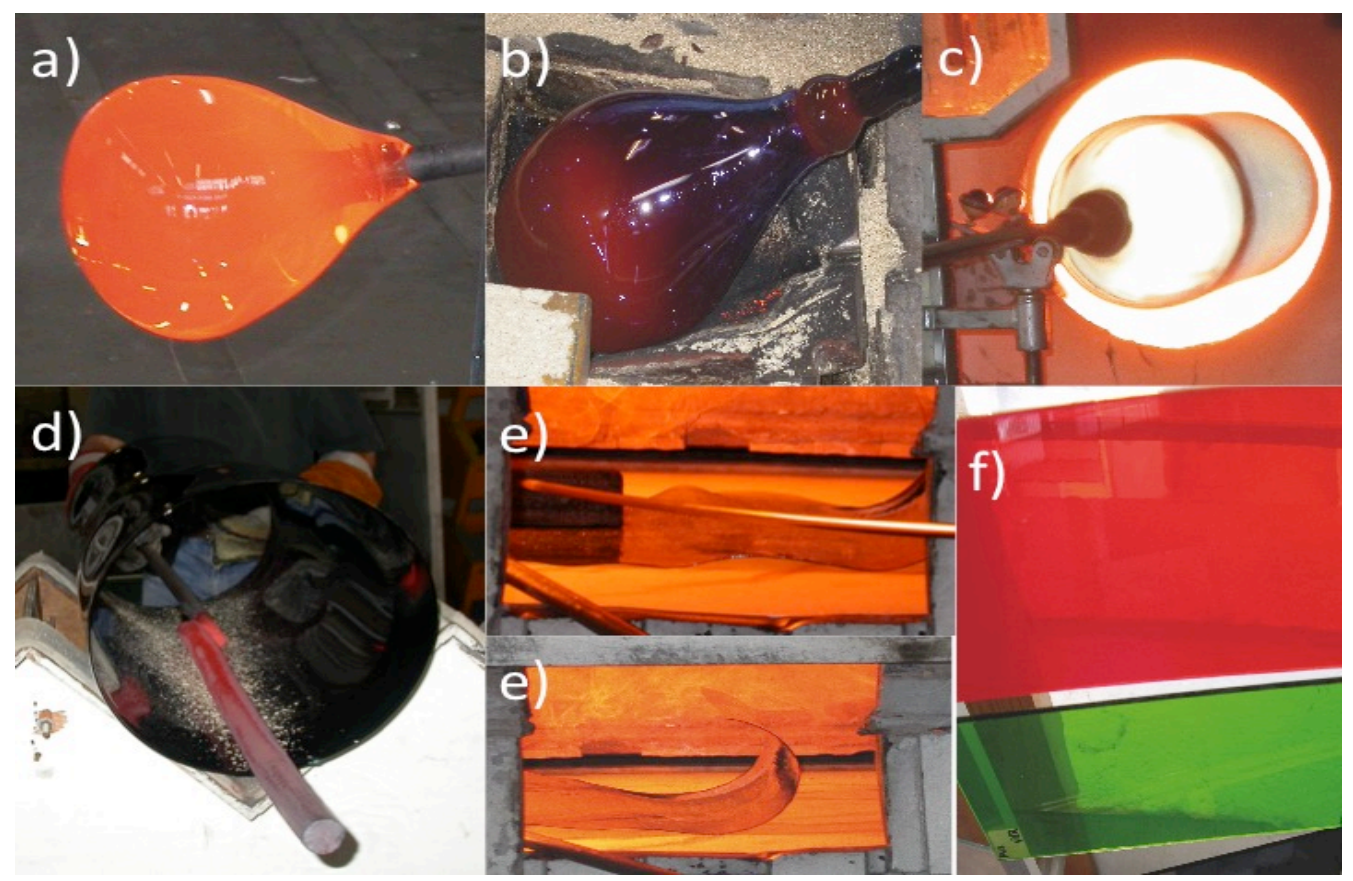

Figure 6: Formation of flat glass using the cylindrical sleeve technique: a) b) and c) a cylinder of glass is formed by blowing, d) each end is removed and one of the cylinder side is cut, e) the cylinder is then softened under fire to obtain a flat window, and f) final product can be colored or uncolored. Pictures Daniel R. Neuville, from the Saint-Just Factory - Saint-Gobain Compagny.

The process cited thereabove was a late evolution of two technics used to produce flat glass, in high demand for the construction of windows and mirrors for religious and royal edifices in Western Europe since the Middle Ages. Indeed, the first productions of flat glass were performed using either the crown or the cylindrical sleeve processes. The crown process consisted in obtaining a cylinder of flat glass from a vase, initially formed by blowing. This cylinder of flat glass can then be cut in any wanted shapes. The cylindrical sleeve process used a different approach, forming a glass sheet from a glass cylinder (Fig. 6). 
Le Losq, Cicconi, Greaves, Neuville. Silicate Glasses. In: Springer Handbook of Glass.

Glasses formed through those processes were expansive, such that their use was reserved to religious or important edifices until the end of the $17^{\text {th }}$ century.

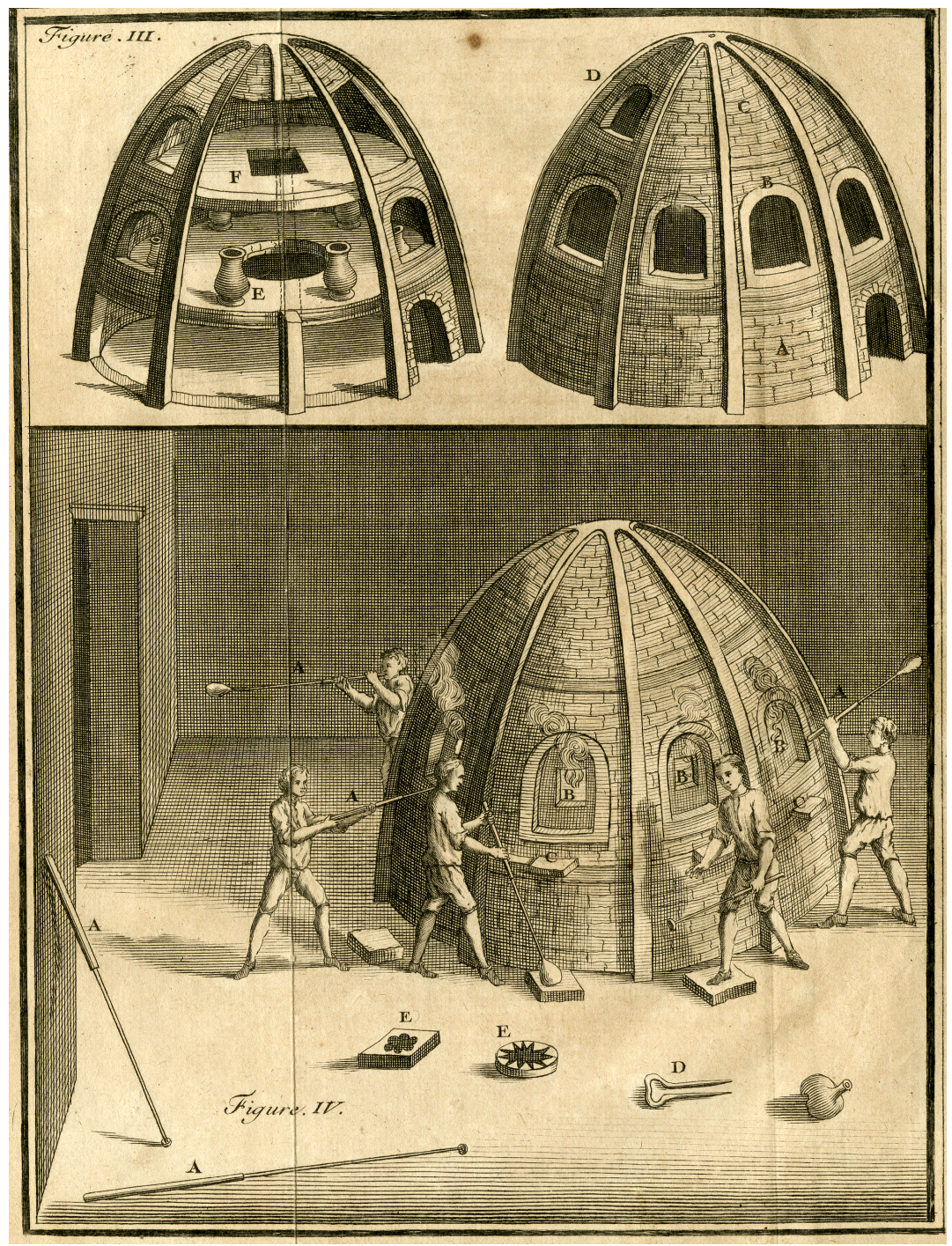

Figure 7: Representation of the three different furnaces needed to made glass and proposed by Agricola. This representation is extracted from "Dans l'art de la verrerie" from Neri, Merret and Kunckel (1752) $[6]$.

While the brazier represented in Figure 2 is one of the first representations of a glass furnace, the one developed since the Middle Aged were highly sophisticated. An example of a furnace used at this time is given by Agricola in De Re Metallica in 1556 and later reported by Neri et al. [6]. Figure 7 shows the representation displayed in Neri et al. [6], in which we distinguish three different furnaces: -i) the first called calcaria was used to prepare oxide and carbonate powders from raw materials (shells, chalk, marls, 
Le Losq, Cicconi, Greaves, Neuville. Silicate Glasses. In: Springer Handbook of Glass. wood, sea salt, vegetable or animal ash...); - ii) the second furnace was typically a pot furnace used to melt the materials generated with the first furnace, in order to obtain from 100 to $300 \mathrm{~kg}$ of glass (a bath furnace could also be used for generating large glass volume of several cubic meters); -iii) a third furnace was used for annealing the glass pieces generated by blowing the silicate melt from the second furnace.

At the end of the Middle Ages and the beginning of the Renaissance, academic societies and the renaissance savants started to make further important progress in knowledge. Such time saw the development of new glasses, and glassmaking technics. For example, the Prince Rupert started to look at some spectacular and curious properties of glass, presented to the Royal Society of London in 1661. Indeed, dropping melts at high temperature in water, Prince Rupert noticed the formation of glass drops very resistant to violent shocks, up to a point after which they exploded suddenly and turned into fine powder. Spectacularly, these first tempered glasses, well known as the Prince Rupert's drops, illustrated the role of internal stresses that accumulate in the absence of annealing (Fig. 8). George Ravenscroft (1632-1683) invented the crystal glass through the addition of an important quantity of lead oxide in the composition. From this invention, patented in 1673 by Ravenscroft, lead-based glass spread among Europe, representing an important turnover as it allowed improving the appearance of glass as well as lowering the melting and working temperatures. In parallel, the naturalist and physicist René-Antoine Ferchault de Réaumur (1683-1757) observed the partial crystallization of a glass and created the first glass-ceramic in 1727. While such aspect was considered to be a defect at this time, it is a particular focus in glass and materials sciences nowadays because glass-ceramic materials open new doors to the manufactures of new strategic materials [e.g., see 14].

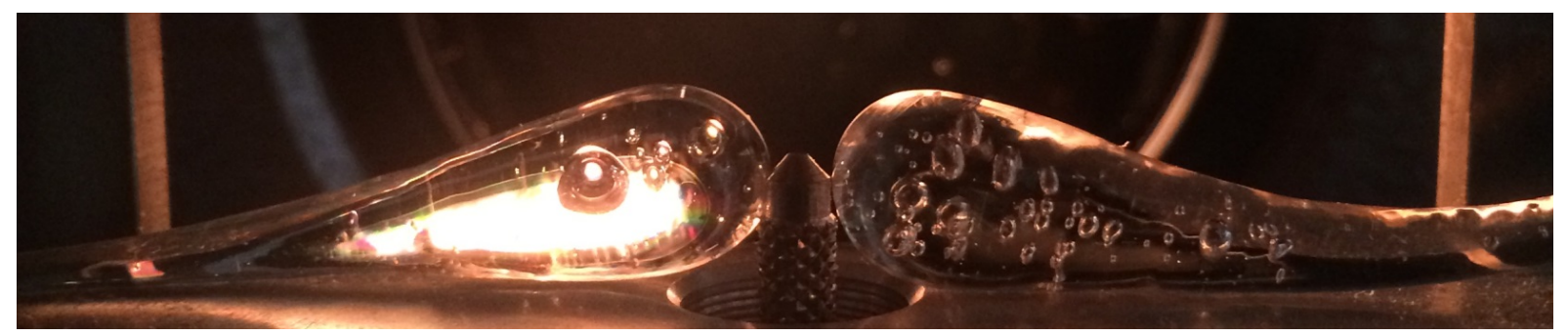

Figure 8: Picture of two glass drops observed under polarized and analyzed light. The sample at the left is unrelaxed, while that at the right was annealed, removing any intern stress. Picture courtesy of Prof. D. de Ligny. 
Le Losq, Cicconi, Greaves, Neuville. Silicate Glasses. In: Springer Handbook of Glass.

The $19^{\text {th }}$ and $20^{\text {th }}$ century saw a rapid evolution of the glass market, as glass was needed as a technological material for various applications. For instance, in 1893, the Duran boro-silicate glass, was developed by Otto Schott, a German glass maker. This glass presented a low thermal expansion, such that the Corning Glass Works company used it to form the first light bulb for Thomas Edison. At the turn of the $20^{\text {th }}$ century, other technical problems appeared with the development of railroad, automobiles and other mechanical transportation means. For instance, the glass globes of signal lanterns on United States of America railroads were sensible to extreme temperature changes (e.g., heavy rain on hot glass), leading them to shatter. This problem was solved by the development of the Nonex and the famous Pyrex ${ }^{\circledR}$ glasses, respectively in 1908 and 1915 by the Corning Glass Works company. Those boro-silicate glasses present a very low thermal expansion, making them particularly suitable for uses in environments with extreme temperature changes. The E glass, a calcium boro-silicate, was subsequently developed for electrical insulators has thus been found to have excellent mechanical properties. From the middle of the 20th century, it was this glass that was produced in the form of fibres to reinforce composite materials. In parallel of the discovery of such new glass compositions, the fast spreading of mechanical glassmaking processes allowed lowering the price of glass, making it suitable for its use in many different areas such as food storage, building or glass lenses for instance. Following World War II, many new glass families were made and developed, and the invention of the float glass process by Sir Alastair Pilkington and Kenneth Bickerstaff between 1953 and 1957 further revolutionized the glass production processes. Nowadays, silicate glasses still represent the largest quantity of human-made glasses. They are used in many aspects of everyday life, e.g. fiber optics, cellphone and computer screens, car windshields. However, the importance of silicate glasses is becoming smaller, thanks to the development of new and exciting glasses, such as, for example, chalcogenide, metallic or fluoride glasses. Such new glasses have a high technological importance, with critical applications as for instance for infrared cameras, photonics or data storage.

From the previous discussion, silicate glasses used in many technical and technological applications through historical times as well as natural geologic glasses present a wide range of chemical composition (Fig. 3). Such large variations in chemical composition are associated with large differences in term of glass properties, e.g., glass transition temperature $T_{g}$, density, hardness, chemical durability. For example, the $T_{g}$ and relative density of simple binary silicate glasses $\mathrm{M}^{\mathrm{n}+}{ }_{2 / \mathrm{n}} \mathrm{O}-\mathrm{SiO}_{2}$ are reported as a function of the molar percentage of $\mathrm{M}^{\mathrm{n}+}{ }_{2 / \mathrm{n}} \mathrm{O}$ in them in Fig. $9(\mathrm{M}=\mathrm{Na}, \mathrm{K}, \mathrm{Mg}, \mathrm{Ca})$; along the $\mathrm{M}^{\mathrm{n}+}{ }_{2 / \mathrm{n}} \mathrm{O}-\mathrm{SiO}_{2}$ binary systems, $T_{g}$ vary non-linearly of hundreds of degrees. In addition, glasses composed of a given amount of $\mathrm{SiO}_{2}$ but different metal cations $\mathrm{M}$ present different $T_{g}$ (Fig. 9a). Density changes are closer to a linear 
Le Losq, Cicconi, Greaves, Neuville. Silicate Glasses. In: Springer Handbook of Glass.

trend that vary quite strongly with composition (Fig. 9b). Such changes in glass properties translate changes in the glass disordered molecular structure upon variations of the glass chemical composition. Indeed, while glasses do not present long-range order arrangement as crystals do, they still present specific molecular arrangements at short and intermediate range order. For instance, the environment at short range order of $\mathrm{Si}^{4+}$ cations is well defined as being a $\mathrm{SiO}_{4}$ tetrahedral units in silicate glasses. At a scale of a few $\mathrm{SiO}_{4}$ tetrahedral units, arrangements of such tetrahedral species in rings and cages is also reported, as it will be presented in the following sections. However, one should remember that even such molecular arrangements are disordered in glasses: for instance, they can present a broad range of bond angle and bond lengths, as shown by the board distribution of the Si-O-Si bond angle in the silica $\mathrm{SiO}_{2}$ glass [15-19].
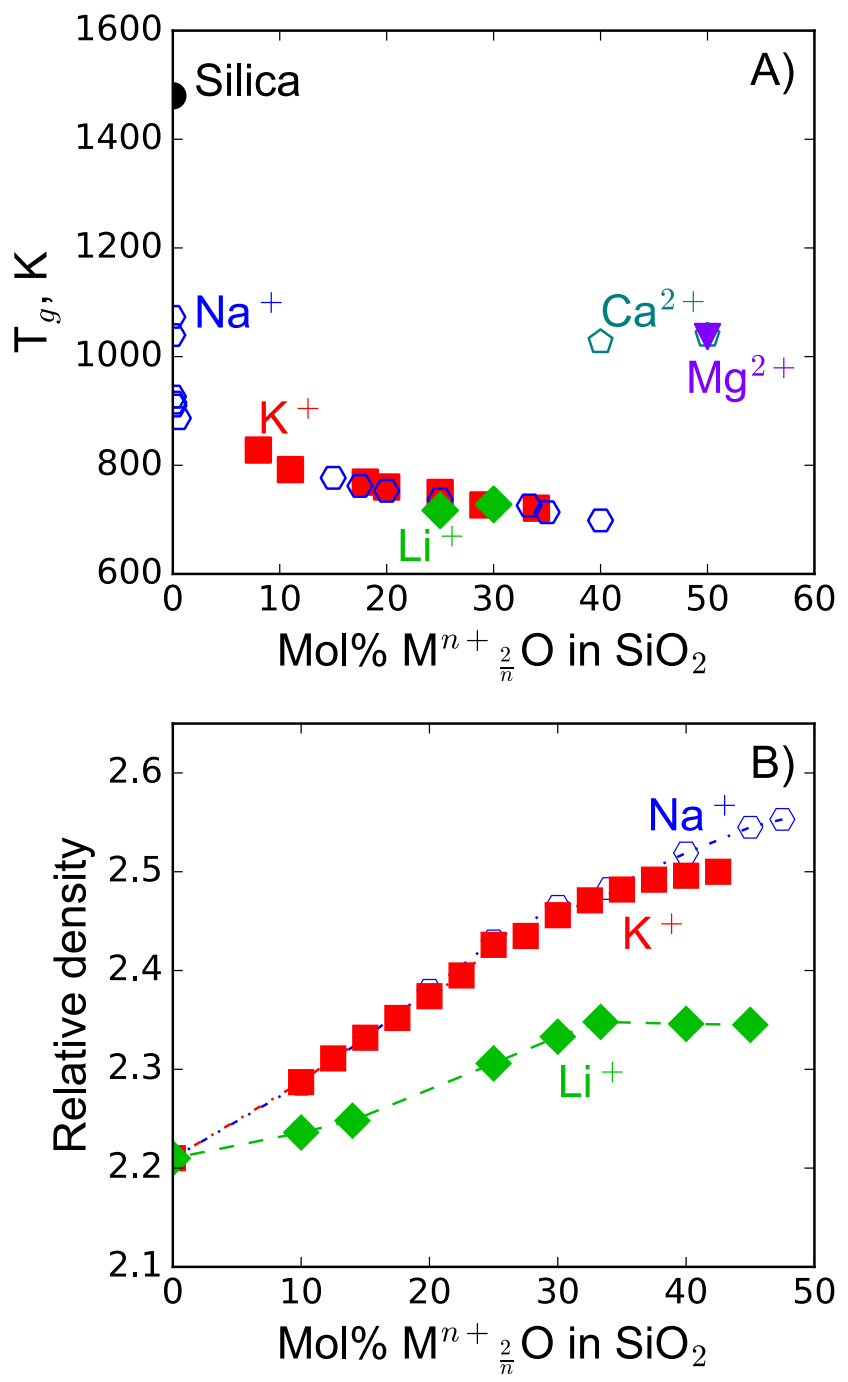
Le Losq, Cicconi, Greaves, Neuville. Silicate Glasses. In: Springer Handbook of Glass.

Figure 9: A) Glass transition temperature $T_{g}$ and B) relative density of binary silicate glasses along the $\mathrm{M}^{n+}{ }_{2 / n} \mathrm{O}-\mathrm{SiO}_{2}$ join. $\mathrm{T}_{\mathrm{g}}$ of $\mathrm{Na}_{2} \mathrm{O}-\mathrm{SiO}_{2}$ and $\mathrm{K}_{2} \mathrm{O}-\mathrm{SiO}_{2}$ glasses compiled by [20]; $\mathrm{T}_{\mathrm{g}}$ of $\mathrm{Li}_{2} \mathrm{O}_{-} \mathrm{SiO}_{2}$ glasses: [21]; $\mathrm{T}_{\mathrm{g}}$ of $\mathrm{MgO}-\mathrm{SiO}_{2}$ and of $\mathrm{CaO}-\mathrm{SiO}_{2}$ glasses: [22, 23]. Density data are from [21, 23-25].

In the present chapter, the structure and properties of silicate glasses will be reviewed. We define silicate glasses as glasses containing dominantly $\mathrm{SiO}_{2}$ as the glass network former oxide component that allows their vitrification. Glasses built upon the presence of other network formers in their structure will be discuss in the following chapters (see chapters XXXXX). Silicate glasses usually contain various elements such as, for example, aluminum, iron, alkali and alkaline-earth metal cations. In a first time, the structure and properties of the silica glass will be briefly reviewed in section 1.2. Then, we will add new levels of complexity by looking at the structure and properties of Al-free and Al-bearing silicate glasses in sections 1.3 and 1.4. Section 1.5 will review multivalent and rare-earth elements in silicate glasses, and redox effects will be discussed, while sec. 1.6 gives a brief overview of volatiles elements dissolved glasses.

\section{$\underline{1.2 \text { Silica glass }}$}

\subsubsection{Structural concepts}

Silicate glasses inherit their names from the basic oxide component that allow their formation: silica oxide or $\mathrm{SiO}_{2}$. Interestingly, the possibility to quench the simple $\mathrm{SiO}_{2}$ melt into glass indicates that $\mathrm{Si}^{4+}$ is a network former cation, similar to other cations such as $\mathrm{Ge}^{3+}$ or $\mathrm{B}^{3+}$ for instance (see chapters XXX for further information). Network former elements in oxide glasses participate in building an interconnected molecular network, forming the backbone of glassy materials. Regarding the pure silica glass, it is composed of $\mathrm{Si}^{4+}$ cations and $\mathrm{O}^{2-}$ anions arranged in $\mathrm{SiO}_{4}$ tetrahedral units with $\mathrm{Si}^{4+}$ at the center and $\mathrm{O}^{2-}$ at the summit. Those $\mathrm{SiO}_{4}$ units are interconnected by their apical bridging oxygen atoms, forming a tridimensional tetrahedral network.

Because of its simple chemistry, one may think that the structure of the silica glass is simple. However, it actually exhibits such a level of complexity that there is no definitive consensus about the threedimensional arrangements of $\mathrm{SiO}_{4}$ tetrahedral units at medium-range order. An early description of the silica glass structure was provided by Zachariasen [26], who proposed the Random Network (RN) model to describe the structure of oxide $\mathrm{AX}_{2}$ glasses (with $\mathrm{A}$ the network former cations and $\mathrm{X}$ the anions). 
Le Losq, Cicconi, Greaves, Neuville. Silicate Glasses. In: Springer Handbook of Glass.

Following this model, $\mathrm{Si}$ and $\mathrm{O}$ structural sites are energetically equivalent, and the $\mathrm{Si}$ and $\mathrm{O}$ atoms randomly distribute between those sites following 4 rules that govern the formation of $\mathrm{AX}_{2}$ glasses:

1) the system contains enough $X$ anions to ensure the formation of triangle or tetrahedra of $X$ anions around the central network former A cations;

2) those triangle/tetrahedra share the apical $X$ anions at their summit;

3) a given $\mathrm{X}$ anion only link 2 A cations;

4) the triangle/tetrahedra only share their summit, and not their faces or edges.

In the silica glass, this model predicts the formation of a three-dimensional disordered network composed of rings and cages of $\mathrm{SiO}_{4}$ interconnected tetrahedral (Fig. 10). First X-ray diffraction data of the silica glass in 1934 corroborated such description [27], and the latest observations of thin 2-dimensional films of silica deposited on graphene further support such view [28] (Fig. 10).

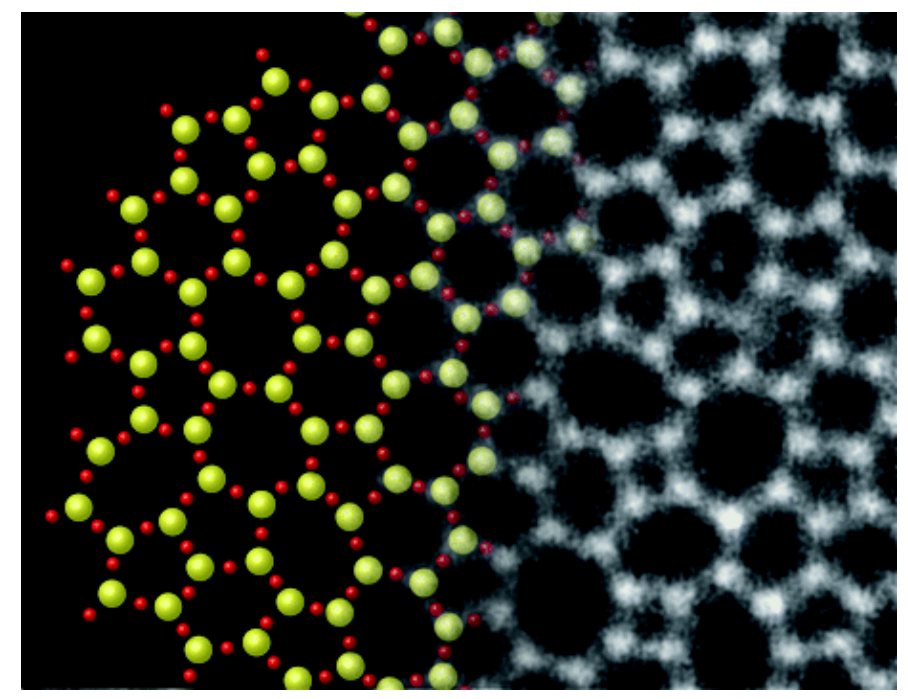

Figure 10: Image linking the transition between the theoretical 2D view the structure of the silica glass as drawn by Zachariasen [26] in 1932 (on the left) and the experimental observation by Huang et al. [28] in 2012 of a thin 2D film of amorphous silica deposited on graphene (on the right), made with using annular dark-field scanning transmission electron microscopy (ADF-STEM). Reprinted with permission from Huang, P.Y., Kurasch, S., Srivastava, A., Skakalova, V., Kotakoski, J., Krasheninnikov, A.V., Hovden, R., Mao, Q., Meyer, J.C., Smet, J., Muller, D.A., Kaiser, U., 2012. Direct Imaging of a TwoDimensional Silica Glass on Graphene. Nano Letters 12, pages 1081-1086, doi:10.1021/nl204423x. Copyright 2012 American Chemical Society. 
Le Losq, Cicconi, Greaves, Neuville. Silicate Glasses. In: Springer Handbook of Glass.

Pre-1990 analysis of X-Ray diffraction data [e.g., 29] and Raman spectra [e.g., 30] of the $\mathrm{SiO}_{2}$ glass as well as early structural calculations [e.g., 31] supported the idea that the structure of the $\mathrm{SiO}_{2}$ glass at medium range order was composed of tetrahedral rings, but no consensus existed about the number of tetrahedral units in the rings. In the Raman spectrum of $\mathrm{SiO}_{2}$, the asymmetric $R$ band centred near $\sim 460$ $\mathrm{cm}^{-1}$, which extends from $\sim 200$ to $\sim 650 \mathrm{~cm}^{-1}$, is actually assigned to Si-O-Si and O-Si-O bending vibrations in such $\mathrm{SiO}_{4}$ rings (Fig. 11).

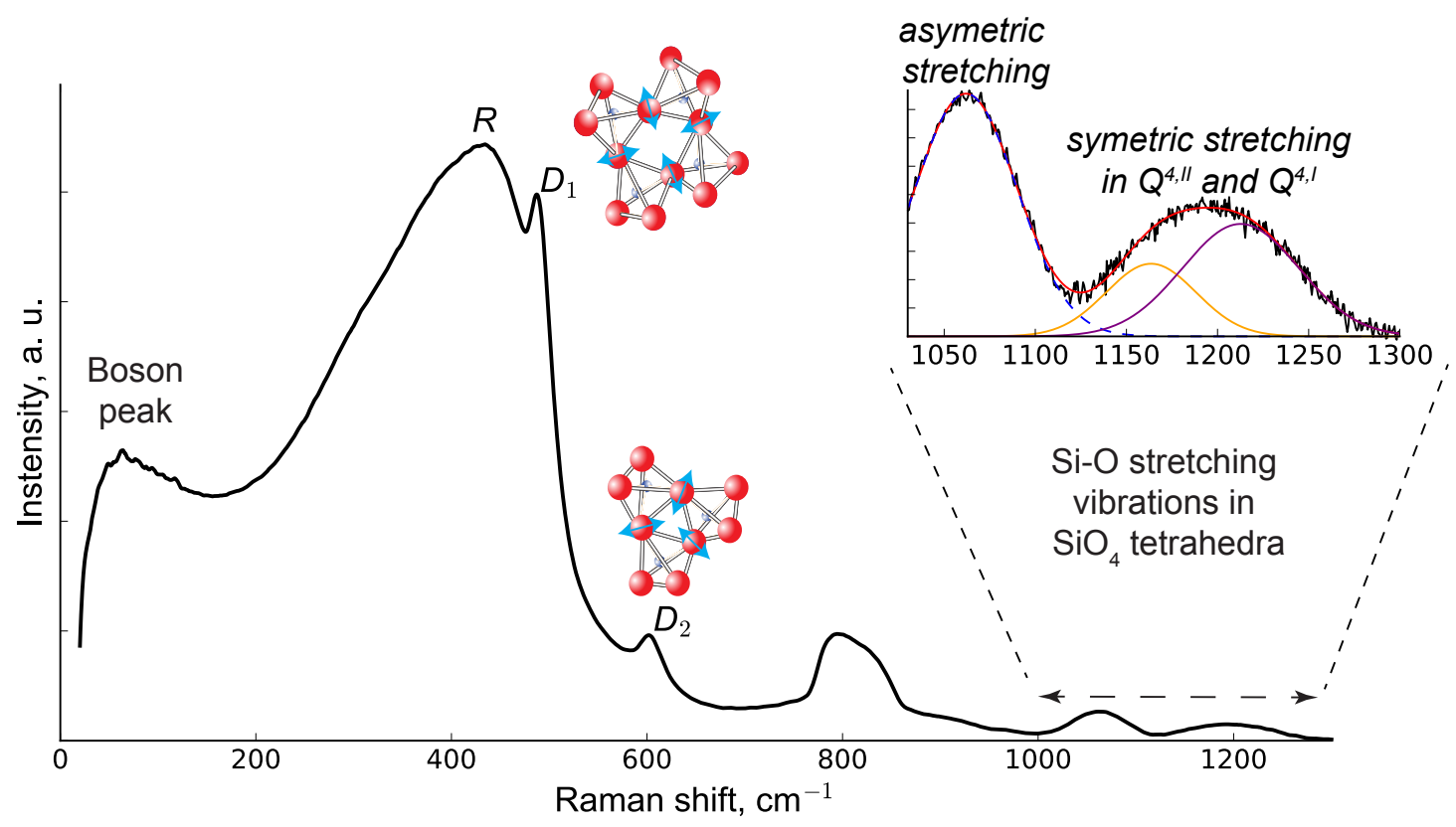

Figure 11: Raman spectrum of the Lybian glass, a glass found in the Lybian desert that probably results from a meteoritic impact. This glass present a composition of 99\% silica and 1\% impurities $\left(\mathrm{Al}_{2} \mathrm{O}_{3}\right.$, alkalis...). The Raman spectrum of this glass is very similar to that of the pure $\mathrm{SiO}_{2}$ glass. It displays: the Boson peak at $\sim 65 \mathrm{~cm}^{-1}$, that can be assignment to collective transverse acoustic vibrational modes [32] promoted in silicate glasses by cooperative inter-tetrahedral librations [33-35]; the $R$ band, an asymmetric band with an intensity maxima near $440 \mathrm{~cm}^{-1}$ that may be assigned to $O$ movements along the Si-O-Si intertetrahedral bonds of tetrahedral rings with 5, 6 or more tetrahedral [36-48]; the $D_{1}$ and $D_{2}$ sharp peaks, assigned to breathing vibrations of four and three membered rings, respectively [39, 41-43, 46, 48-51]; an asymmetric band near $800 \mathrm{~cm}^{-1}$, assigned to asymmetric vibrations of $\mathrm{SiO}_{4}$ units with both $O$ and Si movements [43, 52-54]; a peak near $1065 \mathrm{~cm}^{-1}$, assigned to Si-O asymmetric stretching vibrations in $\mathrm{SiO}_{4}$ units [25, 55-57]; and a broad band between 1100 and $1250 \mathrm{~cm}^{-1}$ that is assigned to $\mathrm{Si}-\mathrm{O}$ symmetric stretching vibrations in $\mathrm{SiO}_{4}$ units [36-38, 43]. 
Le Losq, Cicconi, Greaves, Neuville. Silicate Glasses. In: Springer Handbook of Glass.

At higher frequency, peaks at $\sim 1060 \mathrm{~cm}^{-1}$ and $\sim 1195 \mathrm{~cm}^{-1}$ are observed, and are assigned to Si-BO asymmetric and symmetric stretching modes of $\mathrm{SiO}_{4}$ units, respectively $[30,55,56,58,59]$. Peak-fitting the $\sim 1180 \mathrm{~cm}^{-1}$ band with Gaussian components, Seifert et al. [30] noticed that two peaks were necessary because this $\sim 1180 \mathrm{~cm}^{-1}$ band is asymmetric (Insert in Fig. 11). They interpreted this splitting of the SiO symmetric stretching in $Q^{4}$ units in two components as indicating an asymmetry of the $Q^{4}$ environments in the silica glass. This could be related to a slight asymmetry of the T-O-T inter-tetrahedral angle in $\mathrm{SiO}_{2}$ glass (Fig. 12), as suggested by results from molecular dynamic simulations [18, 60-62], ${ }^{29} \mathrm{Si}$ NMR spectroscopy [19] and X-Ray absorption spectroscopy [15, 29, 63]. Seifert et al. [30] assigned this asymmetry to different puckering extents of 6-membered rings in the structure of the silica glass that yield T-O-T angle differences of $\sim 5-10^{\circ}$. In line with such idea, Henderson et al. [29] discussed the XRay Diffraction (XRD) data for $\mathrm{SiO}_{2}$ as suggesting the coexistence of cristobalite-like and trydimite-like 6-membered rings in silica. Such structural models fall in the category of the crystallite network model of the $\mathrm{SiO}_{2}$ glass, discussed by Wright [64].

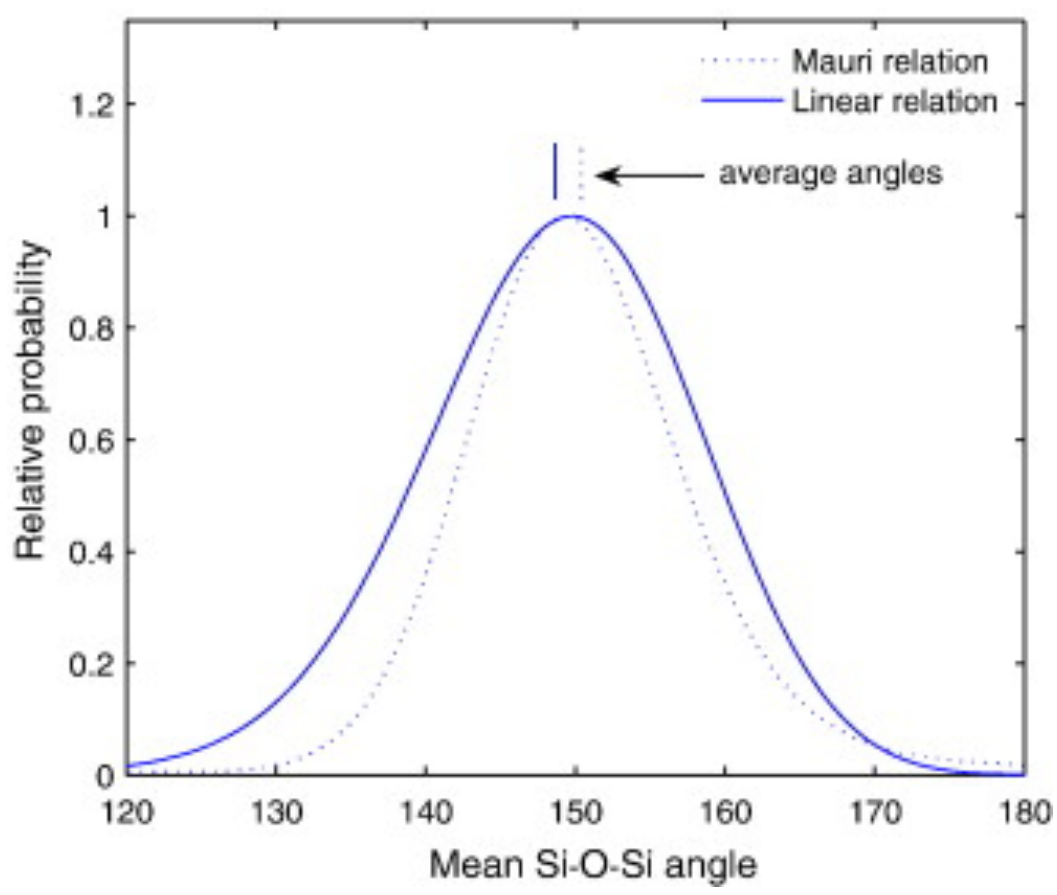

Figure 12: Distribution of the mean Si-O-Si bond angle in silica derived from ${ }^{29} \mathrm{Si}$ NMR spectroscopy, using either a linear relationship between the ${ }^{29}$ Si chemical shifts and Si-O-Si bond angles measured in $\mathrm{SiO}_{2}$ polymorphs and zeolites (plain curve), or a correlation determined by density functional theory by Mauri et al [65] (dotted curve). Reprinted from Malfait [19], Copyright (2008), with permission from Elsevier. 
The idea of different 6-membered rings coexisting in the structure of the silica glass is still presently plausible, as no consensus has been reached on the structure of the silica glass. For instance, Huang et al. [66] recently followed such idea, showing with the help of Molecular Dynamic simulations that the mixing in different quantities of two types of 6-membered rings, presenting shapes close to those found in $\alpha$-cristobalite and $\beta$-cristobalite, may account for variations of the $\mathrm{SiO}_{2}$ bulk modulus and density with pressure. However, most Monte Carlo and Molecular Dynamic simulations [e.g., 18, 47, 51, 60, 67] indicate that, at medium range order, the structure of the silica glass is composed of a distribution of rings with different numbers of $\mathrm{SiO}_{4}$ units, with 5-, 6- and 7-membered rings tending to be dominant (Table 1). Therefore, as rings with different number of tetrahedral units present different T-O-T angles [42, 60], $\mathrm{Si}-\mathrm{O}$ stretching frequency in $\mathrm{SiO}_{4}$ units should vary as a function of the ring statistic in the $\mathrm{SiO}_{2}$ glass. For instance, signals assigned to $\mathrm{Si}-\mathrm{O}$ stretching in $\mathrm{SiO}_{4}$ units in the main 6- and 7-membered rings will give signals at different frequency because they present different $\mathrm{Si}-\mathrm{O}-\mathrm{Si}$ bond angles and $\mathrm{Si}-\mathrm{O}$ bond lengths $[53,54,60]$. Therefore, a repartition of $\mathrm{SiO}_{4}$ units in mostly 5-, 6- and 7-membered rings, as suggested by results from simulations, may actually explain the asymmetry observed in the Raman data. In all cases, the asymmetry of the $\mathrm{R}$ band further agrees with considering the structure of the $\mathrm{SiO}_{2}$ glass as containing a distribution of rings with 3 to more than 8 tetrahedral units. In particular, two sharp peaks at $\sim 590$ and $\sim 606 \mathrm{~cm}^{-1}$ in Raman spectra of $\mathrm{SiO}_{2}$ glasses (Fig. 11) can be assigned to minor fractions of 4- and 3-membered rings in the glass structure, respectively [39, 41, 42, 45-49, 51, 52, 68]. Such observation thus support results from simulations that tends to predict low concentrations of such rings in the glass structure [e.g., 46-48, 51]. The vibrational decoupling of such rings from the remaining part of the glass network allow them to contribute significantly to the glass Raman spectra [49]. Overall, the picture of the structure of the silica glass still is incomplete, but advances in simulations and spectroscopic technics may bring further determining pieces of information in a near future. 
Le Losq, Cicconi, Greaves, Neuville. Silicate Glasses. In: Springer Handbook of Glass.

\begin{tabular}{|c|c|c|}
\hline & Value & References \\
\hline Si-O bond distance & $1.59-1.61 \AA$ & {$[18,67]$} \\
\hline Si-O-Si bond & $146^{\circ}-151^{\circ}$ & [17-19] \\
\hline$\%$ of 3-membered rings & $0.0-0.7 \%$ & \multirow{6}{*}[18,47,51,60]{} \\
\hline$\%$ of 4 -membered rings & $0.0-7.7 \%$ & \\
\hline$\%$ of 5-membered rings & $17.0-23.0 \%$ & \\
\hline$\%$ of 6 -membered rings & $35.0-42.0 \%$ & \\
\hline$\%$ of 7 -membered rings & $17.0-31.5$ & \\
\hline$\% \geq 8$-membered rings & $11.0-17.0$ & \\
\hline
\end{tabular}

Table 1: Examples of structural characteristics of the silica glass, obtained either experimentally or from molecular dynamic simulations. Rather than proposing single values, a range of values is reported in the table.

\subsubsection{Properties of Silica}

The precedent section depicted the structure of the silica glass as consisting of a tri-dimensional arrangement of $\mathrm{SiO}_{4}$ tetrahedral units connected by their summit and forming ring structures in the glass. Such interconnected, polymerized structure yields the highest known glass $T_{g}$, equal to $1480 \mathrm{~K}$ according to the calorimetric measurements of Richet and Bottinga [69] (Fig. 13). 
Le Losq, Cicconi, Greaves, Neuville. Silicate Glasses. In: Springer Handbook of Glass.

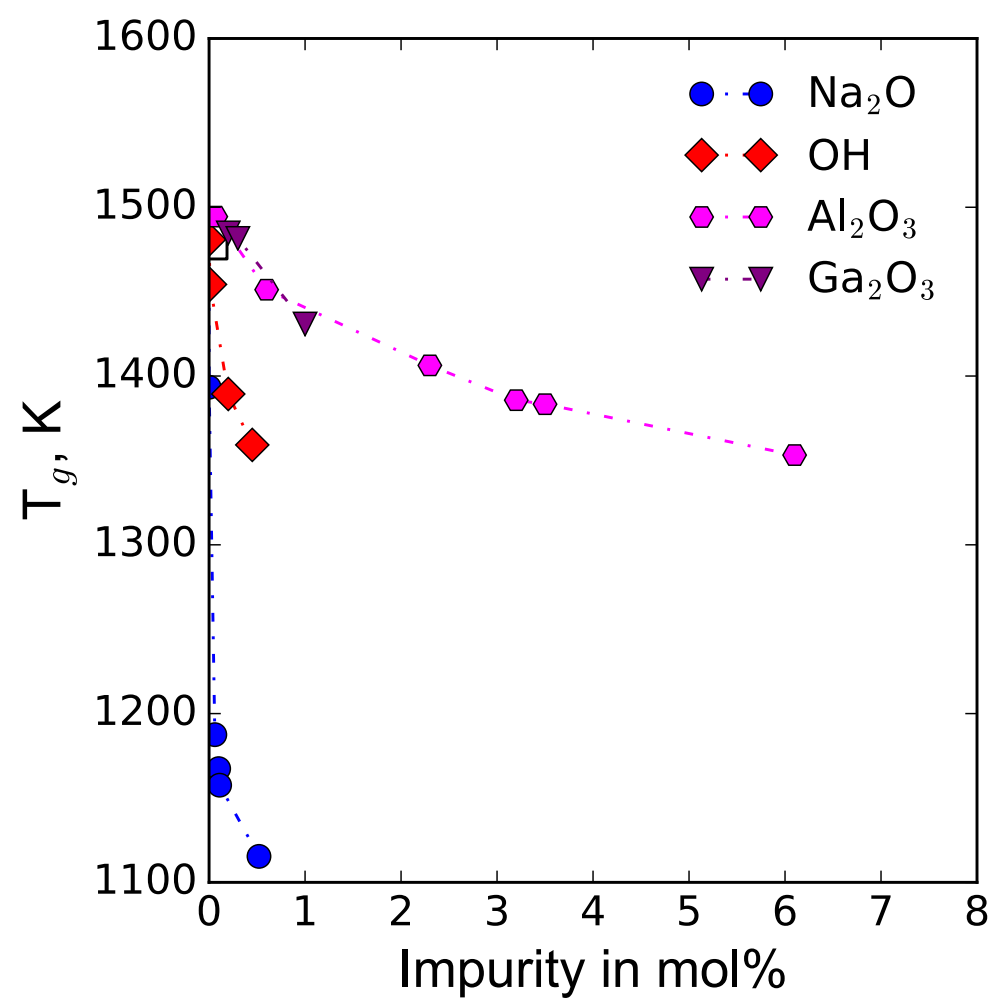

Figure 13: Glass transition temperature $T_{g}$ of the silica glass as a function of the molar concentrations in $\mathrm{Na}_{2} \mathrm{O}$ (blue circles), $\mathrm{OH}$ (red diamonds), $\mathrm{Al}_{2} \mathrm{O}_{3}$ (pink hexagons) or $\mathrm{Ga}_{2} \mathrm{O}_{3}$ impurities (purple inverted triangles), predicted from the viscosity data of Leko et al. [70] assuming that $\log (\eta)=12$ Pa s at $T=T_{g}$. For comparison, the calorimetric $T_{g}$ of Richet and Bottinga [69] is also reported as a black empty square.

Silica actually is the strongest know liquid, in the strong-fragile denomination of liquids that was introduced by Angell [71, 72]. A strong liquid is characterized by a linear or nearly-linear relationship between the logarithm of its viscosity and the $T_{g} / T$ ratio, while fragile liquids present strong departure from this linearity. The fragility $m$ of liquids, equal to the slope of the $\log (\eta)$ vs $T g / T$ curve at $T_{g}$, allows one to quantify such deviations. $m$ tends toward $\sim 20$ for strong liquids such as $\mathrm{SiO}_{2}$, and to much higher values for fragile liquids, such as $\mathrm{B}_{2} \mathrm{O}_{3}$ for instance. The unique interconnexion of the silica tetrahedral network makes the silica glass properties very sensitive to the presence of impurities. For instance, the addition of $\mathrm{OH}$ or $\mathrm{Na}_{2} \mathrm{O}$ in the silica glass produces a dramatic reduction of hundreds of degrees of the silica glass transition temperature $T_{g}$ (Fig. 13). Another example is the thermal diffusivity of the silica glass, which varies between 0.795 and $0.870 \mathrm{~mm}^{2} \mathrm{~s}^{-1}$ at $298 \mathrm{~K}$ depending on the impurities present in the glass [73; see Table 2]. Because of such sensitivity, four different types of silica glasses are usually distinguished depending on the level of impurities they contain [74]: 
Le Losq, Cicconi, Greaves, Neuville. Silicate Glasses. In: Springer Handbook of Glass.

- $\quad$ Type I: glasses produced from natural quartz by electrical fusion under vacuum or under an inert gas atmosphere; they contain about $5 \mathrm{ppm}$ or less of $\mathrm{OH}$ groups, but relatively high contents of melta impurities such as $\mathrm{Al}(30-100 \mathrm{ppm})$ and $\mathrm{Na}(\sim 4 \mathrm{ppm})$. Commercial names are Infrasil, IRVitreosil, G. E. 105, 201,204;

- Type II: glasses produced from quartz crystal powder by flame fusion (Verneuille-process), using an oxygen-hydrogen flame. They present $\mathrm{OH}$ contents ranging between 150 and $400 \mathrm{ppm}$, but much less metal impurities that type I glasses. Commercial names are Herasil, Homosil, Optosil, O.G. Vitreosil, G.E. 104;

- Type III: synthetic silica glasses produced by hydrolyzation of $\mathrm{SiCl}_{4}$. They are free from metallic impurities, but high contents of $\mathrm{OH}(\sim 1000 \mathrm{ppm})$ and $\mathrm{Cl}(\sim 100 \mathrm{ppm})$. Commercial names are Suprasil, Spectrosil, Corning 7940;

- Type IV: synthetic silica glasses produced from $\mathrm{SiCl}_{4}$ in a water vapour-free plasma flame. These glasses, similar to type III glasses, contain $\sim 0.4 \mathrm{ppm} \mathrm{OH}$ and $\sim 200 \mathrm{ppm} \mathrm{Cl}$. Commercial names are Suprasil W, Spectrosil W, Corning 7943.

Another parameter needs to be taken into account when looking at the link between the structure and the properties of the silica glass: the fictive temperature $T_{f}$. Indeed, $T_{g}$ is usually defined as the temperature corresponding to the glass transition upon cooling the melt at a given laboratory cooling rate of $\sim 10^{\circ} / \mathrm{sec}$. However, cooling the glass much faster or slower that the latter value yields different temperatures for the glass transition. Those different values are referred as the fictive temperature, $T_{f}$. As silica is extremely viscous even at high temperatures, changes of hundreds of degrees of $T_{f}$ can be obtained easily by varying the cooling rate from hundreds of degrees per seconds to $\sim 1^{\circ}$ per second. This leads to small variations in the glass density or refractive index, for instance (Table 2). Such variations in the glass density are linked to changes in the silica glass structure: glasses presenting higher $T_{f}$ also present high concentrations of three- and four-membered rings, as shown by the increasing signals of those rings in the Raman spectra of fast-quenched glasses [75]. However, such causal relationships between $T_{f}$, glass structure and properties is complex and depend on the glass composition. For instance, the analysis of a glass with a $75 \%-25 \%$ mixture of $\mathrm{SiO}_{2}-\mathrm{GeO}_{2}$ revealed an opposite correlation between the glass $T_{f}$, density and the ring statistic [75]. 
Le Losq, Cicconi, Greaves, Neuville. Silicate Glasses. In: Springer Handbook of Glass.

\begin{tabular}{|r|c|c|l|}
\hline & Value & Remarks & References \\
\hline Density & $2.2002-2.2060 \mathrm{~g} \mathrm{~cm}^{-3}$ & depends on $T_{f}$ & {$[74]$} \\
\hline Molar Volume & $27.24-27.31 \mathrm{~cm}^{3} \mathrm{~mol}^{-1}$ & depends on $T_{f}$ & Density conversion \\
\hline Thermal diffusivity $D$ & $0.795-0.870 \mathrm{~mm}^{2} \mathrm{~s}^{-1}$ & at $298 \mathrm{~K}$ & {$[73]$} \\
\hline Refractive Index $n$ & $1.4583-1.4589$ & depends on $T_{f}$ & {$[74]$} \\
\hline Calorimetric $T_{g}$ & $1480{ }^{\circ} \mathrm{C}$ & - & {$[69]$} \\
\hline Configurational entropy & $5.1 \pm 2 \mathrm{~J} \mathrm{~mol}^{-1} \mathrm{~K}^{-1}$ & from calorimetric data & {$[69]$} \\
\hline
\end{tabular}

Table 2: Examples of properties of the silica glass.

In addition to $T_{f}$, the densification of the silica glass also modifies the ring statistics, and, hence, its elastic properties. Indeed, upon densification, the frequency of the $\mathrm{R}$ band significantly increases, pointing to a puckering of the rings in the network without significant changes in the Si coordination or Si-O bond distance, at least up to pressure of $\sim 8 \mathrm{GPa}[76,77]$. Such changes are reversible up to $8 \mathrm{GPa}$. After this pressure, irreversible changes are observed and reflect a change in ring statistics [76]. Compared to the ambient pressure $\mathrm{SiO}_{2}$ glass, permanently densified glasses typically exhibit higher concentrations of four and particularly three membered rings [78]. The inter-tetrahedral angles in those rings is unaffected by the densification, contrary to the $\mathrm{Si}-\mathrm{O}-\mathrm{Si}$ angles of large rings that significantly decreases of $\sim 6^{\circ}$ with a 20\% densitification [79]. Molecular dynamic simulations from Huang et al. [66] further suggest that an increase of dense, $\alpha$-cristobalite-like 6-membered rings in $\mathrm{SiO}_{2}$ upon densification may explain the densification mechanism of amourphous $\mathrm{SiO}_{2}$. The authors of this study indicate that the anomalous elastic property of amorphous $\mathrm{SiO}_{2}$, i.e. its decreasing elastic modulus upon compression, actually is explained by the conversion of $\beta$-cristobalite-like 6-membered rings in $\alpha$-cristobalite-like 6 -membered rings upon compression. Their simulation further shows that the introductions of elements such as rare gas or alkali oxides in the $\mathrm{SiO}_{2} 3 \mathrm{D}$ tetrahedral structure further prevent this convertion process, and help reducing the elastic anomaly of the $\mathrm{SiO} 2$ glass.

\section{$\underline{1.3 \text { Aluminium-free Silicate Glasses }}$}

In silicate glasses, other elements are frequently present and play a role different to that of $\mathrm{Si}^{4+}$. Amongst the major cations present in industrial and geologic silicate glasses, we can cite $\mathrm{Al}^{3+}, \mathrm{Fe}^{3+}, \mathrm{Ti}^{4+}, \mathrm{Li}^{+}, \mathrm{Na}^{+}$, 
Le Losq, Cicconi, Greaves, Neuville. Silicate Glasses. In: Springer Handbook of Glass.

$\mathrm{K}^{+}, \mathrm{Fe}^{2+}, \mathrm{Ca}^{2+}$ and $\mathrm{Mg}^{2+}$ (Fig. 1). At the present time, we will focus on a brief description of the Al-free silicate glasses.

As visible in Fig. 13, the properties of the silica glass, such as, for instance, its $T_{g}$, can be greatly affected by addition of small fractions of impurities, such as for instance of $\mathrm{Na}^{+}$metal cations. The latter actually are considered as network modifier cations, which break Si-O-Si bonds, and form ionic bonds with the newly transformed non-bridging apical oxygens. Such process leads to the dramatic depletion in the glass $T_{g}$ observed in Fig. 13. The following section will describe in more detail such processes at the molecular scale, and their effect on the glass properties.

\subsubsection{Network modifier elements and $Q^{n}$ units}

Alkali $(\mathrm{Li}, \mathrm{Na}, \mathrm{K})$ and alkaline-earth $(\mathrm{Ca}, \mathrm{Mg})$ metal cations can be present together with $\mathrm{SiO}_{2}$ in glasses, forming sensu stricto silicate glasses (aluminum free). However, such cations present ionic field strengths (IFS $=\mathrm{Z} / \mathrm{r}^{2}$, with $Z$ the cation electronic charge and $r$ its ionic radius) too low to be able to enter the glass structure in tetrahedral units as $\mathrm{Si}^{4+}$ does. Indeed, according to Dietzel [80], cations presenting large IFS tend to enter in tetrahedral coordination and act as network former cations. For instance, the IFS of $\mathrm{Si}^{4+}$ is equal to $59.1 \AA^{-2}$. Other network former elements can present lower ionic field strength, e.g. $\mathrm{Ge}^{4+}$ in CN 4 presents an IFS of $26.3 \AA^{-2}$, but such values still are high enough such that they play network former roles. On the other hand, cation with IFS lower than $\sim 8 \AA^{-2}$ do not act as network formers in glasses. Instead, they play either a network modifier role, breaking Si-O-Si bonds, or a charge compensator role, ensuring electrical neutrality in the vicinity of trivalent network former cations such as $\mathrm{Al}^{3+}$ (see sec. 1.4; $\mathrm{Al}^{3+}$ IFS $=26.3 \AA^{-2}$ in $\mathrm{CN} 4$ ). In Al-free silicate glasses, introduction of network modifiers thus results in glass depolymerisation: network modifiers break Si-O-Si bonds, and form weak bonds with the nonbridging oxygen (NBO) anions at the summit of the $\mathrm{SiO}_{4}$ tetrahedral units.

As a result of the process previously described, $\mathrm{SiO}_{4}$ tetrahedral units in alkali and alkaline-earth silicate glasses carry different numbers of NBOs and BOs, and, hence, the local environment of $\mathrm{Si}^{4+}$ atoms vary. For instance, the $\mathrm{Si}-\mathrm{BO}$ distances are shorter than the $\mathrm{Si}-\mathrm{NBO}$ distances, as revealed by molecular dynamic simulations from Ispas et al. [81]]. This study provides values of 1.63-1.64 $\AA$ for $\mathrm{Si}-\mathrm{BO}$ distances and 1.58-1.60 $\AA$ for Si-NBO distances in the $\mathrm{Li}_{2} \mathrm{Si}_{4} \mathrm{O}_{9}$ glasses, depending on the potential used for the calculations (empirical or Car-Parrinello ab initio). Such difference in the local environment of $\mathrm{Si}^{4+}$ results in variations of the frequency of Si-O stretching in different tetrahedral units [82, 58]] as well 
Le Losq, Cicconi, Greaves, Neuville. Silicate Glasses. In: Springer Handbook of Glass. as of the ${ }^{29}$ Si NMR frequency $[83,84]$. Those variations can be detected with using Raman and ${ }^{29} \mathrm{Si}$ NMR spectroscopy, respectively. The study of the Raman and ${ }^{29} \mathrm{Si}$ NMR spectra thus allows observing how the glass polymerization changes with its composition [43, 58, 82, 84-88].

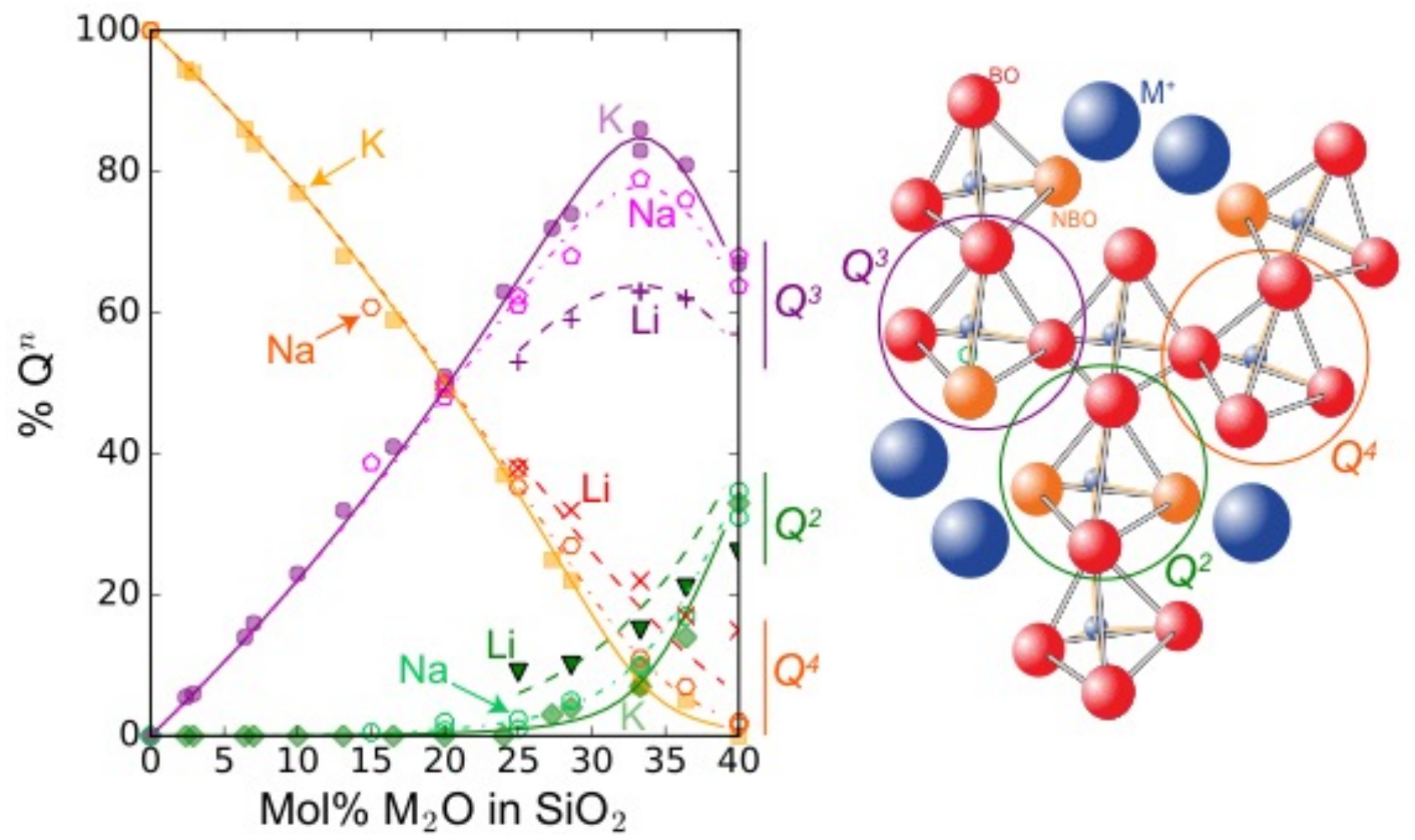

Figure 14: Changes in the fractions of $Q^{n}$ units measured by ${ }^{29}$ Si NMR spectroscopy as a function of the alkali metal content of binary $\mathrm{M}_{2} \mathrm{O}-\mathrm{SiO} \mathrm{O}_{2}$ glasses $(\mathrm{M}=\mathrm{Li}, \mathrm{Na}, \mathrm{K})$. Alkali content is restricted to the 0-40 mol\% range, but can reach higher values for $\mathrm{Na}_{2} \mathrm{O}-\mathrm{SiO}_{2}$ glasses, such that $Q^{l}$ and $Q^{0}$ units also has been detected in $\mathrm{Na}_{2} \mathrm{O}$-rich silicate glasses. On the right is shown a schematic view of the structure of an alkali silicate glasses, in which the $Q^{2}, Q^{3}$ and $Q^{4}$ units are distinguished; NBO and BO refer to non-bridging and bridging oxygen atoms, respectively, and $M^{+}$refers to alkali network modifier cations. $\mathrm{Si}^{4+}$ network former cations are in purple at the center of the tetrahedra. Curves are calculated from the equilibrium constant of the $2 Q^{3}=Q^{2}+Q^{4}$ relationship, with values of $0.008,0.02$ and 0.08 for the $\mathrm{K}, \mathrm{Na}$ and $\mathrm{Li}$ silicate compositions. Data are from [84, 88-90].

Figure 14 illustrates, for instance, how the fractions of tetrahedral units carrying different numbers of $\mathrm{BO}$ and NBOs at their summit vary along the $\mathrm{Li}_{2} \mathrm{O}-\mathrm{SiO}_{2}, \mathrm{Na}_{2} \mathrm{O}-\mathrm{SiO}_{2}$ and $\mathrm{K}_{2} \mathrm{O}-\mathrm{SiO}_{2}$ binary joins, from 0 to $40 \% \mathrm{M}_{2} \mathrm{O}(\mathrm{M}=\mathrm{Li}, \mathrm{Na}, \mathrm{K})$. As illustrated in this figure, a useful way to distinguish tetrahedral units 
Le Losq, Cicconi, Greaves, Neuville. Silicate Glasses. In: Springer Handbook of Glass. containing different numbers of BO and NBO is the $Q^{n}$ notation [85], where $n$ refers to the number of BO carried by the $\mathrm{SiO}_{4}$ tetrahedron $Q$. For example, the silica glass can be considered as composed of (ideally) only $Q^{4}$ units. Contrary to that, a sodium trisilicate $\mathrm{NaSi}_{3} \mathrm{O}_{7}$ glass $\left(75 \mathrm{~mol}_{0} \mathrm{SiO}_{2}\right)$ presents a distribution of $Q^{n}$ units with $48 \% Q^{4}, 50 \% Q^{3}$ and $2 \% Q^{2}$ [84]. Increasing the concentration in network modifier cations promotes the existence of $Q^{n-1}$ units at the expense of $Q^{n}$ units in the glasses (Fig. 14), this effect being proportional to the fraction of added network modifiers. In addition, this effect is not ideal and depends on the ionic field strength of the network modifier cation that is present in the glass (Fig. 14). For instance, lithium silicate glasses are richer in $Q^{2}$ and $Q^{4}$ units than sodium silicate glasses. This translates a tendency of $\mathrm{Li}^{+}$network modifier cations to cluster in the vicinity of $Q^{2}$ units in the network, leading to local enrichment in $Q^{4}$ units by compensation. This clustering may be related to the presence of network modifier percolation channels in the glass structure, as discussed in section 1.3.3. In all cases, increasing the metal cation ionic field strength in silicate glasses shifts the equilibrium:

$Q^{n} \Leftrightarrow Q^{n-1}+Q^{n+1}$

to the right-end side. One should note that, for a given composition, the equilibrium described by eq. (1) may also depend on the glass fictive temperature, which varies with the glass cooling rate. Indeed, higher temperature promote the shift of the reaction described by eq. (1) to the right, as shown by data from Raman spectroscopy and ${ }^{29}$ Si NMR spectroscopy of alkali silicate melts [e.g., 91-94].

The knowledge of the $Q^{n}$ distribution in glasses allows evaluating their ratio of NBO to tetrahedral units, $\mathrm{NBO} / \mathrm{T}$, which is a bulk measure of the glass polymerization. The NBO/T can be calculated from knowledge of the $Q^{n}$ units distribution as:

$\mathrm{NBO} / \mathrm{T}=4 \mathrm{xQ}^{0}+3 \mathrm{x}\left(\mathrm{Q}^{1}\right)+2 \mathrm{x}\left(\mathrm{Q}^{2}\right)+1 \mathrm{x}\left(\mathrm{Q}^{3}\right)$

or from the knowledge of the molar proportions of the different network formers $\mathrm{T}$, network modifier $\mathrm{M}^{\mathrm{i}+}$ and oxygen $\mathrm{O}$ ions, as $[95,96]$ :

$\frac{N B O}{T}=\frac{2 O-4 T}{T}=\sum_{j=1}^{j} \frac{i M_{j}^{i+}}{T}$. 
Le Losq, Cicconi, Greaves, Neuville. Silicate Glasses. In: Springer Handbook of Glass.

The glass chemical composition thus defines its $\mathrm{NBO} / \mathrm{T}$ as well as the distribution of its $Q^{n}$ species. Different models have been proposed to calculate the latter. The binary distribution model, suggested by Dupree et al.[97], predicts that only two species are present in the glass at given $\mathrm{SiO}_{2}$ content, such that the $Q^{n}$ units in the glass are distributed as binary combinations of $\mathrm{Q}^{4}-\mathrm{Q}^{3}, \mathrm{Q}^{3}-\mathrm{Q}^{2}, \mathrm{Q}^{2}-\mathrm{Q}^{1}$ and $\mathrm{Q}^{1}-\mathrm{Q}^{0}$ as observed in silicate minerals. Contrary to that, the random bonding model predicts that the concentration of a $Q^{n}$ unit can be calculated from a random distribution of the NBO and BO between the units. Figure 15 shows a representation of the two models.

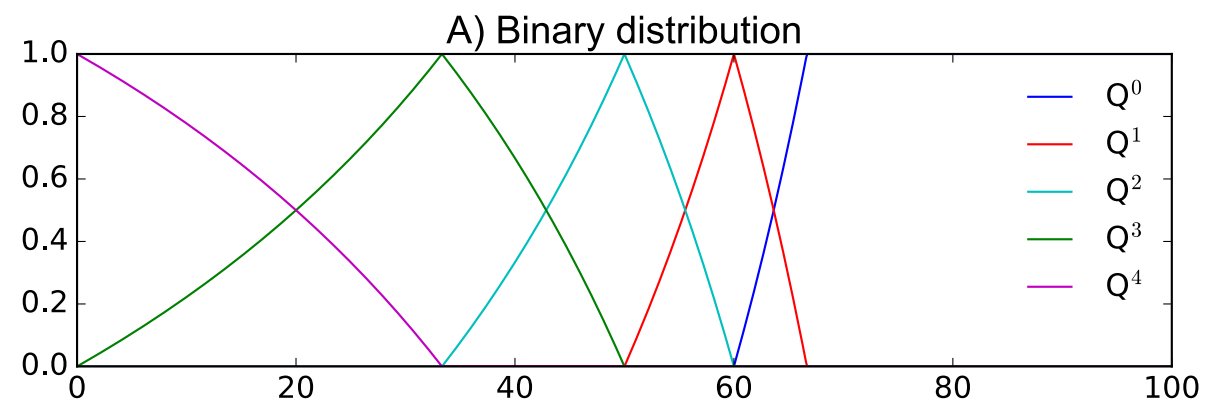

B) Random distribution

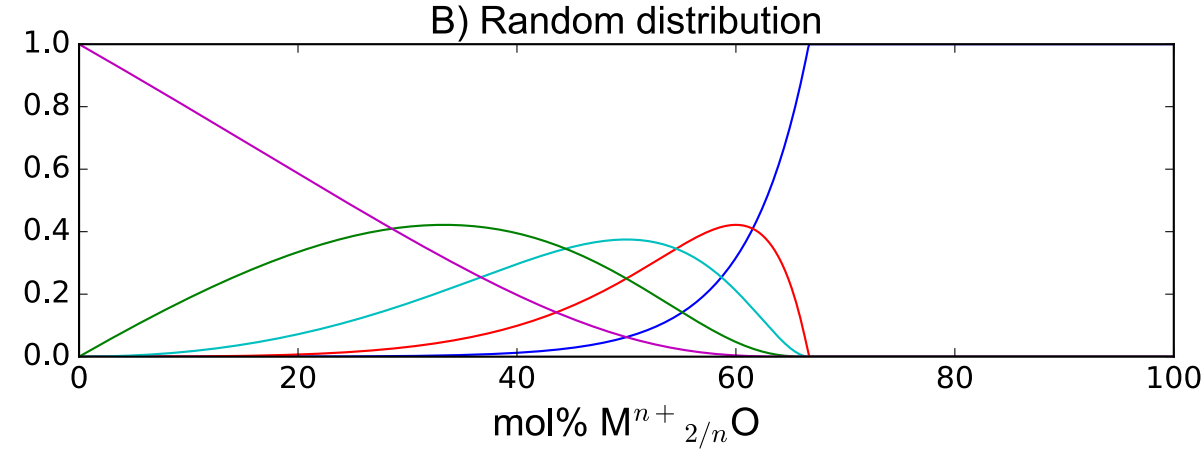

Figure 15: the binary (A) and random bonding (B) models predicting the fractions of the different $Q^{n}$ units as a function of the mol\% of $\mathrm{M}^{n+}{ }_{2 / n} \mathrm{O}$ in $\mathrm{SiO}_{2}$ (M a network modifier element, such as $\mathrm{Li}, \mathrm{Na}, \mathrm{K}, \mathrm{Ca}$ or $M g)$.

It is clear from the comparison of Figs. 14 and 15 that the reality lies between those two extreme visions. Neither the random bonding model nor the binary distribution model describe the measured distribution of $Q^{n}$ units observed in silicate glasses. Furthermore, those models do not account for the temperature dependence of the $Q^{n}$ unit speciation. Indeed, in glasses the $Q^{n}$ unit distribution is frozen-in, but as highlighted previously, it changes with $T$ in the molten state, such that glasses with different $T_{g} \mathrm{~s}$ will present slight variations in their $Q^{n}$ unit distribution [91-93]. Using the thermodynamic theory of affinity, the model of associated solutions was proposed to solve such issues [98-100]. This model is based on 
Le Losq, Cicconi, Greaves, Neuville. Silicate Glasses. In: Springer Handbook of Glass.

the idea that melts are media in which chemical reactions, characterized by their standard Gibbs free energies, proceed in the direction of the equilibrium state. The latter is reached when the total Gibbs free energy of the system reaches a minimum. More recently, Gaddam et al. [101] proposed a new model based on statistical mechanics. This model assumes grand canonical ensemble of silicate units, i.e. the $Q^{n}$ are considered as a statistical ensemble in thermodynamic equilibrium with a reservoir from which they exchange energy and network modifiers. The first test performed with this model, which takes into account the composition and temperature in the calculation of the $Q^{n}$ unit fractions, are promising and may offer a new way to calculate the distribution of $Q^{n}$ units in silicate melts. In particular, this model allows calculating the proportions of $\mathrm{Q}^{\mathrm{n}}{ }_{\mathrm{ijk}}$ units, where the $i j k l$ subscripts represent the $n$ number of the adjacent tetrahedral units to the central $Q$ unit. For instance, a $Q^{4}$ units bonded to 2 other $Q^{4}$ units and 2 $Q^{2}$ units will be described as $Q^{4}{ }_{2244}$. A $Q^{3}$ unit bonded to two other $Q^{3}$ unit and one $Q^{4}$ unit will be written $Q^{3}{ }_{334}$, the fourth subscript being omitted because of the NBO carried by the $Q^{3}$ unit. Such level of refinement has been reach by using ${ }^{29} \mathrm{Si}$ double quantum NMR spectroscopy, which allows discriminating the different $Q^{n}$ units bonded to the central $Q^{n}$ unit (Fig. 16).

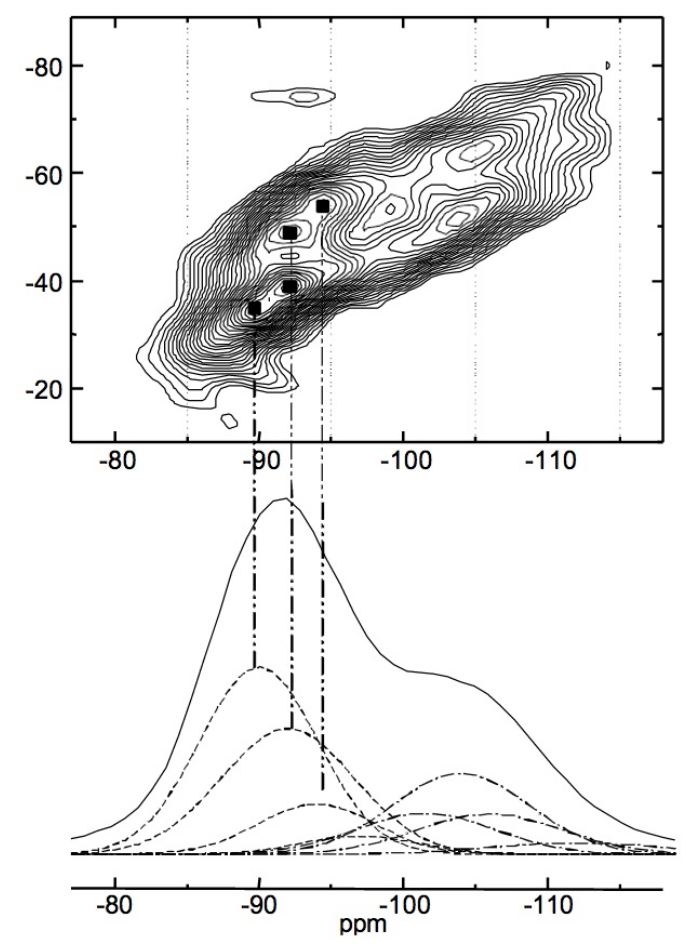

Figure 16: Top: Enlarged ${ }^{29} \mathrm{Si}$ double quantum (DQ) NMR spectrum of a $\mathrm{Na}_{2} \mathrm{Si}_{3} \mathrm{O}_{7}$ glass. The marked peaks with chemical shifts of 89, 92 and 94 ppm on the horizontal axis belong to $Q_{333}^{3}, Q_{334,}^{3} Q^{3}{ }_{344}$ units. These values can be used to fit the $1 D^{29}$ Si NMR spectrum of the glass with Gaussian peaks, as shown at the bottom. Hatched lines are used for the $Q^{3}{ }_{j k l}$ lines whereas long hatched lines with dots are used for 
Le Losq, Cicconi, Greaves, Neuville. Silicate Glasses. In: Springer Handbook of Glass.

the corresponding $Q_{j k l m}^{4}$ resonances in the linedeconvolution. Reprinted from Olivier et al. [102], Copyright (2001), with permission from Elsevier.

In addition to the statistical mechanic model of Gaddam et al. [101], the random connectivity model of Machacek et al. [103] also allows predicting the different fractions of $Q_{i j k l}^{n}$ units in the glass network. It assumes that the tetrahedra are linked fully on a random base. The distribution of $Q^{n}{ }_{i j k l}$ units are calculated using a multinomial distribution. This model can be seen as an extension of the random bonding model presented previously. It thus faces the same limitations, particularly in regards of the effect of temperature as well as the random character of tetrahedral bonding.

\subsection{2 $Q^{n}$ unit distribution: links with glass properties}

In the introduction, we showed that the density of an alkali silicate glass increases upon addition of alkali oxide while its $T_{g}$ dramatically decreases. Such changes actually can be correlated with the changes in the glass structure. In order to calculate the density of silicate glass, Doweidar [24, 104, 105] assigned different partial molar volumes to the different $Q^{n}$ units. His calculations allow to calculate the density of silicate glass, but, maybe more importantly, give some insights about the volume properties of $Q^{n}$ units. Indeed, he reported that, while the volume of $Q^{4}$ units seem to be constant and equal to that in pure $\mathrm{SiO}_{2}$, the volumes of $Q^{3}, Q^{2}$ and $Q^{1}$ units depend on the network modifier present in the glass network (Fig. 17).

First, for a given network modifier, the partial molar volume $V_{m}$ of the $Q^{n}$ units increases in the order $V_{m}\left(Q^{4}\right)<V_{m}\left(Q^{3}\right)<V_{m}\left(Q^{2}\right)<V_{m}\left(Q^{1}\right)<V_{m}\left(Q^{0}\right)$. This trend is explained by the fact that M-O distances are longer than Si-O distances (Table 3), such that $Q^{n}$ species surrounded by more network modifiers have higher partial $V_{m}$. Turning to the linear correlation between the ionic radius of the network modifiers and the volume of the $Q^{n}$ units, such volume effect is explained by the difference in the M-O bond length as the ionic radius of the $\mathrm{M}$ cation increases. Indeed, results from experiments and molecular dynamic simulations show that the ionic radius and M-O bond length are positively correlated (Table 3). 
Le Losq, Cicconi, Greaves, Neuville. Silicate Glasses. In: Springer Handbook of Glass.

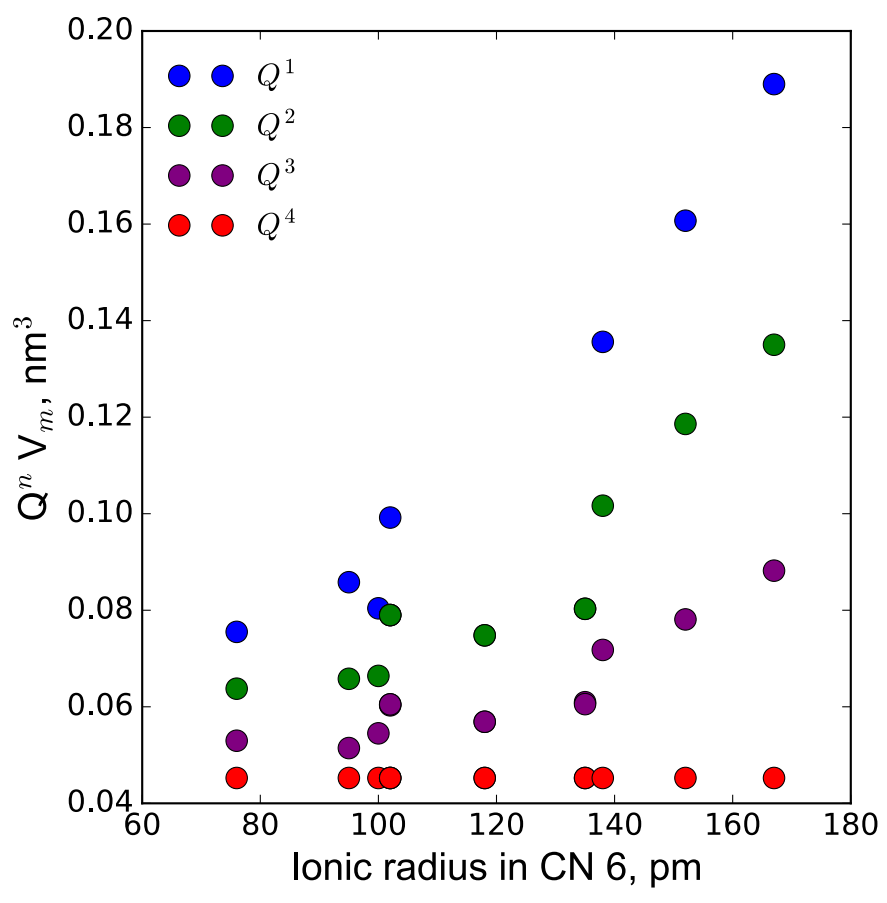

Figure 17: Partial molar volume of $Q^{n}$ units $V_{u}$ estimated by Doweidar $[105,106]$ as a function of the ionic radius of metal network modifier cations ( $\mathrm{Li}, \mathrm{Na}, \mathrm{K}, \mathrm{Rb}, \mathrm{Cs}, \mathrm{Ca}, \mathrm{Sr}, \mathrm{Ba}, \mathrm{Cd}$ ) in silicate glasses. Ionic radius is reported for a constant CN of 6, using values from Shannon [107]. Variations in the true CN of the modifiers may explain some of the scattering in this relationship [e.g., 108-111].

Table 3 show a comparison of $\mathrm{Si}-\mathrm{O}$ and $\mathrm{M}-\mathrm{O}$ distances obtained for alkali tetrasilicate glasses by experimental methods (X-ray and neutron diffraction experiments) and Car-Parrinello molecular dynamic simulations. We note that values from simulation and experiments are in good agreement. Both indicate that Si-NBO distances are shorter than Si-BO distances. Furthermore, in addition to being affected by the ionic radius of the $\mathrm{M}$ element, the $\mathrm{M}-\mathrm{O}$ distance changes as a function of the $\mathrm{O}$ atom: $\mathrm{M}-$ NBO distances appear to be significantly shorter than M-BO distances.

In addition to affecting the glass density and partial molar volume, the large changes in the polymerization of the glass structure that accompanies the changes in the glass chemistry strongly affect the glass thermodynamic and rheological properties. However, those changes are different. For instance, the glass heat capacity is an additive function of the glass composition, such that it can be calculated using a set of partial molar volumes of the glass oxide components, as provided by Richet [112]. In general, the heat capacity of silicate glasses tends to the Dulong and Petit limit $(=3 \mathrm{R}$, with $\mathrm{R}$ the perfect 
Le Losq, Cicconi, Greaves, Neuville. Silicate Glasses. In: Springer Handbook of Glass. gas constant) as $T$ tends to $T_{g}$, such that the glass heat capacity at $T_{g}$ can be calculated using this limit. However, this relationship should not be extended to other type of glasses, because, for instance, the glass heat capacity of $\mathrm{B}_{2} \mathrm{O}_{3}$ at $T_{g}$ only reach values $\sim 0.63 \mathrm{R}$ [see 112 and references therein].

\begin{tabular}{|r|c|c|l|l|l|l|l|l|}
\hline Glass & Si-O & Si-NBO & Si-BO & M-O & M-NBO & M-BO & Method & References \\
\hline $\mathrm{Li}_{2} \mathrm{Si}_{4} \mathrm{O}_{9}$ & $1.60(-)$ & - & - & $1.96(-)$ & - & - & Exp. & {$[113]$} \\
\hline $\mathrm{Li}_{2} \mathrm{Si}_{4} \mathrm{O}_{9}$ & $1.63(-)$ & $1.58(-)$ & $1.64(-)$ & $1.92(-)$ & $1.87(-)$ & - & MD. & {$[81]$} \\
\hline $\mathrm{Na}_{2} \mathrm{Si}_{4} \mathrm{O}_{9}$ & $1.625(11)$ & $1.589(8)$ & $1.65(8)$ & $2.45(40)$ & $2.29(24)$ & $2.52(25)$ & Exp. & {$[114]$} \\
\hline $\mathrm{Na}_{2} \mathrm{Si}_{4} \mathrm{O} 9$ & $1.63(-)$ & $1.58(-)$ & $1.65(-)$ & $2.28(-)$ & - & - & MD. & {$[115]$} \\
\hline $\mathrm{K}_{2} \mathrm{Si}_{4} \mathrm{O}_{9}$ & - & - & - & 2.77 & - & - & MD. & {$[116]$} \\
\hline
\end{tabular}

Table 3: Examples $M-O$ bond distances in tetrasilicate glasses reported from molecular dynamic simulations (MD.) and experimental (Exp.) studies.

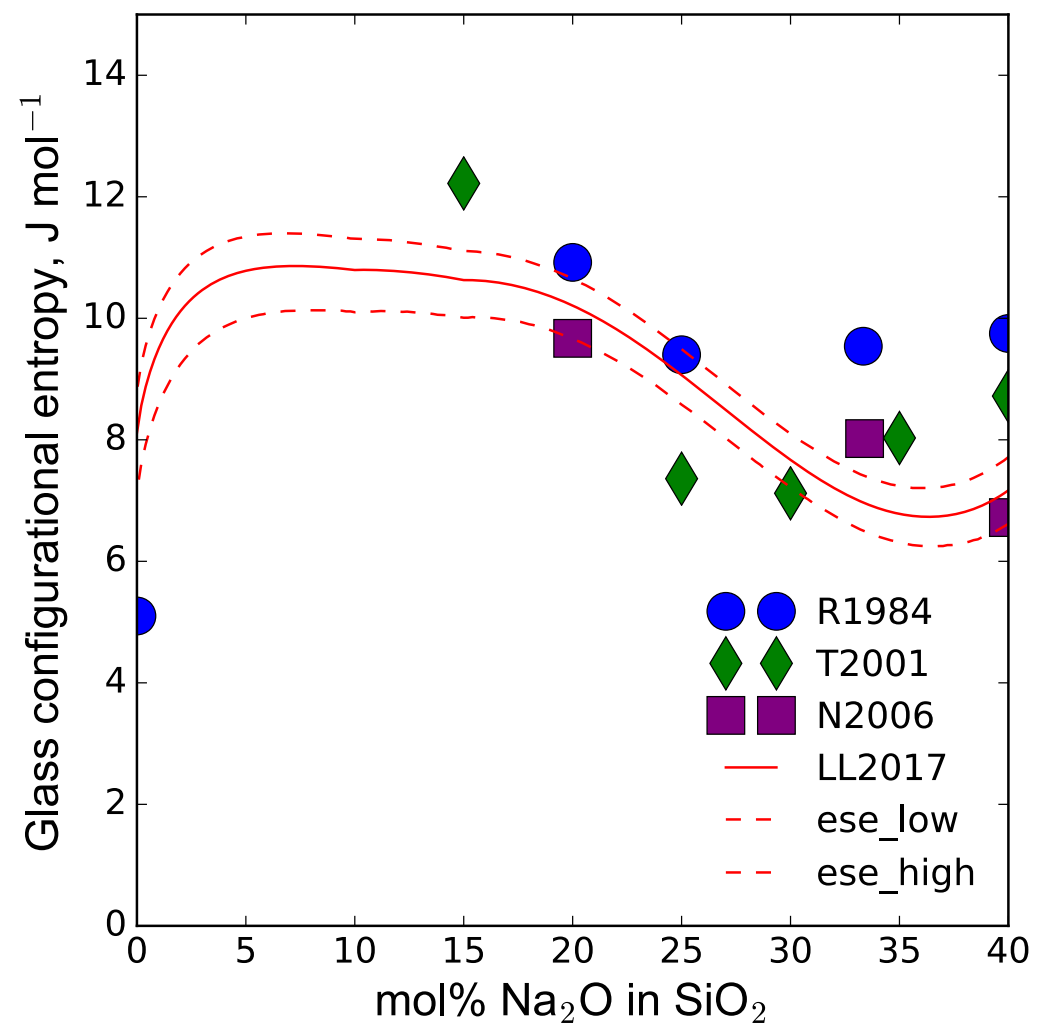

Figure 18: Glass configurational entropy, equal to the melt configurational entropy at $T_{g}$, as a function of the mol\% of $\mathrm{Na}_{2} \mathrm{O}$ added in $\mathrm{SiO}_{2}$. Those values were estimated from the fit of the melt viscosity data using the Adam and Gibbs theory of viscous flow (see chapter XXX), except the value of $5.1 \pm 2 \mathrm{~J} \mathrm{~mol}^{-1}$ 
Le Losq, Cicconi, Greaves, Neuville. Silicate Glasses. In: Springer Handbook of Glass.

for $\mathrm{SiO}_{2}$ that was estimated by [69] using the complete thermodynamic cycle. Errors bars on the points are not reported for clarity; they vary between 0.5 to $2 \mathrm{~J} \mathrm{~mol}^{-1}$. The red plain line (LL2017 in legend) and its associated errors represented by dashed lines (95\% confidence interval) represent the values calculated from the model of Le Losq and Neuville [20]. Other data come from individual fits of the viscosity data by [117; R1984 in legend], [[118; T2001 in legend] and N2006: [[23; N2006 in legend].

While the glass heat capacity is an additive function of the glass composition, the glass configurational entropy at $T_{g}$ is not. It presents complex and non-linear variations as a function of the glass composition (Fig. 18). Values reported in Fig. 18 were calculated using viscosity data, through the Adam and Gibbs theory that relates the viscous flow of silicate melts to their thermodynamic properties (see chapter XXX). Values calculated by different authors scatter significantly, showing the sensitivity of the calculation of the glass configurational entropy $S^{\text {conf }}$ using melt viscosity data to 1) the quality of the viscosity data and 2) the fitting protocols performed by the different authors. Le Losq and Neuville[[20] recently proposed a simple model to calculate $S^{\text {conf }}$ from the distribution of the $Q^{n}$ species in sodium and potassium silicate melts. This model deviates from an idea originally proposed by Mysen [119], which proposed that the configurational heat capacity of silicate melts $C_{p}^{\text {conf }}$ (equal to the difference between the melt $C_{p}$ at $T$ and the $C_{p}$ glass at $T_{g}$ ) can be calculated from partial molar heat capacity values $C_{p}^{Q^{n}}$ assigned to different $Q^{n}$ units:

$C_{p}^{\text {conf }}=\sum_{n=0}^{4} x_{Q^{n}} C_{p}^{Q^{n}}$

with $x_{Q^{n}}$ the fractions of the $Q^{n}$ units. Figure 19 shows that such model allows reproducing fairly well the $C_{p}^{\text {conf }}$ values derived from calorimetric measurements on alkali silicate glasses and melts. 
Le Losq, Cicconi, Greaves, Neuville. Silicate Glasses. In: Springer Handbook of Glass.

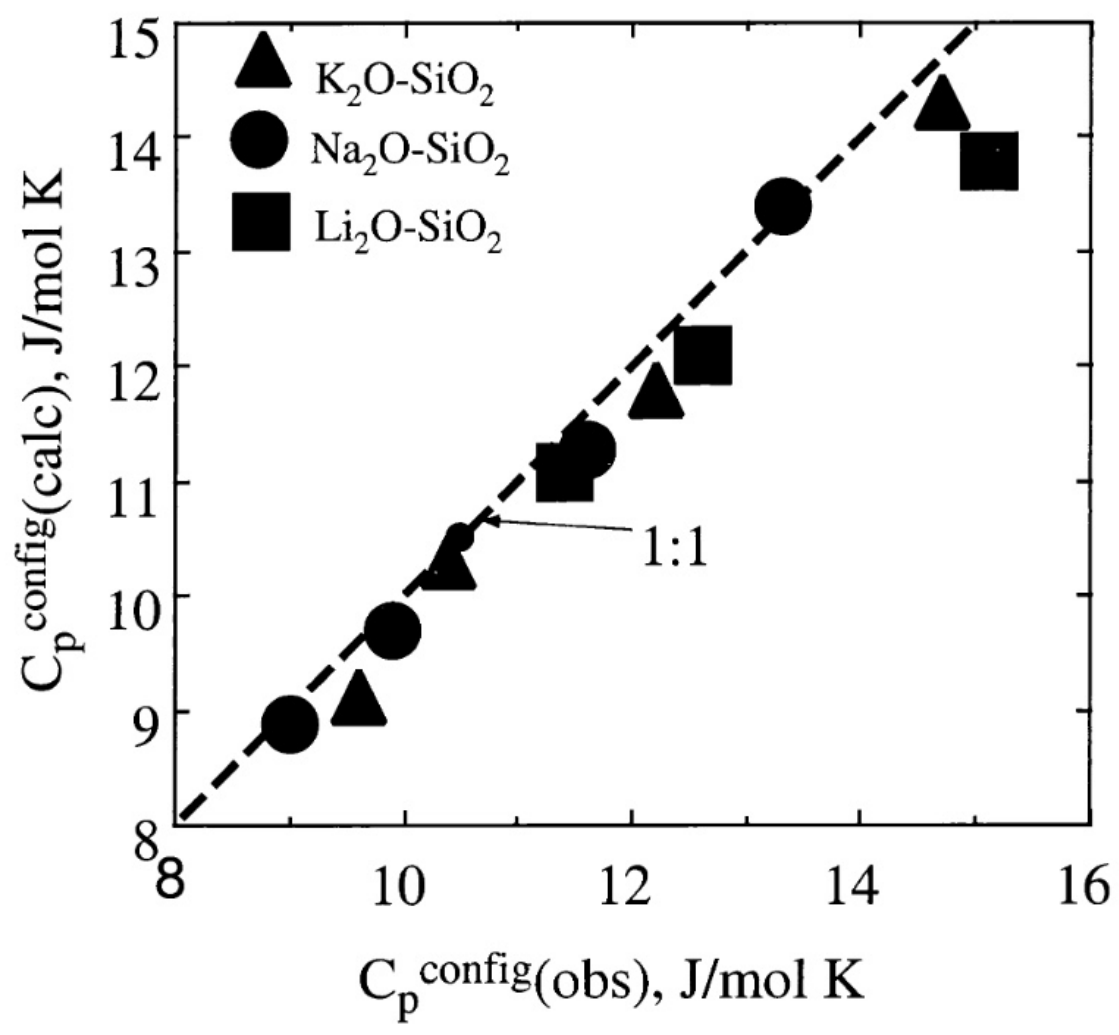

Figure 19: Comparison of the $C_{p}^{\text {conf }}$ values calculated by Mysen [94] using the model resumed in eq. (2) at $1400^{\circ} \mathrm{C}$ and values derived from measurements. Reprinted from Mysen [94], Copyright (1999), with permission from Elsevier.

Following the idea of Mysen [119], Le Losq and Neuville [20] assigned $S^{\text {conf }}$ partial molar values to the different $Q^{2}, Q^{3}$ and $Q^{4}$ units in the melt, allowing one to calculate the topological contribution to the configurational entropy of the glass, i.e. the entropy arising from the disorder in the tetrahedral network in term of $\mathrm{Si}-\mathrm{O}$ bond distances and $\mathrm{Si}-\mathrm{O}-\mathrm{Si}$ bond length. Indeed, the configurational entropy of glasses can be divided in topological $S^{\text {topo }}$ and chemical $S^{\text {mix }}$ contributions as:

$S^{\text {conf }}=S^{\text {topo }}+S^{\text {mix }}$.

$S^{\text {topo }}$ originates from the disorder in the glass network, in term of Si-O bond distances and Si-O-Si bond length for instance. $S^{\text {mix }}$ represents the excess of entropy generated by the mixing of different elements in similar structural positions. Le Losq and Neuville [[20] thus calculated $S^{\text {topo }}$ as:

$S^{\text {topo }}=\sum_{n=2}^{4} x_{Q^{n}} S_{Q^{n}}^{\text {conf }}$, 
Le Losq, Cicconi, Greaves, Neuville. Silicate Glasses. In: Springer Handbook of Glass. and $S^{m i x}$ as:

$S_{S i}^{m i x}=-x_{S i} / x_{O} * 2 R * \sum_{n=2}^{4} x_{Q^{n}} \ln \left(x_{Q^{n}}\right)$,

with $R$ the perfect gaz constant, and $x_{S i}$ and $x_{O}$ the atomic fractions of $\mathrm{Si}^{4+}$ and $\mathrm{O}^{2-}$. In eq. (6), different $S_{Q^{n}}^{\text {conf }}$ values are used for potassium and sodium silicate melts as the coupling between the $\mathrm{M}$ alkali modifier and the $Q^{n}$ tetrahedral species varies with the ionic radius of M. The factor 2 in eq. (7) arises when working using an $\mathrm{O}_{2}$ base to express the thermodynamic values (i.e. the structural formula is expressed using an $\mathrm{O}_{2}$ base). This simple model allows one to calculate the configurational entropy of alkali silicate glasses with a good accuracy, falling in between the individual values reported by previous studies (Fig. 18). Adopting a thermodynamic and structural point of view, this model further provides pieces of information regarding the origin of the evolution of the silicate glass $T_{g}$ along the binary $\mathrm{M}_{2} \mathrm{O}$ $\mathrm{SiO}_{2}$ join (Fig. 20).

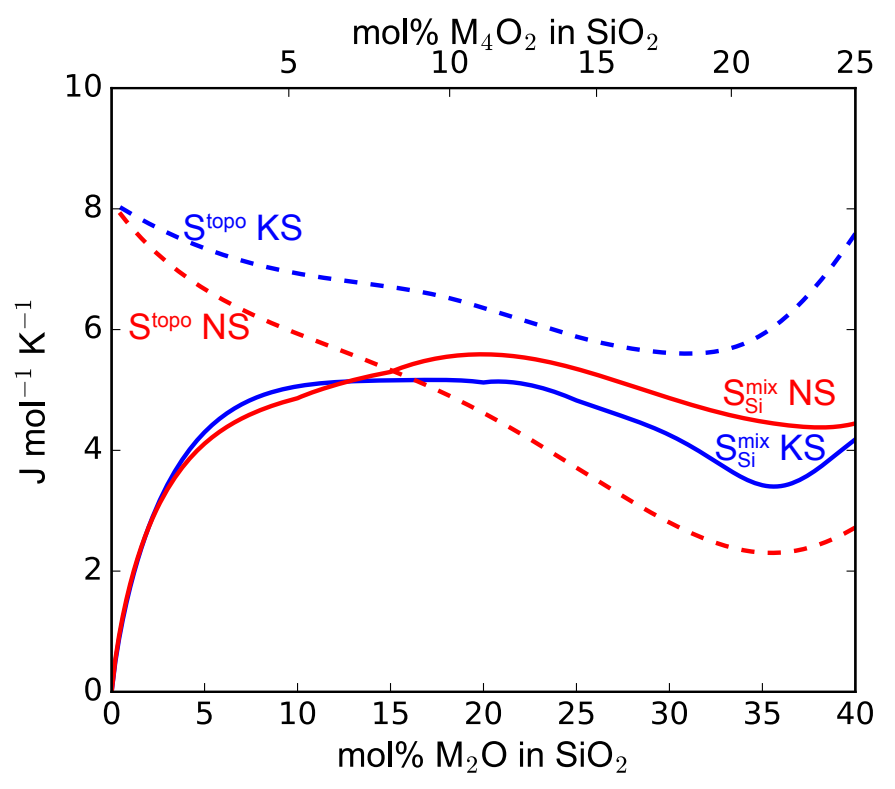

Figure 20: Variation of the topological and mixing contributions to the entropy of potassium and sodium silicate melts as predicted by equation 3 and 4, respectively, as a function of the concentration in alkali oxide in the melt. Values from [20].

Indeed, the model predicts that the apparition of $Q^{3}$ species upon addition of a few mol\% alkali oxide in $\mathrm{SiO}_{2}$ leads to a large, dramatic increase in the chemical contribution to the glass configurational entropy because Si can mix between the existing $Q^{4}$ and the newly formed $Q^{3}$ units. In other term, this illustrates 
Le Losq, Cicconi, Greaves, Neuville. Silicate Glasses. In: Springer Handbook of Glass.

that the introduction of NBO in the glass network allows new configurational environments for $\mathrm{Si}$, and lowers the melt viscosity and glass $T_{g}$. The model further predicts that the glass topological entropy varies nearly linearly (Fig. 20), being driven by the changes in the $Q^{n}$ unit distribution. This model remains to be further tested by new research, but together with the works of Mysen [[94, 119] and Doweidar [24, $104,105]$, it illustrates that the $Q^{n}$ unit distribution can be a useful tool for modelling the properties of silicate glasses.

\subsubsection{Structure at medium range order and the Mixed Alkali Effect}

While at short range order, the structure of silicate glasses can be described as a mixture of interconnected $Q^{n}$ units with interstitial network modifier elements forming ionic bonds with NBOs as discussed in the previous section, such vision is difficult to extrapolate at the medium range order. Indeed, the network modifier cations have high coordination numbers, and are surrounded by both BO and NBOs from several $Q^{n}$ units [e.g., 120, 121]. For instance, in aluminum-free silicate glasses, $\mathrm{Ca}^{2+}$ and $\mathrm{Mg}^{2+}$ coordinence numbers are of $\sim 4-5[109,122-124]$, whereas that of $\mathrm{Na}^{+}$is $\sim 6[110,111,125]$. The network modifier cations thus have defined local environment, such that the RN model (see section 1.1) cannot account for their distribution in silicate glasses because it assumes their random repartition in the free volume in the silicate network [126]. An alternative model is thus needed to describe the arrangement of the different network former and modifiers cations in the glass structure.

Two models were proposed to account for the environment of network modifiers in silicate glasses. From the interpretation of X-ray absorption results [126-129], Greaves and co. proposed the Modified Random Network (MRN) model. It depicts the glass structure as a tri-dimensional arrangement of dynamic channels of network modifier metal cations percolating through a disrupted silicate tetrahedral network. Such channels are dynamic features in the molten state, and become frozen-in in the glasses below $T_{g}$. However, the interpretations of ${ }^{23} \mathrm{Na}$ and ${ }^{17} \mathrm{O} \mathrm{NMR}$ data on sodium silicate and alumino-silicate glasses lead Lee and co. [130-132] to propose an alternative model: the Perturbed Cation Distribution (PCD) model. The PCD model assumes a relatively homogeneous distribution of metal cations in the glass network, neither random nor forming clusters. It describes network modifiers as surrounded by both NBO and BO anions, as indicated by NMR data [e.g., 132]. Whether one adopts the MRN or the PCD model to describe the glass structure, the adopted model needs to explain an effect that greatly affect the glass properties: the Mixed Modifier Effect. This effect is also called the Mixed Alkali Effect (MAE) or 
Le Losq, Cicconi, Greaves, Neuville. Silicate Glasses. In: Springer Handbook of Glass.

the Mixed Alkaline-earth Effect (MME) in the literature. To avoid confusion, we chose to use the MME denomination in the present handbook.

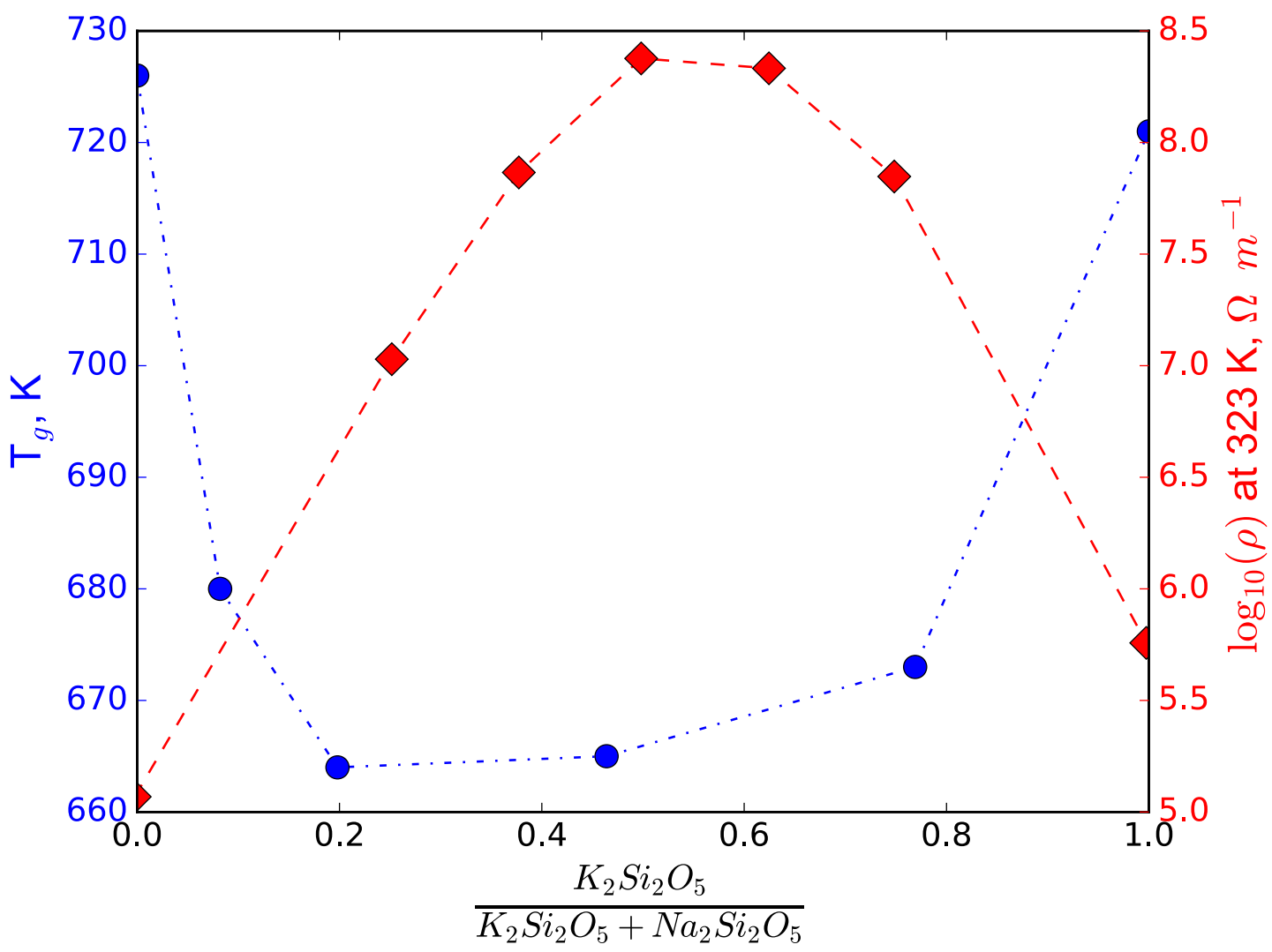

Figure 21: Glass transition temperature $T_{g}$ and logarithm of the electrical resistivity at $373 \mathrm{~K}_{\text {of }} \mathrm{K}_{2} \mathrm{Si}_{2} \mathrm{O}_{5^{-}}$ $\mathrm{Na}_{2} \mathrm{Si}_{2} \mathrm{O}_{5}$ mixed glasses, as a function of the fraction of $\mathrm{K}$ in the glasses. The Mixed Modifier Effect (MME) refers to the non-linear and large deviations of many glasses properties when mixing two network modifier elements in the glasses. Data from [133-135].

The MME refers to the strong and non-linear changes in silicate glass properties that can occur upon mixing two metal cations [e.g., see 136, 137 and references cited therein]. Figure 21 illustrates this effect on the $T_{g}$ and the electric resistivity of glasses that are mixtures of $\mathrm{K}_{2} \mathrm{Si}_{2} \mathrm{O}_{5}$ and $\mathrm{Na}_{2} \mathrm{Si}_{2} \mathrm{O}_{5}$. Upon mixing $\mathrm{Na}^{+}$and $\mathrm{K}^{+}$in the glasses, a large depression in the glass $T_{g}$ is observed while the electric resistivity increases of several orders of magnitude. The MME usually results in maxima or minima of the glass properties when the ratio $A /(A+B)$ between the mixed $A$ and $B$ cations reach 0.5 . This effect has been extensively documented for $\mathrm{Na}$ and $\mathrm{K}$ in silicate glasses [e.g., see 136, 137 and references therein], but it also occurs in silicate glasses when mixing different alkaline-earth cations such as, for instance, Ca and $\operatorname{Mg}[22,138,139]]$. In Al-free silicate glasses, mixing alkali modifier cations seems to lead to larger 
Le Losq, Cicconi, Greaves, Neuville. Silicate Glasses. In: Springer Handbook of Glass.

deviations to linearity than mixing alkaline-earth modifier cations [139]. The MME also occurs in Albearing silicate glasses [140-143], but recent data suggest that it may be more complex that the MME in Al-free silicate glasses [57], such that it will be treated separately in the case of Al-bearing glasses in sec. 1.4.5. In all cases, the MME affects various glass properties, such as, for instance, the glass $T_{g}$, Vickers hardness, compressibility, electrical resistivity or ionic conductivity (e.g., Fig. 21).

The source of the MME has been an extensive subject of study, and no real consensus about its origin has yet been reached because of the complexity of ionic diffusion in glasses. The MRN model of the glass structure was initially accounting for this effect by assuming that the diffusions of two different modifier cations were affected by the presence of each other in the channels [128]. Greaves and Ngai [121] further refined the MRN model to explain the MAE. They proposed that the alkali modifiers diffuse in the channels through a mechanism of cooperative intrachannel hopping. According to them, the increase in electrical resistivity observed upon mixing modifier cations (Fig. 21) reflects radical changes and differences in the diffusion coefficients of the modifier cations. Such cation diffusivity can be calculated as a function of the $R_{M-M}$ inter-cationic distances, the hopping attempt frequency $v_{o}$, the diffusion frequency factor $D_{o}$, the activation enthalpy $W$, the Boltzmann constant $k$ and the temperature $T$ as [129]:

$D_{0}=R_{M-M}^{2} v_{o} / 6$

$(e q D o G N)$

$D=D_{0} e^{-W / k T}$

$(\mathrm{eqDGN})$

Figure 22 shows the results of such calculation: the diffusivity of $\mathrm{Na}$ and $\mathrm{K}$ are calculated at 25, 200 and $350^{\circ} \mathrm{C}$ in mixed $\mathrm{Na}-\mathrm{K}$ trisilicate glasses; this allows the calculation of the electrical conductivity. The agreement between the model and experimental data is also shown, and the model reproduces fairly well the predicted deviations. However, looking in details, it predicts too strong depletion of the electrical conductivity at $\mathrm{K} /(\mathrm{K}+\mathrm{Na}) \sim 0.5$. 
Le Losq, Cicconi, Greaves, Neuville. Silicate Glasses. In: Springer Handbook of Glass.

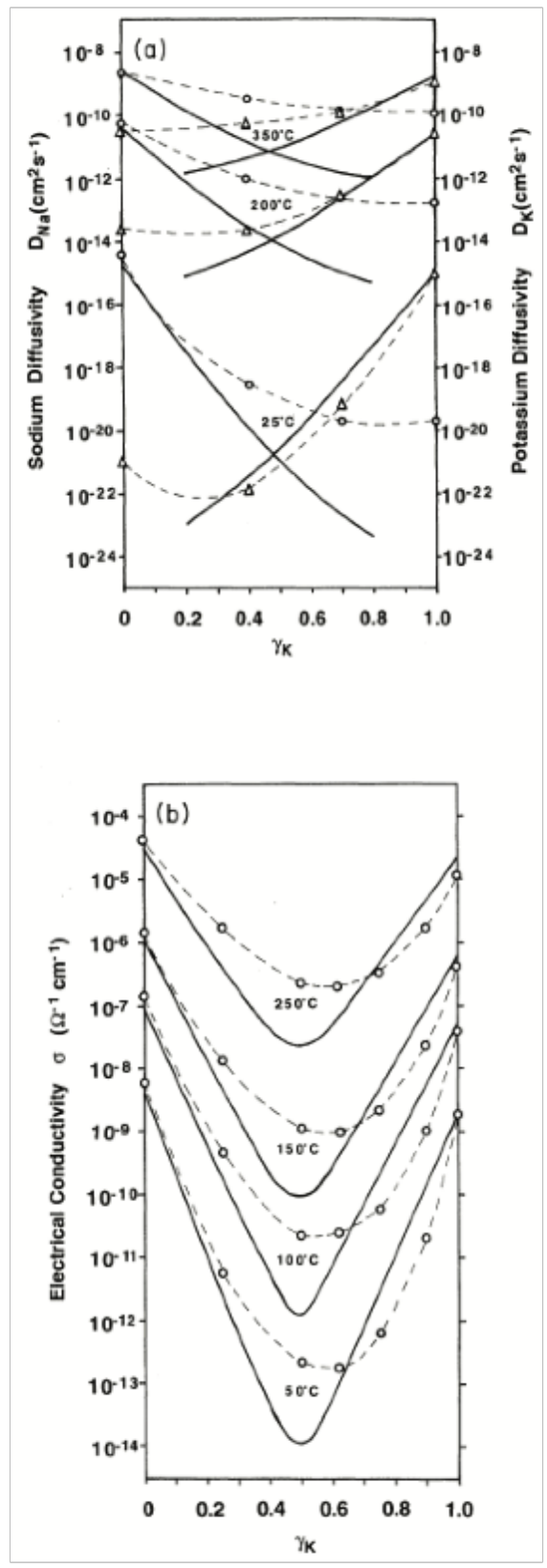

Figure 22: A) Isothermal diffusion coefficients and B) electrical conductivities for the mixed alkali glasses $0.25[\mathrm{~K} \gamma \mathrm{KNal}-\gamma \mathrm{K}]_{2} \mathrm{O}-0.75 \mathrm{SiO}_{2}$. Points are experimental data, dashed lines are interpolations of those data, and the plain lines are the prediction by the model proposed by Greaves and Ngai [129]. Reprinted figure with permission from G.N. Greaves and K.L. Ngai, Physical Review B. 52, 6358-6380, 1995, doi:10.1103/PhysRevB.52.6358. Copyright (1995) by the American Physical Society

In all cases, the existence of ionic diffusive pathway for modifier cations, as depicted by the MRN model, has been supported by results from atomic force microscopy [e.g., 144], molecular dynamic simulation [e.g., 145, 146], NMR [e.g., 102] and inelastic neutron scattering [e.g., 147-150] experiments. In the 
Le Losq, Cicconi, Greaves, Neuville. Silicate Glasses. In: Springer Handbook of Glass.

framework of the Adam and Gibbs [151] theory of viscous flow, which describes liquid relaxation, and hence, viscous flow as a cooperative re-arrangement mechanism of sub-systems in the liquid, the minima in $T_{g}$ (and, hence, viscosity) observed upon mixing $\mathrm{Na}$ and $\mathrm{K}$ in silicate melts is explained by an excess of configurational entropy at $T_{g}$ that originates from a random mixing of pairs of alkali metals [117], as shown by ${ }^{17} \mathrm{O}$ Dynamic Angle Spinning NMR experiments [152]. This interpretation supports the cooperative inter-diffusion and mixing of metal cations in ionic channels percolating through a disrupted silicate tetrahedral network. It is interesting to note that the MAE affects properties that are related to the diffusivity of the network modifiers, but it affects much less properties related to the silicate tetrahedral network. Indeed, mixing alkali elements in silicate glasses yields to nearly-linear variations in the fraction of the $Q^{n}$ species [see 20 and references cited therein] as well as in that of NBO in the network [152]. Similarly, molar volume or density of silicate glasses are only slightly affected by the MAE [136, 137].

As highlighted previously, not all data support the clustering of modifiers in percolation channels. Lee and co. [130-132] observed that modifier cations are interacting with both BO and NBOs, such that they should be homogeneously distributed in the glass network. Recently, Angeli et al. [153] also interpreted ${ }^{17} \mathrm{O}$ MQMAS data as showing a uniform distribution of $\mathrm{Na}$ in sodium silicate glasses, because the twodimensional projection of the ${ }^{17} \mathrm{O}$ NMR chemical shift and quadrupolar coupling constant distributions for $\mathrm{BO}$ oxygens in the $\mathrm{Na}_{2} \mathrm{Si}_{2} \mathrm{O}_{5}$ and the $\mathrm{SiO}_{2}$ glasses are not overlapping. Therefore, ${ }^{23} \mathrm{Na}$ and ${ }^{17} \mathrm{O} \mathrm{NMR}$ results on silicate and alumino-silicate glasses seem to support the alternative Perturbed Cation Distribution (PCD) model, which neither implies a random distribution of the modifiers nor their segregation in specific regions of the network. The PCD model particularly predicts that if different network modifier cations are present in the glass network, they present various degree of ordering between them. The model thus introduces a parameter $Q_{m}$ that describes the degree of intermixing between different network modifier cation: $Q_{m}=1$ for a chemical order favoring dissimilar pairs, $Q_{m}=$ 0 for a random mixing and $Q_{m}=-1$ for clustering of similar cations $[120,131]$. For instance, as indicated earlier, 2D Dynamic Angle Spinning NMR data support a random mixing of $\mathrm{Na}$ and $\mathrm{K}$ in silicate glasses [152], resulting in an excess of entropy that explains the observed minima in the glass transition temperature during the Na-K mixing (e.g., Fig. 21 ). Contrary to that, ${ }^{17} \mathrm{O}$ MAS and 3 QMAS NMR data on $\mathrm{Ca}$ and $\mathrm{Na}$ silicate glasses indicate that those two cations mix in dissimilar pairs [120], this explaining why the random mixing model does no explain the viscosity variations upon mixing $\mathrm{Na}$ and $\mathrm{Ca}$ in silicate melts [23]. Similarly, Ba shows a stronger affinity for NBO than $\mathrm{Na}$ in $\mathrm{Ba}-\mathrm{Na}$ silicate melts, while in Ba$\mathrm{Mg}$ silicate melts, a $\mathrm{Ba}$ and $\mathrm{Mg}$ are not randomly ordered around the NBOs [121]. Overall, those results 
Le Losq, Cicconi, Greaves, Neuville. Silicate Glasses. In: Springer Handbook of Glass.

lead Lee [131] to suggest that most results from NMR spectroscopy point to $Q_{m}$ variations in silicate glasses between 0 and 1 , and that values $<0$, corresponding to clustering, are unlikely.

While ${ }^{23} \mathrm{Na}$ and ${ }^{17} \mathrm{O}$ NMR from Lee and co. [120, 121, 130-132] or Angeli et al. [153] support the PCD model for accounting of the metal cation distribution in silicate glasses, it must be said that other ${ }^{29} \mathrm{Si}$ NMR data point in favour of the MRN model. Results of Olivier et al. [102] from ${ }^{29} \mathrm{Si}$ Double Qantum NMR experiments and MD simulations indicate that $Q^{4}$ units are connected to both $Q^{4}$ and $Q^{3}$ units, supporting the existence of silica-rich domains as depicted in the MRN model. Performing ${ }^{29} \mathrm{Si}$ and ${ }^{17} \mathrm{O}$ experiments on potassium silicate glasses with $\mathrm{SiO}_{2}$ contents higher than $75 \mathrm{~mol} \%$, Sen and Youngman [88] identified two different type of $Q^{4}$ units in silica-rich potassium silicate glasses: some $Q^{4}$ are connected to $Q^{3}$ units (called $Q^{4-3}$ units by Sen and Youngman) while others are only connected to $Q^{4}$ units (called $Q^{4-4}$ units by Sen and Youngman). They proposed that $\mathrm{Q}^{3}$ and $\mathrm{Q}^{4}$ units were actually mixing randomly, but this naturally yields to a clustering of $Q^{3}$ units in a $Q^{4}$ rich network. According to those authors, increasing the $\mathrm{mol} \% \mathrm{~K}_{2} \mathrm{O}$ content about a particular threshold, equal to $7.5 \mathrm{~mol} \% \mathrm{~K}_{2} \mathrm{O}$, yields to a three-dimensional percolation of those clusters. This ultimately forms the ionic percolation channels depicted by the MRN model. Sen and Youngman further indicate that such interpretation would explain why results from molecular dynamic simulation from [154] indicated that the MAE was not occurring a very low alkali concentration.

The presence of silica-rich domain in silicate glasses as well as the dependence of the MRN on the modifier nature also is supported by Raman spectroscopy data on alkali silicate glasses. For instance, Matson et al. [155] observed that the alkali ionic radius was influencing the Raman signals in the 200$700 \mathrm{~cm}^{-1}$ portion of Raman spectra of alkali silicate glasses. In particular, they observed that the 200-500 $\mathrm{cm}^{-1}$ portion of the Raman spectra of Li silicate glasses was similar to that of the $\mathrm{SiO}_{2}$ glass, as illustrated in figure 23 . 
Le Losq, Cicconi, Greaves, Neuville. Silicate Glasses. In: Springer Handbook of Glass.

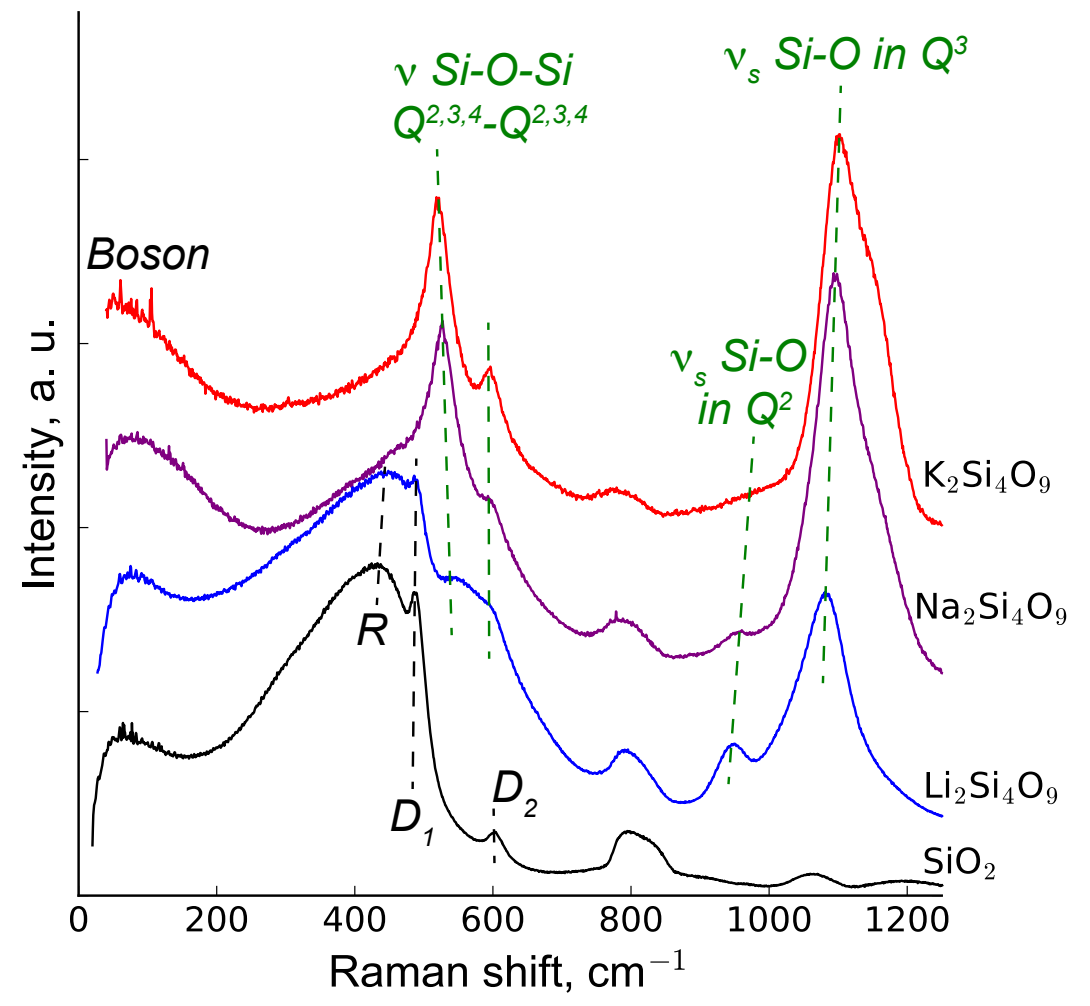

Figure 23: Raman spectra of silica and alkali tetrasilicate glasses. The Boson peak at $\sim 60-80 \mathrm{~cm}^{-1} \mathrm{can}$ be assignment to collective transverse acoustic vibrational modes [32] promoted in silicate glasses by cooperative inter-tetrahedral librations [33-35]. In the Raman spectra of the $\mathrm{SiO}_{2}$ glass, the peaks between 200 and $700 \mathrm{~cm}^{-1}$, with in particular the $R, D_{1}$ and $D_{2}$ signals, are assigned to vibrations of rings of $Q^{4}$ tetrahedral units, see section 1.3.1 and figure 11 for details. In sodium and potassium silicate, new peaks at $\sim 520$ and $\sim 595 \mathrm{~cm}^{-1}$ appear; they do not result from the shift of the pre-existing peaks in $\mathrm{SiO}_{2}$, but are assigned to Si-O-Si vibrations involving $Q^{3}$ and $Q^{2}$ units [43] (those signals are annotated $v_{s}$ Si$O-S i Q^{2,3,4}-Q^{2,3,4}$ in the figure). The change in the 200-700 $\mathrm{cm}^{-1}$ Raman signal occurring upon addition of $\mathrm{Na}$ or $\mathrm{K}$ in $\mathrm{SiO}_{2}$ thus indicate a breaking of the three-dimensional tetrahedral network in those glasses. However, we observe that the 200-500 $\mathrm{cm}^{-1}$ signals from the $\mathrm{Li}_{2} \mathrm{Si}_{4} \mathrm{O}_{9}$ glass are very similar to those in $\mathrm{SiO}_{2}$. As this glass contain more $Q^{2}$ and $Q^{4}$ units than the $\mathrm{Na}_{2} \mathrm{Si}_{4} \mathrm{O}_{9}$ or $\mathrm{K}_{2} \mathrm{Si}_{4} \mathrm{O}_{9}$ glasses (Fig 14), this suggests that it exists silica-like molecular complexes containing $Q^{4}$ units in this glass, and, hence, support the modified random network of the structure of silicate glasses. The peaks between 900 and $1300 \mathrm{~cm}^{-1}$ are assigned to Si-O vibrations in $Q^{n}$ units $[43,58,82,155]$. In particular, the peaks near 950 and $1100 \mathrm{~cm}^{-1}$ are assigned to Si-O symmetric stretching vibrations in $Q^{2}$ and $Q^{3}$ units, respectively. Spectra are from $[20,75,156]$. 
Le Losq, Cicconi, Greaves, Neuville. Silicate Glasses. In: Springer Handbook of Glass.

Indeed, signals in the $200-700 \mathrm{~cm}^{-1}$ portion of the Raman spectra of silicate glasses are assigned to breathing vibrations of the Si-O-Si bonds [36, 38, 39, 41, 43, 44, 53, 54, 58]. The Raman spectra of LS4 presents a maximum near $460 \mathrm{~cm}^{-1}$ and a small sharp peak at $490 \mathrm{~cm}^{-1}$. Those signals are very similar to those found in the $\mathrm{SiO}_{2}$ Raman spectra, where they are assigned to breathing vibrations of rings with 4 or more tetrahedral units (Fig. 11 and sec. 1.2.1). Contrary to that, the Raman spectra of the sodium and potassium tetrasilicate glasses do not present such signals, but two new peaks centred at 518 and $595 \mathrm{~cm}^{-}$

${ }^{1}$, assigned to Si-O-Si vibrations involving $Q^{3}$ and $Q^{2}$ units [43, 155, 157-159]. According to Matson et al[155], the similarity between the Raman spectra of the $\mathrm{SiO}_{2}$ and $\mathrm{Li}_{2} \mathrm{Si}_{4} \mathrm{O}_{9}$ glasses indicate the presence of silica-rich regions in the Li silicate glass. Therefore, a dissociation of $Q^{3}$ species into $Q^{2}$ and $Q^{4}$ species higher in the Li silicate than in the $\mathrm{Na}$ and $\mathrm{K}$ silicate glasses (Figure 14) may actually suggest a segregation of Li around $Q^{2}$ units, and of $Q^{4}$ units in silica-like regions as depicted by the MRN model. For lithium silicate glasses, such interpretation is supported by the ${ }^{29} \mathrm{Si}\left\{{ }^{7} \mathrm{Li}\right\}$ rotational echo double resonance spectroscopy results from Voig et al[160]]. Indeed, almost independently of the silica content, the $\mathrm{Li}^{7}$ dipolar filed measured at the $Q^{3}$ sites is stronger than that measured at the $Q^{4}$ sites in Li silicate glasses. This supports the clustering of $\mathrm{Li}$ in the network of silicate glasses. To conclude, it should be noted that the precedent interpretation yields to an interesting fact. In alkali silicate glasses, increasing the IFS of network modifiers seems to lead the alkalis to cluster around $Q^{n-1}$ units at the expense of $Q^{n}$ units, and, hence, affect the distribution of the $Q^{n}$ units in the glass (Fig. 14). As a result, the $Q^{n}$ distribution actually tends toward that predicted by a random mixing of NBO and $\mathrm{BO}$ amongst $Q^{n}$ units (Fig. 15), while one may have been tempted to draw the opposite conclusion. This arises from the fact that randomness is not correlated with homogeneity, but, on the contrary, rather may led to heterogeneity as proposed by Sen and Youngman [88].

\section{$\underline{1.4 \text { Aluminum in silicate glasses }}$}

Addition of aluminum in silicate glasses is known to improve their mechanical properties, such as, for instance, their chemical durability or their hardness. Aluminum is thus vastly used in technical glasses in the industry to confer interesting properties to the final products. For instance, at the present era of smartphones and tablets, one well known example of an alumino-silicate glass is the Gorilla ${ }^{\circledR}$ Glass from the Corning ${ }^{\circledR}$ company. However, the interest in alumino-silicate glasses is not limited to the industrial domain. Indeed, alumino-silicate glasses are common products of geological processes, deriving from the rapid quench of magmatic liquids. For instance, they can be entrapped in crystals in deep magma 
Le Losq, Cicconi, Greaves, Neuville. Silicate Glasses. In: Springer Handbook of Glass.

chambers, and, once retrieved at the surface, they provide fundamental information about geological processes on Earth [e.g., 161-163] or the Moon [164, 165]. On a fundamental note, if we assume the presence of a magmatic ocean at the surface of the Earth after its formation 4.567 Ga ago [see 166 and references cited therein], it then must be said that the properties of the alumino-silicate melt composing the magma ocean drove the segregation of Earth iron core and the formation of Earth mantle and crust. This illustrates the importance of aluminium in silicate melts, which, hence, deserves a particular attention.

\subsubsection{Local environment of aluminum}

As previously highlighted, numerous studies have documented the effect of the addition of aluminum in silicate composition on the glass properties. For instance, adding $\mathrm{Al}$ in a $\mathrm{NaSi}_{3} \mathrm{O}_{7}$ glass produces a large, non-linear increase in its glass transition temperature (Fig. 24). Such variation points to the fact that $\mathrm{Al}^{3+}$ enters in the structure of silicate glasses as a network former element, mostly in tetrahedral coordination $[83,167-170]$.

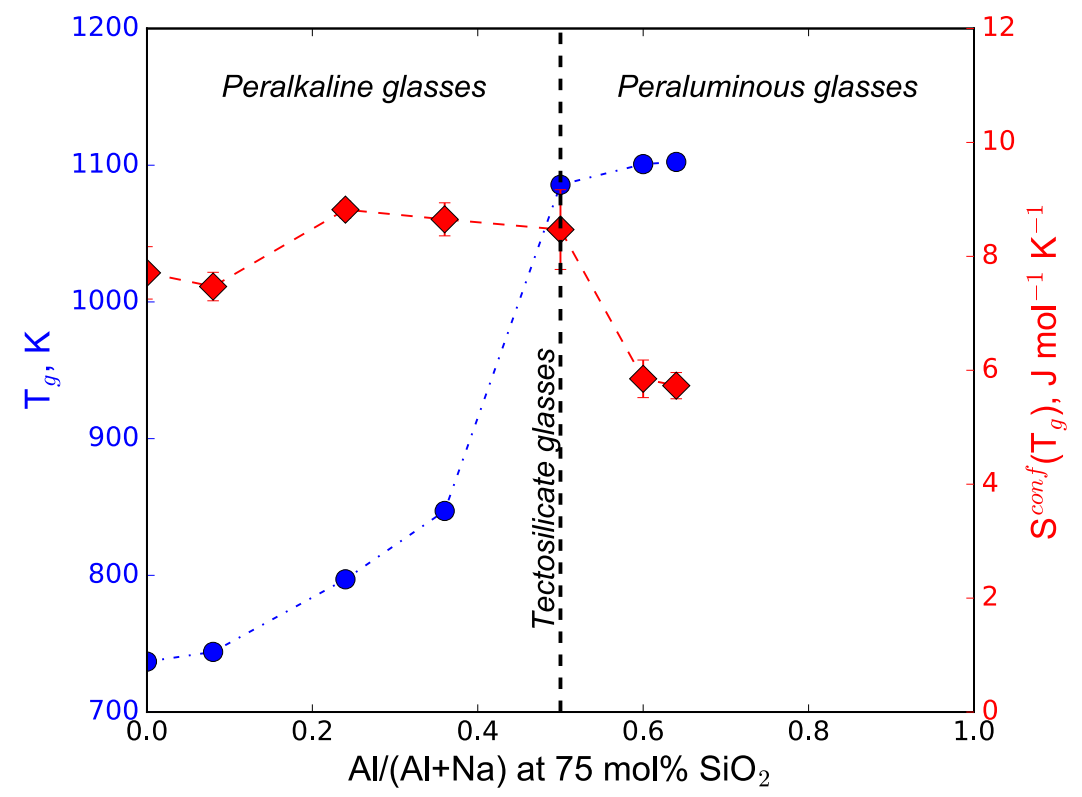

Figure 24: Glass transition temperature $T_{g}$ and configurational entropy at $T_{g}$ of alumino-silicate glasses containing 75 mol\% $\mathrm{SiO}_{2}$ and different $\mathrm{Al} /(\mathrm{Al}+\mathrm{Na})$ ratios. Peralkaline glasses present an $\mathrm{Al} /(\mathrm{Al}+\mathrm{M})$ ratio $<0.5\left(\mathrm{M}=\mathrm{Na}^{+}, \mathrm{K}^{+}, \mathrm{Mg}^{2+}, \mathrm{Ca}^{2+}\right.$, etc. $)$, tectosilicate glasses a ratio of $0.5\left(\left[\mathrm{Al}^{3+}\right]=\left[\mathrm{M}^{+, 2+}\right]\right)$, and peraluminous glasses present an $\mathrm{Al} /(\mathrm{Al}+\mathrm{M})$ ratio $>0.5$. Data from [25]. 
Le Losq, Cicconi, Greaves, Neuville. Silicate Glasses. In: Springer Handbook of Glass. Results from ${ }^{27} \mathrm{Al}$ NMR spectroscopy show that Al also can be present in 5- and 6-fold coordination, in low concentrations that depend on the glass composition [25, 124, 171-175]. Indeed, the ratio between $\mathrm{Al}$ and the alkali/alkaline-earth metal cations $\mathrm{M}^{+, 2+}$ in the glasses, $\mathrm{Al} / \mathrm{M}$, is of fundamental importance in determining the role of the metal cation as well as the coordination and environment of aluminum. When $\mathrm{Al} / \mathrm{M}<1$, the composition is peralkaline (Fig. 24). In such case, one part of the $\mathrm{M}$ cations compensates the electrical charge deficits around $\mathrm{AlO}_{4}{ }^{-}$units, due to the fact that $\mathrm{Al}^{3+}$ substitutes for $\mathrm{Si}^{4+}$ in the tetrahedral units. The remaining part of $\mathrm{M}$ cations acts as network modifiers. When $\mathrm{Al} / \mathrm{M}=1$, the glass has a tectosilicate composition. The amount of aluminum and metal cations is the same, such that all metal cations should compensate for the charge deficit of $\mathrm{AlO}_{4}{ }^{-}$units and the glass should be fully polymerized, i.e. ideally constituted of only $Q^{4}$ units. In reality, as ideality and glasses are antagonistic concepts, a few percent of NBO can be present in tectosilicate glasses [176-178] (sec. 1.4.4). When Al/M $>1$, the composition is peraluminous: there is an excess of aluminum in the network compared to chargebalancing metal cations.

From ${ }^{27} \mathrm{Al}$ NMR data $[25,171-174]$, a small fraction of $\mathrm{Al}$ is present in $5\left({ }^{[5]} \mathrm{Al}\right.$ or $\left.\mathrm{AlO}_{5}\right)$ and $6\left({ }^{[6]} \mathrm{Al}\right.$ or $\mathrm{AlO}_{6}$ ) fold coordination in tectosilicate and peraluminous glasses; the higher the $\mathrm{Al} / \mathrm{M}$, the higher the fractions of ${ }^{[5]} \mathrm{Al}$ and possibly of ${ }^{[6]} \mathrm{Al}$. Figure 25 illustrates this dependence in the $\mathrm{CaO}-\mathrm{Al}_{2} \mathrm{O}_{3}-\mathrm{SiO}_{2}$ diagram. In this ternary diagram, a significant fraction of Al already is in CN 5 in the peralkaline domain. At all silica contents, increasing the Al content up to reaching the peraluminous domain leads to a very important increase of the ${ }^{[5]} \mathrm{Al}$ fraction in the glasses. In peraluminous Ca-bearing glasses, Neuville et al. $[174]$ also reported a small fraction $(<3 \%)$ of ${ }^{[6]} \mathrm{Al}$ at very high $\mathrm{Al} / \mathrm{Ca}$ ratios. 
Le Losq, Cicconi, Greaves, Neuville. Silicate Glasses. In: Springer Handbook of Glass.

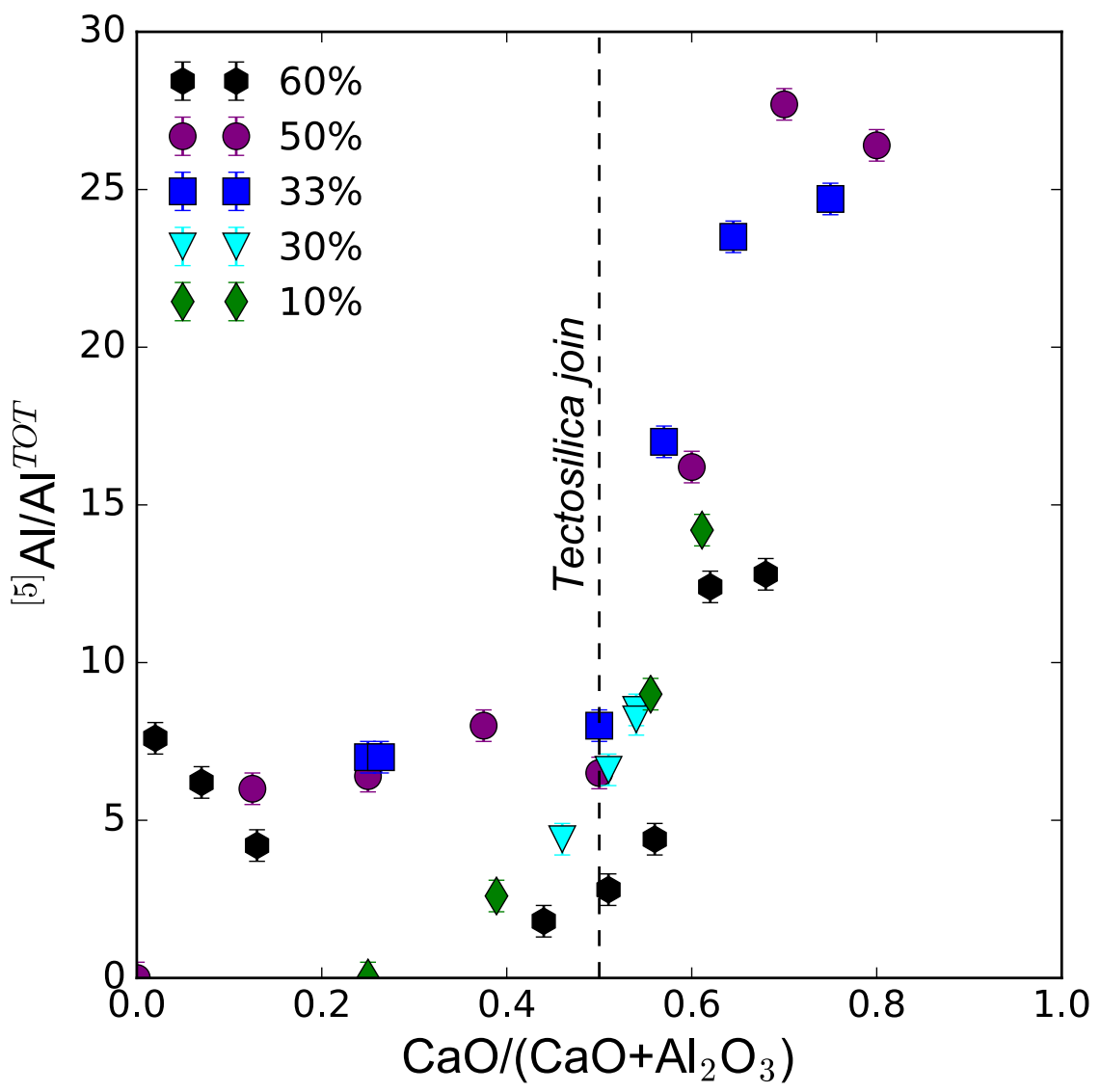

Figure 25: fraction of ${ }^{[5]} \mathrm{Al}$ (five-fold coordinated Al) represented as a function of the ratio $\mathrm{CaO} /\left(\mathrm{CaO}+\mathrm{Al}_{2} \mathrm{O}_{3}\right)$ in silicate glasses. Data acquired through ${ }^{27} \mathrm{Al} \mathrm{NMR}$ spectroscopy at different silica concentration are represented by black hexagons (60\% $\left.\mathrm{SiO}_{2}\right)$, purple circles (50\%), blue squares (33\%), inverted cyan triangles (30\%) and green diamonds (10\%). Data at 50, 33 and 10\% are from Neuville et al. [174] and data at 30 and $60 \%$ are from Thompson and Stebbins [178].

The fractions of ${ }^{[4]} \mathrm{Al},{ }^{[5]} \mathrm{Al}$ and ${ }^{[6]} \mathrm{Al}$ not only depends on the $\mathrm{Al} / \mathrm{M}$ ratio, but also on the ionic field strength of the M cation [179-182]. Indeed, Ca alumino-silicate glasses already present a few percents of ${ }^{[5]} \mathrm{Al}$ in peralkaline glasses $[174,183]$, while Na alumino-silicate glasses don't [25]. In general, alkaline-earth alumino-silicate glasses present higher fractions of ${ }^{[5]} \mathrm{Al}$ and ${ }^{[6]} \mathrm{Al}$ than alkali aluminosilicate melts. Differences are also observed between different alkaline-earth alumino-silicate glasses: for instance, $\mathrm{Sr}, \mathrm{Ca}$ and $\mathrm{Mg}$ tectosilicate glasses with $50 \mathrm{~mol} \% \mathrm{SiO}_{2}$ present ${ }^{[5]} \mathrm{Al}$ fractions of $0.02,0.07$ and 0.12 , respectively [see also results from 182, 184]. In Y and Lu tectosilicate glasses with the same $\mathrm{SiO}_{2}$ content $(50 \mathrm{~mol} \%),{ }^{[5]} \mathrm{Al}$ fractions reach $\sim 21$ and $26 \%$, respectively [185]. Figure 26 illustrates the correlation between the fraction of ${ }^{[5]} \mathrm{Al}$ and the ionic field strength of metal cations: increasing the IFS of the metal cations in alumino-silicate glasses seems to promote ${ }^{[5]} \mathrm{Al}$ at the expanse of ${ }^{[4]} \mathrm{Al}$. 
Le Losq, Cicconi, Greaves, Neuville. Silicate Glasses. In: Springer Handbook of Glass.

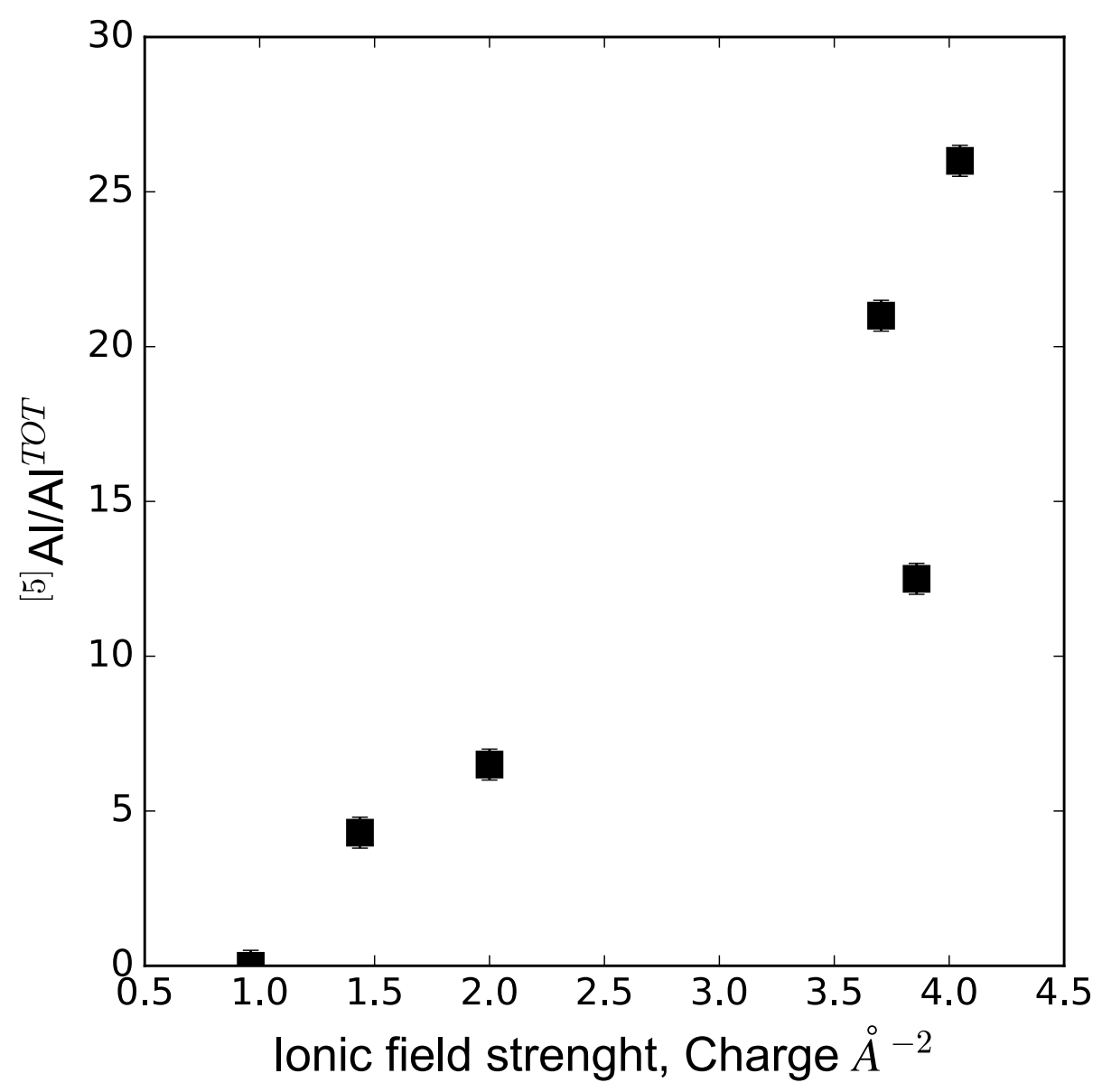

Figure 26: Fraction of ${ }^{[5]}$ Al detected by ${ }^{27}$ Al NMR spectroscopy in tectosilicate glasses with 50 mol\% $\mathrm{SiO}_{2}$ as a function of the ionic field strength of the non-network former cations in the glass (i.e., Sr, Ca, $\mathrm{Mg}, \mathrm{Na}, \mathrm{Y}$ and Lu). For ensuring consistency, and because the CN of metal cation in tectosilicate glasses is not perfectly known, the cation ionic field strength has been calculated at a constant CN of 6 for all cations. Therefore, scattering in this figure may result from variations in the CN of the different cations. Ionic radii have are from Shannon [107]; data are from [174, 184-186]

In addition to the effect of the glass chemical composition, the conditions of the glass formation also influence the fractions of ${ }^{[4]} \mathrm{Al},{ }^{[5]} \mathrm{Al}$ and ${ }^{[6]} \mathrm{Al}$ in the glass. Increasing the parental melt temperature and pressure leads to increase the coordination of $\mathrm{Al}$ in the retrieved glasses, particularly for tectosilicate and peraluminous compositions $[179,187,175,188-190,25]$. As a result, the glass quench rate and quench pressure affects the glass fractions of ${ }^{[4]} \mathrm{Al},{ }^{[5]} \mathrm{Al}$ and ${ }^{[6]} \mathrm{Al}$. Glasses formed at high pressure (several GPa) will contain large amounts of ${ }^{[5]} \mathrm{Al}$ and ${ }^{[6]} \mathrm{Al}$, with several percent to tens of percent increases in their proportions depending on the pressure in the 1-10 GPa range $[[179,180,190,191]$. 
Le Losq, Cicconi, Greaves, Neuville. Silicate Glasses. In: Springer Handbook of Glass.

The effect of temperature on the fraction of highly coordinated Al polyhedral units in the glass is more complex. Indeed, different trends have been reported as a function of the glass composition. In pure alkali or alkaline-earth alumino-silicate glasses, increasing the quench rate and, hence, glass $T_{f}$ generally leads to a potential increase of a few percent the fraction of ${ }^{[5]} \mathrm{Al}$, as supported by ${ }^{27} \mathrm{Al}$ NMR data from Stebbins et al. [192] and Thompson and Stebbins [193] on Ca alumino-silicate glasses. In agreement with that, Allwardt et al. [187] reported increasing ${ }^{[5]} \mathrm{Al}$ fraction in a $\mathrm{Na}_{3} \mathrm{AlSi}_{7} \mathrm{O}_{17}$ glass (synthesized at $10 \mathrm{GPa}$ ) with increasing the glass $T_{f}$. However, they also reported a decreasing ${ }^{[5]} \mathrm{Al}$ fraction in a $\mathrm{NaAlSi}_{3} \mathrm{O}_{8}$ glass (also synthesized at $10 \mathrm{GPa}$ ) with increasing the glass $T_{f}$. Such observation is intriguing since Le Losq et al. [25] measured in situ higher fractions of ${ }^{[5]} \mathrm{Al}$ and ${ }^{[6]} \mathrm{Al}$ with increasing temperature in $\mathrm{NaAlSi}_{3} \mathrm{O}_{8}$ and other $\mathrm{Na}$ alumino-silicate melts (peralkaline and peraluminous), using in situ laser-heated ${ }^{27} \mathrm{Al}$ NMR spectroscopy (Fig. 27). Therefore, an additional effect (potentially of pressure) may have affected the temperature effect in the observations of Allwardt et al. [187] on the $\mathrm{NaAlSi}_{3} \mathrm{O}_{8}$ glass. In a Na-K aluminosilicate glass synthesized at a pressure of 3.5 GPa, Malfait et al. [190] also reported negligible changes in the Al speciation with changing the glass $T_{f}$.

Therefore, from this review, increasing $T_{f}$ in alkali and alkaline-earth alumino-silicate glasses tend to increase the fraction of highly coordinated Al species. This effect is small compared to that of pressure: it is only of a few \% for quench rate variations of several orders of magnitude [e.g., 193]. Furthermore, it also probably depends on the melt composition. The latter dependence is illustrated in Fig. 27, which shows ${ }^{27} \mathrm{Al}$ NMR spectra acquired on Na alumino-silicate glasses at room temperature and acquired on their corresponding melts at high temperature [25]. While ${ }^{27} \mathrm{Al}$ NMR spectra from peralkaline glasses and melts $(\mathrm{Na} /(\mathrm{Na}+\mathrm{Al})<0.5)$ show a peak at a comparable chemical shift that can be assigned to ${ }^{[4]} \mathrm{Al}$, the tectosilicate and peraluminous glasses and melts 27Al NMR spectra present significant differences: they are broader and, for the peraluminous composition, shifted to lower ${ }^{27} \mathrm{Al}$ chemical shifts. Those differences are assigned to the presence of ${ }^{[5]} \mathrm{Al}$ and even ${ }^{[6]} \mathrm{Al}$ in those tectosilicate and peraluminous composition. 
Le Losq, Cicconi, Greaves, Neuville. Silicate Glasses. In: Springer Handbook of Glass.

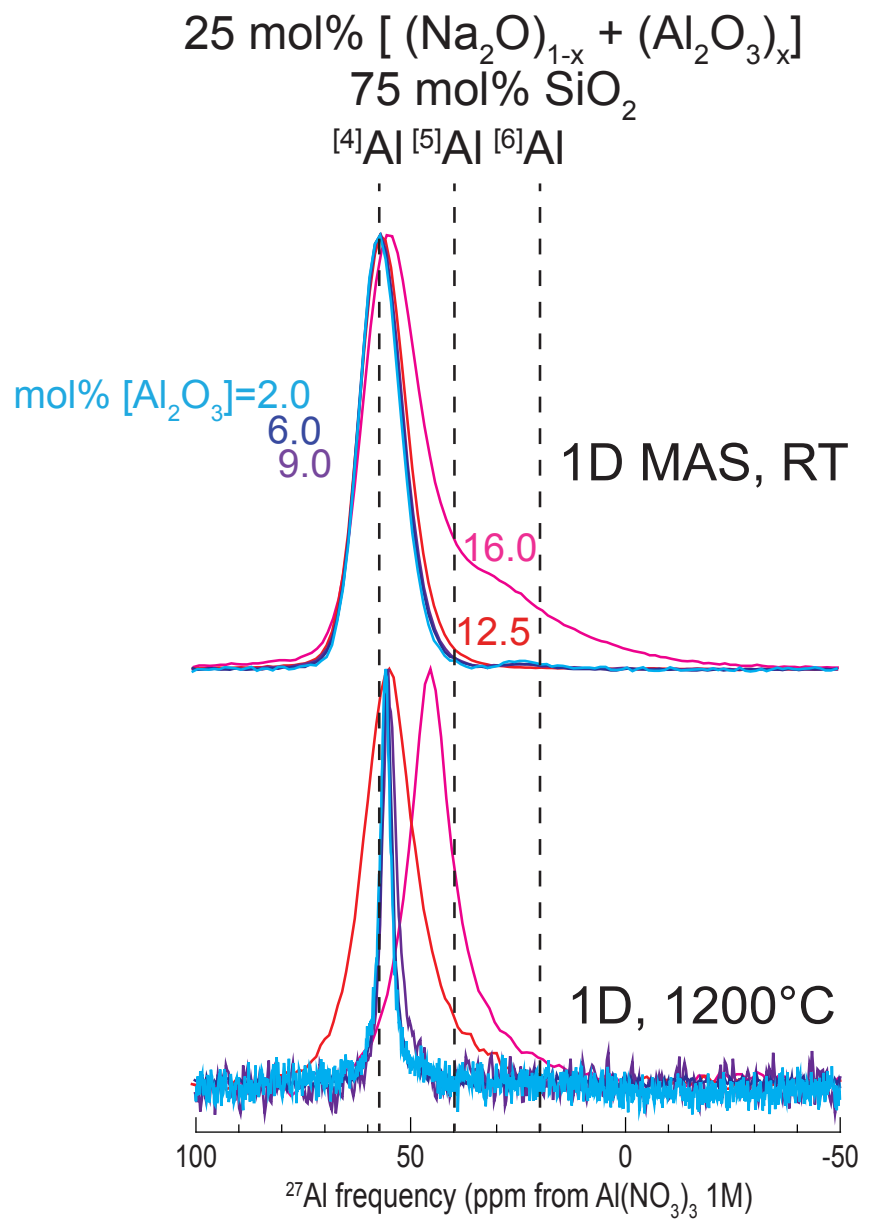

Figure 27: ${ }^{27} \mathrm{Al}$ NMR spectra acquired at room temperature and at $1200^{\circ} \mathrm{C}$ on sodium alumino-silicate glasses and melts presenting different Na/Al ratios. The peralkaline glasses and melts show no significant difference, as Al is at $\sim 99 \%$ in CN4. In tectosilicate and peraluminous compositions, the broadening of the ${ }^{27}$ Al NMR signal indicate the existence of Al in 5- and even 6-fold coordination at high temperature.

From observations shown in Fig. 27, effects of melt composition, discussed previously in the case of glasses, seem to be enhanced in the molten state. As a result, depending on the glass composition, changing the quench rate leads to different outcomes in term of the Al coordination number. Data from boro-alumino-silicate composition further corroborate this idea. Indeed, while both Morin et al. [182] and $\mathrm{Wu}$ and Stebbins [194] reported decreasing coordination of $\mathrm{Al}$ with increasing the $T_{f}$ of $\mathrm{Na}, \mathrm{Ba}, \mathrm{Ca}$, La and Y aluminoborosilicate, Kiczenski et al. [195] reported an inverse trend in the multi-component boro-alumino-silicate E glass ${ }^{1}$, used as the reinforcing phase in fiberglass. Morin et al. [182] explained

${ }^{1}$ Glass $E$ composition in mol\%: $57.3 \% \mathrm{SiO}_{2}, 6.0 \%$ B203, 8.7\% $\mathrm{Al}_{2} \mathrm{O}_{3}, 24.9 \% \mathrm{CaO}, 0.9 \% \mathrm{MgO}, 0.8 \%$ $\mathrm{Na}_{2} \mathrm{O}, 0.8 \% \mathrm{~F}_{2}$. 
Le Losq, Cicconi, Greaves, Neuville. Silicate Glasses. In: Springer Handbook of Glass.

their observations by a coupling between B and Al species in the melt, and suggested that the reverse trend reported by Kiczenski et al. [195] may arise from an increase in association of F with Al at higher temperatures. Therefore, it appears that coupling of Al with other network former elements such as boron or with volatile elements may have an influence on the final coordination of $\mathrm{Al}$ in the glass, and its dependence on the glass $T_{f}$.

\subsubsection{Aluminum coordination and glass properties: examples}

The changes in the aluminum coordination number are affecting various properties of the glass. In particular, increasing the aluminum coordination is an important component in the densification mechanism of alumino-silicate glasses [179]. Indeed, there is a clear trend between the change in the glass molar volume with pressure and the average Al coordination (Fig. 28). The scatter visible in Fig. 28 indicates that other mechanisms occur, such as changes in the mean inter-tetrahedral angle and compression of the sites of modifier and charge-compensator cations [179, 180, 191, 196]]. The melt composition may be an important control in determining which mechanism prevails [180, 191].

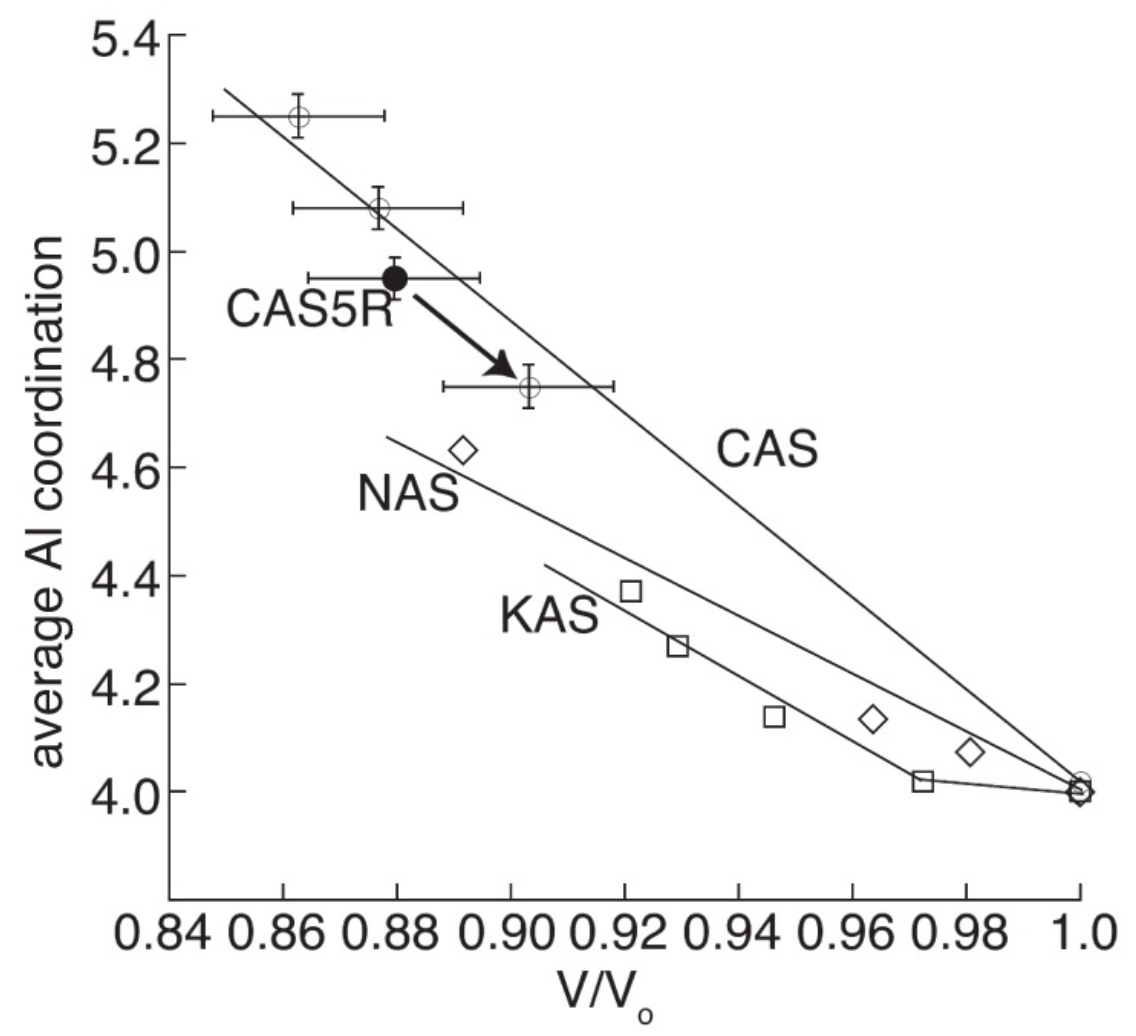

Figure 28: Average Al coordination in $\mathrm{Ca}_{3} \mathrm{Al}_{2} \mathrm{Si}_{2} \mathrm{O}_{18}$ (CAS\& $\mathrm{CAS5R}$ ), $\mathrm{Na}_{3} \mathrm{AlSi}_{3} \mathrm{O}_{9}(\mathrm{NAS})$ and $\mathrm{K}_{3} \mathrm{AlSi}_{3} \mathrm{O}_{9}$ (KAS) glasses reported as a function of their relative molar volume, calculated as the ratio between their 
Le Losq, Cicconi, Greaves, Neuville. Silicate Glasses. In: Springer Handbook of Glass.

molar volume at high pressure $(3-10 \mathrm{GPa})$ and that at room pressure. Reproduced from Allwardt JR (2005) Aluminum coordination and the densification of high-pressure aluminosilicate glasses. American Mineralogist 90:1218-1222. doi: 10.2138/am.2005.1836, Copyright (2005), with permission from the Mineralogical Society of America.

In addition to the role of highly-coordinated Al species in densified glasses, their presence affect the mechanical properties of the glasses. By combining molecular dynamic simulations and MAS NMR spectroscopy, Iftekhar et al. [185] showed that, in $\mathrm{Re}_{2} \mathrm{O}_{3}-\mathrm{Al}_{2} \mathrm{O}_{3}-\mathrm{SiO}_{2}(\mathrm{Re}=\mathrm{Y}, \mathrm{Lu})$ glasses, there is a direct correlation $(\mathrm{R}=0.9)$ between the Vickers hardness and the mean coordination number of Al (Fig. 29).

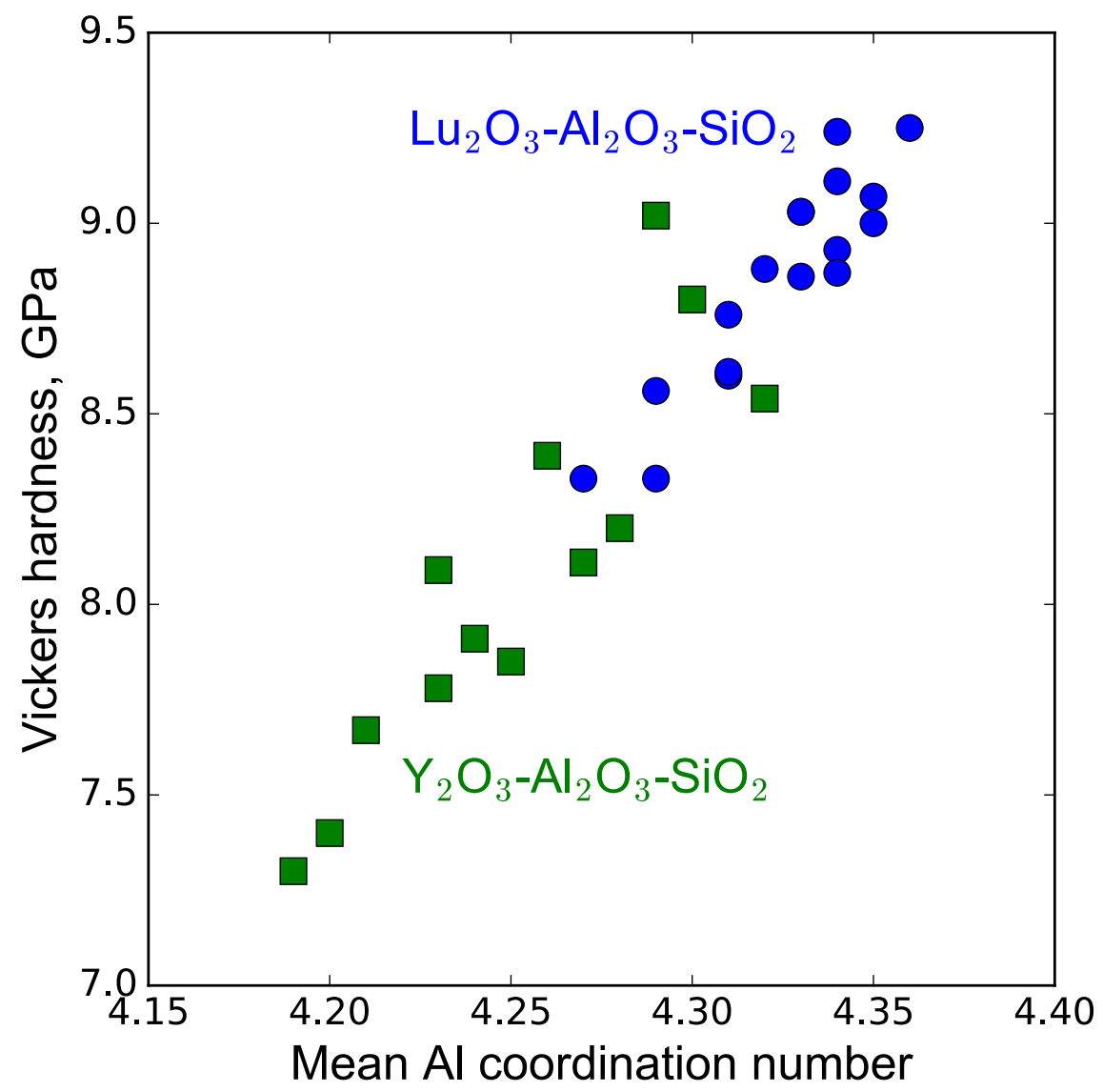

Figure 29: Vickers hardness versus average $\mathrm{Al}$ coordination in $\mathrm{Re}_{2} \mathrm{O}_{3}-\mathrm{Al}_{2} \mathrm{O}_{3}-\mathrm{SiO}_{2}(\mathrm{Re}=\mathrm{Y}, \mathrm{Lu})$ glasses with various compositions $\left(0.99 \leq \mathrm{Al} / \mathrm{Lu} \leq 2.4\right.$ and $\sim 99 \leq \mathrm{mol} \% \mathrm{SiO}_{2} \leq \sim 65$ for $\mathrm{Lu}_{2} \mathrm{O}_{3}-\mathrm{Al}_{2} \mathrm{O}_{3}-\mathrm{SiO}_{2}$ glasses; $0.72 \leq \mathrm{Al} / \mathrm{Y} \leq 1.77$ and $\sim 41 \leq \mathrm{mol} \% \mathrm{SiO}_{2} \leq \sim 68$ for $\mathrm{Y}_{2} \mathrm{O}_{3}-\mathrm{Al}_{2} \mathrm{O}_{3}-\mathrm{SiO}_{2}$ glasses). Data from [185]. 
Le Losq, Cicconi, Greaves, Neuville. Silicate Glasses. In: Springer Handbook of Glass.

Iftekhar et al. [185] interpreted such relationship as showing that ${ }^{[5]} \mathrm{Al}$ and ${ }^{[6]} \mathrm{Al}$ form strong ${ }^{[5]} \mathrm{Al}-\mathrm{O}-\mathrm{T}$ and ${ }^{[6]} \mathrm{Al}-\mathrm{O}-\mathrm{T}$ bonds in the network, enhancing its connectivity, and, hence, its structural strengths. The increase in connectivity following the apparition of ${ }^{[5]} \mathrm{Al}$ and ${ }^{[6]} \mathrm{Al}$ in the glass structure is further corroborated by the increase in the $T_{g}$ of glasses with increasing the fraction of aluminium in peraluminous glasses (Fig. 24; [25]). The variation of the viscosity of Na peraluminous silicate melts further support such idea. Indeed, close to $T_{g}$, the viscosity of $\mathrm{Na}$ alumino-silicate melts increases with increasing the $\mathrm{Al} /\left(\mathrm{Al}+\mathrm{Na}^{+}\right)$ratio in the peraluminous domain at iso-temperature $[[25,169]$, while at high temperature it decreases $[168,197]$. This effect occurs because of the decoupling between the aluminosilicate and metal cation sub-lattices relaxation at $T_{g}$ [198]: $\mathrm{Na}^{+}$cations diffuse rapidly in a frozen-in polyhedral alumino-silicate network at, or close to, $T_{g}$. In such conditions, ${ }^{[5]} \mathrm{Al}$ and ${ }^{[6]} \mathrm{Al}$ participate in ordering the network in glasses, as shown by the large decrease in the glasses configurational entropy at $T_{g}$ with increasing $\mathrm{Al} /(\mathrm{Al}+\mathrm{Na})$ from 0.5 to 0.7 in $\mathrm{Na}$ alumino-silicate compositions (Fig. 24). At high temperature, relaxation of all cations tends toward the same values. In such conditions, the presence of ${ }^{[5]} \mathrm{Al}$ and ${ }^{[6]} \mathrm{Al}$ in the melts seems to favor the diffusion of oxygen and, hence, to enhance viscous flow $[25,199]$.

\subsubsection{Aluminum, glass polymerization, and the Al avoidance rule}

Sections 1.4.1 and 1.4.2 illustrated that aluminum enters preferentially in $\mathrm{CN} 4$ in glasses, the proportion of CN 5 and 6 being small and dependent on the glass pressure synthesis and composition, and, in a minor extent, $T_{f}$. The overall effect of adding aluminium in silicate glasses thus results in increasing their polymerization, as $\mathrm{Al}$ enters as a network former into the glass ionic framework. In particular, Al enters in $Q^{4}$ units in the glasses with a tendency to avoid formation of Al-O-Al bonds (the so-called Alavoidance rule or Lowenstein rule [200]) that depends on the melt chemical composition [131, 201, 202]. According to Mysen et al. [203], $\mathrm{Al}$ in $Q^{4}$ units represent at least $70 \%$ of the total aluminum in the perakaline domain in $\mathrm{Na}$ alumino-silicate glasses. A resulting effect of aluminum preference to reside in $Q^{4}$ units in glasses is to shift the equilibrium $2 Q^{3} \Leftrightarrow Q^{2}+Q^{4}$ to the right end side at constant NBO/T values with increasing the ratio $\mathrm{Al} /\left(\mathrm{Al}+\mathrm{M}^{\mathrm{n}+}{ }_{2 / \mathrm{n}}\right)$ in peralkaline glasses [203]. The least depolymerized units in the glasses present the lowest $\mathrm{Al} / \mathrm{Si}$ ratio, i.e. $\mathrm{Al}$ avoids entering in depolymerized units.

The "preference" of $\mathrm{Al}$ for polymerized environments probably results from the minimization of the energy deficit of Al polyhedral units: carrying NBO will lead to a very strong electrical charge deficit for $\mathrm{AlO}_{\mathrm{z}}$ units $(\mathrm{z}=4,5,6)$. The Al-avoidance effect further results of such concept: Al-O-Al bonds are 
Le Losq, Cicconi, Greaves, Neuville. Silicate Glasses. In: Springer Handbook of Glass.

avoided as they are energetically not favorable. However, Al-avoidance is not perfectly respected in alumino-silicate glasses, as shown by results from ${ }^{29} \mathrm{Si}$ Magic Angle Spinning (MAS) and ${ }^{17} \mathrm{O}$ triple quantum MAS (3QMAS) spectroscopy on $\mathrm{Ca}$, Li and $\mathrm{Na}$ alumino-silicate glasses [[132, 201, 202, 204] as well as by results from MD simulations [e.g., 205, 206]. For instance, results for ${ }^{29} \mathrm{Si}$ NMR spectroscopy show that the degree of $\mathrm{Al}$ avoidance in $\mathrm{Na}$ alumino-silicate melts is higher than that in $\mathrm{Ca}$ alumino-silicate glasses [201]. A useful parameter for quantifying such degree of Al avoidance is the $Q$ parameter: $Q=1$ in case of perfect $\mathrm{Al}$ avoidance (no Al-O-Al bonds), and 0 in case of a purely random Al-Si distribution $[131,201]$. In alkaline-earth and alkali tectosilicate melts, $Q$ values range from 0.65 to 0.99; Figure 30 show how $Q$ values decrease with increasing the ionic field strength of the charge compensating metal cation in the glass framework [201, 204].

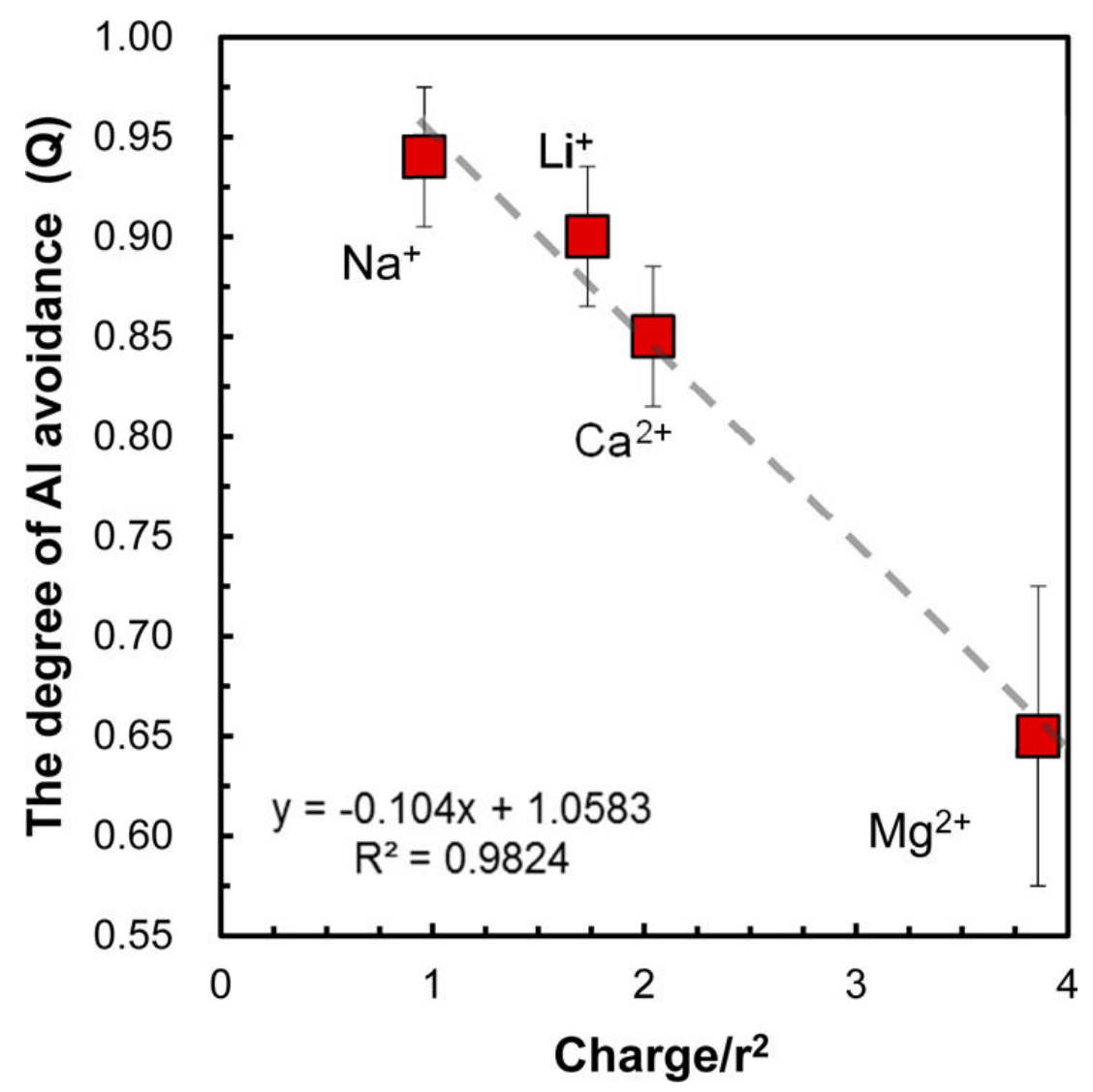

Figure 30: Relationship between the degree of Al avoidance in alumino-silicate melts and the ionic field strength of the metal cation. Reprinted with permission from Lee SK, Kim H-I, Kim EJ, Mun KY, Ryu S (2016) Extent of Disorder in Magnesium Aluminosilicate Glasses: Insights from ${ }^{27} \mathrm{Al}$ and ${ }^{17} \mathrm{O} N M R$. J Phys Chem C 120:737-749. doi: 10.1021/acs.jpcc.5b10799 Copyright (2016) American Chemical Society. 
Le Losq, Cicconi, Greaves, Neuville. Silicate Glasses. In: Springer Handbook of Glass.

It thus seems that the IFS of metal cations influences linearly the degree of Al avoidance in aluminosilicate glasses. However, Lee [207] warrant that increasing the cation IFS at values higher than that of $\mathrm{Mg}^{2+}$ may lead to deviation from the linear trend observed in Fig. 30, because of the formation of highlycoordinated ${ }^{[5]} \mathrm{Al}$ and ${ }^{[6]} \mathrm{Al}$ species and possibly of Al-NBO bonds in such systems.

The degree of $\mathrm{Al}$ avoidance can further be related to the thermodynamic properties of the glass, and, in particular, to their configurational entropy. Indeed, the $\mathrm{Si}-\mathrm{Al}$ ordering implies a non-random process for the integration of $\mathrm{Al}$ in $Q^{4}$ units. The analysis of the Raman spectra of tectosilicate glasses reveal the presence of two bands at $\sim 1140-1170$ and 1180-1210 $\mathrm{cm}^{-1}$ (Fig. 31), which are assigned to Si-O stretching in $Q^{4}$ units [30, 57, 58, 208].
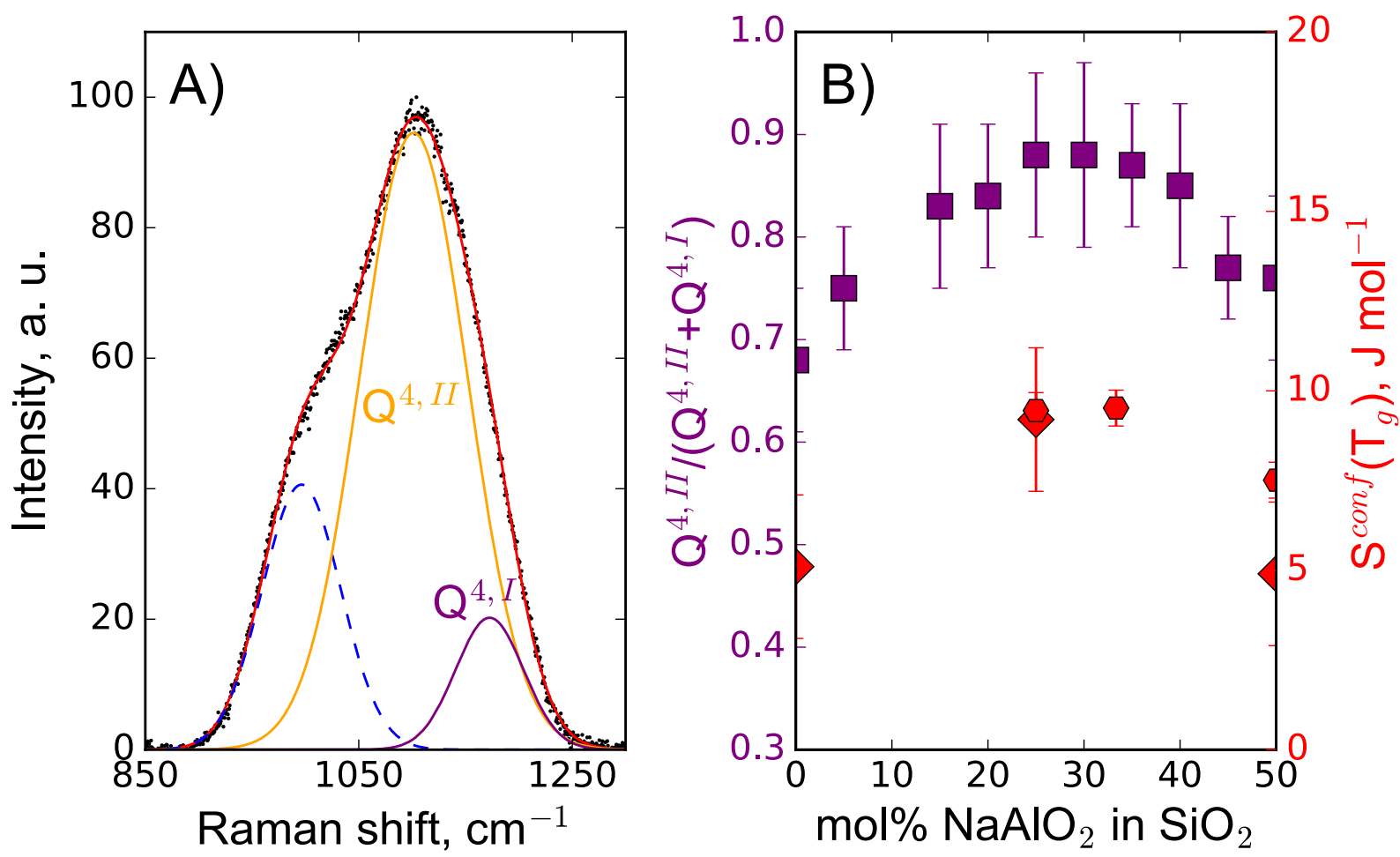

Figure 31: A) 850-1300 $\mathrm{cm}^{-1}$ portion of the Raman spectrum of thee $\mathrm{NaAlSi}_{3} \mathrm{O}_{8}$ glass, presenting an $\mathrm{Al} / \mathrm{Si}$ ratio of 0.5. The dotted blue peak is assigned to T-BO asymmetric stretching in $\mathrm{TO}_{4}$ units, while the peaks in purple $\left(Q^{4, I}\right)$ and orange $\left(Q^{4, I I}\right)$ are assigned to $T$-O symmetric stretching in $\mathrm{TO}_{4}$ units $[25,57$ and references therein]. In B), the ratio of the area of the $Q^{4, I}$ Raman peak other the sum of the areas of the $Q^{4, I}$ and $Q^{4, I I}$ Raman peaks (purple squares) is represented as a function of the mol\% $\mathrm{NaAlO}_{2}$ added in $\mathrm{SiO}_{2}$. It presents variations very similar to those of the glass configurational entropy at $T_{g}, S^{\text {conf }}\left(T_{g}\right)($ Red diamonds [69] and hexagons [209]). 
Le Losq, Cicconi, Greaves, Neuville. Silicate Glasses. In: Springer Handbook of Glass.

Similar to the observations made in the $\mathrm{SiO}_{2}$ glass (Sec. 1.2.1), the splitting of the Si-O stretching signal in $Q^{4}$ units in two bands indicate a slight asymmetry of the distribution of T-O-T angles in tectosilicate glasses, in agreement with results from molecular dynamic simulations on alumino-silicate glasses and melts [205, 206, 210]. Neuville and Mysen [208] noticed a similarity between the variations of the entropy of configuration at $T_{g}, S^{c o n f}\left(T_{g}\right)$, of the glasses between the $\mathrm{NaAlSiO}_{4}$ and the $\mathrm{SiO}_{2}$ composition (Fig. $31 \mathrm{~b}$ ), with the formation of a convex curvature. Such curvature in the variations of the glass $S^{\text {conf }}\left(T_{g}\right)$ is similar to the one that can be generated by mixing two cations in similar environments. The data of Neuville and Mysen [208] actually provide further information about the mechanism of Si substitution by $\mathrm{Al}$ in the glasses network. Indeed, the increase of the area ratio between the two peaks assigned to $\mathrm{Si}$ O stretching in $Q^{4}$ units, $Q^{4, I I} /\left(Q^{4, I I}+Q^{4, I}\right)$, with increasing $\mathrm{NaAlO}_{2}$ in $\mathrm{SiO}_{2}$ below $25 \mathrm{~mol} \%$ suggest that Al enters primarily in an environment associated with the $Q^{4, I I}$ signal. As the Raman shift of the $Q^{4, I I}$ peak is lower than that of the $Q^{4, I}$ peak (Fig. 31), we expect the T-O-T bond angle of the environment associated with this signal to be lower than that of the environment associated with the $Q^{4, I}$ peak [53, 54]. Therefore, Al tends to enter in $Q^{4}$ units with "small" T-O-T angles in a first time, up to an Al/Si ratio of 0.5, after which $\mathrm{Al}$ substitutes for $\mathrm{Si}$ in the second environment. This comportment may relate to the length of Al-O bonds, which are longer than Si-O bonds (Table 4). As there is an inverse correlation between T-O bond distances and T-O-T bond angles [211], this will explain the affinity of Al for the $Q^{4, I I}$ site.

\begin{tabular}{|l|l|l|l|l|l|l|}
\hline System & $\mathrm{Si}-\mathrm{O}$ & $\mathrm{Al}-\mathrm{O}$ & $\mathrm{M}-\mathrm{O}$ & Methods & Reference & \\
\hline $\mathrm{Li}_{2} \mathrm{O}-\mathrm{Al}_{2} \mathrm{O}_{3}-\mathrm{SiO}_{2}$ & $\begin{array}{l}1.59- \\
1.61 *\end{array}$ & $1.71-1.73 *$ & $2.05^{*}$ & Mod. & {$[212]$} & \\
\hline $\mathrm{Na}_{2} \mathrm{O}-\mathrm{Al}_{2} \mathrm{O}_{3}-\mathrm{SiO}_{2}$ & $\begin{array}{l}1.59- \\
1.61\end{array}$ & $1.72-1.78$ & $2.4-2.6$ & Exp., Mod. & $\begin{array}{l}{[205, \quad 211,} \\
213]\end{array}$ & \\
\hline $\mathrm{K}_{2} \mathrm{O}-\mathrm{Al}_{2} \mathrm{O}_{3}-\mathrm{SiO}_{2}$ & - & - & $3.00-3.06$ & Exp. & {$[214]$} & \\
\hline $\mathrm{CaO}-\mathrm{Al}_{2} \mathrm{O}_{3}-\mathrm{SiO}_{2}$ & $\begin{array}{l}1.60- \\
1.63\end{array}$ & $1.72-1.77$ & $2.32-2.45$ & Exp., Mod. & $\begin{array}{l}{[206,215-} \\
217]\end{array}$ & \\
\hline $\mathrm{MgO}-\mathrm{Al}_{2} \mathrm{O}_{3}-\mathrm{SiO}_{2}$ & $1.61-$ & $1.75-1.77$ & $1.98-2.05$ & {$[218]$} & {$[207]$} & \\
& 1.62 & & & & & \\
\hline
\end{tabular}


Le Losq, Cicconi, Greaves, Neuville. Silicate Glasses. In: Springer Handbook of Glass.

Table 4: Examples of ranges of bond lengths for common metal cations in alumino-silicate melts, reported in the literature by experimental (Exp.) and modeling (Mod.) studies of alkali and alkalineearth alumino-silicate glasses. *values derived from figures.

Other pieces of explanation may account for the variations of $S^{c o n f}\left(T_{g}\right)$ along the binary join, as proposed by Toplis et al. [209] or Lee and Stebbins [201]. The former indicated that the variations of the glass $S^{\text {conf }}\left(T_{g}\right)$ along the $\mathrm{SiO}_{2}-\mathrm{NaAlO}_{2}$ join originate from variations of the topology of the glass network as well as from chemical contributions from cation mixing, the former being dominant and approximately equal to $\sim 5.1 \mathrm{~J}$ mol-1 $\mathrm{K}^{-1}$ while the later accounts for the concave shape of the entropy variations. Lee and Stebbins [201]] further modelled the chemical variation using a mixing of the different Si-O-Si, Si$\mathrm{O}-\mathrm{Al}$ and Al-O-Al bonds in the network. From this model, in case of a perfect Si-Al ordering (perfect Al

avoidance, $Q=1), S^{\text {conf }}\left(T_{g}\right)$ between the $\mathrm{SiO}_{2}$ and $\mathrm{NaAlSiO}_{4}$ compositions is expected to show a maximum at the $\mathrm{NaAlSi}_{3} \mathrm{O}_{8}$ composition with an $\mathrm{Al} / \mathrm{Si}=0.5\left(25 \mathrm{~mol} \% \mathrm{NaAlO}_{2}\right)$ [201, 209]. The $Q$ values in $\mathrm{Na}$ tectosilicate melts are between 0.93-0.99, implying strong to nearly perfect Al avoidance [201]. Therefore, such model accounts for the observations made in Fig. 31.

\subsubsection{NBO, tectosilicate glasses and triclusters}

The study of tectosilicate glasses has been of particular interest in the literature as it brings information on the comportment of metal cations that act as charge compensators of the various Al polyhedral units. While tectosilicate glasses are ideally fully polymerized, there is actually a non-negligible number of NBO oxygens in their structure, subsequently called non-stoichiometric NBO. Stebbins and Xu [176] were among the first to report a direct experimental evidence of this, as they estimated using ${ }^{17} \mathrm{O}$ MAS NMR spectroscopy that $\sim 5 \%$ of non-stoichiometric NBO are present in a calcium tectosilicate glass with $\sim 50 \mathrm{~mol} \% \mathrm{SiO}_{2}$. Other experimental studies further reported fractions of a few percents of nonstoichiometric NBO in tectosilicate glasses, as listed in Table 5. 
Le Losq, Cicconi, Greaves, Neuville. Silicate Glasses. In: Springer Handbook of Glass.

\begin{tabular}{|l|l|l|l|l|}
\hline $\begin{array}{l}\text { Compensating } \\
\text { cation }\end{array}$ & $\mathrm{Si} /(\mathrm{Si}+\mathrm{Al})$ & $\%$ non-stoichiometric NBO & Remark & Ref. \\
\hline $\mathrm{Ca}$ & 0 & $5(-)$ & - & {$[219]$} \\
\hline $\mathrm{Ca}$ & 0.3 & $5.9(4)$ & - & {$[178]$} \\
\hline $\mathrm{Ca}$ & 0.33 & $5(1)$ & - & {$[220]$} \\
\hline $\mathrm{Ca}$ & 0.43 & $8(-)$ & & \\
\hline $\mathrm{Ca}$ & 0.5 & $5(1.0)$ & - & {$[176]$} \\
\hline $\mathrm{Ca}$ & 0.5 & $7.6(1.9)-9.4(2.4)$ & for 2 different $T_{f}$ & {$[192]$} \\
\hline $\mathrm{Ca}$ & 0.6 & $2.7(4)$ & - & {$[178]$} \\
\hline $\mathrm{Ca}$ & 0.75 & $1(-)$ & - & {$[221]$} \\
\hline $\mathrm{Ba}$ & 0.3 & $5.0(7)$ & - & {$[181]$} \\
\hline $\mathrm{K}$ & 0.6 & $0.9(4)-1.6(4)$ & - & {$[178]$} \\
\hline $\mathrm{K}$ & 0.8 & n.d. & - & {$[178]$} \\
\hline
\end{tabular}

Table 5: Proportion of NBO in percent in tectosilicate glasses, measured by various NMR spectroscopy technics (principally $\left.{ }^{17} \mathrm{O} N \mathrm{NR}\right)$.

At fixed $\mathrm{SiO}_{2}$ content, the variations of the fraction of non-stoichiometric NBO with the $\mathrm{M}^{\mathrm{n}+}{ }_{2 / \mathrm{n}} \mathrm{O} /($ $\mathrm{M}^{\mathrm{n}+}{ }_{2 / \mathrm{n}} \mathrm{O}+\mathrm{Al}_{2} \mathrm{O}_{3}$ ) ratio describe linear trends (Fig. 32). The disappearance of non-stoichiometric NBOs occur in the peraluminous domain, for $\mathrm{M}^{\mathrm{n}+}{ }_{2 / \mathrm{n}} \mathrm{O} /\left(\mathrm{M}^{\mathrm{n}+}{ }_{2 / \mathrm{n}} \mathrm{O}+\mathrm{Al}_{2} \mathrm{O}_{3}\right)<0.5$ (reciprocally $\mathrm{M}^{\mathrm{n}+}{ }_{2 / \mathrm{n}} \mathrm{O} /($ $\left.\left.\mathrm{M}^{\mathrm{n}+}{ }_{2 / \mathrm{n}} \mathrm{O}+\mathrm{Al}_{2} \mathrm{O}_{3}\right)>0.5\right)$.

While up to 9 percent of non-stoichiometric NBO are reported in Ca tectosilicate glasses, the fractions reported in $\mathrm{K}$ tectosilicate glasses are lower (Fig. 32). An effect of the ionic field strength of the modifier cation thus appears possible: reducing the cation ionic field strength apparently results in a reduced content of non-stoichiometric NBO in the glass[178]. However, very few direct data are available in other systems (e.g., Na-bearing glasses) to test this statement, such that it should be considered with caution. Indirect evidences from Raman spectroscopy and viscosity measurements suggested the presence of non-stoichiometric NBOs in $\mathrm{Na}$ and $\mathrm{Mg}$ tectosilicate glasses $[177,197]$, but do not provide any quantification. The molecular dynamic simulation results from Xiang et al. [205] on Na aluminosilicate glasses with $60 \mathrm{~mol} \% \mathrm{SiO}_{2}$ indicate that, at such silica concentration, the tectosilicate glass may 
Le Losq, Cicconi, Greaves, Neuville. Silicate Glasses. In: Springer Handbook of Glass.

contain 4-5\% non-stoichiometric NBO, depending on the potential used during the calculations. Such value is an estimation to consider with caution, because of the high fictive temperature of simulated glasses that may affect the modelled structure [222]. In addition to a potential effect of the metal cation ionic field strength, the existing data on the Ca tectosilicate glasses suggest that the non-stoichiometric NBO content also may vary with the $\mathrm{Si} /(\mathrm{Si}+\mathrm{Al})$ ratio of the glass [178]. Indeed, it is comprised between 5 and $8 \%$ for $0<\mathrm{Si} /(\mathrm{Si}+\mathrm{Al})<0.5$, and then decreases down to the percent level at $\mathrm{Si} /(\mathrm{Si}+\mathrm{Al})>0.5$ (Table 5).

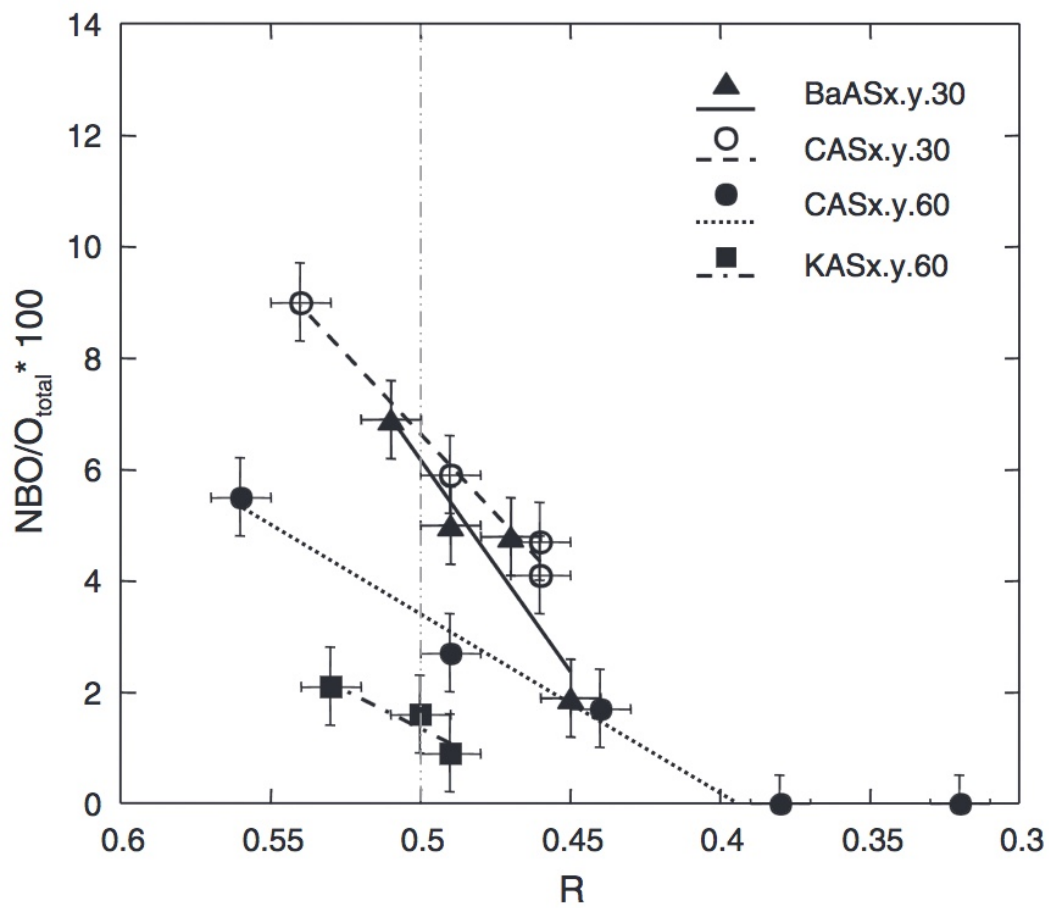

Figure 32: Proportion of non-stoichiometric non-bridging oxygens NBO relatively to the total proportion of oxygens in the network of tectosilicate glasses as a function of the ratio $R$ of the concentrations of metal cation and aluminum $\mathrm{M}^{n+}{ }_{2 / n} \mathrm{O} /\left(\mathrm{M}^{n+}{ }_{2 / n} \mathrm{O}+\mathrm{Al}_{2} \mathrm{O}_{3}\right)$. BaASx.y.30: barium tectosilicate glasses with 30 mol\% $\mathrm{SiO}_{2}$; CASx.y.30 and CASx.y.60: calcium tectosilicate glasses with 30 and $60 \mathrm{~mol}_{0} \mathrm{SiO}_{2}$, respectively; KASx.y.60: potassium tectosilicate glasses with 60 mol\% $\mathrm{SiO}_{2}$. Lines fits are shown as guides to the eye. Reprinted from Thompson LM, Stebbins JF (2012) Non-stoichiometric non-bridging oxygens and five-coordinated aluminum in alkaline earth aluminosilicate glasses: Effect of modifier cation size. Journal of Non-Crystalline Solids 358:1783-1789. doi: 10.1016/j.jnoncrysol.2012.05.022. Copyright (2012), with permission from Elsevier.

In addition of ${ }^{[5]} \mathrm{Al}$ and non-stoichiometric $\mathrm{NBO}$, the study of tectosilicate glasses and melts further brought to light the possibility of the existence of tri-coordinated oxygen atoms in such compositions. 
Le Losq, Cicconi, Greaves, Neuville. Silicate Glasses. In: Springer Handbook of Glass.

Lacy [223] originally proposed the idea of the presence of triclusters in alumino-silicate melts. This idea was pursued by Toplis et al. [197], to explain why, at fixed $\mathrm{SiO}_{2}$ concentration, the isothermal viscosity of $\mathrm{Na}$ alumino-silicate melts with varying $\mathrm{Al} / \mathrm{Na}$ ratios form a maximum centered in the peraluminous domain at liquidus temperatures, and not, as expected, on the tectosilicate join. Following Lacy's idea, Toplis et al. [197] proposed that such oxygen triclusters was linking either $2 \mathrm{SiO}_{4}$ tetrahedra to one $\mathrm{AlO}_{4}$ tetrahedron, or two $\mathrm{AlO}_{4}$ tetrahedra with one $\mathrm{SiO}_{4}$ tetrahedron. Such linkage will allow the presence of non-stoichiometric NBO in tectosilicate and peraluminous glasses following the reactions [197]:

$2 \mathrm{M}^{n+}{ }_{1 / n} \mathrm{AlO}_{2}+\mathrm{SiO}_{2} \Leftrightarrow \mathrm{M}^{n+}{ }_{1 / n} \mathrm{Al}_{2} \mathrm{SiO}_{5.5}+\mathrm{M}^{n+}{ }_{1 / n} \mathrm{O}_{0.5}$

or

$M^{n+}{ }_{1 / n} \mathrm{AlO}_{2}+2 \mathrm{SiO}_{2} \Leftrightarrow \mathrm{AlSi}_{2} \mathrm{O}_{5.5}+\mathrm{M}^{n+}{ }_{1 / n} \mathrm{O}_{0.5}$,

with $\mathrm{M}_{1 / n}^{n+} \mathrm{Al}_{2} \mathrm{SiO}_{5.5}$ and $\mathrm{AlSi}_{2} \mathrm{O}_{5.5}$ the triclusters. However, as highlighted in the previous paragraph, the presence of non-stoichiometric NBOs occur simultaneously with the presence of excess ${ }^{[5]} \mathrm{Al}$ in the structure of the melts. Stebbins et al. [192] highlighted that the formation of ${ }^{[5]} \mathrm{Al}$ and $\mathrm{NBO}$ could be related through some mechanism implying both species. Indeed, the fall of the non-stoichiometric NBO content in the peraluminous region seem to relate to the rise of the ${ }^{[5]} \mathrm{Al}$ content in the glasses (see figures 32 and 25, sec. 1.4.1). Stebbins et al. [192] further noted than increasing the glass fictive temperature was leading to increase both the $\mathrm{NBO}$ and ${ }^{[5]} \mathrm{Al}$ contents, an observation confirmed by the recent ${ }^{17} \mathrm{O}$ data on Ca tectosilicate glasses of Thompson and Stebbins [193]. The latter reported increases of up to 1.7\% of the NBO fractions in Ca tectosilicate glasses with increasing their $T_{f}$ of $\sim 100-140^{\circ}$. However, they found that such increases depend on the glass composition in a complex way. In general, the links between the formation of non-stoichiometric $\mathrm{NBO}$ and ${ }^{[5]} \mathrm{Al}$ in glasses are not fully clear, leading Thompson and Stebbins [[178] to propose that several mechanisms probably are playing at the same time.

The presence of oxygen triclusters in glasses thus cannot be excluded. However, while molecular dynamic simulations also suggest their presence in the network of alumino-silicate glasses [e.g., 205, 206], the only direct experimental observation of such oxygen triclusters have been made on a $\mathrm{Ca}$ aluminate glass by Iuga et al. [219] using heteronuclear high-resolution NMR spectroscopy. We finally should note that, while oxygen triclusters have been proposed as linking three Al- and Si-bearing 
Le Losq, Cicconi, Greaves, Neuville. Silicate Glasses. In: Springer Handbook of Glass.

tetrahedral units, it also is possible that ${ }^{[5]} \mathrm{Al}$ and potentially ${ }^{[6]} \mathrm{Al}$ polyhedra carry three-coordinated oxygen anions, ${ }^{[3]} \mathrm{O}$, at some of their summit. Indeed, Le Losq et al. [25] noticed that ${ }^{[3]} \mathrm{O}$ are present at the summits of ${ }^{[5]} \mathrm{Al}$ and ${ }^{[6]} \mathrm{Al}$ species in Sillimanite or in other minerals like Low or High Albite for instance [see 224 for instance]], while ${ }^{[4]} \mathrm{Al}$ and ${ }^{[4]}$ Si species are linked by two-fold coordinated oxygen anions $\left({ }^{[2]} \mathrm{O}\right)$ in such minerals. As a result, those authors proposed that ${ }^{[3]} \mathrm{O}$ may be present in the structure of tectosilicate and peraluminous glasses, but they connect highly coordinated Al species to other tetrahedral units rather than only tetrahedral units. This explanation will allow understanding why, for instance, both the viscosity of the $\mathrm{NaAlSi}_{3} \mathrm{O}_{8}$ melt and its $\mathrm{NBO}$ content decreases with increasing pressure $[225,226]$. Indeed, such paradox can be explained assuming that the formation of ${ }^{[5]} \mathrm{Al}$ apportion the existing NBOs, but also favor the diffusivity of $\mathrm{O}$ species in the melt such that it lowers its viscosity. However, this proposition does not explain the positive correlation between the $T_{f}$ of Ca tectosilicate glasses and their non-stoichiometric NBO and ${ }^{[5]} \mathrm{Al}$ contents, reported by Stebbins et al. [192] and Thompson and Stebbins [193]. Indeed, assuming ${ }^{[5]} \mathrm{Al}$ apportion NBOs in the glass network, a decreasing fraction of non-stoichiometric NBO might be expected upon increasing the glass $T_{f}$ and ${ }^{[5]} \mathrm{Al}$ fraction. Such contradiction illustrates that the links between glass composition, structure, ${ }^{[5]} \mathrm{Al}$, nonstoichiometric NBO and possibly ${ }^{[3]} \mathrm{O}$ (either as triclusters or bonded to ${ }^{[5]} \mathrm{Al}$ ) are not yet understood, and that several mechanisms that depend on melt composition and temperature probably occur simultaneously.

\subsubsection{Medium range order structure in alumino-silicate glasses and the Mixed Alkali Effect}

From the above description of the environment of aluminum at short-range order in alumino-silicate glasses, the structure at medium-range order of such glasses is complex as it needs to accommodate a few particularities. In particular, models for describing the structure at medium range order of aluminosilicate glasses need to account for the intimate relationship between $\mathrm{AlO}_{4}$ units (and possibly $\mathrm{AlO}_{5}$ and $\mathrm{AlO}_{6}$ units) and the charge-compensator metal cations. Furthermore, the models should account for the fact that the distribution of $\mathrm{Al}$ and $\mathrm{Si}$ in $Q^{n}$ units presents a certain degree of randomness, depending on the metal cation ionic radius. As aluminum presence shift the equilibrium (6) to the right [203], its presence in silicate melts potentially promotes regions rich in inter-connected $Q^{4}$ units and regions rich in $Q^{2}$ units surrounded by network modifier cations. Therefore, it is tempting to extend the MRN model of Greaves $[126,127]$ to the case of charge-compensating cations in alumino-silicate glasses. 
Le Losq, Cicconi, Greaves, Neuville. Silicate Glasses. In: Springer Handbook of Glass.

Following this line of thinking, Greaves and Ngai [129] proposed the Charge-Compensated Random Network (CCRN) model. Applied to tectosilicate glasses, it depicts their structure as composed of segregated regions rich in compensating metallic and aluminum ions. Indeed, the specific coordination of charge-compensator cations may lead to a distribution of those elements that is not random in the alumino-silicate network. Such idea may explain the weak and particular mixed alkali effects (MAE) observed in alkali tectosilicate glasses (Fig. 33). Indeed, the mixture of the $\mathrm{NaAlSi}_{3} \mathrm{O}_{8}$ and $\mathrm{KAlSi}_{3} \mathrm{O}_{8}$ glasses leads to deviations from linearity in the glasses $T_{g}$ that are not explained by a random mixing of $\mathrm{Na}$ and $\mathrm{K}$ in the alumino-silicate network [57]. $T_{g}$ variations suggest that $\mathrm{Na}$ and $\mathrm{K}$ have specific and different environments in alumino-silicate glasses. In particular, they probably present different coordination numbers, as observed in different alumino-silicate glasses and minerals: values between 6 and 8 have been reported for $\mathrm{Na}$ [109-111], whereas values between 9 and 12 have been reported for $\mathrm{K}^{+}$ $[214,224,227]$. Translating such $\mathrm{CN}$ values in ionic radius, ionic radius values range between 102 and $118 \mathrm{pm}$ for $\mathrm{Na}^{+}$and 155 and $164 \mathrm{pm}$ for $\mathrm{K}^{+}$, using the Shannon [107] ionic radius dataset.

We should note that the ionic radius of $\mathrm{K}^{+}$even exceed that of $\mathrm{O}^{2-}$, of $\sim 135 \mathrm{pm}$ [107]. Indeed, $\mathrm{O}^{2-}$ actually is one of the largest ion in usual silicate glasses, as the ionic radius of the common $\mathrm{Ca}^{2+}, \mathrm{Mg}^{2+}, \mathrm{Na}^{+}$or $\mathrm{Li}^{+}$cations are much smaller than that of $\mathrm{O}^{2-}$. Le Losq and Neuville [57] suggested that such large $\mathrm{K}^{+}$ ionic radius and $\mathrm{CN}$ in alumino-silicate compositions may promote the segregation of $\mathrm{K}^{+}$ions in ionic percolation channels, with "walls" rich in $\mathrm{AlO}_{4}$ units. Such hypothesis may explain the variations of the $T_{g}$ and configuration entropy of Na-K tectosilicate glasses reported in Fig. 33 because it implies a nonrandom mixing of $\mathrm{Na}$ and $\mathrm{K}$ in the glass structure. In addition, it implies that, compared to $\mathrm{Na}^{+}$, less configurations are available to accommodate $\mathrm{K}^{+}$in the aluminosilicate network, explaining the higher $T_{g}$ and lower configurational entropy of the potassic tectosilicate glasses. 
Le Losq, Cicconi, Greaves, Neuville. Silicate Glasses. In: Springer Handbook of Glass.

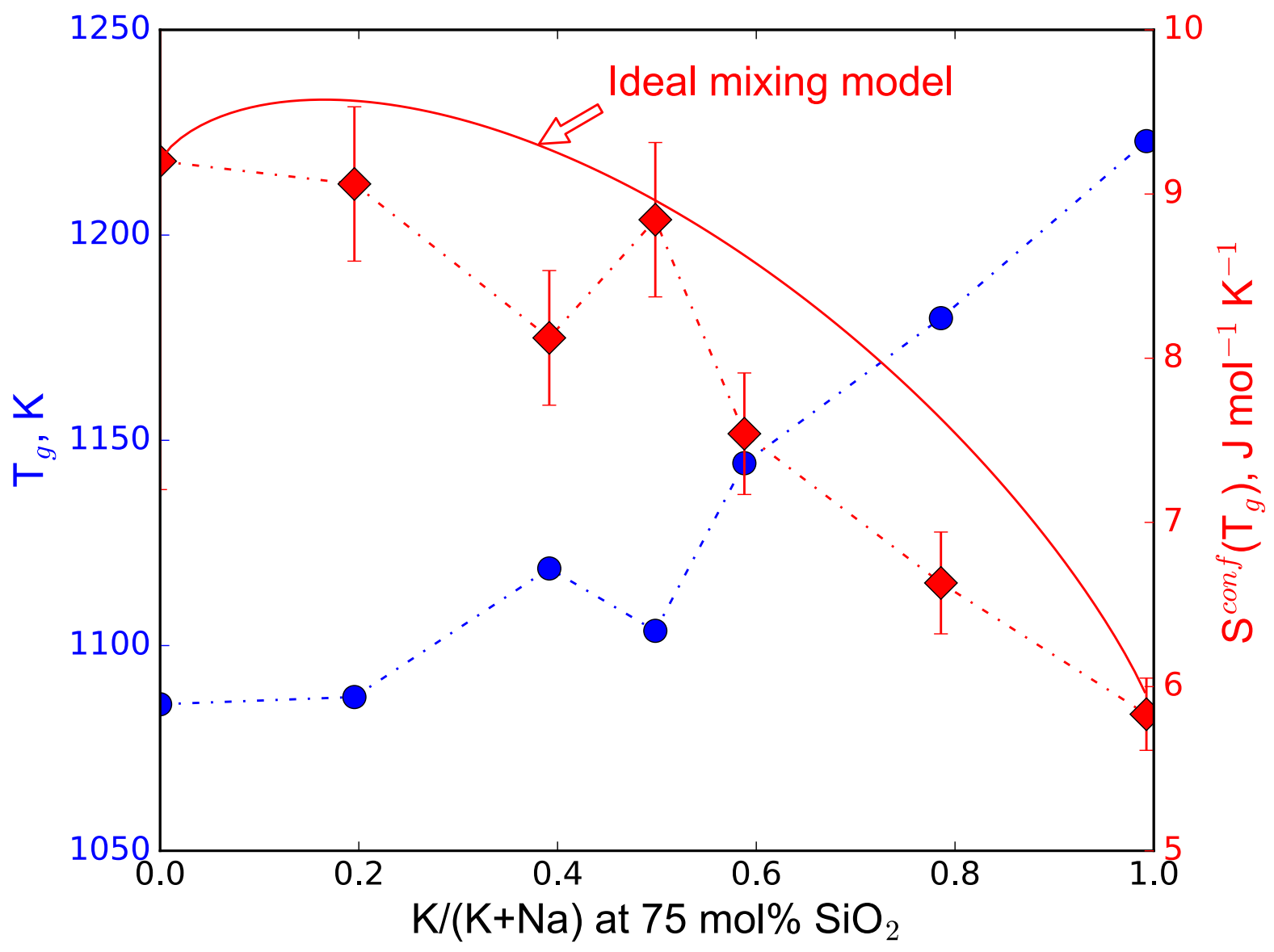

Figure 33: Viscous glass transition temperature $T_{g}$ and configurational entropy at the glass transition temperature $S^{\text {conf }}\left(T_{g}\right)$ of $\mathrm{NaAlSi}_{3} \mathrm{O}_{8}-\mathrm{KAlSi}_{3} \mathrm{O}_{8}$ glasses as a function of the glass $\mathrm{K} /(\mathrm{K}+\mathrm{Na})$ ratio. $S^{\text {conf }}\left(\mathrm{T}_{g}\right)$ values have been determined performing a global fit of the viscosity data in the binary $\mathrm{NaAlSi}_{3} \mathrm{O}_{8^{-}}$ $\mathrm{KAlSi}_{3} \mathrm{O}_{8}$ system from [57, 228], with using the framework of the Adam and Gibbs equation linking viscosity, heat capacity and entropy (see chapter XXX and [117]). A common high temperature viscosity limit was used during the fit. Dotted lines are guides for the eyes. The plain line illustrates the entropy variations expected between the end-member in the case of an ideal mixing of the Na and K cations in the alumino-silicate framework [see 22, 117, 140].

This hypothesis of different local environments and segregation of the charge-compensator $\mathrm{Na}^{+}$and $\mathrm{K}^{+}$ cations in aluminosilicate glasses is corroborated by results from Raman spectroscopy of the Na-K tectosilicate glasses. Indeed, Le Losq and Neuville [57] reported that, upon substituting $\mathrm{Na}$ by $\mathrm{K}$ in $\mathrm{NaAlSi}_{3} \mathrm{O}_{8}-\mathrm{KAlSi}_{3} \mathrm{O}_{8}$ glasses, the peak assigned to T-O stretching around $\sim 1100 \mathrm{~cm}^{-1}$ was shifting to a higher frequency. In addition, the intensities of two peaks at $\sim 570 \mathrm{~cm}^{-1}$ and $\sim 590 \mathrm{~cm}^{-1}$, assigned to breathing vibrations in three-membered rings containing different amounts of $\mathrm{Al}$ [57, 229], change with 
Le Losq, Cicconi, Greaves, Neuville. Silicate Glasses. In: Springer Handbook of Glass.

the glasses $\mathrm{K} /(\mathrm{K}+\mathrm{Na})$ ratio. In particular, the intensity of the $590 \mathrm{~cm}^{-1}$ peak increases with substitution of $\mathrm{Na}$ by $\mathrm{K}$, pointing to an increase of the fraction of three-membered rings containing only Si atoms. Following this observation, Le Losq and Neuville [57] suggested that, while K cations enter in the glass network, they distort the tetrahedral cages that accommodate them, leading to a general increase of the mean T-O-T angle. Si atoms segregates in denser regions, represented by the Si-bearing three-membered rings. Overall, the variations suggest a segregation of the glass network in Si-rich and Al-K rich regions in tectosilicate glasses. This hypothesis implies that the mixing of the charge compensator $\mathrm{Na}^{+}$and $\mathrm{K}^{+}$is not ideal, as they occupy different structural positions, such that the variations of the glass $T_{g}$ and configurational entropy at $T_{g}$ upon Na-K mixing reported in Fig. 33 are closer to linear trends obtained by a mechanical mixing of two Na-Al-Si-O and K-Al-Si-O sub-lattices than to non-linear trends resulting from an ideal Na-K mixing in a single $\mathrm{Si}-\mathrm{Al}-\mathrm{O}$ sub-lattice.

From the above discussion, the CCRN model could explain the mixing of $\mathrm{Na}$ and $\mathrm{K}$ as chargecompensator in alkali silicate melts, with a non-ideal mixing of the two alkali cations in different structural environment. However, the absence of an "ideal” MAE in tectosilicate glasses is not general. Indeed, Hummer and Arndt [140] indicated that the variations of viscosity and $T_{g}$ in mixed $\mathrm{Ca}_{2} \mathrm{Al}_{2} \mathrm{Si}_{3} \mathrm{O}_{8}$ - $\mathrm{NaAlSi}_{3} \mathrm{O}_{8}$ melts can be modelled using an ideal mixing entropic model, implying a random mixing of $\mathrm{Na}$ and $\mathrm{Ca}$ in the melt structure. In peralkaline melts, a MAE also is observed when mixing $\mathrm{Ca}$ and $\mathrm{Mg}$ for instance. Indeed, the configurational entropy at $T_{g}$ of mixed $\mathrm{Ca}_{3} \mathrm{Al}_{2} \mathrm{Si}_{3} \mathrm{O}_{12}-\mathrm{Mg}_{3} \mathrm{Al}_{2} \mathrm{Si}_{3} \mathrm{O}_{12}$ tectosilicate glasses follow variations that can be modelled with assuming an excess of entropy generated by a random mixing of pairs of $\mathrm{Ca}$ and $\mathrm{Mg}$ cations in the glasses [22]]. Similarly, a MAE affects the $T_{g}$, the Vickers microhardness as well as the configurational heat capacity $\mathrm{C}_{\mathrm{p}}{ }^{\text {conf }}\left(\mathrm{T}_{\mathrm{g}}\right)$ values $\left(\mathrm{C}_{\mathrm{p}}{ }^{\text {conf }}\left(T_{g}\right)=\mathrm{C}_{\mathrm{p}}{ }^{\text {liquid }}\left(T_{g}\right)-\right.$ $\mathrm{C}_{\mathrm{p}}{ }^{\text {glass }}\left(T_{g}\right)$ ) of Na-Ca-Mg peralkaline glasses containing $60 \mathrm{~mol} \% \mathrm{SiO}_{2}$ and $16 \mathrm{~mol} \% \mathrm{Al}_{2} \mathrm{O}_{3}$ has recently been reported [142]. Those data show the occurrence of a continuous MAE, as observed when mixing $\mathrm{Ca}$ and $\mathrm{Mg}$ or $\mathrm{Na}$ and $\mathrm{K}$ in silicate glasses (Fig. 34). 
Le Losq, Cicconi, Greaves, Neuville. Silicate Glasses. In: Springer Handbook of Glass.
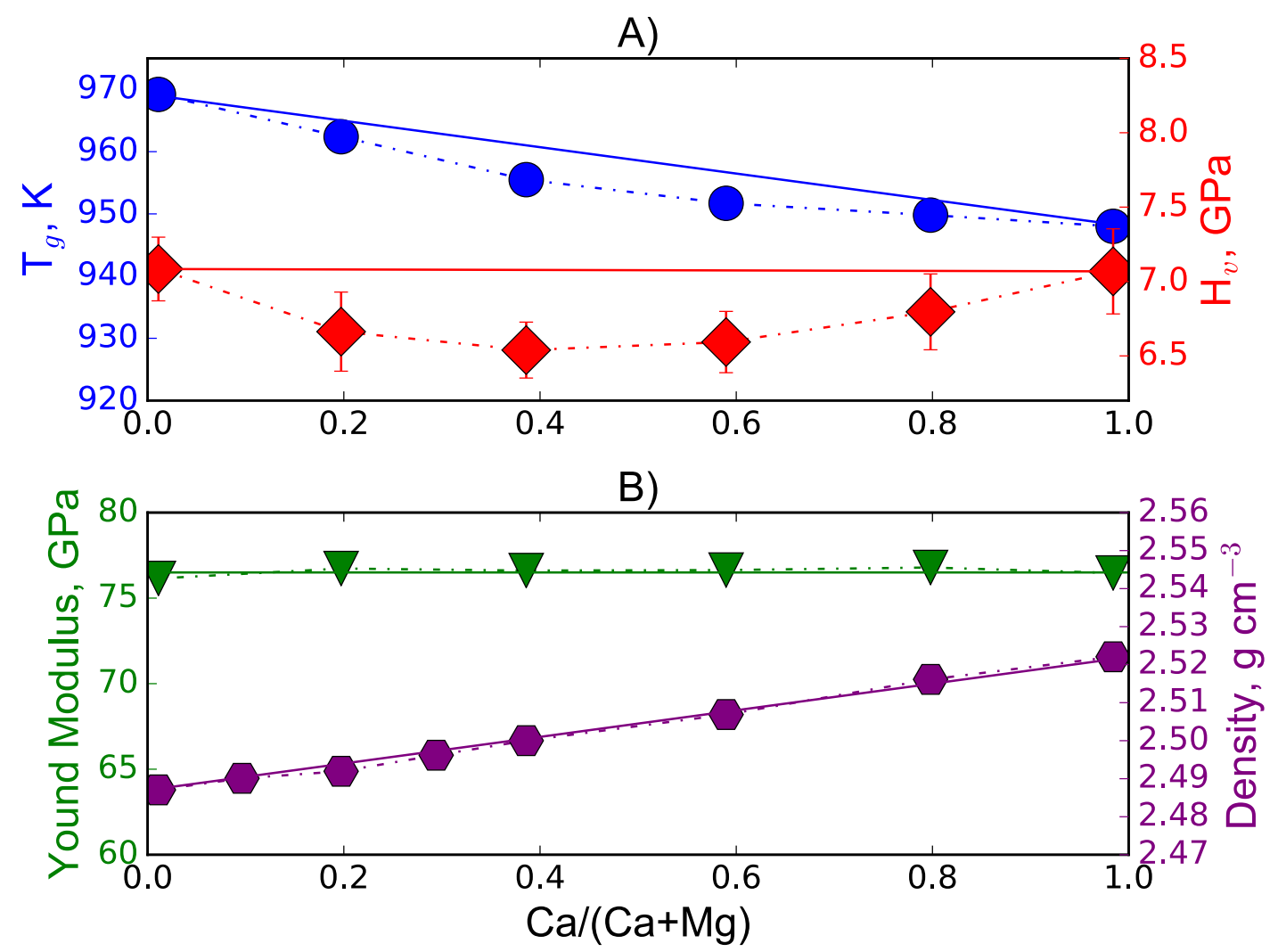

Figure 34: A) Glass transition temperature $T_{g}$ and Vickers hardness $H_{v}$ as well as B) Young modulus and density of glasses as a function of the $\mathrm{Ca} /(\mathrm{Ca}+\mathrm{Mg})$ ratio of glasses composed of $60 \mathrm{~mol} \% \mathrm{SiO}_{2}, 16 \mathrm{~mol} \%$ $\mathrm{Al}_{2} \mathrm{O}_{3}, 15.8 \mathrm{~mol} \% \mathrm{Na}_{2} \mathrm{O}$ and the remaining proportion as $\mathrm{CaO}+\mathrm{MgO}$. While glass $\mathrm{T}_{g}$ and $\mathrm{H}_{v}$ values show significant deviations to linearity, marking the occurrence of a Mixed Alkaline-earth Effect, the glass Young modulus and density vary linearly as a function of $\mathrm{Ca} /(\mathrm{Ca}+\mathrm{Mg})$. Data from [142].

It is interesting to note that the MAE affects properties that depends on the diffusivity of the metal cations, but not properties that relate on the structure of the alumino-silicate network in itself, such as, for instance, elastic properties or glass density (Fig. 34). For instance, Figure 34 shows that, while the Young modulus of $\mathrm{Ca}-\mathrm{Mg}-\mathrm{Na}$ aluminsoilicate glasses vary linearly upon $\mathrm{Ca}-\mathrm{Mg}$ mixing, a MAE affects the Vickers hardness. Kjeldsen et al. [142] indicate that, as the Vickers hardness actually is related to the plastic flow of the glass, the occurrence of the MAE is not surprising. On the other hand, glass density and Young modulus, not affected by MAE, are related to the structural arrangements in the glass. This can be explained by the fact that structural characteristics of the glass network tend to vary linearly upon mixing metal cations between endmember compositions. For instance, data in Al-free silicate melts point to negligible or linear variations of the $Q^{n}$ unit distribution upon mixing metal cations in the glasses. Indeed, Hater et al. [230] did not observe systematic change of the $Q^{n}$ unit distribution upon $\mathrm{Rb}-\mathrm{Na}$ 
Le Losq, Cicconi, Greaves, Neuville. Silicate Glasses. In: Springer Handbook of Glass. mixing in alkali trisilicate glasses using ${ }^{29} \mathrm{Si}$ and ${ }^{23} \mathrm{Na}$ Magic Angle Spinning (MAS) NMR spectroscopy. ${ }^{23} \mathrm{Na},{ }^{7} \mathrm{Li}$, and ${ }^{29} \mathrm{Si} \mathrm{NMR}$ data from $(\mathrm{Na}, \mathrm{Li})_{2} \mathrm{Si}_{2} \mathrm{O}_{5}$ glasses also suggest an intimate, uniform mixing of the $\mathrm{Li}$ and $\mathrm{Na}$ alkali metal cations without significant changes in the silicate tetrahedral network [231]. On the other hand, using ${ }^{6} \mathrm{Li},{ }^{7} \mathrm{Li}$ and ${ }^{29} \mathrm{Si}$ static NMR spectroscopy, Bray et al. [232] observed a linear change of the fraction of $Q^{3}$ units upon mixing $\mathrm{Li}$ and $\mathrm{K}$ in disilicate glasses. The ${ }^{29} \mathrm{Si}$ static NMR data from Emerson and Bray [233] further suggest a slight departure from linearity of the $Q^{3}$ unit fraction when mixing $\mathrm{Na}_{2} \mathrm{Si}_{2} \mathrm{O}_{5}$ and $\mathrm{Cs}_{2} \mathrm{Si}_{2} \mathrm{O}_{5}$ glasses. Such interpretation may be coherent with ${ }^{17} \mathrm{O}$ Dynamic Angle Spinning NMR data from mixed $\mathrm{Na}_{2} \mathrm{Si}_{2} \mathrm{O}_{5}-\mathrm{K}_{2} \mathrm{Si}_{2} \mathrm{O}_{5}$ glasses [152], showing slightly non-linear changes of the fractions of Bridging (BO) and Non-Bridging (NBO) oxygen anions with changes in the glasses $\mathrm{K} /(\mathrm{K}+\mathrm{Na})$ ratios. Recent analysis of Raman spectra of mixed $(\mathrm{K}, \mathrm{Na}) \mathrm{Si}_{3} \mathrm{O}_{7}$ and $(\mathrm{K}, \mathrm{Na})_{2} \mathrm{Si}_{2} \mathrm{O}_{9}$ glasses by Le Losq and Neuville[20] further indicate that the $Q^{n}$ distribution of mixed Na-K silicate glasses vary almost linearly upon Na-K mixing; when combined with the data from [152], it appears that slight deviation to linearity appear at high alkali concentration but do no excess a few percent[20]]. Therefore, almost linear variations of the glass $Q^{n}$ unit distribution are suggest by NMR and Raman spectroscopy results. This may explain why, for instance, the glass density tends to vary linearly upon metal mixing in silicate and alumino-silicate melts (Fig. 34, see also [137] for instance). Indeed, as presented in section 1.3.1, it is possible to relate the volume of $Q^{n}$ units to the density of the glasses, such that nearly linear variations of the $\mathrm{Q}^{\mathrm{n}}$ unit fractions upon mixing metal cations in silicate and alumino-silicate glasses should result in linear variations of the glass density, as observed (Fig. 34).

The contrast between the variations of $T_{g}$ upon mixing $\mathrm{Na}$ and $\mathrm{K}$ in tectosilicate glasses (Fig. 33) and $\mathrm{Ca}$ and $\mathrm{Mg}$ in Na-Ca-Mg peralkaline glasses (Fig. 34) directly points to the complexity of the MAE. Charge compensators with very dissimilar ionic radius, like $\mathrm{Na}$ and $\mathrm{K}$ (Table 6 ), appear to mix non-randomly in the glass structure, while cations with similar ionic radius, like $\mathrm{Ca}$ and $\mathrm{Mg}$, appear to mix more randomly. However, even the apparent ideal mixing reported in $\mathrm{Ca}-\mathrm{Mg}$ alumino-silicate melts, observed from a thermodynamic point of view [22], may not necessarily be perfect. Indeed, recent data from ${ }^{17} \mathrm{O}$ MAS and 3QMAS NMR spectroscopy indicate that, in mixed $\mathrm{Ca}_{3} \mathrm{Al}_{2} \mathrm{Si}_{3} \mathrm{O}_{12}-\mathrm{Mg}_{3} \mathrm{Al}_{2} \mathrm{Si}_{3} \mathrm{O}_{12}$ glasses, the mixing of $\mathrm{Ca}$ and $\mathrm{Mg}$ around $\mathrm{NBO}$ is not perfectly random [234]. A slight excess of $\mathrm{Mg}-\mathrm{NBO}$ pairing is observed, implying that extra $\mathrm{Ca}$ must be associated with $\mathrm{BO}$ from $\mathrm{Al}-\mathrm{O}-\mathrm{Si}$ bonds according to Kelsey et al. .[234]. The latter authors indicate that the $S^{\text {conf }}\left(T_{g}\right)$ values of mixed $\mathrm{Ca}_{3} \mathrm{Al}_{2} \mathrm{Si}_{3} \mathrm{O}_{12}-\mathrm{Mg}_{3} \mathrm{Al}_{2} \mathrm{Si}_{3} \mathrm{O}_{12}$ glasses, calculated from the viscosity of the melts [22], are actually slightly lower than the values modelled using an ideal, random mixing of $\mathrm{Ca}$ and $\mathrm{Mg}$ in the melts structure. As a result, Kelsey et al. [234] indicate that some ordering might take place. In addition, they discuss the fact that the simple 
Le Losq, Cicconi, Greaves, Neuville. Silicate Glasses. In: Springer Handbook of Glass. random mixing model of the $S^{\text {conf }}\left(T_{g}\right)$ of $\mathrm{Ca}_{3} \mathrm{Al}_{2} \mathrm{Si}_{3} \mathrm{O}_{12}-\mathrm{Mg}_{3} \mathrm{Al}_{2} \mathrm{Si}_{3} \mathrm{O}_{12}$ may be too simple, as it considers the mixing of the glasses as a binary system. Further complexity actually may arise from a change of the $\mathrm{Al}$ avoidance or an increasing fraction of ${ }^{[5]} \mathrm{Al}$ in the glasses when substituting $\mathrm{Ca}$ by $\mathrm{Mg}$.

\begin{tabular}{|l|l|l|l|l|}
\hline Cation & $\begin{array}{l}\text { Coordination } \\
\text { number }\end{array}$ & $\begin{array}{l}\text { Corresponding } \\
\text { Ionic radius } \\
\text { from Shannon } \\
{[107], \AA}\end{array}$ & Method & Reference \\
\hline $\mathrm{Na}$ & $6-8$ & $1.02-1.18$ & Exp., Mod. & {$[110,111,125]$} \\
\hline $\mathrm{K}$ & $9-11$ & $1.55-1.64^{*}$ & Exp. & {$[214]$} \\
\hline $\mathrm{Ca}$ & $5-7$ & $1.00^{*}-1.06$ & Exp., Mod. & {$[206,215-217]$} \\
\hline $\mathrm{Mg}$ & $\sim 5$ & 0.66 & {$[218]$} & {$[213]$} \\
\hline
\end{tabular}

Table 6: Examples of ionic radius reported in experimental (Exp.) and/or modeling (Mod.) studies of the structure of $\mathrm{Na}, \mathrm{K}, \mathrm{Ca}$ and Mg alumino-silicate glasses. *: no value for this $\mathrm{CN}$ is provided by Shannon [107], such that the value for the closest CN is reported hereby.

Therefore, while the data from [22] show that considering $\mathrm{Ca}$ and $\mathrm{Mg}$ as randomly mixing in the structure of alumino-silicate glasses yields a good approximation for modelling the properties of the $\mathrm{Ca}-\mathrm{Mg}$ alumino-silicate melts and glasses, NMR data invite to refine such approach. In particular, future models may have to account for the influence of the metal IFS on preferences for NBO/BO bonding and for Al charge compensation, as well as on ${ }^{[5]} \mathrm{Al}$ generation and on the $\mathrm{Al}$ avoidance extent. Furthermore, another level of complexity appears when considering that, in the structure of peralkaline glasses, network modifiers (NM) and charge compensators (CC) mix between themselves (NM-NM or CC-CC mixing) and potentially between each-other (NM-CC mixing). According to Greaves and Ngai [129], the structure of such peralkaline compositions should be described as a mix of the CCRN and MRN model. Charge compensator and network modifier metal cations thus will be represented as residing in different type of channels. While the local environment of charge compensator cations will be rich in $\mathrm{Al}^{3+}$ ions, that of the network modifier cations will be rich in NBOs. Other representations of the structure of aluminosilicate melts and the repartition of metal cations in it come from the perturbed distribution model, which depicts the network modifiers and charge compensators as randomly distributed nor segregating in clusters in the network, as suggested by ${ }^{17} \mathrm{O}$ NMR data that show that $\mathrm{Na}^{+}$interacts with $\mathrm{BO}$ from Si-O- 
Le Losq, Cicconi, Greaves, Neuville. Silicate Glasses. In: Springer Handbook of Glass.

Si, Si-O-Al and Al-O-Al bonds in Na tectosilicate glasses [130]. To this date, the exact representation of the structure of alumino-silicate glasses and of the repartition of metal cations in them remains an open topic of research.

\subsubsection{Elastic properties and density of alumino-silicate glasses}

The macroscopic elastic moduli of structural glasses are generally controlled by the glass atomic density and the mean inter-atomic forces. Different metal cations will affect differently the latter properties, such that the nature of metal cations in glasses directly correlate with the glass Shear, Bulk and Young's moduli (Fig. 35).

Therefore, elastic properties of glasses are closely related to the cations present in the glass. On the other hand, the glass Poisson ratio $v$ is differently affected by the glass chemical composition. Weigel et al. [235]] showed that the Poisson ratios of $\mathrm{M}^{\mathrm{n}+}{ }_{1 / \mathrm{n}} \mathrm{AlSiO}_{4}$ glasses ( $\mathrm{m}=\mathrm{Li}, \mathrm{Na}, \mathrm{K}, \mathrm{Ca}, \mathrm{Mg}, \mathrm{Sr}, \mathrm{Ba}, \mathrm{Zn}$ ) showed no correlation with the glass molar volume, but were divided in 2 global mean values, depending on the charge of the metal cation present in the glass. Indeed, while the Poisson ratio of alkali-bearing glasses was $\sim 0.234$, that of alkaline-earth bearing glasses was $\sim 0.265$. Such difference arises from the different structure of alkali and alkaline-earth tectosilicate glasses, as shown by the strong difference of their Raman spectra [e.g., 30]. Such differences in glass structure implies a difference in the atomic packing density $C_{g}$ of the glasses, which, in turn, affects the glass Poisson ratio [236 and references therein]. In this regard, the lower Poisson ratio of alkali $\mathrm{M}^{\mathrm{n}+}{ }_{1 / \mathrm{n}} \mathrm{AlSiO}_{4}$ glasses compared to alkaline-earth $\mathrm{M}^{\mathrm{n}+}{ }_{1 / \mathrm{n}} \mathrm{AlSiO}_{4}$ glasses reported by Weigel et al. [235] highlight a difference in the 3D arrangement of the glass structure. As a result, 3D arrangements at medium-range order in alumino-silicate glasses seem influenced by the electric charge of the charge compensator metal cations. 
Le Losq, Cicconi, Greaves, Neuville. Silicate Glasses. In: Springer Handbook of Glass.

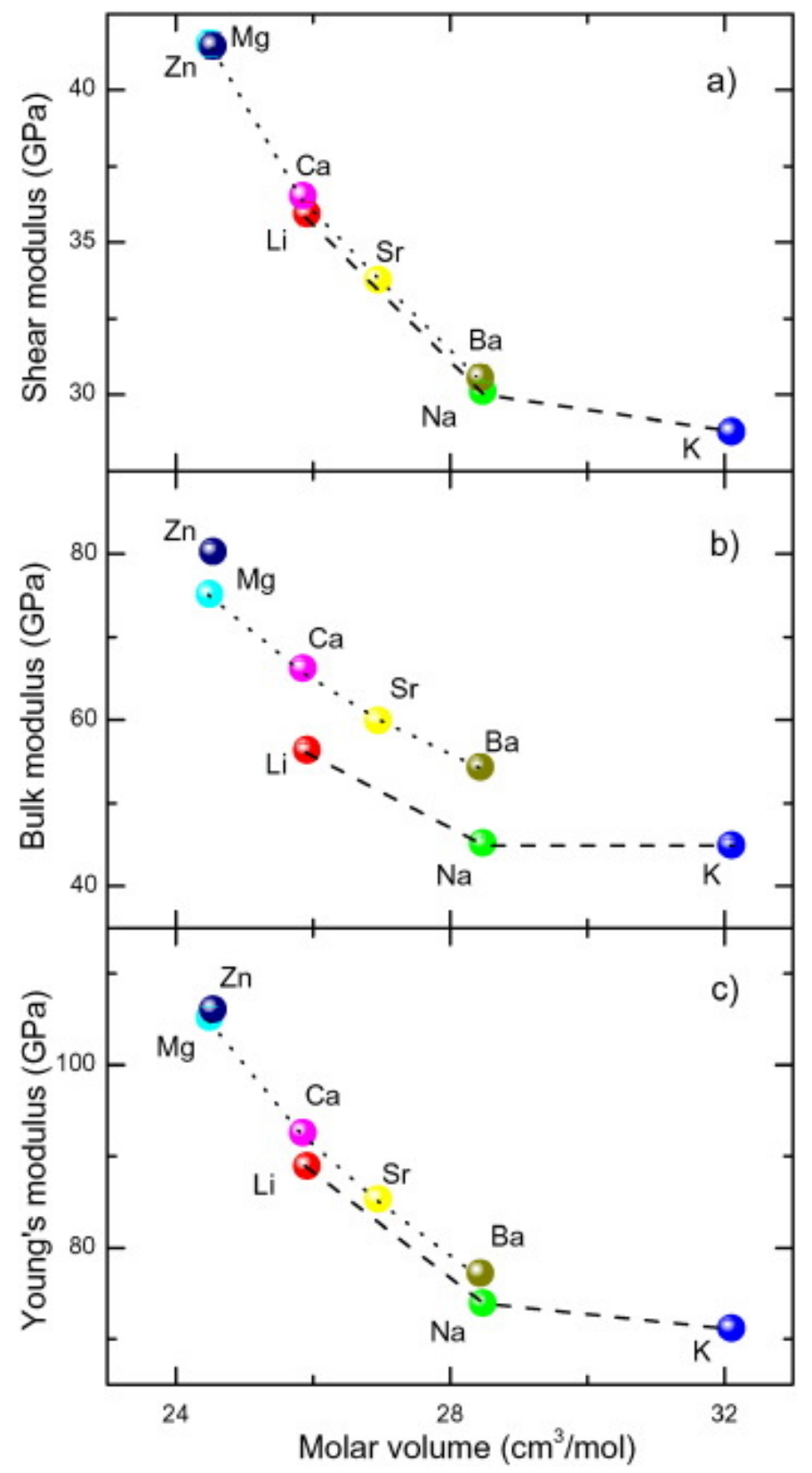

Figure 35: Elastic moduli of $\mathrm{M}^{n+}{ }_{1 / n} \mathrm{AlSiO}_{4}$ glasses ( $m=\mathrm{Li}, \mathrm{Na}, \mathrm{K}, \mathrm{Ca}, \mathrm{Mg}, \mathrm{Sr}, \mathrm{Ba}, \mathrm{Zn}$ ) as a function of the glasses' molar volume. Reprinted from Weigel C, Le Losq C, Vialla R, Dupas C, Clément S, Neuville DR, Rufflé B (2016) Elastic moduli of $\mathrm{XAlSiO}_{4}$ aluminosilicate glasses: effects of charge-balancing cations. Journal of Non-Crystalline Solids 447:267-272. doi: 10.1016/j.jnoncrysol.2016.06.023. Copyright (2016), with permission from Elsevier. 
Le Losq, Cicconi, Greaves, Neuville. Silicate Glasses. In: Springer Handbook of Glass.

\subsection{Multivalent elements in silicate glasses}

All natural glasses and most of manmade glasses contain several multivalent elements, such as, for instance, $\mathrm{Fe}, \mathrm{Cr}, \mathrm{V}, \mathrm{Cr}$, and $\mathrm{Eu}$, in different concentrations. Many properties of silicate glasses and melts depend on the nature, the concentration and the oxidation state of such multivalent elements. For instance, the redox states and the coordination of multivalent elements present in glasses determine their color and optical properties [e.g., 237; see chapter XX for further details]. Several authors recently reported the influence of the bulk composition on the photoluminescence tunability of rare-earth elements [238-240], showing that by adjusting the optical basicity of the host glassm it is possible to control both Eu redox and the glass optical properties. Another example is the viscosity of iron-bearing silicate melts, which is controlled by the oxidation state of Fe at given temperature [e.g., 241-243]. In addition to such effects, the oxidation state of multivalent elements further represents a probe for studying the conditions of glass formation in geologic systems. Indeed, the redox state of multivalent elements reflects the temperature and oxygen fugacity of magmatic sources [244], such that it can be used to retrieve the temperature of ancient geologic systems [e.g., 162]. Multivalent element oxidation state further affects the partitioning of elements and mass transfers processes within the Earth [245, 241, 246, 242, 243]. As a result, understanding the behavior of such multivalent elements in silicate melts is particularly important in Materials and Earth sciences.

Reduction-Oxidation (redox) reactions involve the transfer of electrons between chemical species forming the redox couple of a given element, as for instance $\mathrm{Fe}^{2+}$ and $\mathrm{Fe}^{3+}$. In silicate melts, oxygen is generally the electron carrier, such that the redox state (ratio of the different species) of a given element is driven by changes in the oxygen chemical potential. In Earth and Material sciences, oxygen fugacity $\left(f_{\mathrm{O} 2}\right)$ is conventionally used to describe the oxygen chemical potential. Redox equilibria in glass-forming melts have been exhaustively discussed by the early studies of Schreiber [247-253]. In brief, the redox equilibrium of a multivalent element can be described as

$$
4 M_{m e l t}^{m+}+2 n O_{m e l t}^{2-} \leftrightarrow 4 M_{m e l t}^{(m-n)+}+n O_{2}
$$

with $n$ representing the number of electron transferred. This relationship is controlled by several factors, such as temperature, oxygen fugacity, and bulk chemical composition. 
Le Losq, Cicconi, Greaves, Neuville. Silicate Glasses. In: Springer Handbook of Glass.

\subsubsection{Temperature, Oxygen Fugacity, and Pressure effects}

Increasing temperature shifts the RedOx equilibrium (10) toward reduced species, as it favors the endothermic reaction according to the Van't Hoff law [250]. The log of the redox equilibria $\mathrm{M}^{(\mathrm{m}-\mathrm{n})} / \mathrm{M}^{\mathrm{m}+}$ vary linearly with reciprocal temperature [e.g., 254-257], with a slope that is equal to the enthalpy of reduction, $\Delta H$, via an approximation of the Van't Hoff relation [250, 254]:

$\log \left(\frac{\left[M^{(m-n)}\right]}{\left[M^{M+}\right]}\right)=-\frac{\Delta H}{2.303 R T}+b$

$\Delta H$ is always endothermique, leading to the reduction of the glass-forming silicate melt as temperature increases [250].

The effect of oxygen fugacity is opposite to that of $\mathrm{T}$ : increasing $f_{O 2}$ favours the stabilisation of the most oxidized specie. This can be expressed for multivalent elements dilute in silicate melts by manipulating equation (10) to obtain:

$-\log \left(f_{O_{2}}\right)=\frac{4}{n} \log \left(\frac{\left[M^{(m-n)}\right]}{\left[M^{m+}\right]}\right)+k$

with $n$ the number of exchanged electrons. For a given composition, and at constant temperature, the relationship described by eq. (12) should yield a straight line with slope equal to $4 / n$. This has been experimentally corroborated for many redox couples [e.g., 244, 250, 258, 259]. Tacking the redox couple $\mathrm{Fe}^{2+} / \mathrm{Fe}^{3+}$ as an example (fundamental for both Earth and Material science problems), studies showed that the slope of the $\log \left(f_{\mathrm{O}_{2}}\right)$ vs $\log \left(\frac{\left[\mathrm{Fe}^{2+}\right]}{\left[\mathrm{Fe}^{3+}\right]}\right)$ relationship was close to the ideal value of 4 (or 0.25 if using the $\log \left(\frac{\left[\mathrm{Fe}^{3+}\right]}{\left[\mathrm{Fe}^{2+}\right]}\right)$ vs $\log \left(f_{\mathrm{O}_{2}}\right)$ relationship) $[244,259,250]$. However, the melt composition influences slightly this value, such that it may not be ideal in all cases. For example, Mysen et al. [259] reported a slight decrease of the slope according to the ionic potential of the alkaline-earth cation in alkaline-earth silicate glasses. This trend is corroborated by the recent result of Cicconi et al. [260], who observed that the mean ionic field strength of the alkali metal cations influence the slope of the $\log \left(f_{\mathrm{O}_{2}}\right)$ vs $\log \left(\frac{\left[\mathrm{Fe}^{2+}\right]}{\left[\mathrm{Fe}^{3+}\right]}\right)$ relationship in multicomponent glasses. 
Le Losq, Cicconi, Greaves, Neuville. Silicate Glasses. In: Springer Handbook of Glass.

While the effects of oxygen fugacity and temperature on the redox state of multivalent elements are reasonably understood and characterized, that of pressure has been the subject of only few studies and remains very elusively known. In general, existing studies indicate that higher pressures promote reduced species in many compounds. For instance, reduction of $\mathrm{Fe}^{3+}, \mathrm{Cu}^{2+}$ and $\mathrm{Mn}^{3+}$ occurs at high pressure in solid compounds [261-263]. Experimental data confirmed that such behavior occurs for Fe in silicate melts $[264,265]$, as the volume change accompanying the reduction of $\mathrm{Fe}^{3+}$ in $\mathrm{Fe}^{2+}$ favors the reduction reaction [e.g., see 257]. Such changes are small: the $\mathrm{Fe}^{3+} / \mathrm{Fe}_{\mathrm{TO}}$ ratio only changes of a few \% per GPa, at most, when $\mathrm{P}$ varies between 0 to $7 \mathrm{GPa}[264,265]$. At higher pressure, changes in Fe $\mathrm{CN}$ can be expected and may affect the pressure effect because of the influence of Fe $\mathrm{CN}$ on the volume change associate with the $\mathrm{Fe}^{3+}-\mathrm{Fe}^{2+}$ redox reaction. While data on the effect of pressure on the Fe redox state are scarce, those existing for other systems are even less abundant (if simply non-existent). The data of Burnham and Berry [266] indicate that the Ce redox state may not be influenced by pressure, but those authors indicated that pressure may also favor stabilization of $\mathrm{Ce}^{4+}$. Data for other elements in silicate melts are virtually inexistent.

\subsubsection{Compositional effects}

The chemical composition of the initial melt heavily influences the redox equilibrium, as shown by existing experimental studies devoted to Fe [267-269], and to a lesser extent to Ti [247], $\mathrm{Cr}$ [247, 270], Mo [271], V [272], Sn [273], Ce and Eu [247, 266, 274, 275]. The optical basicity [276-280] of the glass generally correlates well with the redox state of multivalent elements in the melt equilibrated at given T$f_{\mathrm{O} 2}$ conditions [e.g., 252, 266]. The general glass optical basicity can be calculated from the different basicity of metal cation and network former oxides [e.g., 280]. Increasing the melt basicity results in a shift of the redox equilibrium (eq. 10) toward the reduced species (Fig. 36). In silicate glasses, metal cation present higher optical basicity than network former cations, such that increasing the fraction of metal cations promotes reduction of multivalent species. This relationship induces a general correlation of the redox equilibrium with the glass polymerization, i.e. the equilibrium constant of eq. 10 is correlated with the glass $\mathrm{NBO} / \mathrm{T}$. The common network former cations present close optical basicity in silicate glasses [e.g., $\mathrm{A} 12 \mathrm{O} 3=0.59, \mathrm{SiO} 2=0.48, \mathrm{TiO} 2=0.58,279]$. As a result, their influences on the Fe redox state are analogous, either in simplified quaternary system $\mathrm{CaO}-\mathrm{MgO}-\mathrm{Al}_{2} \mathrm{O}_{3}-\mathrm{SiO}_{2}[269]$ as well as in natural melts [281, 282]. As metal cation can present large differences in optical basicity [e.g., from 0.39 for $\mathrm{H} 2 \mathrm{O}$ to 1.40 for $\mathrm{K} 2 \mathrm{O}, 279$ ], they influence differently the equilibrium constant of eq. 10. A consequence of this is that the glass $\mathrm{NBO} / \mathrm{T}$ may not be the best parameter to truly capture the control of 
Le Losq, Cicconi, Greaves, Neuville. Silicate Glasses. In: Springer Handbook of Glass.

the melt chemical composition on the redox behavior of multivalent elements because it does not distinguish between different metal cations.
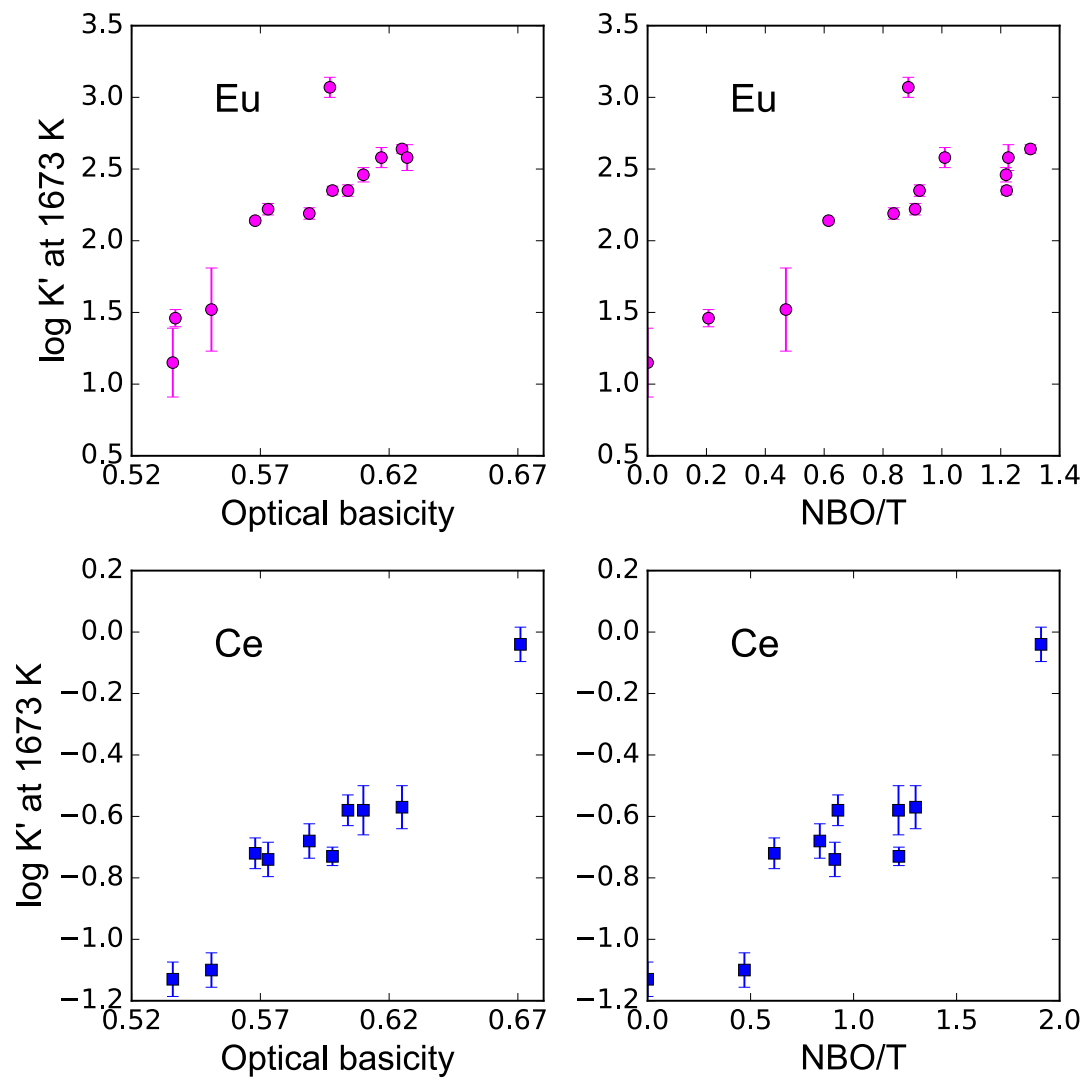

Figure 36: logarithm of the equilibrium constant of eq. (12) at 1673 for Eu and Ce in alumino-silicate melts as a function of the optical basicity or of the NBO/T. Note the outlier in the Eu plots: this data was acquired on a glass, contrary to other points that were acquired on melts. As a result, Eu oxidation state in the glass does not represent that in the melt. Burnham and Berry [266] assign this difference to potential interactions between Eu and Fe upon cooling. Data from [266, 283].

The links between the chemical composition, the glass optical basicity and polymerization, and the redox state of multivalent elements has been studied well for iron-bearing compositions, because of the interests for iron in both Earth and Material sciences. In general, increasing the content of metal cations as well as the glass $\mathrm{Al} /(\mathrm{Al}+\mathrm{Si})$ ratio result in reducing $\mathrm{Fe}$ at given $\mathrm{T}-\mathrm{f}_{\mathrm{O} 2}$ conditions $[252,267,269]$. As different metal cation present different optical basicity, complex effects between the metal cation composition of the glass and itsa iron redox state further have been reported. For instance, Dickenson and Hess [268] observed that the $\mathrm{Fe}^{2+} / \mathrm{Fe}_{\text {TOT }}$ ratio weakly increases with increasing the glass $\mathrm{K} 2 \mathrm{O} /\left(\mathrm{K}_{2} \mathrm{O}+\mathrm{Al}_{2} \mathrm{O}_{3}\right)$ ratio in peralkaline melts, whereas the opposite is observed in peraluminous compositions. In $\mathrm{Ca}$ aluminosilicate 
Le Losq, Cicconi, Greaves, Neuville. Silicate Glasses. In: Springer Handbook of Glass. glasses, Mysen et al. [269] reported a general decrease of the $\mathrm{Fe}^{2+} / \mathrm{Fe}_{\mathrm{TO}}$ ratio with the glass $\mathrm{M} /(\mathrm{M}+\mathrm{Al})$ ratio.

From the analysis of 75 peralkaline $\mathrm{K}_{2} \mathrm{O}-\mathrm{FeO}-\mathrm{SiO}_{2}$ glasses, Tangeman et al. [284] reported an increase of $\mathrm{Fe}^{2+} / \mathrm{Fe}_{\text {Tот }}$ ratio with increasing $\left[\mathrm{K}_{2} \mathrm{O}\right]$. In peralkaline multicomponent glasses, Vetere et al. (2014) reported that both high $\mathrm{NBO} / \mathrm{T}$ and high $\mathrm{Na} /(\mathrm{Na}+\mathrm{K})$ stabilize $\mathrm{Fe}^{3+}$ in the melt. A stabilization of $\mathrm{Fe}^{3+}$ in $\mathrm{CN} 4$ by addition of $\mathrm{K}_{2} \mathrm{O}$ was also suggested by several authors [268, 281, 282, 285]. For basaltic and other complex melts, the oxidizing power of metal cations depend on their ionic field strength [e.g., 268, $282,286]$. In addition to the effect of the metal cation ionic field strength, its role in the glass network must be taken into account to explain the Fe redox state variations observed depending on the glass composition. As previously highlighted, glass optical basicity and NBO/T are parameters too simplistic to precisely depict the relationship between glass chemistry and the oxidation state of multivalent elements.

The case of multivalent elements can be further complicated by a potential change of their role in the glass structure as a function of their redox. Indeed, while $\mathrm{Fe}^{2+}$ is commonly considered as a network modifier element, $\mathrm{Fe}^{3+}$ acts as a network former elements as shown by increases in viscosity following oxidation of $\mathrm{Fe}$ (Fig. 37). Interestingly, the change of the melt viscosity at given temperature as a function of the Fe oxidation state further depends on the metal cation in the melt, illustrating the interplay between metal cations and $\mathrm{Fe}^{3+}$ for charge compensation. Regarding the local environment of $\mathrm{Fe}$ in silicate glasses, data on simplified and multicomponent systems, often, are contradictory. Ferric iron is mainly regarded as 4-fold coordinated, although higher coordination numbers have been also reported [260, 269, 287-298]. Regarding $\mathrm{Fe}^{2+}$, its structural environment is even more debated. The presence of $\mathrm{Fe}^{2+}$ in $\mathrm{CN}$ 6 has been reported [241, 288, 299], along with trigonal bipyramidal and tetrahedral coordination [300304]. Usually, it is safe to assert that $\mathrm{Fe}^{2+}$ has an average coordination close to 5, which could be possibly translated as a coexistence of 4-, 5- and 6- or just the simultaneous presence of 4- and 6- fold $\mathrm{Fe}^{2+}$ coordinated [260]. 
Le Losq, Cicconi, Greaves, Neuville. Silicate Glasses. In: Springer Handbook of Glass.

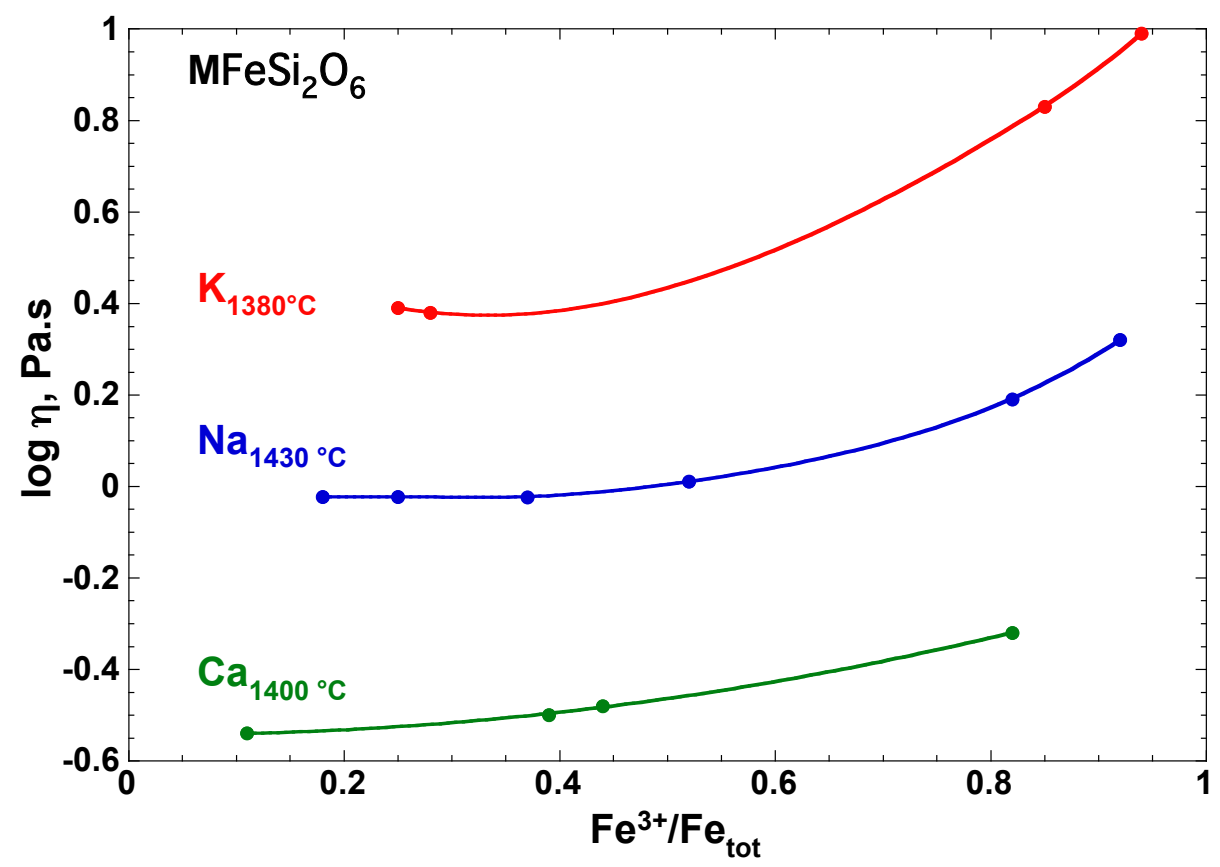

Figure 37: Viscosity ( $\log \mathrm{Pa}$ ) of alkali ferrosilicate melts at constant temperature as a function of the $\mathrm{Fe}^{3+} / \mathrm{Fe}_{\text {Tот }}$ ratio. Data from $[241,243,246]$.

\subsection{Volatile elements in silicate glasses}

Volatile elements are present in glasses in various proportions, depending on the origin of the glass. Industrial melts formed by batch melting (Sec. 1.1) contain gaseous inclusions of $\mathrm{CO}_{2}, \mathrm{CO}, \mathrm{N}_{2}$ and $\mathrm{H}_{2} \mathrm{O}$. In addition, those gaseous inclusions are usually removed by chemical fining, through introduction of sodium chloride, antimony oxide and sodium sulfate as fining agents in the melts. As a result, industrial glasses typically contain the $\mathrm{H}, \mathrm{C}, \mathrm{S}$ and $\mathrm{Cl}$ volatile elements at the ppm to hundreds of ppm concentration levels. For instance, we saw in sec. 1.2 that different levels of enrichments in those elements partly define the different categories of industrial silica glasses, because of their effect on the glass properties (e.g., Fig. 13).

Geologic glasses also contain the $\mathrm{H}, \mathrm{C}, \mathrm{S}$ and $\mathrm{Cl}$ volatile elements, and also possibly $\mathrm{F}$. Water and carbone dioxide concentrations in geologic melts can reach values as high as 6-7 wt\% and a few thousands ppm, respectively. The knowledge of their concentrations in volcanic products is critical in assessing the eruptive history of volcanic edifices, because of the strong effect of water on the viscosity and density of 
Le Losq, Cicconi, Greaves, Neuville. Silicate Glasses. In: Springer Handbook of Glass.

silicate melts [305-315]. The F, $\mathrm{Cl}$ and $\mathrm{S}$ volatile elements are present at lower levels of concentrations, but still can be present at concentrations of hundreds to thousands of ppm in geologic glasses. In this section, we will give a brief overview of the exiting knowledge on those common volatile elements in industrial and geologic silicate glasses.

\subsubsection{Water}

Large variations of water concentrations between glasses entrapped at depth in geologic systems, as glass inclusions in crystals, and glasses formed at the Earth surface testify of the extensive degassing of magmas upon their journey to the Earth surface, this degassing being associated with a dramatic evolution of their viscosity [305-310]. The effect of dissolved water on magma viscosity implies a correlation between the fraction of degassed water during volcanic eruptions and their explosive nature, as observed, for instance, for phonolitic magmas [316, 317]. For example, the famous eruption of $79 \mathrm{CE}$ of the Mt Vesuvius (Italy) that destroyed the cities of Pompeii and Herculaneum and killed their inhabitants $[318,319]$ is associated with the eruption of a magma that lost $\sim 5-6 \mathrm{wt} \%$ of water during its journey to surface [320,321], this dramatically increasing its viscosity [317], yielding to its explosive rupture in the volcanic conduit [322-324]. In contrast, the current eruption at the summit of the Mt Erebus (Antarctica) of a magma presenting a similar chemical composition but that contain only $\sim 0.2 \mathrm{wt} \%$ water results in the establishment of a permanent lava lake in the volcanic crater [e.g., 317 and references cited therein]. Such dramatic contrast illustrates the importance of water in Earth science problems.

The solution mechanism of water in silicate glasses involves the presence of $\mathrm{H}_{2} \mathrm{O}$ molecules $\left(\mathrm{H}_{2} \mathrm{O}_{\text {mol }}\right)$, which can react with the oxygens $\mathrm{O}$ of the silicate network to form $\mathrm{OH}$ groups:

$\mathrm{H}_{2} \mathrm{O}_{\text {mol (melt) }}+\mathrm{O}^{2-}{ }_{\text {(melt) }}<=>2 \mathrm{OH}^{-}{ }_{(\text {melt })}$.

${ }^{1} \mathrm{H}$ and ${ }^{29} \mathrm{Si}$ NMR as well as Raman and IR spectroscopic studies observed and documented the occurrence of the reaction depicted by eq. (13) in silicate glasses and melts [114, 156, 325-341]. In this simple model, $\mathrm{H}_{2} \mathrm{O}_{\text {mol }}$ reacts predominantly with bridging oxygens (BO), breaking T-O-T bonds (with T $=\mathrm{Si}, \mathrm{Al})$, so that equation (13) can be rewritten as:

$\mathrm{H}_{2} \mathrm{O}_{\text {mol (melt) }}+\mathrm{T}-\mathrm{O}-\mathrm{T}_{\text {(melt) }}<=>2 \mathrm{~T}-\mathrm{OH}$ (melt) 
Le Losq, Cicconi, Greaves, Neuville. Silicate Glasses. In: Springer Handbook of Glass.

Equation (14) implies formation of non-bridging oxygens (NBO) when the reaction shifts to the right. This reaction usually does not proceed to completion. Indeed, both $\mathrm{H}_{2} \mathrm{O}_{\text {mol }}$ and $\mathrm{OH}$ groups coexist in silicate melts, and hence glasses, in proportions defined by temperature [342-345], water concentration [e.g., 330, 346] and melt composition [156, 338, 344, 346-348].

From eq. (14), water addition in silicate melts and glasses results in their depolymerisation. The ratio of non-bridging oxygens over tetrahedral units, NBO/T, can be used to quantify such effect (see sec. 1.3.1., eq. 3): the higher it is, the higher the fraction of NBO in the melt, the lower the melt polymerization. For instance, solution of $\sim 10 \mathrm{wt} \%$ of water in Na-bearing aluminosilicate melts can result in NBO/T increases of $\sim 60 \%$ [339]. This, in fine, results in a great decrease of the glass $T_{g}$. Figure 38 illustrates this effect: reporting the reduced glass transition temperature $T_{g}^{*}$ of hydrous glass as a function of their water content, a general trend is observed with large changes of the $T_{g}$ that decreases by a factor of 2 with addition of $\sim$ $10 \mathrm{wt} \%$ water.

Deubener et al. [349] showed that the $T_{g}$ of hydrous glasses can be calculated from the knowledge of the glasses concentrations in $\mathrm{H}_{2} \mathrm{O}_{\text {mol }}$ and $\mathrm{OH}^{-}$and anhydrous $T_{g}{ }^{G N}$ values (i.e. the $T_{g}$ of glasses synthesized at ambient conditions, which typically contain $\sim 0.02 \mathrm{wt} \%$ water according to Deubener et al. [349]). Indeed, the reduced $T_{g}^{*}$ is equal to:

$T_{g}^{*}=\frac{C_{G} \times \frac{T_{g}^{G}}{T_{g}^{G N}}+A \times C_{O H^{-}} \times \frac{T_{g}^{O H^{-}}}{T_{g}^{G N}}+B \times C_{H_{2} O} O_{m o l} \times \frac{T_{g}^{H_{2} O_{m o l}}}{T_{g}^{G N}}}{C_{G}+A \times C_{O H^{-}}+B \times C_{\mathrm{H}_{2} O} \mathrm{O}}$,

with $C_{G}=\left(1-C_{w}\right)$ where $C_{w}$ is the total glass water content, $C_{O H^{-}}$the concentration of hydroxyl groups $\mathrm{OH}^{-}$and $C_{\mathrm{H}_{2} \mathrm{O}_{m o l}}$ the concentration of $\mathrm{H}_{2} \mathrm{O}_{\text {mol }}$ species in the glass. $T_{g}^{G}, T_{g}^{G N}, T_{g}^{O H^{-}}$and $T_{g}^{\mathrm{H}_{2} \mathrm{O}_{m o l}}$ respectively represent the $T_{g}$ of the strictly anhydrous glass, the $T_{g}$ of the glass synthesized under air conditions (usually containing $\sim 0.02 \mathrm{wt} \%$ water), and the virtual $T_{g}$ of the $\mathrm{OH}^{-}$groups and $\mathrm{H}_{2} \mathrm{O}_{\text {mol }}$ species. From the refinement of the model performed by Deubener et al. [349] that is visible in Fig. $38, \frac{T_{g}^{G}}{T_{g}^{G N}}=$ 1.01 and $\frac{T_{g}^{O H^{-}}}{T_{g}^{G N}}=\frac{T_{g}^{\mathrm{H}_{2} \mathrm{O}_{m o l}}}{T_{g}^{G N}}=0.22$. The $A$ and $B$ parameters depend on the melt NBO/T as $A=35$ $7.58 * N B O / T$ and $B=7-3.03 * N B O / T$. The hydrous glass $T_{g}$ can thus be obtained from the knowledge of $T_{g}^{G N}$. This model allows simple estimations of the $T_{g}$ of hydrous glasses, as shown in the study of Behrens 
Le Losq, Cicconi, Greaves, Neuville. Silicate Glasses. In: Springer Handbook of Glass.

and Yamashita [344] of the speciation of water in Na silicate glasses and melts. It further corroborates the observation that the glass composition has an effect on the influence of water on the hydrous glass $T_{g}$, because the parameters $A$ and $B$ depend on the glass NBO/T. Besides, the dependence of water speciation on glass composition yielded Deubener et al. [349] to introduce a calculation of the glass $\mathrm{OH}^{-}$ and $\mathrm{H}_{2} \mathrm{O}_{\text {mol }}$ concentrations that depends on the glass anhydrous NBO/T.

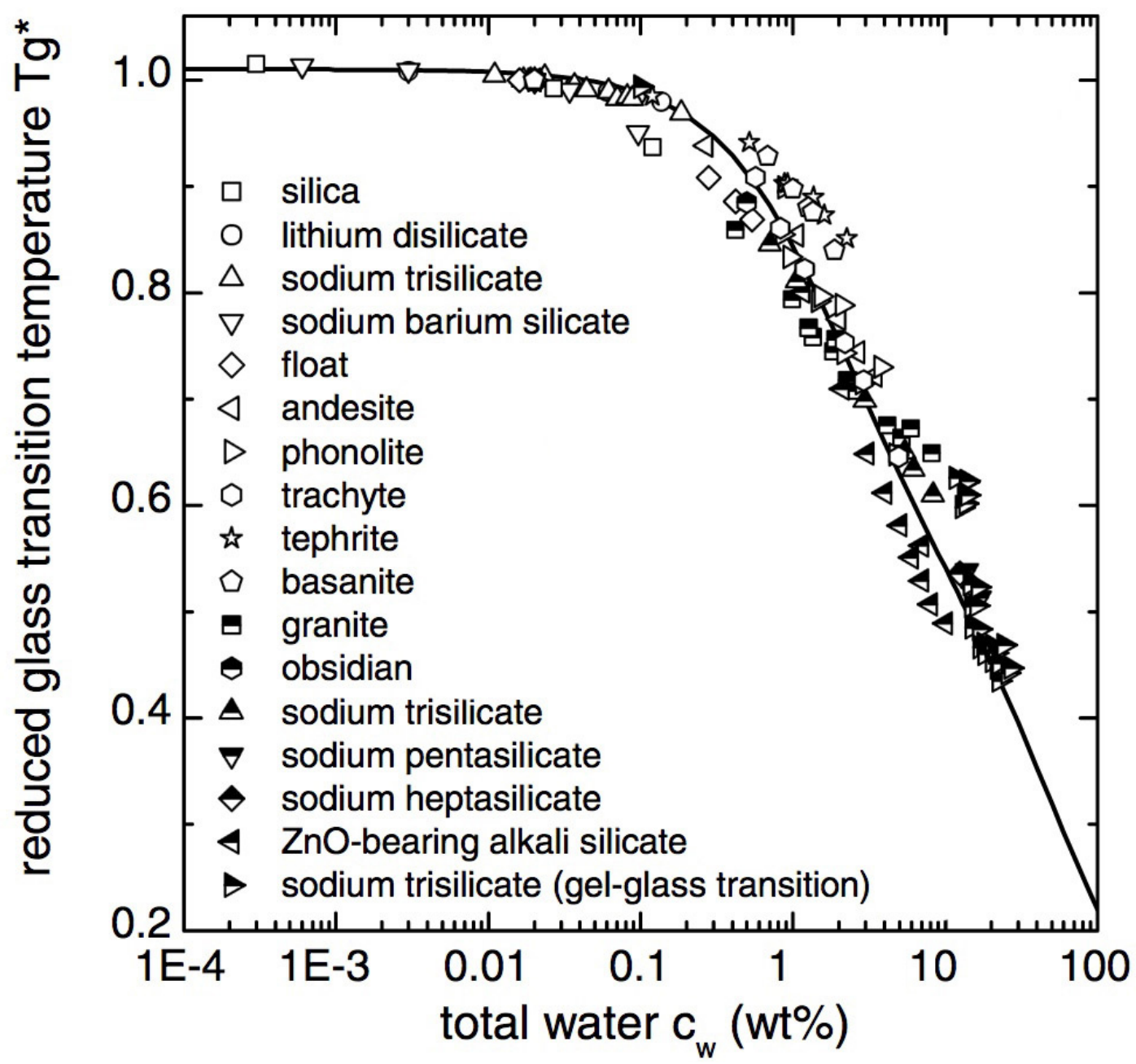

Figure 38: Reduced glass transition temperature $T_{g}{ }^{*}$ as a function of the total content of water in the glasses in wt $\% . T_{g}{ }^{*}=T_{g}^{\text {hydrous }} / T_{g}{ }^{G N}$, with $T_{g}{ }^{G N}$ the $T_{g}$ of the glass with 0.02 wt\% water, a content typical of glass synthesized at ambient conditions. See Fig. 1 for examples of compositions of the basanite, tephrite, trachyte, phonolite, andesite, granite and obsidian geologic glasses. The curve represents the model of Deubener et al. [349]. Reproduced with minor alterations from Deubener J, Müller R, Behrens H, Heide $G$ (2003) Water and the glass transition temperature of silicate melts, Journal of Non-Crystalline Solids 330:268-273, Copyright (2003), with permission from Elsevier. 
Le Losq, Cicconi, Greaves, Neuville. Silicate Glasses. In: Springer Handbook of Glass.

While the modeling approach described previously is practical and coherent, the effect of the glass composition on the speciation of water actually is more complex that a simple dependence on the glass $\mathrm{NBO} / \mathrm{T}$. For instance, the IFS of alkali elements strongly affect the water speciation and bonding in Alfree silicate glasses (Fig. 39): the higher the alkali IFS, the higher the ratio $\left[\mathrm{H}_{2} \mathrm{O}_{\mathrm{mol}}\right] /\left[\mathrm{OH}^{-}\right]$. This translates a direct effect of the IFS of the alkali element on the equilibrium constant of the disproportionation reaction of $\mathrm{H}_{2} \mathrm{O}_{\text {mol }}$ species in the glass network (eq. 13). ${ }^{29} \mathrm{Si}$ NMR and Raman spectroscopy results on alkali silicate glasses further reveal a change in the bonding of the $\mathrm{OH}^{-}$groups within the glass structure [156]: alkali cations with high IFS favor the formation of $\mathrm{M}-\mathrm{OH}$ bonds ( $\mathrm{M}$ the alkali cation) in the glass network (Fig. 39). For instance, in hydrous $\mathrm{Li}_{2} \mathrm{Si}_{4} \mathrm{O}_{9}$ glasses, up to $\sim 50 \%$ of the $\mathrm{OH}^{-}$groups can be bonded to $\mathrm{Li}^{+}$, the remaining fraction forming $\mathrm{Si}-\mathrm{O}-\mathrm{H}$ bonds $[[156]$
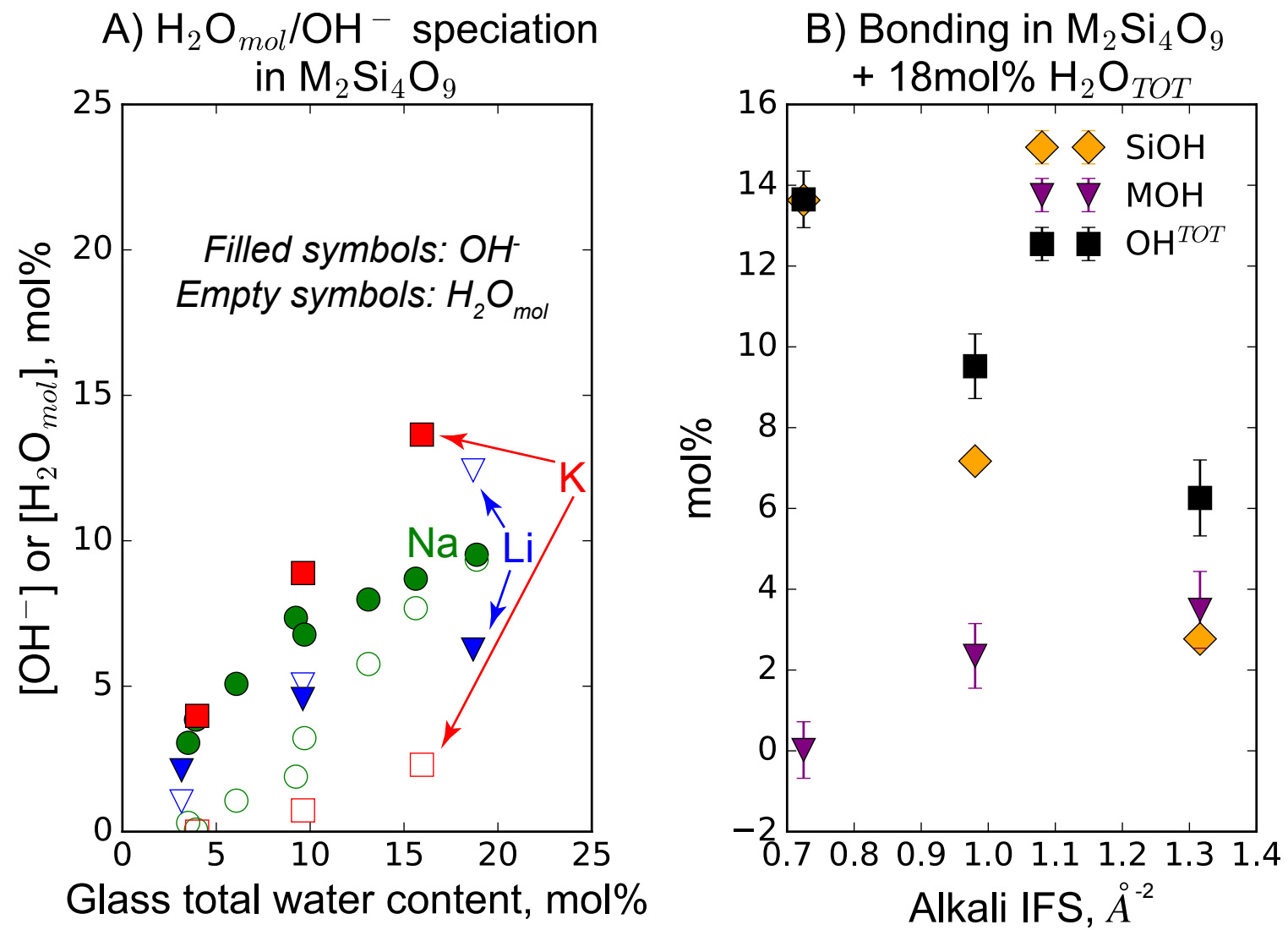

Figure 39: A) Concentration in mol\% of $\mathrm{OH}^{-}$(filled symbols) or $\mathrm{H}_{2} \mathrm{O}_{\text {mol }}$ (empty symbols) species in $\mathrm{M}_{2} \mathrm{Si}_{4} \mathrm{O}_{9}$ glasses; $\left.\mathrm{B}\right)$ Concentrations of $\mathrm{OH}^{-}$groups bonded to $\mathrm{Si}(\mathrm{SiOH})$ or the alkalis $\mathrm{M}(\mathrm{MOH})$ in $\mathrm{M}_{2} \mathrm{Si}_{4} \mathrm{O}_{9}$ glasses represented as a function of the ionic field strength of the alkali element. The total content of $\mathrm{OH}^{-}$groups in the $\mathrm{M}_{2} \mathrm{Si}_{4} \mathrm{O}_{9}$ glasses is also reported and is equal to the sum of the SiOH and MOH contents. Data from [[156, 344] 
Le Losq, Cicconi, Greaves, Neuville. Silicate Glasses. In: Springer Handbook of Glass.

Spectroscopic data thus indicate the occurrence of other mechanisms for the solution of water in silicate glasses. The formation of M-OH groups, documented by ${ }^{1} \mathrm{H}$ and ${ }^{29} \mathrm{Si}$ NMR spectroscopy as well as Raman spectroscopy and molecular dynamic simulations studies in silicate and aluminosilicate glasses [156, $338,350-354$ ], should occur through the reaction of $\mathrm{H}_{2} \mathrm{O}_{\text {mol }}$ species with Si-O-M bonds ( $\mathrm{M}$ a network modifier element), following the mechanisms [350]:

$\mathrm{H}_{2} \mathrm{O}_{\mathrm{mol}}+\mathrm{Si}-\mathrm{O}-\mathrm{M}<=>\mathrm{SiOH}+\mathrm{MOH}$

and

$2 \mathrm{Si}-\mathrm{O}-\mathrm{M}+\mathrm{H}_{2} \mathrm{O}_{\mathrm{mol}}<=>\mathrm{SiOSi}+2 \mathrm{MOH}$.

The reactions depicted by eqs. (14), (15) and (16) result in different outcomes for the melt polymerisation. Eq. (14) implies that water solution induces glass depolymerisation, but eq. (15) implies that water solution has no effect on the melt polymerisation (constant NBO/T). On the contrary, eq. (16) even implies a polymerisation of the melt as water solution subtracts the $\mathrm{M}$ elements from their network modifier role. Xue and Kanzaki [350] indicate that eq. (16) occurs only in very depolymerized melts. Eq. (15) should thus be the main process that account for the reaction of water with Si-O-M bonds. Interestingly, it predicts that $1 \mathrm{~mol}$ of $\mathrm{H}_{2} \mathrm{O}_{\text {mol }}$ should give equal amounts of $\mathrm{SiOH}$ and $\mathrm{MOH}$ entities. Such ratio corresponds to that observed by Le Losq et al. [156] in an $\mathrm{Li}_{2} \mathrm{Si}_{4} \mathrm{O}_{9}$ glass with $\sim 18$ mol\% total $\mathrm{H}_{2} \mathrm{O}$ (Fig. 39), such that eq. (15) may be the main equilibrium accounting for the speciation of water in this glass.

In Al-bearing glasses, the mechanisms depicted by eqs. (14), (15) and (16) should remain valid. Reactions between $\mathrm{H}_{2} \mathrm{O}_{\text {mol }}$ species and charge-compensator cations as well as Si-O-Al and Al-O-Al bonds are also possible. In $\mathrm{Na}$ tectosilicate glasses, a strong reaction of water with charge-compensator cations was proposed by Kohn et al. [332] on the basis of ${ }^{29} \mathrm{Si},{ }^{27} \mathrm{Al},{ }^{23} \mathrm{Na}$ and ${ }^{1} \mathrm{H}$ NMR spectroscopy results from a hydrous $\mathrm{NaAlSi}_{3} \mathrm{O}_{8}$ glass. Indeed, those authors observed that the ${ }^{23} \mathrm{Na} \mathrm{NMR}$ signals from $\mathrm{NaAlSi}_{3} \mathrm{O}_{8}$ glasses change significantly with water addition while their ${ }^{29} \mathrm{Si}$ and ${ }^{27} \mathrm{Al}$ NMR signals seemed barely affected. As a result, they proposed that water was mostly reacting with $\mathrm{Na}^{+}$charge-compensator cations. Following this study, further data were acquired on $\mathrm{NaAlSi}_{3} \mathrm{O}_{8}, \mathrm{NaAlSiO}_{4}$ and $\mathrm{CaAl}_{2} \mathrm{Si}_{6.6} \mathrm{O}_{17.3}$ glasses, leading Kohn and co. $[355,356]$ to propose that water reacts with charge-compensator elements rather than with T-O-T bonds in tectosilicate glasses. They explained the strong decrease in $T_{g}$ and viscosity of 
Le Losq, Cicconi, Greaves, Neuville. Silicate Glasses. In: Springer Handbook of Glass. such glasses and melts [e.g., 357] as resulting from a weakening of T-O-T bonds due to their protonation. Such hypothesis is questioned by recent ${ }^{1} \mathrm{H}-{ }^{29} \mathrm{Si}$ and ${ }^{1} \mathrm{H}_{-}{ }^{27} \mathrm{Al}$ heteronuclear correlation NMR experiments $[340,351,358,359]$, which indicate formation of $\mathrm{SiOH}$ and $\mathrm{AlOH}$ bonds in tectosilicate glasses, with a repartition of proton between them that is a function of the $\mathrm{Al} /(\mathrm{Al}+\mathrm{Si})$ ratio as well as of the degree of $\mathrm{Al}$ avoidance.

While the relationships between glass chemical composition and water solution mechanisms are complex, as highlighted by the previous discussion, some other properties intriguingly depend on the glass water content in a simple fashion. For instance, the partial molar volume of water, $\mathrm{V}_{m}\left(\mathrm{H}_{2} \mathrm{O}\right)$, seems to tend toward a unique value in silicate glasses [311-313]. Using density measurements on various water-bearing geologic and simple silicate glasses (mostly Al-bearing), Richet et al. [[313] showed that $V_{m}\left(\mathrm{H}_{2} \mathrm{O}\right)=12.0 \pm 0.5 \mathrm{~cm}^{3} \mathrm{~mol}^{-1}$. Using such value, it is possible to calculate the density of hydrous silicate glasses, $\rho\left(G_{H y d}\right)$, from the knowledge of their anhydrous density, $\rho\left(G_{A n h}\right)$, using the following equations:

$V_{m}\left(G_{A n h}\right)=M_{w}\left(G_{A n h}\right) / \rho\left(G_{A n h}\right)$,

$V_{m}\left(G_{H y d}\right)=x_{G} V_{m}\left(G_{A n h}\right)+x_{W} V_{m}\left(H_{2} O\right)$,

$M_{w}\left(G_{H y d}\right)=x_{G} M_{w}\left(G_{A n h}\right)+x_{W} M_{w}\left(H_{2} \mathrm{O}\right)$,

$\rho\left(G_{H y d}\right)=M_{w}\left(G_{H y d}\right) / V_{m}\left(G_{H y d}\right)$,

where $V_{m}\left(G_{A n h}\right)$ and $V_{m}\left(G_{A n h}\right)$ represent the molar volumes of the anhydrous and hydrous glasses, $M_{w}\left(G_{A n h}\right)$ and $M_{w}\left(G_{H y d}\right)$ their molar masses, $M_{w}\left(H_{2} O\right)=18.02$, and $x_{G}$ and $x_{W}$ the relative fractions of anhydrous glass and water $\left(x_{G}+x_{W}=1\right)$.

Despite slight differences between different studies in the provided estimations of $V_{m}\left(\mathrm{H}_{2} \mathrm{O}\right)$, ex and in situ experiments on silicate melts tend to corroborate the assumption that $V_{m}\left(\mathrm{H}_{2} \mathrm{O}\right)$ is independent of glass composition. [312, 314, 315, 360]. However, from water solubility measurements, Mysen [339] indicated that, if $V_{m}\left(H_{2} \mathrm{O}\right)$ was constant at a value of $\sim 12.5 \mathrm{~cm}^{3} \mathrm{~mol}^{-1}$, the $\mathrm{H}_{2} \mathrm{O}$ activity coefficient must increase with the glass $\mathrm{Al} /(\mathrm{Al}+\mathrm{Si})$ to explain water solubility values observed in $\mathrm{Na}$ silicate and aluminosilicate glasses. On the other hand, keeping the $\mathrm{H}_{2} \mathrm{O}$ activity coefficient constant would imply changing $V_{m}\left(\mathrm{H}_{2} \mathrm{O}\right)$ of a few $\mathrm{cm}^{3} \mathrm{~mol}^{-1}$. Small variations in $V_{m}\left(\mathrm{H}_{2} \mathrm{O}\right)$ in glasses actually may be coherent with spectroscopic observations. Indeed, ${ }^{1} \mathrm{H}$ NMR spectroscopy data reveal strong differences in the O- 
Le Losq, Cicconi, Greaves, Neuville. Silicate Glasses. In: Springer Handbook of Glass.

$\mathrm{O}$ distances around protons in alkali silicate glasses (Fig. 40), such that $V_{m}\left(\mathrm{H}_{2} \mathrm{O}\right)$ in such glasses must depend on their composition [[341] in particular, the alkali IFS seems to exert a significant influence on $V_{m}\left(\mathrm{H}_{2} \mathrm{O}\right)$.

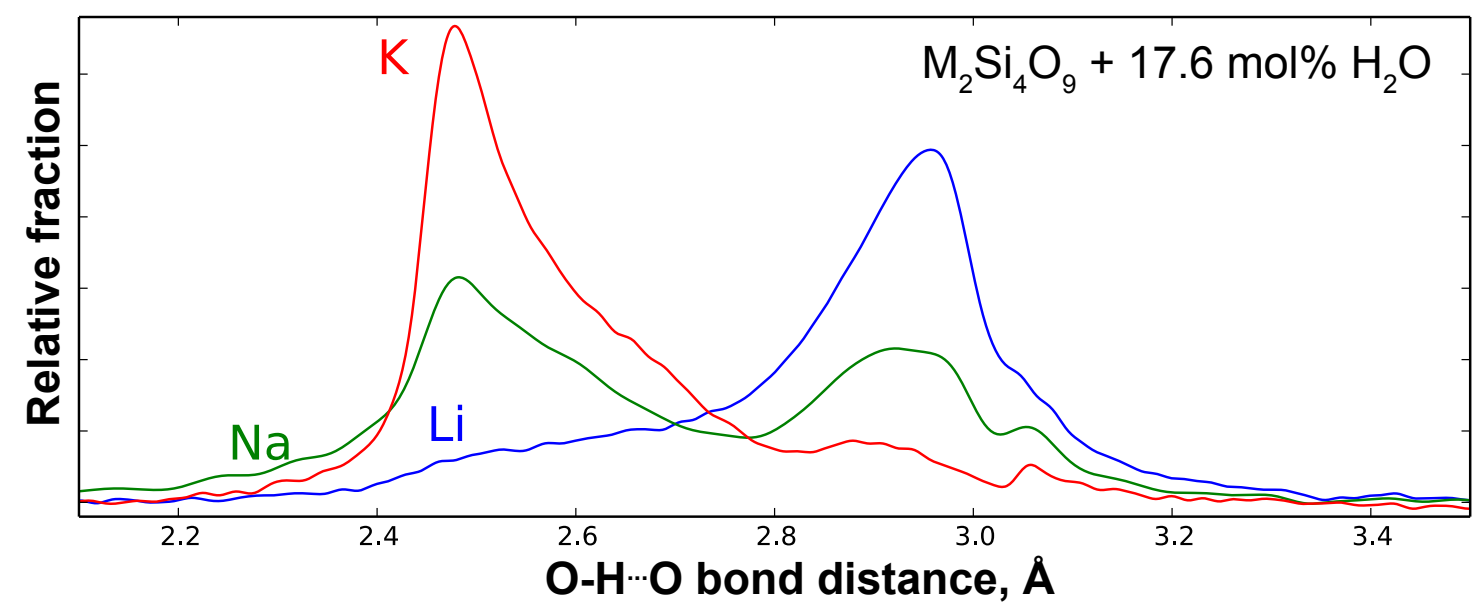

Figure 40: Relative fraction of protons in alkali tetrasilicate glasses as a function of the $O-H^{\cdots} \mathrm{O}$ bond distance. Glasses contain 17.6 mol\% nominal water; data are from [341].

Therefore, while $V_{m}\left(\mathrm{H}_{2} \mathrm{O}\right)$ appears to be constant in most aluminosilicate glasses, as suggested by the comparable O-H stretching Raman signals from various Al-bearing geologic glasses for instance [361, 362], compositions rich in metal cations may depart from such trend, and, hence, present different $V_{m}\left(\mathrm{H}_{2} \mathrm{O}\right)$ as a function of the IFS of the metal cations.

The partial molar volume of water in glasses is not the only property that does not depend on water speciation or glass composition. Indeed, analysing different Al-bearing silicate glasses, Bouhifd et al. [363] showed that the partial molar heat capacity of water in glasses, $\mathrm{C}_{p}\left(\mathrm{H}_{2} \mathrm{O}\right)$, do not depend on glass composition and can be calculated as:

$C_{p}\left(H_{2} \mathrm{O}\right)=-122.319+341.631 \times 10^{-3} T+63.4426 \times 10^{-5} / T^{2}$.

Calculating $\mathrm{C}_{p}\left(\mathrm{H}_{2} \mathrm{O}\right)$ with eq. (21) and using partial $\mathrm{C}_{p}$ values for the other glass oxide components [e.g., 112] allows one to calculate the heat capacity of hydrous silicate glasses. Further recent calorimetric data on water-bearing tephrite and foidite glasses [364], Al-bearing silicate glasses $\left(\sim 40-50 \mathrm{~mol}^{\circ} \mathrm{SiO}_{2}\right)$ rich 
Le Losq, Cicconi, Greaves, Neuville. Silicate Glasses. In: Springer Handbook of Glass.

in $\mathrm{Ca}$ and $\mathrm{Mg}$, corroborate the independence of $\mathrm{C}_{p}\left(\mathrm{H}_{2} \mathrm{O}\right)$ on melt composition. However, those data suggest that the $C_{p}$ values of the $\mathrm{OH}^{-}$and $\mathrm{H}_{2} \mathrm{O}_{\text {mol }}$ species are different, and vary with the degree of polymerisation. Such remarks highlight, again, the complex effect of composition on the speciation and bonding of water in silicate glasses.

\subsubsection{Carbon and Sulphur}

Carbone is much less soluble that water in silicate glasses: usual concentrations range between a few ppm to a few thousands of ppm [e.g., see the model of 365 and references cited therein]. Increasing glass synthesis pressure largely promotes carbon solubility, whereas the effect of temperature is weaker and not well known [366]. Under redox conditions typical of geologic environments or industrial furnaces, $\mathrm{CO}_{2}$ and $\mathrm{CO}_{3}{ }^{2-}$ are the most common form of carbon molecules found in silicate glasses, as evidenced by molecular dynamic simulation [367]], Raman spectroscopy [368, 369] and experiments [370, 371], for instance. Formation of CO molecules is observed only in very reducing conditions [372].

Like water, the interactions of carbon with the structure of silicate glasses depend on the carbon speciation as well as on glass composition. Raman spectroscopy data indicate that $\mathrm{CO}_{2}$ enters in the glass structure mostly as $\mathrm{CO}_{3}{ }^{2-}$ molecules, which interact mostly with $\mathrm{NBO}$ and network modifier cations [329]. Raman bands due to $\mathrm{CO}_{2}$ and $\mathrm{CO}_{3}{ }^{2-}$ in silicate glasses actually have been known for long [372376]: a weak band at $\sim 650 \mathrm{~cm}^{-1}$ corresponds to a bending mode of $\mathrm{CO}_{3}{ }^{2-}$ (out of the molecule plane), a strong band at $\sim 1080-1090 \mathrm{~cm}^{-1}$ is associated with the symmetric stretching mode $\left(v_{1}\right)$ of $_{\mathrm{CO}_{3}}{ }^{2-}$ and a doublet in the region of $1400-1500 \mathrm{~cm}^{-1}$ due to the asymmetric stretching vibrations $\left(v_{3}\right)$ of $\mathrm{CO}_{3}{ }^{2-}$. Molecular $\mathrm{CO}_{2}$, when present, gives rise to two bands in the 1270-1400 $\mathrm{cm}^{-1}$ range (see [[[377]; for comparison, the molecular $\mathrm{CO}_{2}$ doublet in gas hydrates is at 1274-1382 $\mathrm{cm}^{-1}$ [[378]). Combining Raman spectroscopy with IR and NMR spectroscopy, Brooker et al. [[372] showed that increasing the glass $\mathrm{Al} /(\mathrm{Al}+\mathrm{Si})$ ratio along the $\mathrm{SiO}_{2}-\mathrm{NaAlO}_{2}$ binary join promotes solution of carbon as $\mathrm{CO}_{3}{ }^{2-}$, at the expense of molecular $\mathrm{CO}_{2}$. IR spectroscopy results further indicate that the availability of NBO promote solution of $\mathrm{CO}_{3}{ }^{2-}$ in the glass [[379]. From the Molecular Dynamic simulation data of Guillot and Sator [[367], this results from a preferential association of $\mathrm{CO}_{3}{ }^{2-}$ carbonate groups with NBO in the melts, such that the availability of NBO controls the dissolution of carbonate ions. In addition, the MD simulation results show that network modifier cations are not randomly distributed in close vicinity of the carbonate groups, explaining why the solubility of carbon also varies as a function of the metal cation present in the glass [370, 379]. 
Le Losq, Cicconi, Greaves, Neuville. Silicate Glasses. In: Springer Handbook of Glass.

In addition to melt composition, the synthesis temperature also affect the ratio of $\mathrm{CO}_{3}{ }^{2-} / \mathrm{CO}_{2}$ in the glasses. In agreement with molecular simulation data [367], results from synchrotron infrared experiments in diamond anvil cells [380] reveal that, in Al-bearing silicate melts, $\mathrm{CO}_{3}{ }^{2-}$ carbonate groups convert in $\mathrm{CO}_{2}$ molecules with increasing the melt temperature. Therefore, $\mathrm{CO}_{2}$-bearing glasses quenched at different rates may present differences in their $\mathrm{CO}_{3}{ }^{2-} / \mathrm{CO}_{2}$ ratios.

The important structural changes resulting from the solution of $\mathrm{CO}_{2}$ in glasses result in variations of the glass properties. For instance, Bourgue and Richet [381] showed that both the relative density and $T_{g}$ of a potassium silicate glass decrease upon $\mathrm{CO}_{2}$ solution (Fig. 41).

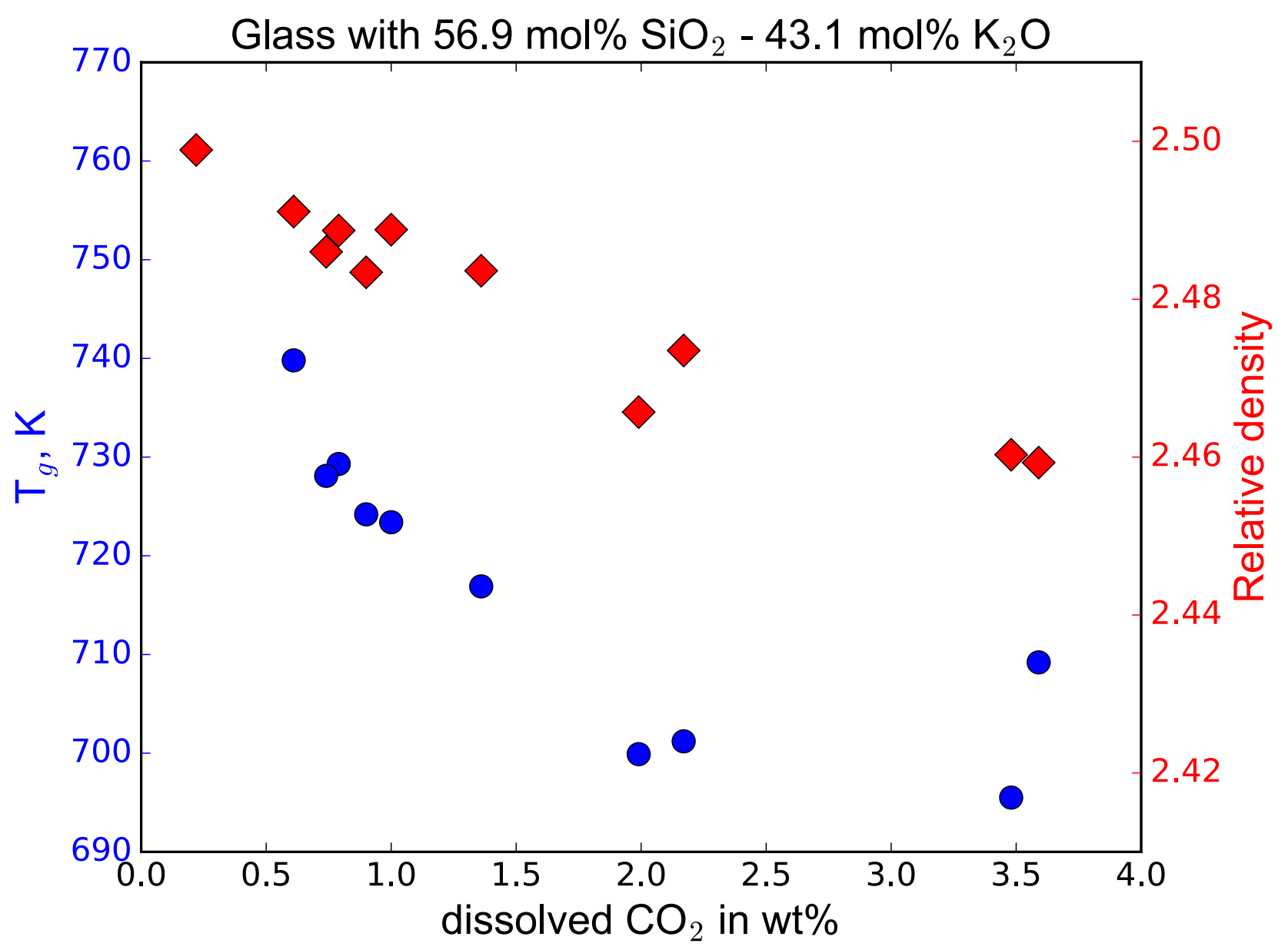

Figure 41: $T_{g}$ and relative density of a potassium silicate glass, as a function of the fraction of $\mathrm{CO}_{2}$ dissolved as $\mathrm{CO}_{3}{ }^{2-}$. Data from [381]. 
Le Losq, Cicconi, Greaves, Neuville. Silicate Glasses. In: Springer Handbook of Glass.

From the density measurement presented in Fig. 41, Bourgue and Richet [381] derived a constant partial molar volume of $\mathrm{CO}_{2}, V_{m}\left(\mathrm{CO}_{2}\right)$, for silicate glasses of $25.6 \pm 0.8 \mathrm{~cm}^{3} \mathrm{~mol}^{-1}$. They further indicate that $\mathrm{CO}_{2}$ seems to have no effect on the glass thermal expansion coefficient, at least up to $2.2 \mathrm{wt} \%$ dissolved $\mathrm{CO}_{2}$. The $V_{m}\left(\mathrm{CO}_{2}\right)$ indicated by Bourgue and Richet [381] agrees with other estimates for $V_{m}\left(\mathrm{CO}_{2}\right)$ in melts at high temperature, which range between 20 and $30 \mathrm{~cm}^{3} \mathrm{~mol}^{-1}[367,382,383]$.

In parallel to Carbon, Sulfur is the other element that is commonly found in concentrations of hundreds to thousands of ppm in both geologic and industrial glasses. In the latter, $\mathrm{S}$ is introduced during the addition of fining agents in the glass-making chain process. Those fining agents are introduced to aid refining the glass as well as the dissolution of silica. But $\mathrm{S}$ is not only present in glasses aimed at commercial application. Indeed, it is an important element of interest in the glass matrix used to confine nuclear wastes. As a result, the understanding of the reaction between $\mathrm{S}$ and the molecular structure of such glass confining matrix is an important goal for the long-term storage of nuclear waste [384]. In Earth sciences, sulphur is of wide interest because of its role in geological and biogeochemical processes [385].

A difficulty in understanding the solution mechanisms of sulphur in silicate glasses is its multivalent character. Indeed, sulfur present four different oxidation states: $\mathrm{S}^{2-}, \mathrm{S}^{0}, \mathrm{~S}^{4+}$ and $\mathrm{S}^{6+}$. However, mostly $\mathrm{S}^{2-}$ and $\mathrm{S}^{6+}$ have been detected in silicate glasses, as a function of their synthesis redox. For instance, $\mathrm{S} \mathrm{K}-$ edge XANES data suggest that $\mathrm{S}$ is dissolved as $\mathrm{S}^{2-}$ and $\mathrm{S}^{6+}$ in natural and industrial glasses [386-390]. $\mathrm{S}^{4+}$ was reported in early studies [[e.g., 387] but actually this results from an artifact due to a change of $\mathrm{S}$ oxidation state under the irradiation of a synchrotron X-ray beam [390]. Presence of $\mathrm{S}^{6+}$ as $\mathrm{SO}_{4}{ }^{2-}$ in silicate glasses is corroborated by Raman data: $\mathrm{S}-\mathrm{O}$ stretching in $\mathrm{SO}_{4}{ }^{2-}$ yields a characteristic signal at 990-1000 $\mathrm{cm}^{-1}$ [391-394]. Raman signals at $\sim 2574 \mathrm{~cm}^{-1}$ and $\sim 400 \mathrm{~cm}^{-1}$ have been detected in $\mathrm{S}^{2-}$ bearing glasses and have been assigned to $\mathrm{H}-\mathrm{S}$ and Fe-S vibrations, respectively [394]. Therefore, $\mathrm{S}^{2-}$ bonds with $\mathrm{H}^{+}$in Fe-free hydrous glasses and with $\mathrm{Fe}^{2+}$ in Fe-bearing glasses [395]. Sulphur thus reacts differently in the melt as a function of its oxidation state and of the melt composition.

The S solubility in glasses will vary depending on $\mathrm{S}$ oxidation state as well as on temperature, pressure at glass formation, and glass chemical composition [396]. The solubility of sulfide, $\mathrm{S}^{2-}$, is strongly affected by the iron concentration of the melt because of the importance of sulfide saturation on the sulfur solution process following the equation [[397] 
Le Losq, Cicconi, Greaves, Neuville. Silicate Glasses. In: Springer Handbook of Glass.

$\mathrm{FeO}$ melt $+1 / 2 \mathrm{~S}_{2 \text { melt }} \Leftrightarrow \mathrm{FeS}_{\text {sulfide melt }}+1 / 2 \mathrm{O}_{2 \text { sulfide melt . }}$

Presence of dissolved water and the melt composition affect the equilibrium constant of eq. (22), and, hence, the solubility of $\mathrm{S}^{2-}$ [398]. The solubility of sulfate, $\mathrm{S}^{6+}$, is further driven by the concentration of $\mathrm{Ca}$ in the melt as its solution mechanism can be described by the equation [396]:

$\mathrm{S}^{6+}{ }_{\text {melt }}+4 \mathrm{O}^{2-}{ }_{\text {melt }}+\mathrm{Ca}^{2+}{ }_{\text {melt }} \Leftrightarrow \mathrm{CaSO}_{4}$ anhydrite .

Various empirical models have been proposed to calculate the sulfur solubility at sulfide and sulfate saturation, either based on empirical approaches [396-399] or thermodynamic modeling [396, 400, 401], the latest one $[396,398]$ allowing one to calculate the sulfur solubility in glass-forming silicate melts with an accuracy of typically $\pm 10 \%$ (relative).

\subsubsection{Halogens}

$\mathrm{F}$ and $\mathrm{Cl}$ are halogen elements that are commonly found in silicate glasses in low concentrations $(\leq 1$ $\mathrm{wt} \%$ ). In geosciences, $\mathrm{F}$ and $\mathrm{Cl}$ are of interest because they both can affect, for instance, the viscosity and liquidus of magmas. They further are used as geochemical tracers, allowing to reconstruct the eruptive dynamics of volcanic edifices [402]. In industrial glasses, $\mathrm{F}$ and $\mathrm{Cl}$ can be added to silica to modify its photonic properties [403, 404]. For instance, F reduces the silica glass refractive index (Fig. 42), and, hence, can be introduced for loss reduction in optical fibers. The $\mathrm{Cl}_{2}$ gas is used for dehydration during the fabrication process of silica glass, leading to $\mathrm{Cl}$ impurities that affect the glass refractive index.

In silica glass, termination of $\mathrm{Si}-\mathrm{O}-\mathrm{Si}$ bonds by $\mathrm{F}$ and $\mathrm{Cl}$ seem to be the preferred interpretation for the solution mechanism of $\mathrm{F}$ and $\mathrm{C}[404]$. The solution of $\mathrm{F}$ in Al-free and Al-bearing glasses is a more complex process. Raman and NMR spectroscopy data indicate the occurrence of Si-F, Al-F and M-F complexes [405-410], in proportions that depend on the glass $\mathrm{Al} /(\mathrm{Al}+\mathrm{Si})$ and metal cation IFS. From ${ }^{19} \mathrm{~F}$ $\mathrm{NMR}$ data on $\mathrm{Mg}, \mathrm{Na}$ and $\mathrm{La} \mathrm{Al}$-free and Al-bearing silicate glasses, increasing the metal cation IFS promotes the formation of M-F bonds [407]. Such trend explains the findings of Bassner et al. [409], who noticed that $\mathrm{F}$ was preferentially associated with $\mathrm{Ca}$ in $\mathrm{Ca}-\mathrm{Na}$ aluminosilicate glasses, despite the much lower concentration of $\mathrm{Ca}$ in the investigated glass. The latter authors further indicate that glass water content affect the F-Al and F-M fractions: it seems that $\mathrm{F}^{-}$and $\mathrm{OH}^{-}$groups occupy similar $\mathrm{Al}$ 
Le Losq, Cicconi, Greaves, Neuville. Silicate Glasses. In: Springer Handbook of Glass.

environments, and that $\mathrm{F}$ cannot compete with $\mathrm{OH}$ groups for populating those environments. Small fractions of $\mathrm{Si}-\mathrm{F}$ and high fractions of $\mathrm{Al}-\mathrm{F}$ bonding are further evident from Raman spectroscopy and NMR results [405-408, 410]. The proportions of the different M-F, Al-F and, in a smaller extent, Si-F complexes depend on the $\mathrm{Al} /(\mathrm{Al}+\mathrm{Si})$ ratio of the glasses $[406,410]$, resulting in a control of the solubility of $\mathrm{F}$ by the glass $\mathrm{Al} /(\mathrm{Al}+\mathrm{Si})$ ratio[410]. In addition, the formation of $\mathrm{Al}-\mathrm{F}$ and possibly $\mathrm{Si}-\mathrm{F}$ bonds in the network of alumino-silicate glasses result in their depolymerisation, as observed by Raman spectroscopy [406, 410].
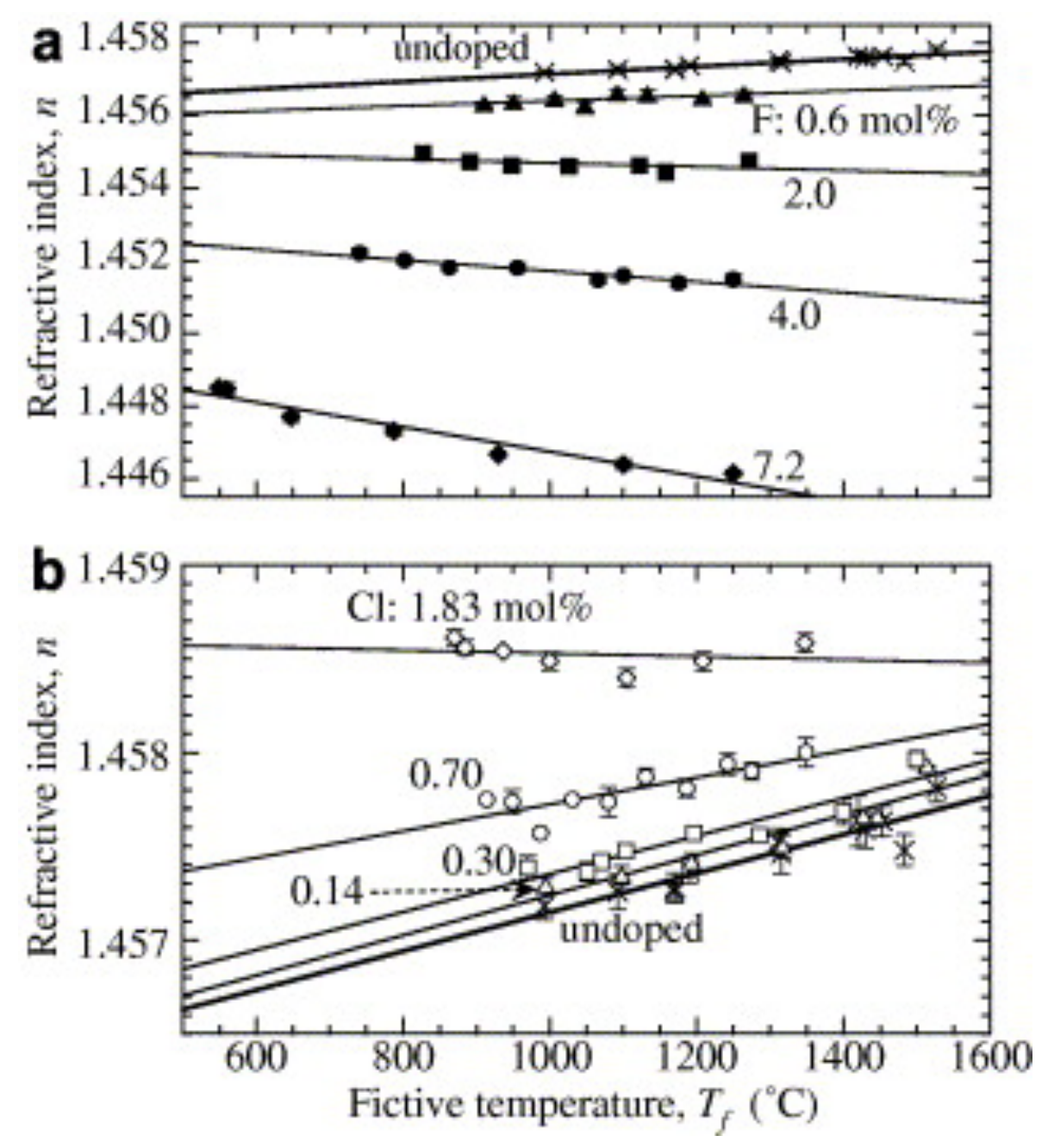

Figure 42: Refractive indices of halogen-doped silica glasses at $633 \mathrm{~nm}$ as a function of fictive temperature: (a) $\mathrm{F}$-and (b) Cl-doped silica glasses. Solid lines are approximate linear fittings. Reprinted from Kakiuchida $H$, Sekiya EH, Shimodaira N, Saito K, Ikushima AJ (2007) Refractive index and density changes in silica glass by halogen doping. Journal of Non-Crystalline Solids 353:568-572, doi:10.1016/j.jnoncrysol.2006.10.025, Copyright (2007), with permission from Elsevier. 
Le Losq, Cicconi, Greaves, Neuville. Silicate Glasses. In: Springer Handbook of Glass.

Dissolution of $\mathrm{Cl}$ leads to a different pattern: according to Dalou et al. [410], it slightly depolymerizes the structure in Al-free melts, while it tends to polymerize that of Al-bearing melts. Such variations in the effect of $\mathrm{Cl}$ on melt polymerization may explain $\mathrm{Cl}$ effect on melt viscosity. Indeed, Baasner et al. [411] report an increase of melt viscosity for peralkaline $\mathrm{Na}_{2} \mathrm{O}-\mathrm{CaO}-\mathrm{Al}_{2} \mathrm{O}_{3}-\mathrm{SiO}_{2}$ melts; a decrease of melt viscosity is observed in peraluminous melts, and may be assigned to Al-Cl bonding favored by the absence of $\mathrm{Ca}$ and $\mathrm{Na}$ network modifiers available for bonding with $\mathrm{Cl}$. Indeed, formation of $\mathrm{M}-\mathrm{Cl}$ complexes seems to be the main mechanisms of $\mathrm{Cl}$ solution in the glasses [410, 412-416]. Such solution mechanism is corroborated by the fact that the metal cation IFS influence the solubility of $\mathrm{Cl}$ : at given $\mathrm{Al} /(\mathrm{Al}+\mathrm{Si})$, cations with higher IFS promote solution of $\mathrm{Cl}[410] . \mathrm{Cl}$ thus may have the tendency to bond with metal cations that present high IFS, as shown by the Cl XANES data of Evans et al. [415]. Indeed, the latter suggest that, in $\mathrm{CaO}-\mathrm{MgO}-\mathrm{Al}_{2} \mathrm{O}_{3}-\mathrm{SiO}_{2}$ glasses with variables amounts of $\mathrm{Na}_{2} \mathrm{O}, \mathrm{K}_{2} \mathrm{O}$ and $\mathrm{MnO}$, $\mathrm{Cl}$ preferentially associates with $\mathrm{Ca}$ and $\mathrm{Mg}$.

\subsection{Conclusion}

- The backbone of the molecular disordered structure of silicate glasses is the tri-dimentionnal network of interconnected $Q^{4}$ tetrahedral units containing $\mathrm{Si}$ at the center and $\mathrm{O}$ at the summits. At medium range order, tetrahedral units can form tri-dimentional molecular arrangements (e.g., rings and cages) that influence the glass elastic properties.

- Metal cations play a role of network modifiers, breaking Si-O-Si inter-tetrahedral bonds, decreasing the network polymerization as they produce the transformation of bridging oxygens to non-bridging oxygens. $Q^{0}, Q^{1}, Q^{2}$, and $\mathrm{Q}^{3}$ units are formed upon addition of network modifiers, in proportion that depends on the fraction of added modifiers and of its Ionic Field Strength. Indeed, as described by the Modified Random Network model, modifiers tend to cluster in the network, potentially forming percolation channels that percolates through the disrupted tetrahedral network. The fractions of $Q^{n}$ units as well as the medium range order organization of the network controls the glass properties, such as its entropy, density and $T_{g}$.

- Aluminum enters mostly in four-fold coordination in $Q^{4}$ units. Metal cations in vicinity do not modify the network but charge-compensate the electric charge deficit of $\mathrm{AlO}_{4}{ }^{-}$units. $\mathrm{AlO}_{5}$ and $\mathrm{AlO}_{6}$ units are present in low fractions in the glasses, depending on the $\mathrm{Al} /(\mathrm{Al}+\mathrm{M})$ ratio as well as on the charge compensator IFS; similar conclusions are drawn for the presence of non- 
Le Losq, Cicconi, Greaves, Neuville. Silicate Glasses. In: Springer Handbook of Glass.

stoichiometric non-bridging oxygens. Presence of non-stoichiometric $\mathrm{NBO}$ and $\mathrm{AlO}_{5}$ units influence the glass properties related to its plastic flow, such as its $T_{g}$ and Vickers hardness.

- Multivalent elements in silicate glasses present oxidation states that mostly depend on temperature, oxygen fugacity and melt composition applied during the glass formation process. Coordination state of multivalent elements can be a complex function of melt composition, as shown by the various findings for Fe.

- Volatile elements are commonly present in small concentrations in geologic and industrial silicate glasses. Despite such low concentrations, they play determining roles on the glass structure and on its rheological properties. It is found that most volatile elements actually react with metal cations $\mathrm{M}$ as well as $\mathrm{Al}$ and $\mathrm{Si}$ cations, in proportions that depends on the $\mathrm{M}$ cation IFS and the glass $\mathrm{Al} /(\mathrm{Al}+\mathrm{Si})$ and $\mathrm{Al} /(\mathrm{Al}+\mathrm{M})$ ratios. In addition, glass composition also affect the speciation of the volatile elements in different species, as does the oxygen fugacity and temperature during the glass synthesis.

\section{X References}

1. Henrivaux MJ (1897) Le verre et le cristal, P. Vicq-Dunod et Cie. Flammarion, Paris

2. Pliny TE (1855) Chap. 65: THE ORIGIN OF GLASS. Nat. Hist. XXXVI:

3. Rasmussen SC (2012) Origins of Glass: Myth and Known History. In: Glass Chang. World. Springer Berlin Heidelberg, Berlin, Heidelberg, pp 11-19

4. Rasmussen SC (2012) How Glass Changed the World. doi: 10.1007/978-3-642-28183-9

5. Gandy W (1898) The Romance of Glass-making. S. W. Partridge \& co., London

6. Neri A, Merret C, Kunckel J (1752) L'Art de la Verrerie, Druant et Pissot. Paris

7. Oppenheim AL, Brill RH, Barag D, Von Saldern A (1970) Glass and Glassmaking in Ancient Mesopotamia. An edition of the cuneiform texts which contain instructions for glassmakers, with a catalogue of surviving objects. The Corning Museum of Glass Press, Corning, N.Y

8. Kurkjian CR, Prindle WR (1998) Perspectives on the history of glass composition. J Am Ceram Soc 81:795-813.

9. Brill RH, Rising BA (1999) Chemical analyses of early glasses. Corning Museum of Glass, Corning, N.Y

10. Brill RH, Rising BA (1999) Chemical analyses of early glasses. Corning Museum of Glass, Corning, N.Y 
Le Losq, Cicconi, Greaves, Neuville. Silicate Glasses. In: Springer Handbook of Glass.

11. Fontaine SD, Foy D (2007) L'épave Ouest-Embiez 1, Var : le commerce maritime du verre brut et manufacturé en Méditerranée occidentale dans l'Antiquité. Rev Archéologique Narbonnaise 40:235-265. doi: 10.3406/ran.2007.1182

12. Rasmussen SC (2012) Reinventing an Old Material: Venice and the New Glass. In: Glass Chang. World. Springer Berlin Heidelberg, pp 37-50

13. Vernioles J (2013) Les sites vitrifiés de France: inventaire et mode de réalisation. Ph.D., University Paris 1

14. Neuville DR, Cormier L, Caurant D, Montagne L (2017) From Glass to Crystal. Nucleation, growth and phase separation: from research to applications. EDP Sciences, France

15. Mozzi RL, Warren BE (1969) The structure of vitreous silica. J Appl Crystallogr 2:164-172.

16. Neuefeind J, Liss K-D (1996) Bond angle distribution in amorphous germania and silica. Berichte Bunsenges Für Phys Chem 100:1341-1349. doi: 10.1002/bbpc.19961000812

17. Clark TM, Grandinetti PJ, Florian P, Stebbins JF (2004) Correlated structural distributions in silica glass. Phys Rev B. doi: 10.1103/PhysRevB.70.064202

18. Tucker MG, Keen DA, Dove MT, Trachenko K (2005) Refinement of the Si-O-Si bond angle distribution in vitreous silica. J Phys Condens Matter 17:S67. doi: 10.1088/0953-8984/17/5/008

19. Malfait WJ, Halter WE, Verel R (2008) 29Si NMR spectroscopy of silica glass: T1 relaxation and constraints on the Si-O-Si bond angle distribution. Chem Geol 256:269-277. doi: 10.1016/j.chemgeo.2008.06.048

20. Le Losq C, Neuville DR (2017) Molecular structure, configurational entropy and viscosity of silicate melts: Link through the Adam and Gibbs theory of viscous flow. J Non-Cryst Solids 463:175-188. doi: 10.1016/j.jnoncrysol.2017.02.010

21. Le Losq C (2012) Rôle des éléments alcalins et de l'eau sur les propriétés et la structure des aluminosilicates fondus et vitreux : implications volcanologiques. University Paris VII - Denis Diderot

22. Neuville DR, Richet P (1991) Viscosity and mixing in molten (Ca, Mg) pyroxenes and garnets. Geochim Cosmochim Acta 55:1011-1019. doi: 10.1016/0016-7037(91)90159-3

23. Neuville DR (2006) Viscosity, structure and mixing in (Ca, Na) silicate melts. Chem Geol 229:28-41. doi: 10.1016/j.chemgeo.2006.01.008

24. Doweidar H (1996) The density of alkali silicate glasses in relation to the microstructure. J NonCryst Solids 194:155-162.

25. Le Losq C, Neuville DR, Florian P, Henderson GS, Massiot D (2014) The role of $\mathrm{Al}^{3+}$ on rheology and structural changes of sodium silicate and aluminosilicate glasses and melts. Geochim Cosmochim Acta 126:495-517. doi: 10.1016/j.gca.2013.11.010

26. Zachariasen WH (1932) The atomic arrangement in glass. J Am Chem Soc 54:3841-3851. 
Le Losq, Cicconi, Greaves, Neuville. Silicate Glasses. In: Springer Handbook of Glass.

27. Warren BE (1934) X-Ray determination of the structure of glass.

28. Huang PY, Kurasch S, Srivastava A, Skakalova V, Kotakoski J, Krasheninnikov AV, Hovden R, Mao Q, Meyer JC, Smet J, Muller DA, Kaiser U (2012) Direct Imaging of a Two-Dimensional Silica Glass on Graphene. Nano Lett 12:1081-1086. doi: 10.1021/n1204423x

29. Henderson GS, Fleet ME, Bancroft GM (1984) An x-ray scattering study of vitreous KFeSi3O8 and $\mathrm{NaFeSi} 3 \mathrm{O} 8$ and reinvestigation of vitreous $\mathrm{SiO} 2$ using quasi-crystalline modelling. J NonCryst Solids 68:333-349. doi: 10.1016/0022-3093(84)90015-2

30. Seifert F, Mysen BO, Virgo D (1982) Three-dimensional network structure of quenched melts (glass) in the systems $\mathrm{SiO}_{2}-\mathrm{NaAlO}_{2}, \mathrm{SiO}_{2}-\mathrm{CaAl}_{2} \mathrm{O}_{4}$ and $\mathrm{SiO}_{2}-\mathrm{MgAl}_{2} \mathrm{O}_{4}$. Am Mineral 67:696717.

31. Bell RJ, Dean P (1972) The structure of vitreous silica: Validity of the random network theory. Philos Mag 25:1381-1398. doi: 10.1080/14786437208223861

32. Shintani H, Tanaka H (2008) Universal link between the boson peak and transverse phonons in glass. Nat Mater 7:870-877.

33. Bucheneau U, Prager M, Nücker N, Dianoux AJ, Ahmad N, Phillips WA (1986) Low-frequency modes in vitreous silica. Phys Rev B 34:5665-5673.

34. Chumakov AI, Monaco A, Crichton WA, Bosak A, Rüffer R, Meyer A, Kargl F, Comez L, Fioretto D, Giefers H, Roitsch S, Wortmann G, Manghnami MH, Hushur A, Williams Q, Balogh J, Parlinski K, Jochym P, Piekarz P (2011) Equivalence of the Boson Peak in glasses to the transverse acoustic van Hove singularity in crystals. Phys Rev Lett 106:225501-1:5.

35. Courtens E, Foret M, Hehlen B, Vacher R (2001) The vibrational modes of glasses. Solid State Commun 117:187-200.

36. Bell RJ, Bird NF, Dean P (1968) The vibrational spectra of vitreous silica, germania and beryllium fluoride. J Phys C Proc Phys Soc 1:299-303.

37. Bell RJ, Dean P, Hibbins-Butler DC (1970) Bell-JPC-70-3.pdf. J Phys Chem Solid State Phys 3:2111-2118.

38. Bell RJ, Dean P, Hibbins-Butler DC (1971) Normal mode assignments in vitreous silica, germania and beryllium fluoride. J Phys C Solid State Phys 4:1214-1220.

39. Sharma SK, Mammone JF, Nicol MF (1981) Raman investigation of ring configurations in vitreous silica. Nature 292:140-141.

40. McMillan PF, Piriou B (1982) The structures and vibrational spectra of crystals and glasses in the silica-alumina system. J Non-Cryst Solids 53:279-298.

41. Galeener FL (1982) Planar rings in glasses. Solid State Commun 44:1037-1040.

42. Galeener FL (1982) Planar rings in vitreous silica. J Non-Cryst Solids 49:53-62. 
Le Losq, Cicconi, Greaves, Neuville. Silicate Glasses. In: Springer Handbook of Glass.

43. McMillan PF (1984) Structural studies of silicate glasses and melts - Applications and limitations of Raman spectroscopy. Am Mineral 69:622-644.

44. McMillan PF, Wolf GH, Poe BT (1992) Vibrational spectroscopy of silicate liquids and glasses. Chem Geol 96:351-366.

45. McMillan PF, Poe BT, Gillet P, Reynard B (1994) A study of $\mathrm{SiO}_{2}$ glass and supercooled liquid to $1950 \mathrm{~K}$ via high-temperature Raman spectroscopy. Geochim Cosmochim Acta 58:3653-3664.

46. Pasquarello A, Car R (1998) Identification of Raman defect lines as signatures of ring structures in vitreous silica. Phys Rev Lett 80, No. 23:5145-5147.

47. Umari P, Gonze X, Pasquarello A (2003) Concentration of small ring structures in vitreous silica from a first-principles analysis of the Raman spectrum. Phys Rev Lett 90:1-4.

48. Rahmani A, Benoit M, Benoit C (2003) Signature of small rings in the Raman spectra of normal and compressed amorphous silica: A combined classical and ab initio study. Phys. Rev. B 68:

49. Galeener FL, Barrio RA, Martinez E, Elliott RJ (1984) Vibrational decoupling of rings in amourphous solids. Phys Rev Lett 53:2429-2432.

50. Sharma SK, Philpotts JA, Matson DW (1985) Ring distributions in alkali- and alkaline-earth aluminosilicate framework glasses - A Raman spectroscopic study. J Non-Cryst Solids 71:403410.

51. Umari P, Pasquarello A (2002) Modeling of the Raman spectrum of vitreous silica: concentration of small ring structures. Phys B 316-317:572-574.

52. Kalampounias AG (2006) A low-frequency Raman study of glassy, supercooled and molten silica and the preservation of the Boson peak in the equilibrium liquid state. J Non-Cryst Solids 352:4619-4624.

53. Galeener FL (1979) Band limits and the vibrational spectra of tetrahedral glasses. Phys Rev B 19:4292-4397.

54. Sen PN, Thorpe MF (1977) Phonons in $\mathrm{AX}_{2}$ glasses: From molecular to band-like modes. Phys Rev B 15:4030-4038.

55. Sarnthein J, Pasquarello A, Car R (1997) Origin of the High-Frequency Doublet in the Vibrational Spectrum of Vitreous SiO2. Science 275:1925-1927. doi: 10.1126/science. 275.5308 .1925

56. Spiekermann G, Steele-MacInnis M, Schmidt C, Jahn S (2012) Vibrational mode frequencies of silica species in $\mathrm{SiO}_{2}-\mathrm{H}_{2} \mathrm{O}$ liquids and glasses from ab initio molecular dynamics. J Chem Phys 136:154501. doi: 10.1063/1.3703667

57. Le Losq C, Neuville DR (2013) Effect of the $\mathrm{Na} / \mathrm{K}$ mixing on the structure and the rheology of tectosilicate silica-rich melts. Chem Geol 346:57-71. doi:

http://dx.doi.org/10.1016/j.chemgeo.2012.09.009 
Le Losq, Cicconi, Greaves, Neuville. Silicate Glasses. In: Springer Handbook of Glass.

58. Mysen BO, Finger LW, Virgo D, Seifert FA (1982) Curve-fitting of Raman spectra of silicate glasses. Am Mineral 67:686-695.

59. Pasquarello A, Sarnthein J, Car R (1998) Dynamic structure factor of vitreous silica from first principles: Comparison to neutron-inelastic-scattering experiments. Phys Rev B 14133-14140.

60. Rino JP, Ebbsjö I, Kalia RK, Nakano A, Vashishta P (1993) Structure of rings in vitreous $\$\{\backslash \text { mathrm }\{\mathrm{SiO}\}\}_{-}\{2\} \$$. Phys Rev B 47:3053-3062. doi: 10.1103/PhysRevB.47.3053

61. Benoit M, Ispas S, Jund P, Jullien R (2000) Model of silica glass from combined classical and ab initio molecular-dynamics simulations. Eur Phys J B - Condens Matter Complex Syst 13:631636. doi: $10.1007 / \mathrm{s} 100510050079$

62. Yuan X, Cormack AN (2003) $\mathrm{Si}-\mathrm{O}-\mathrm{Si}$ bond angle and torsion angle distribution in vitreous silica and sodium silicate glasses. J Non-Cryst Solids 319:31-43. doi: 10.1016/S00223093(02)01960-9

63. Poulsen HF, Neuefeind J, Neumann H-B, Schneider JR, Zeidler MD (1995) Amorphous silica studied by high energy X-ray diffraction. J Non-Cryst Solids 188:63-74. doi: 10.1016/00223093(95)00095-X

64. Wright AC (1994) Neutron scattering from vitreous silica. V. The structure of vitreous silica: What have we learned from 60 years of diffraction studies? J Non-Cryst Solids 179:84-115. doi: 10.1016/0022-3093(94)90687-4

65. Mauri F, Pasquarello A, Pfrommer BG, Yoon Y-G, Louie SG (2000) Si-O-Si bond-angle distribution in vitreous silica from first-principles $\$\{\}^{\wedge}\{29\} \backslash$ mathrm $\{\mathrm{Si}\} \$$ NMR analysis. Phys Rev B 62:R4786-R4789. doi: 10.1103/PhysRevB.62.R4786

66. Huang L, Yuan F, Guerette M, Zhao Q, Sundararaman S (2017) Tailoring structure and properties of silica glass aided by computer simulation. J Mater Res 32:174-182. doi: 10.1557/jmr.2016.397

67. Van Ginhoven RM, Jónsson H, Corrales LR (2005) Silica glass structure generation for ab initio calculations using small samples of amorphous silica. Phys Rev B. doi:

10.1103/PhysRevB.71.024208

68. Pasquarello A (2001) First-principles simulation of vitreous systems. Curr Opin Solid State Mater Sci 5:503-508.

69. Richet $\mathrm{P}$, Bottinga Y (1984) Glass transitions and thermodynamic properties of amorphous $\mathrm{SiO}_{2}$, $\mathrm{NaAlSi}_{\mathrm{n}} \mathrm{O}_{2 \mathrm{n}+2}$ and $\mathrm{KAlSi}_{3} \mathrm{O}_{8}$. Geochim Cosmochim Acta 48:453-470. doi: 10.1016/00167037(84)90274-6

70. Leko, V. K., Gusakova, N. J., Meshcheryakova, E. V., Prokhorova, T. I. (1977) The effect of impurity alkali oxides, hydroxyl groups, $\mathrm{Al} 2 \mathrm{O} 3$, and $\mathrm{Ga} 2 \mathrm{O} 3$ on the viscosity of vitreous silica. Sov J Glass Phys Chem 3:204-210.

71. Angell CA (1985) Spectroscopy simulation and scattering, and the medium range order problem in glass. J Non-Cryst Solids 73:1-17. 
Le Losq, Cicconi, Greaves, Neuville. Silicate Glasses. In: Springer Handbook of Glass.

72. Angell CA (1991) Relaxation in liquids, polymers and plastic crystals — strong/fragile patterns and problems. J Non-Cryst Solids 131:13-31.

73. Hofmeister AM, Whittington AG (2012) Effects of hydration, annealing, and melting on heat transport properties of fused quartz and fused silica from laser-flash analysis. J Non-Cryst Solids 358:1072-1082. doi: 10.1016/j.jnoncrysol.2012.02.012

74. Brückner R (1970) Properties and structure of vitreous silica. I. J Non-Cryst Solids 5:123-175. doi: 10.1016/0022-3093(70)90190-0

75. Heili M, Poumellec B, Burov E, Gonnet C, Le Losq C, Neuville DR, Lancry M (2016) The dependence of Raman defect bands in silica glasses on densification revisited. J Mater Sci 51:1659-1666. doi: 10.1007/s 10853-015-9489-8

76. Hemley RJ, Mao HK, Bell PM, Mysen BO (1986) Raman Spectroscopy of Si\$ $\{\backslash \text { mathrm }\{\mathrm{O}\}\}_{-}\{2\} \$$ Glass at High Pressure. Phys Rev Lett 57:747-750. doi: 10.1103/PhysRevLett.57.747

77. Weigel C, Foret M, Hehlen B, Kint M, Clément S, Polian A, Vacher R, Rufflé B (2016) Polarized Raman spectroscopy of $\$ \mathrm{v}-\{\backslash \text { mathrm }\{\mathrm{SiO}\}\}_{-}\{2\} \$$ under rare-gas compression. Phys Rev B 93:224303. doi: 10.1103/PhysRevB.93.224303

78. Burgin J, Guillon C, Langot P, Vallée F, Hehlen B, Foret M (2008) Vibrational modes and local order in permanently densified silica glasses: Femtosecond and Raman spectroscopy study. Phys Rev B. doi: 10.1103/PhysRevB.78.184203

79. Hehlen B (2010) Inter-tetrahedra bond angle of permanently densified silicas extracted from their Raman spectra. J Phys Condens Matter 22:025401. doi: 10.1088/0953-8984/22/2/025401

80. Dietzel A (1942) Die Kationfeldstërken und ihre Beziehungen zu entlasungs-vorgängen, zur verbindunsbildung und zu den Scmelzpunkten von Silikaten. Z Für Elektrochem 48:9.

81. Ispas S, Charpentier T, Mauri F, Neuville DR (2010) Structural properties of lithium and sodium tetrasilicate glasses: Molecular dynamics simulations versus NMR experimental and firstprinciples data. Solid State Sci 12:183-192. doi: 10.1016/j.solidstatesciences.2009.06.033

82. Virgo D, Mysen BO, Kushiro I (1980) Anionic Constitution of 1-Atmosphere Silicate Melts: Implications for the Structure of Igneous Melts. Science 208:1371-1373. doi: 10.1126/science.208.4450.1371

83. Engelhardt G, Nofz M, Forkel K, Wihsmann FG, Mägi M, Samoson A, Lippmaa E (1985) Structural studies of calcium aluminosilicate glasses by high resolution solid state ${ }^{29} \mathrm{Si}$ and ${ }^{27} \mathrm{Al}$ magic angle spinning nuclear magnetic resonance. Physic Chem Glas 26:157-165.

84. Maekawa H, Maekawa T, Kawamura K, Yokokawa T (1991) The structural groups of alkali silicate glasses determined from ${ }^{29}$ Si MAS-NMR. J Non-Cryst Solids 127:53-64. doi: 10.1016/0022-3093(91)90400-Z 
Le Losq, Cicconi, Greaves, Neuville. Silicate Glasses. In: Springer Handbook of Glass.

85. Schramm CM, de Jong BHWS, Parziale VE (1984) ${ }^{29}$ Si Magic Angle Spinning NMR study on local silicon environments in amorphous and crystalline lithium silicates. J Am Chem Soc 106:4396-4402.

86. Dupree R, Holland D, Williams DS (1986) The structure of binary alkali silicate glasses. J NonCryst Solids 81:185-200. doi: 10.1016/0022-3093(86)90269-3

87. Emerson, J. F., Stallworth, P. E., Bray, P. J. (1989) High-Filed 29Si NMR studies of alkali silicate glasses. J Non-Cryst Solids 113:253-259.

88. Sen S, Youngman RE (2003) NMR study of Q-speciation and connectivity in $\mathrm{K}_{2} \mathrm{O}-\mathrm{SiO}_{2}$ glasses with high silica content. J Non-Cryst Solids 331:100-107. doi: 10.1016/j.jnoncrysol.2003.08.071

89. Zhang P, Dunlap C, Florian P, Grandinetti PJ, Farnan I, Stebbins JF (1996) Silicon site distributions in an alkali silicate glass derived by two-dimensional ${ }^{29} \mathrm{Si}$ nuclear magnetic resonance. J Non-Cryst Solids 204:294-300. doi: 10.1016/S0022-3093(96)00601-1

90. Davis MC, Kaseman DC, Parvani SM, Sanders KJ, Grandinetti PJ, Massiot D, Florian P (2010) $\mathrm{Q}^{\mathrm{n}}$ Species Distribution in $\mathrm{K}_{2} \mathrm{O} \cdot 2 \mathrm{SiO}_{2}$ Glass by ${ }^{29} \mathrm{Si}$ Magic Angle Flipping NMR. J Phys Chem A 114:5503-5508. doi: 10.1021/jp100530m

91. Brandriss ME, Stebbins JF (1988) Effects of temperature on the structures of silicate liquids: 29Si NMR results. Geochim Cosmochim Acta 52:2659-2669. doi: 10.1016/00167037(88)90034-8

92. Mysen BO, Frantz JD (1993) Structure of silicate melts at high temperature: In-situ measurements in the system $\mathrm{BaO}-\mathrm{SiO}_{2}$. Am Mineral 78:699-709.

93. Mysen BO, Frantz JD (1993) Structure and properties of alkali silicate melts at magmatic temperatures. Eur J Mineral 5:393-407.

94. Mysen BO (1999) Structure and properties of magmatic liquids: From haplobasalt to haploandesite. Geochim Cosmochim Acta 63:95-112.

95. Mysen BO, Virgo D, Seifert FA (1982) The structure of silicate melts: Implications for chemical and physical properties of natural magma. Rev Geophys 20:353-383. doi:

10.1029/RG020i003p00353

96. Mysen, B. O., Virgo, D., Seifert, F. A. (1985) Relationships between properties and structure of aluminosilicate melts. Am Mineral 70:88-105.

97. Dupree R, Holland D, McMillan PW, Pettifer RF (1984) The structure of soda-silica glasses: A mas NMR study. J Non-Cryst Solids 68:399-410. doi: 10.1016/0022-3093(84)90020-6

98. Shakhmatkin BA, Vedishcheva NM, Shultz MM, Wright AC (1994) The thermodynamic properties of oxide glasses and glass-forming liquids and their chemical structure. J Non-Cryst Solids 177:249-256. doi: 10.1016/0022-3093(94)90538-X

99. Vedishcheva NM, Shakhmatkin BA, Shultz MM, Wright AC (1996) The thermodynamic modelling of glass properties: a practical proposition? J Non-Cryst Solids 196:239-243. doi: 10.1016/0022-3093(95)00593-5 
Le Losq, Cicconi, Greaves, Neuville. Silicate Glasses. In: Springer Handbook of Glass.

100. Schneider J, Mastelaro VR, Zanotto ED, Shakhmatkin BA, Vedishcheva NM, Wright AC, Panepucci H (2003) Qn distribution in stoichiometric silicate glasses: thermodynamic calculations and 29Si high resolution NMR measurements. J Non-Cryst Solids 325:164-178. doi: 10.1016/S0022-3093(03)00332-6

101. Gaddam A, Montagne L, Ferreira JMF (2016) Statistics of silicate units in binary glasses. J Chem Phys 145:124505. doi: 10.1063/1.4963341

102. Olivier L, Yuan X, Cormack AN, Jäger C (2001) Combined ${ }^{29}$ Si double quantum NMR and MD simulation studies of network connectivities of binary $\mathrm{Na}_{2} \mathrm{O} \cdot \mathrm{SiO}_{2}$ glasses: new prospects and problems. J Non-Cryst Solids 293:53-66.

103. Machacek J, Gedeon O, Liska M (2006) Group connectivity in binary silicate glasses. J NonCryst Solids 352:2173-2179. doi: 10.1016/j.jnoncrysol.2006.01.036

104. Doweidar $\mathrm{H}$ (1998) Density-structure correlations in $\mathrm{Na}_{2} \mathrm{O}-\mathrm{Al}_{2} \mathrm{O}_{3}-\mathrm{SiO}_{2}$ glasses. J Non-Cryst Solids 240:55-65.

105. Doweidar H (1999) Density-structure correlations in silicate glasses. J Non-Cryst Solids 249:194-200. doi: 10.1016/S0022-3093(99)00310-5

106. Doweidar H, Feller S, Affatigato M, Tischendorf B, Ma C, Hammarsten E (1999) Density and molar volume of extremely modified alkali silicate glasses. Phys Chem Glas 40:339-344.

107. Shannon RD (1976) Revised effective ionic radii and systematic studies of interatomic distances in halides and chalcogenides. Acta Crystallogr A 32:751-767. doi:

$10.1107 / \mathrm{S} 0567739476001551$

108. Stebbins JF (1998) Cation sites in mixed-alkali oxide glasses: correlations of NMR chemical shift data with site size and bond distance. Solid State Ion 112:137-141. doi: 10.1016/S01672738(98)00224-0

109. Cormier L, Ghaleb D, Neuville DR, Delaye J-M, Calas G (2003) Chemical dependence of network topology of calcium aluminosilicate glasses: a computer simulation study. J Non-Cryst Solids 332:255-270. doi: 10.1016/j.jnoncrysol.2003.09.012

110. Neuville DR, Cormier L, Flank A-M, Prado RJ, Lagarde P (2004) Na K-edge XANES spectra of minerals and glasses. Eur J Mineral 16:809-816.

111. George AM, Stebbins JF (1996) Dynamics of $\mathrm{Na}$ in sodium aluminosilicate glasses and liquids. Phys Chem Miner 23:526-534.

112. Richet P (1987) Heat capacity of silicate glasses. Chem Geol 62:111-124. doi: 10.1016/00092541(87)90062-3

113. Uhlig H, Hoffmann MJ, Lamparter H-P, Aldinger F, Bellissent R, Steeb S (1996) Short-Range and Medium-Range Order in Lithium Silicate Glasses, Part I: Diffraction Experiments and Results. J Am Ceram Soc 79:2833-2838. doi: 10.1111/j.1151-2916.1996.tb08716.x 
Le Losq, Cicconi, Greaves, Neuville. Silicate Glasses. In: Springer Handbook of Glass.

114. Zotov N, Keppler H (1998) The structure of sodium tetrasilicate glass from neutron diffraction, reverse Monte Carlo simulations and Raman spectroscopy. Phys Chem Miner 25:259-267.

115. Ispas S, Benoit M, Jund P, Jullien R (2002) Structural properties of glassy and liquid sodium tetrasilicate: comparison between ab initio and classical molecular dynamics simulations. J NonCryst Solids 307-310:946-955. doi: 10.1016/S0022-3093(02)01549-1

116. Du J, Corrales LR (2006) Compositional dependence of the first sharp diffraction peaks in alkali silicate glasses: A molecular dynamics study. J Non-Cryst Solids 352:3255-3269. doi:

10.1016/j.jnoncrysol.2006.05.025

117. Richet $\mathrm{P}$ (1984) Viscosity and configurational entropy of silicate melts. Geochim Cosmochim Acta 48:471-483. doi: 10.1016/0016-7037(84)90275-8

118. Toplis MJ (2001) Quantitative links between microscopic properties and viscosity of liquids in the system $\mathrm{SiO}_{2}-\mathrm{Na}_{2} \mathrm{O}$. Chem Geol 174:321-331. doi: 10.1016/S0009-2541(00)00323-5

119. Mysen BO (1995) Experimental, in situ, high-temperature studies of properties and structure of silicate melts relevant to magmatic processes. Eur J Mineral 7:745-766.

120. Lee SK, Stebbins JF (2003) Nature of Cation Mixing and Ordering in Na-Ca Silicate Glasses and Melts. J Phys Chem B 107:3141-3148. doi: 10.1021/jp027489y

121. Lee SK, Mysen BO, Cody GD (2003) Chemical order in mixed-cation silicate glasses and melts. Phys Rev B. doi: 10.1103/PhysRevB.68.214206

122. George AM, Stebbins JF (1998) Structure and dynamics of magnesium in silicate melts: A hightemperature 25Mg NMR study. Am Mineral 83:1022-1029.

123. Li D, Peng M, Murata T (1999) Coordination and local structure of magnesium in silicate minerals and glasses: Mg K-Edge XANES study. Can Mineral 37:199-206.

124. Neuville DR, Cormier L, Flank A-M, Briois V, Massiot D (2004) Al speciation and Ca environment in calcium aluminosilicate glasses and crystals by $\mathrm{Al}$ and $\mathrm{Ca} \mathrm{K}$-edge X-ray absorption spectroscopy. Chem Geol 213:153-163.

125. Cormier L, Neuville DR (2004) $\mathrm{Ca}$ and $\mathrm{Na}$ environments in $\mathrm{Na}_{2} \mathrm{O}-\mathrm{CaO}-\mathrm{Al}_{2} \mathrm{O}_{3}-\mathrm{SiO}_{2}$ glasses: influence of cation mixing and cation-network interactions. Chem Geol 213:103-113.

126. Greaves GN, Fontaine A, Lagarde P, Raoux D, Gurman SJ (1981) Local structure of silicate glasses. Nature 293:611-616.

127. Greaves GN (1985) Exafs and the structure of glass. J Non-Cryst Solids 71:203-217.

128. Greaves GN (1989) EXAFS, glass structure and diffusion. Philos Mag Part B 60:793-800.

129. Greaves GN, Ngai KL (1995) Reconciling ionic-transport properties with atomic structure in oxide glasses. Phys Rev B 52:6358-6380. doi: 10.1103/PhysRevB.52.6358

130. Lee SK, Stebbins JF (2003) The distribution of sodium ions in aluminosilicate glasses: a highfield Na-23 MAS and 3Q MAS NMR study. Geochim Cosmochim Acta 67:1699-1709. 
Le Losq, Cicconi, Greaves, Neuville. Silicate Glasses. In: Springer Handbook of Glass.

131. Lee SK (2005) Microscopic origins of macroscopic properties of silicate melts and glasses at ambient and high pressure: Implications for melt generation and dynamics. Geochim Cosmochim Acta 69:3695-3710. doi: 10.1016/j.gca.2005.03.011

132. Lee S, Stebbins J (2009) Effects of the degree of polymerization on the structure of sodium silicate and aluminosilicate glasses and melts: An ${ }^{17 \$} \mathrm{O}$ NMR study. Geochim Cosmochim Acta 73:1109-1119.

133. Poole, J.P. (1948) Viscosité à basse temperature des verres alcalino-silicatés. Verres Refract 2:222-228.

134. Poole JP (1949) Low-temperature viscosity of alkali silicate glasses. J Am Ceram Soc 32:230233.

135. Mazurin O, Borisovskii E (1957) Neutralization reduction of electrical conductivity in silica glasses. Sov Phys-Tech Phys 2:243-254.

136. Isard JO (1969) The mixed alkali effect in glass. J Non-Cryst Solids 1:235-261.

137. Day DE (1976) Mixed alkali glasses - Their properties and uses. J Non-Cryst Solids 21:343-372.

138. Roling B, Ingram MD (2000) Mixed alkaline-earth effects in ion conducting glasses. J NonCryst Solids 265:113-119. doi: 10.1016/S0022-3093(99)00899-6

139. Calahoo C, Zwanziger JW (2017) The mixed modifier effect in ionic conductivity and mechanical properties for $\mathrm{xMgO}-(50-\mathrm{x}) \mathrm{CaO}-50 \mathrm{SiO} 2$ glasses. J Non-Cryst Solids 460:6-18. doi: 10.1016/j.jnoncrysol.2017.01.017

140. Hummel W, Arndt J (1985) Variation of viscosity with temperature and composition in the plagioclase system. Contrib Mineral Petrol 90:83-92.

141. Lapp JC, Shelby JE (1987) The mixed alkali effet in lithium-sodium aluminosilicate glasses. J Non-Cryst Solids 95-96:889-896.

142. Kjeldsen J, Smedskjaer MM, Mauro JC, Youngman RE, Huang L, Yue Y (2013) Mixed alkaline earth effect in sodium aluminosilicate glasses. J Non-Cryst Solids 369:61-68. doi:

10.1016/j.jnoncrysol.2013.03.015

143. Smedskjaer MM, Rzoska SJ, Bockowski M, Mauro JC (2014) Mixed alkaline earth effect in the compressibility of aluminosilicate glasses. J Chem Phys 140:054511. doi: 10.1063/1.4863998

144. Frischat GH, Poggemann JF, Heide G (2004) Nanostructure and atomic structure of glass seen by atomic force microscopy. J Non-Cryst Solids 345-346:197-202.

145. Vessal B, Greaves GN, Marten PT, Chadwick AV, Mole R, Houde-Walter S (1992) Cation microsegregation and ionic mobility in mixed alkali glasses. Nature 356:504-506. doi: $10.1038 / 356504 \mathrm{a} 0$

146. Du J, Cormack AN (2004) The medium range structure of sodium silicate glasses: a molecular dynamics simulation. J Non-Cryst Solids 349:66-79. doi: 10.1016/j.jnoncrysol.2004.08.264 
Le Losq, Cicconi, Greaves, Neuville. Silicate Glasses. In: Springer Handbook of Glass.

147. Meyer A, Horbach J, Kob W, Kargl F, Schober H (2004) Channel formation and intermediate range order in sodium silicate melts and glasses. Phys Rev Lett 93:1-4.

148. Kargl F, Meyer A (2004) Inelastic neutron scattering on sodium aluminosilicate melts: sodium diffusion and intermediate range order. Chem Geol 213:165-172. doi:

10.1016/j.chemgeo.2004.08.040

149. Kargl F, Meyer A, Koza MM, Schober H (2006) Formation of channels for fast-ion diffusion in alkali silicate melts: A quasielastic neutron scattering study. Phys Rev B. doi:

10.1103/PhysRevB.74.014304

150. Kargl F, Meyer A (2008) Na-relaxation and intermediate range structure in sodium-potassium silicate melts. Chem Geol 256:278-285. doi: 10.1016/j.chemgeo.2008.06.046

151. Adam G, Gibbs JH (1965) On the temperature dependence of cooperative relaxation properties in glass-forming liquids. J Chem Phys 139-146.

152. Florian P, Vermillion KE, Grandinetti PJ, Farnan I, Stebbins JF (1996) Cation distribution in mixed alkali disilicate glasses. J Am Chem Soc 118:3493-3497.

153. Angeli F, Villain O, Schuller S, Ispas S, Charpentier T (2011) Insight into sodium silicate glass structural organization by multinuclear NMR combined with first-principles calculations. Geochim Cosmochim Acta 75:2453-2469. doi: 10.1016/j.gca.2011.02.003

154. Balasubramanian S, Rao KJ (1995) A molecular dynamics study of the mixed alkali effect in silicate glasses. J Non-Cryst Solids 181:157-174. doi: 10.1016/0022-3093(94)00489-7

155. Matson DW, Sharma SK, Philpotts JA (1983) The structure of high-silica alkali-silicate glasses. A Raman spectroscopic investigation. J Non-Cryst Solids 58:323-352. doi: 10.1016/00223093(83)90032-7

156. Le Losq C, Mysen BO, Cody GD (2015) Water and magmas: insights about the water solution mechanisms in alkali silicate melts from infrared, Raman, and ${ }^{29} \mathrm{Si}$ solid-state NMR spectroscopies. Prog Earth Planet Sci. doi: 10.1186/s40645-015-0052-7

157. Brawer SA, White WB (1975) Raman spectroscopic investigation of the structure of silicate glasses. I. The binary alkali silicates. J Chem Phys 63:2421-2432. doi: 10.1063/1.431671

158. Brawer SA, White WB (1977) Raman spectroscopic investigation of the structure of silicate glasses (II). Soda-alkaline earth-alumina ternary and quaternary glasses. J Non-Cryst Solids 23:261-278. doi: 10.1016/0022-3093(77)90009-6

159. Furukawa T, Fox KE, White WB (1981) Raman spectroscopic investigation of the structure of silicate glasses. III. Raman intensities and structural units in sodium silicate glasses. J Chem Phys 75:3226-3237. doi: 10.1063/1.442472

160. Voigt U, Lammert H, Eckert H, Heuer A (2005) Cation clustering in lithium silicate glasses: Quantitative description by solid-state NMR and molecular dynamics simulations. Phys Rev B 72:064207. 
Le Losq, Cicconi, Greaves, Neuville. Silicate Glasses. In: Springer Handbook of Glass.

161. Saal AE, Hart SR, Shimizu N, Hauri EH, Layne GD (1998) Pb Isotopic Variability in Melt Inclusions from Oceanic Island Basalts, Polynesia. Science 282:1481-1484. doi:

$10.1126 /$ science. 282.5393 .1481

162. Berry AJ, Danyushevsky LV, O’Neill HSC, Newville M, Sutton SR (2008) Oxidation state of iron in komatiitic melt inclusions indicates hot Archaean mantle. Nature 455:960-963. doi: 10.1038/nature07377

163. Spandler C, O’Neill HSC, Kamenetsky VS (2007) Survival times of anomalous melt inclusions from element diffusion in olivine and chromite. Nature 447:303-306. doi: 10.1038/nature05759

164. Roedder E, Weiblen PW (1970) Silicate Liquid Immiscibility in Lunar Magmas, Evidenced by Melt Inclusions in Lunar Rocks. Science 167:641-644. doi: 10.1126/science.167.3918.641

165. Hauri EH, Weinreich T, Saal AE, Rutherford MC, Orman JAV (2011) High Pre-Eruptive Water Contents Preserved in Lunar Melt Inclusions. Science 333:213-215. doi:

$10.1126 /$ science. 1204626

166. Elkins-Tanton LT (2012) Magma Oceans in the Inner Solar System. Annu Rev Earth Planet Sci 40:113-139. doi: 10.1146/annurev-earth-042711-105503

167. Day DE, Rindone GE (1962) Properties of soda aluminosilicate glasses: III, coordination of aluminum ions. J Am Ceram Soc 45:579-581.

168. Riebling EF (1966) Structure of sodium aluminosilicate melts containing at least $50 \mathrm{~mol} \%$ $\mathrm{SiO}^{\text {lcircs }}$ C. J Chem Phys 44:2857-2865.

169. Taylor TD, Rindone GE (1970) Properties of Soda Aluminosilicate Glasses: V, LowTemperature Viscosities. J Am Ceram Soc 53:692-695.

170. McKeown DA, Galeener FL, Brown Jr GE (1984) Raman studies of Al coordination in silicarich sodium aluminosilicate glasses and some related minerals. J Non-Cryst Solids 68:361-378.

171. McMillan PF, Kirkpatrick RJ (1992) Al coordination in magnesium aluminosilicate glasses. Am Mineral 77:898-900.

172. Stebbins JF, Kroeker S, Lee SK, Kiczenski TJ (2000) Quantification of five- and six-coordinated aluminum ions in aluminosilicate and fluoride-containing glasses by high-field, high-resolution ${ }^{27}$ Al NMR. J Non-Cryst Solids 275:1-6.

173. Toplis MJ, Kohn SC, Smith ME, Poplett JF (2000) Fivefold-coordinated aluminum in tectosilicate glasses observed by triple quantum MAS NMR. Am Mineral 85:1556-1560.

174. Neuville DR, Cormier L, Massiot D (2006) Al coordination and speciation in calcium aluminosilicate glasses: Effects of composition determined by ${ }^{27 \$} \mathrm{Al}$ MQ-MAS NMR and Raman spectroscopy. Chem Geol 229:173-185.

175. Florian P, Sadiki N, Massiot D, Coutures JP (2007) ${ }^{27}$ Al NMR Study of the Structure of Lanthanum- and Yttrium-Based Aluminosilicate Glasses and Melts. J Phys Chem B 111:97479757. doi: 10.1021/jp072061q 
Le Losq, Cicconi, Greaves, Neuville. Silicate Glasses. In: Springer Handbook of Glass.

176. Stebbins JF, Xu Z (1997) NMR evidence for excess non-bridging oxygen in an aluminosilicate glass. Nature 390:60-62.

177. Mysen BO, Toplis MJ (2007) Structural behavior of $\mathrm{Al}^{3+\$}$ in peralkaline, metaluminous, and peraluminous silicate melts and glasses at ambient pressure. Am Mineral 92:933-946.

178. Thompson LM, Stebbins JF (2011) Non-bridging oxygen and high-coordinated aluminum in metaluminous and peraluminous calcium and potassium aluminosilicate glasses: High-resolution $17 \mathrm{O}$ and 27Al MAS NMR results. Am Mineral 96:841-853.

179. Allwardt JR (2005) Aluminum coordination and the densification of high-pressure aluminosilicate glasses. Am Mineral 90:1218-1222. doi: 10.2138/am.2005.1836

180. Kelsey KE, Stebbins JF, Singer DM, Brown Jr. GE, Mosenfelder JL, Asimow PD (2009) Cation field strength effects on high pressure aluminosilicate glass structure: Multinuclear NMR and La XAFS results. Geochim Cosmochim Acta 73:3914-3933. doi: 10.1016/j.gca.2009.03.040

181. Thompson LM, Stebbins JF (2012) Non-stoichiometric non-bridging oxygens and fivecoordinated aluminum in alkaline earth aluminosilicate glasses: Effect of modifier cation size. J Non-Cryst Solids 358:1783-1789. doi: 10.1016/j.jnoncrysol.2012.05.022

182. Morin EI, Wu J, Stebbins JF (2014) Modifier cation (Ba, Ca, La, Y) field strength effects on aluminum and boron coordination in aluminoborosilicate glasses: the roles of fictive temperature and boron content. Appl Phys A 116:479-490. doi: 10.1007/s00339-014-8369-4

183. Takahashi S, Neuville DR, Takebe H (2015) Thermal properties, density and structure of percalcic and peraluminus $\mathrm{CaO}-\mathrm{A} 12 \mathrm{O} 3-\mathrm{SiO} 2$ glasses. J Non-Cryst Solids 411:5-12. doi: 10.1016/j.jnoncrysol.2014.12.019

184. Novikov AN, Neuville DR, Hennet L, Gueguen Y, Thiaudière D, Charpentier T, Florian P Al and Sr environment in tectosilicate glasses and melts: Viscosity, Raman and NMR investigation. Chem Geol. doi: 10.1016/j.chemgeo.2016.11.023

185. Iftekhar S, Pahari B, Okhotnikov K, Jaworski A, Stevensson B, Grins J, Edén M (2012) Properties and Structures of RE2O3-A12O3-SiO2 ( $\mathrm{RE}=\mathrm{Y}, \mathrm{Lu})$ Glasses Probed by Molecular Dynamics Simulations and Solid-State NMR: The Roles of Aluminum and Rare-Earth Ions for Dictating the Microhardness. J Phys Chem C 116:18394-18406. doi: 10.1021/jp302672b

186. Neuville DR, Cormier L, Massiot D (2004) Al environment in tectosilicate and peraluminous glasses: A 27Al MQ-MAS NMR, Raman, and XANES investigation. Geochim Cosmochim Acta 68:5071-5079. doi: 10.1016/j.gca.2004.05.048

187. Allwardt JR, Poe BT, Stebbins JF (2005) The effect of fictive temperature on Al coordination in high-pressure (10 GPa) sodium aluminosilicate glasses. Am Mineral 90:1453-1457.

188. Kanehashi K, Stebbins JF (2007) In situ high temperature 27Al NMR study of structure and dynamics in a calcium aluminosilicate glass and melt. J Non-Cryst Solids 353:4001-4010. doi: 10.1016/j.jnoncrysol.2007.06.030 
Le Losq, Cicconi, Greaves, Neuville. Silicate Glasses. In: Springer Handbook of Glass.

189. Neuville DR, Cormier L, de Ligny D, Roux J, Flank A-M, Lagarde P (2008) Environments around $\mathrm{Al}, \mathrm{Si}$, and $\mathrm{Ca}$ in aluminate and aluminosilicate melts by $\mathrm{X}$-ray absorption spectroscopy at high temperature. Am Mineral 93:228-234. doi: 10.2138/am.2008.2646

190. Malfait WJ, Verel R, Ardia P, Sanchez-Valle C (2012) Aluminum coordination in rhyolite and andesite glasses and melts: Effect of temperature, pressure, composition and water content. Geochim Cosmochim Acta 77:11-26. doi: 10.1016/j.gca.2011.11.011

191. Bista S, Stebbins JF, Hankins WB, Sisson TW (2015) Aluminosilicate melts and glasses at 1 to 3 GPa: Temperature and pressure effects on recovered structural and density changes. Am Mineral 100:2298-2307. doi: 10.2138/am-2015-5258

192. Stebbins JF, Dubinsky EV, Kanehashi K, Kelsey KE (2008) Temperature effects on nonbridging oxygen and aluminum coordination number in calcium aluminosilicate glasses and melts. Geochim Cosmochim Acta 72:910-925. doi: 10.1016/j.gca.2007.11.018

193. Thompson LM, Stebbins JF (2013) Interaction between composition and temperature effects on non-bridging oxygen and high-coordinated aluminum in calcium aluminosilicate glasses. Am Mineral 98:1980-1987. doi: 10.2138/am.2013.4511

194. Wu J, Stebbins JF (2010) Quench rate and temperature effects on boron coordination in aluminoborosilicate melts. J Non-Cryst Solids 356:2097-2108.

195. Kiczenski TJ, Du L-S, Stebbins J (2005) The effect of fictive temperature on the structure of Eglass: A high resolution, multinuclear NMR study. J Non-Cryst Solids 351:3571-3578. doi: 10.1016/j.jnoncrysol.2005.09.026

196. Lee SK, Cody GD, Fei Y, Mysen BO (2006) The effect of Na/Si on the structure of sodium silicate and aluminosilicate glasses quenched from melts at high pressure: A multi-nuclear (Al27, Na-23, O-17) 1D and 2D solid-state NMR study. Chem Geol 229:162-172. doi: 10.1016/j.chemgeo.2006.01.018

197. Toplis MJ, Dingwell DB, Lenci T (1997) Peraluminous viscosity maxima in $\mathrm{Na}_{2} \mathrm{O}-\mathrm{Al}_{2} \mathrm{O}_{3}-\mathrm{SiO}_{2}$ liquids: The role of triclusters in tectosilicate melts. Geochim Cosmochim Acta 61:2605-2612. doi: 10.1016/S0016-7037(97)00126-9

198. Gruener G, Odier O, De Sousa Meneses D, Florian P, Richet P (2001) Bulk and local dynamics in glass-forming liquids: A viscosity, electrical conductivity, and NMR study of aluminosilicate melts. Phys Rev B 64:024206-1:5.

199. Neuville D, Cormier L, Montouillout V, Massiot D (2007) Local Al site distribution in aluminosilicate glasses by ${ }^{27 \$}$ Al MQMAS NMR. J Non-Cryst Solids 353:180-184.

200. Loewenstein W (1954) The distribution of aluminium in the tetrahedra of silicates and aluminates. Am Mineral 39:92-97.

201. Lee SK, Stebbins JF (1999) The degree of aluminum avoidance in aluminosilicate glasses. Am Mineral 84:937-945. 
Le Losq, Cicconi, Greaves, Neuville. Silicate Glasses. In: Springer Handbook of Glass.

202. Lee SK, Stebbins JF (2002) Extent of intermixing among framework units in silicate glasses and melts. Geochim Cosmochim Acta 66:303-309.

203. Mysen BO, Lucier A, Cody GD (2003) The structural behavior of $\mathrm{Al}^{3+\$}$ in peralkaline melts and glasses in the system $\mathrm{Na}_{2} \mathrm{O}-\mathrm{Al}_{2} \mathrm{O}_{3}-\mathrm{SiO}_{2}$. Am Mineral 88:1668-1678.

204. Lee SK, Stebbins J (2000) Al-O-Al and Si-O-Si sites in framework aluminosilicate glasses with $\mathrm{Si} / \mathrm{Al}=1$ : quantification of framework disorder. J Non-Cryst Solids 270:260-264.

205. Xiang Y, Du J, Smedskjaer MM, Mauro JC (2013) Structure and properties of sodium aluminosilicate glasses from molecular dynamics simulations. J Chem Phys 139:044507. doi: $10.1063 / 1.4816378$

206. Bauchy M (2014) Structural, vibrational, and elastic properties of a calcium aluminosilicate glass from molecular dynamics simulations: The role of the potential. J Chem Phys 141:024507. doi: $10.1063 / 1.4886421$

207. Lee SK, Kim H-I, Kim EJ, Mun KY, Ryu S (2016) Extent of Disorder in Magnesium Aluminosilicate Glasses: Insights from 27Al and 17O NMR. J Phys Chem C 120:737-749. doi: 10.1021/acs.jpcc.5b10799

208. Neuville DR, Mysen BO (1996) Role of aluminium in the silicate network: In situ, hightemperature study of glasses and melts on the join $\mathrm{SiO}_{2}-\mathrm{NaAlO}_{2}$. Geochim Cosmochim Acta 60:1727-1737.

209. Toplis MJ, Dingwell DB, Hess K-U, Lenci T (1997) Viscosity, fragility, and configurational entropy of melts along the join $\mathrm{SiO} \sim 2-\mathrm{NaAlSiO} \sim 4$. Am Mineral 82:979-990.

210. Vuilleumier R, Sator N, Guillot B (2009) Computer modeling of natural silicate melts: What can we learn from ab initio simulations. Geochim Cosmochim Acta 73:6313-6339. doi: 10.1016/j.gca.2009.07.013

211. Navrotsky A, Geisinger KL, McMillan P, Gibbs GV (1985) The tetrahedral framework in glasses and melts - inferences from molecular orbital calculations and implications for structure, thermodynamics, and physical properties. Phys Chem Miner 11:284-298. doi: 10.1007/BF00307406

212. Li W, Garofalini SH (2004) Molecular dynamics simulation of lithium diffusion in Li2OA12O3-SiO2 glasses. Solid State Ion 166:365-373. doi: 10.1016/j.ssi.2003.11.015

213. Zirl DM, Garofalini SH (1990) Structure of Sodium Aluminosilicate Glasses. J Am Ceram Soc 73:2848-2856. doi: 10.1111/j.1151-2916.1990.tb06685.x

214. Jackson WE, Brown GE, Ponader CW (1987) X-ray absorption study of the potassium coordination environment in glasses from the NaAlSi3O8-KAlSi3O8 binary. J Non-Cryst Solids 93:311-322. doi: 10.1016/S0022-3093(87)80177-1

215. Petkov V, Gerber T, Himmel B (1998) Atomic ordering in Ca x/2 Al x Si 1- x O 2 glasses ( $\mathrm{x}=0$, $0.34,0.5,0.68$ ) by energy-dispersive X-ray diffraction. Phys Rev B 58:11982. 
Le Losq, Cicconi, Greaves, Neuville. Silicate Glasses. In: Springer Handbook of Glass.

216. Petkov V, Billinge SJL, Shastri SD, Himmel B (2000) Polyhedral units and network connectivity in calcium aluminosilicate glasses from high-energy X-ray diffraction. Phys Rev Lett 85:3436.

217. Cormier L, Neuville DR, Calas G (2000) Structure and properties of low-silica calcium aluminosilicate glasses. J Non-Cryst Solids 274:110-114. doi: 10.1016/S0022-3093(00)00209-X

218. Guignard M, Cormier L (2008) Environments of $\mathrm{Mg}$ and $\mathrm{Al}$ in $\mathrm{MgO}-\mathrm{Al} 2 \mathrm{O} 3-\mathrm{SiO} 2$ glasses: A study coupling neutron and X-ray diffraction and Reverse Monte Carlo modeling. Chem Geol 256:111-118. doi: 10.1016/j.chemgeo.2008.06.008

219. Iuga D, Morais C, Gan Z, Neuville DR, Cormier L, Massiot D (2005) NMR Heteronuclear Correlation between Quadrupolar Nuclei in Solids. J Am Chem Soc 127:11540-11541.

220. Stebbins JF, Lee SK, Oglesby JV (1999) Al-O-Al oxygen sites in crystalline aluminates and aluminosilicate glasses; high-resolution oxygen-17 NMR results. Am Mineral 84:983-986. doi: 10.2138/am-1999-5-635

221. Oglesby JV, Zhao P, Stebbins JF (2002) Oxygen sites in hydrous aluminosilicate glasses: The role of Al-O-Al and H 2 O. Geochim Cosmochim Acta 66:291-301.

222. Harvey J-P, Asimow PD (2015) Current limitations of molecular dynamic simulations as probes of thermo-physical behavior of silicate melts. Am Mineral 100:1866-1882. doi: 10.2138/am2015-5159

223. Lacy ED (1963) Aluminium in glasses and melts. Physic Chem Glas 4:234-238.

224. Deer WA, Howie RA, Zussman J (1992) An introduction to the rock-forming minerals. Longman Group Limited, London

225. Kushiro I (1978) Viscosity and structural changes of albite $\left(\mathrm{NaAlSi}_{3} \mathrm{O}_{8}\right)$ melt at high pressures. Earth Planet Sci Lett 41:87-90.

226. Lee SK, Cody GD, Fei Y, Mysen BO (2004) Nature of polymerization and properties of silicate melts and glasses at high pressure. Geochim Cosmochim Acta 68:4189-4200. doi:

10.1016/j.gca.2004.04.002

227. Taylor M, Brown GE (1979) Structure of mineral glasses-I. The feldspar glasses $\mathrm{NaAlSi}_{3} \mathrm{O}_{8}$, $\mathrm{KAlSi}_{3} \mathrm{O}_{8}, \mathrm{CaAl}_{2} \mathrm{Si}_{2} \mathrm{O}_{8}$. Geochim Cosmochim Acta 43:61-75.

228. Urbain G, Bottinga Y, Richet P (1982) Viscosity of liquid silica, silicates and alumino-silicates. Geochim Cosmochim Acta 46:1061-1072. doi: 10.1016/0016-7037(82)90059-X

229. Kubicki JD, Sykes D (1993) Molecular orbital calculations of vibrations in three-membered aluminosilicate rings. Phys Chem Miner 19:381-391. doi: 10.1007/BF00202975

230. Hater W, Müller-Warmuth W, Meier M, Frischat GH (1989) High-resolution solid-state NMR studies of mixed-alkali silicate glasses. J Non-Cryst Solids 113:210-212. 
Le Losq, Cicconi, Greaves, Neuville. Silicate Glasses. In: Springer Handbook of Glass.

231. Ali F, Chadwick AV, Greaves GN, Jermy MC, Ngai KL, Smith ME (1995) Examination of the mixed-alkali effect in $(\mathrm{Li}, \mathrm{Na})$ disilicate glasses by nuclear magnetic resonance and conductivity measurements. Solid State Nucl Magn Reson 5:133-143.

232. Bray PJ, Emerson JF, Lee D, Feller SA, Bain DL, Feil DA (1991) NMR and NQR studies of glass structure. J Non-Cryst Solids 129:240-248.

233. Emerson JF, Bray PJ (1994) Nuclear magnetic resonance and transmission electron microscopy studies of mixed-alkali silicate glasses. J Non-Cryst Solids 169:87-95.

234. Kelsey KE, Allwardt JR, Stebbins JF (2008) Ca-Mg mixing in aluminosilicate glasses: An investigation using 17O MAS and 3QMAS and 27Al MAS NMR. J Non-Cryst Solids 354:46444653. doi: 10.1016/j.jnoncrysol.2008.05.049

235. Weigel C, Le Losq C, Vialla R, Dupas C, Clément S, Neuville DR, Rufflé B (2016) Elastic moduli of XA1SiO4 aluminosilicate glasses: effects of charge-balancing cations. J Non-Cryst Solids 447:267-272. doi: 10.1016/j.jnoncrysol.2016.06.023

236. Greaves GN, Greer AL, Lakes RS, Rouxel T (2011) Poisson's ratio and modern materials. Nat Mater 10:823-837. doi: 10.1038/nmat3134

237. Hunault MOJY, Galoisy L, Lelong G, Newville M, Calas G (2016) Effect of cation field strength on Co2+ speciation in alkali-borate glasses. J Non-Cryst Solids 451:101-110. doi: 10.1016/j.jnoncrysol.2016.06.025

238. Wang C, Peng M, Jiang N, Jiang X, Zhao C, Qiu J (2007) Tuning the Eu luminescence in glass materials synthesized in air by adjusting glass compositions. Mater Lett 61:3608-3611. doi: 10.1016/j.matlet.2006.11.133

239. Farias AM, Sandrini M, Viana JRM, Baesso ML, Bento AC, Rohling JH, Guyot Y, De Ligny D, Nunes LAO, Gandra FG, Sampaio JA, Lima SM, Andrade LHC, Medina AN (2015) Emission tunability and local environment in europium-doped $\mathrm{OH}-$-free calcium aluminosilicate glasses for artificial lighting applications. Mater Chem Phys 156:214-219. doi:

10.1016/j.matchemphys.2015.03.002

240. Cicconi MR, Veber A, de Ligny D, Rocherullé J, Lebullenger R, Tessier F (2017) Chemical tunability of europium emission in phosphate glasses. J Lumin 183:53-61. doi: 10.1016/j.jlumin.2016.11.019

241. Dingwell DB, Virgo D (1987) The effet of oxydation state on the viscosity of melts in the system $\mathrm{Na}_{2} \mathrm{O}-\mathrm{FeO}-\mathrm{Fe}_{2} \mathrm{O}_{3}-\mathrm{SiO}_{2}$. Geochim Cosmochim Acta 51:195-205.

242. Dingwell DB (1989) Shear viscosities of ferrosilicate liquids. Am Mineral 74:1038-1044.

243. Dingwell DB (1991) Redox viscometry of some Fe-bearing silicate melts. Am Mineral 76:15601562.

244. Fudali RF (1965) Oxygen fugacities of basaltic and andesitic magmas. Geochim Cosmochim Acta 29:1063-1075. 
Le Losq, Cicconi, Greaves, Neuville. Silicate Glasses. In: Springer Handbook of Glass.

245. Mysen BO, Scarfe CM, Cronin DJ (1985) Viscosity and structure of iron- and aluminum-bearing calcium silicate melts at 1 atm. Am Mineral 70:487-498.

246. Dingwell, D. B., Virgo, D. (1988) Viscosities of melts in the Na2O-FeO-Fe2O3-SiO2 system and factors controlling relative viscosities of fully polymerized silicate melts. Geochim Cosmochim Acta 52:395-403.

247. Schreiber HD (1977) Redox states of Ti, Zr, Hf, Cr, and EU in basaltic magmas - an experimental study. Lunar Planet Sci Conf Proc 8:1785-1807.

248. Schreiber HD, Thanyasiri T, Lach JJ (1978) Redox equilibria of Ti, Cr, and Eu in silicate melts-reduction potentials and mutual interactions. Phys Chem Glas 19:126-139.

249. Schreiber HD, Lauer HV, Thanyasiri T (1980) The redox state of cerium in basaltic magmas: an experimental study of iron-cerium interactions in silicate melts. Geochim Cosmochim Acta 44:1599-1612. doi: 10.1016/0016-7037(80)90120-9

250. Schreiber HD (1986) Redox processes in glass-forming melts. J Non-Cryst Solids 84:129-141.

251. Schreiber HD (1987) An electrochemical series of redox couples in silicate melts: A review and applications to geochemistry. J Geophys Res Solid Earth 92:9225-9232. doi: 10.1029/JB092iB09p09225

252. Schreiber HD, Kochanowski BK, Schreiber CW, Morgan AB, Coolbaugh MT, Dunlap TG (1994) Compositional dependence of redox equilibria in sodium silicate glasses. J Non-Cryst Solids 177:340-346. doi: 10.1016/0022-3093(94)90548-7

253. Schreiber HD, Wilk Jr NR, Schreiber CW (1999) A comprehensive electromotive force series of redox couples in soda-lime-silicate glass. J Non-Cryst Solids 253:68-75. doi: 10.1016/S00223093(99)00344-0

254. Johnston WD (1964) Oxidation-Reduction Equilibria in Iron-Containing Glass. J Am Ceram Soc 47:198-201. doi: 10.1111/j.1151-2916.1964.tb14392.x

255. Mysen $\mathrm{BO}$ (1987) Redox equilibria and coordination of $\mathrm{Fe} 2+$ and $\mathrm{Fe} 3+$ in silicate glasses from 57Fe Mossbauer spectroscopy. J Non-Cryst Solids 95:247-254.

256. Mysen BO, Virgo D (1989) Redox equilibria, structure, and properties of Fe-bearing aluminosilicate melts: Relationships among temperature, composition, and oxygen fugacity in the system Na_2O-Al_2O_3-SiO_2-Fe-O. Am Mineral 74:58-76.

257. Kress VC, Carmichael IS (1991) The compressibility of silicate liquids containing Fe2O3 and the effect of composition, temperature, oxygen fugacity and pressure on their redox states. Contrib Mineral Petrol 108:82-92.

258. Lauer HV, Morris RV (1977) Redox Equilibria of Multivalent Ions in Silicate Glasses. J Am Ceram Soc 60:443-451. doi: 10.1111/j.1151-2916.1977.tb15530.x

259. Mysen BO, Virgo D, Seifert F (1984) Redox equilibria of iron in alkaline earth silicate melts: relationships between melt structure, oxygen fugacity, temperature and properties of iron-bearing silicate liquids. Am Mineral 69:834-847. 
Le Losq, Cicconi, Greaves, Neuville. Silicate Glasses. In: Springer Handbook of Glass.

260. Cicconi MR, Giuli G, Ertel-Ingrisch W, Paris E, Dingwell DB (2015) The effect of the $[\mathrm{Na} /(\mathrm{Na}+\mathrm{K})]$ ratio on Fe speciation in phonolitic glasses. Am Mineral 100:1610-1619. doi: 10.2138/am-2015-5155

261. Drickamer HG, Bastron VC, Fisher DC, Grenoble DC (1970) The high-pressure chemistry of iron. J Solid State Chem 2:94-104. doi: 10.1016/0022-4596(70)90038-1

262. Wang PJ, Drickamer HG (1973) Reduction of Cu(II) at high pressure. J Chem Phys 59:713-717. doi: $10.1063 / 1.1680080$

263. Gibbons RV, Ahrens TJ, Rossman GR (1974) A spectrographic interpretation of the shockproduced color change in rhodonite $\left(\mathrm{MnSiO}_{3}\right)$ : The shock-induced reduction of $\mathrm{Mn}$ (III) to Mn(II). Am Mineral 59:177-182.

264. O'Neill HSC (2006) An experimental determination of the effect of pressure on the Fe3+/ Fe ratio of an anhydrous silicate melt to 3.0 GPa. Am Mineral 91:404-412. doi: 10.2138/am.2005.1929

265. Zhang HL, Hirschmann MM, Cottrell E, Withers AC (2017) Effect of pressure on Fe $3+/ \Sigma F e$ ratio in a mafic magma and consequences for magma ocean redox gradients. Geochim Cosmochim Acta 204:83-103. doi: 10.1016/j.gca.2017.01.023

266. Burnham AD, Berry AJ, Halse HR, Schofield PF, Cibin G, Mosselmans JFW (2015) The oxidation state of europium in silicate melts as a function of oxygen fugacity, composition and temperature. Chem Geol 411:248-259. doi: 10.1016/j.chemgeo.2015.07.002

267. Paul A, Douglas RW (1965) Ferrous-ferric equilibrium in binary alkali silicate glasses. Phys Chem Glas 6:207.

268. Dickenson MP, Hess PC (1982) Redox equilibria and the structural role of iron in aluminosilicate melts. Contrib Mineral Petrol 78:352-357. doi: 10.1007/BF00398931

269. Mysen, B. O., Virgo, D., Neumann, E.-R., Seifert, F. A. (1985) Redox equilibria and the structural states of ferric and ferrous iron in melts in the system $\mathrm{CaO}-\mathrm{MgO}-\mathrm{AI} 203-\mathrm{SiO} 2-\mathrm{Fe}-\mathrm{O}$ : relationships between redox equilibria, melt structure and liquidus phase equilibria. Am Mineral 70:317-331.

270. Berry AJ, O'Neill HSC, Scott DR, Shelley JMG (2006) The effect of composition on Cr2+/Cr3+ in silicate melts. Am Mineral 91:1901-1908.

271. O'Neill HSC, Eggins SM (2002) The effect of melt composition on trace element partitioning: an experimental investigation of the activity coefficients of $\mathrm{FeO}, \mathrm{NiO}, \mathrm{CoO}, \mathrm{MoO} 2$ and $\mathrm{MoO} 3$ in silicate melts. Chem Geol 186:151-181. doi: 10.1016/S0009-2541(01)00414-4

272. Giuli G, Paris E, Mungall J, Romano C, Dingwell D (2004) V oxidation state and coordination number in silicate glasses by XAS. Am Mineral 89:1640-1646.

273. Farges F, Linnen RL, Brown GE (2006) REDOX AND SPECIATION OF TIN IN HYDROUS SILICATE GLASSES: A COMPARISON WITH Nb, Ta, Mo AND W. Can Mineral 44:795810. doi: $10.2113 /$ gscanmin.44.3.795 
Le Losq, Cicconi, Greaves, Neuville. Silicate Glasses. In: Springer Handbook of Glass.

274. Morris RV, Haskin LA (1974) EPR measurement of the effect of glass composition on the oxidation states of europium. Geochim Cosmochim Acta 38:1435-1445. doi: 10.1016/00167037(74)90097-0

275. Cicconi MR, Giuli G, Paris E, Ertel-Ingrisch W, Ulmer P, Dingwell DB (2012) Europium oxidation state and local structure in silicate glasses. Am Mineral 97:918-929.

276. Duffy JA, Ingram MD (1976) An interpretation of glass chemistry in terms of the optical basicity concept. J Non-Cryst Solids 21:373-410. doi: 10.1016/0022-3093(76)90027-2

277. Duffy JA (1993) A review of optical basicity and its applications to oxidic systems. Geochim Cosmochim Acta 57:3961-3970. doi: 10.1016/0016-7037(93)90346-X

278. Lebouteiller A, Courtine P (1998) Improvement of a Bulk Optical Basicity Table for Oxidic Systems. J Solid State Chem 137:94-103. doi: 10.1006/jssc.1997.7722

279. Ottonello G, Moretti R, Marini L, Vetuschi Zuccolini M (2001) Oxidation state of iron in silicate glasses and melts: a thermochemical model. Chem Geol 174:157-179. doi: 10.1016/S00092541(00)00314-4

280. Moretti R (2005) Polymerisation, basicity, oxidation state and their role in ionic modelling of silicate melts. Ann Geophys. doi: 10.4401/ag-3221

281. Sack RO, Carmichael ISE, Rivers M, Ghiorso MS (1980) Ferric-Ferrous equilibria in natural silicate liquids at 1 bar. Contrib Mineral Petrol 75:369-376.

282. Kilinc A, Carmichael ISE, Rivers ML, Sack RO (1983) The Ferric-Ferrous ratio of natural silicate liquids equilibrated in air. Contrib Mineral Petrol 83:136-140.

283. Burnham AD, Berry AJ (2014) The effect of oxygen fugacity, melt composition, temperature and pressure on the oxidation state of cerium in silicate melts. Chem Geol 366:52-60. doi: 10.1016/j.chemgeo.2013.12.015

284. Tangeman JA, Lange R, Forman L (2001) Ferric-ferrous equilibria in K2O-FeO-Fe2O3-SiO2 melts. Geochim Cosmochim Acta 65:1809-1819. doi: 10.1016/S0016-7037(00)00561-5

285. Kress VC, Carmichael ISE (1988) Stoichiometry of the iron oxidation reaction in silicate melts. Am Mineral 73:1267-1274.

286. Thornber CR, Roeder PL, Foster JR (1980) The effect of composition on the ferric-ferrous ratio in basaltic liquids at atmospheric pressure. Geochim Cosmochim Acta 44:525-532. doi: 10.1016/0016-7037(80)90048-4

287. Dyar MD (1985) A review of Moessbauer data on inorganic glasses; the effects of composition on iron valency and coordination. Am Mineral 70:304-316.

288. Virgo D, Mysen BO (1985) The structural state of iron in oxidized vs. reduced glasses at 1 atm: A57Fe Mössbauer study. Phys Chem Miner 12:65-76. doi: 10.1007/BF01046829 
Le Losq, Cicconi, Greaves, Neuville. Silicate Glasses. In: Springer Handbook of Glass.

289. Hannoyer B, Lenglet M, Dürr J, Cortes R (1992) Spectroscopic evidence of octahedral iron (III) in soda-lime silicate glasses. J Non-Cryst Solids 151:209-216. doi: 10.1016/00223093(92)90031-E

290. Galoisy L, Calas G, Arrio MA (2001) High-resolution XANES spectra of iron in minerals and glasses: structural information from the pre-edge region. Chem Geol 174:307-319.

291. Partzsch GM, Lattard D, McCammon C (2004) Mossbauer spectroscopic determination of $\mathrm{Fe}^{3+\$} / \mathrm{Fe}^{2+\$}$ in synthetic basaltic glass: a test of empirical $\mathrm{fO}_{2}$ equations under superliquidus and subliquidus conditions. Contrib Mineral Petrol 145:565-580.

292. Farges F, Lefrère Y, Rossano S, Berthereau A, Calas G, Brown Jr. GE (2004) The effect of redox state on the local structural environment of iron in silicate glasses: a combined XAFS spectroscopy, molecular dynamics, and bond valence study. J Non-Cryst Solids 344:176-188. doi: 10.1016/j.jnoncrysol.2004.07.050

293. Jackson WE, Farges F, Yeager M, Mabrouk PA, Rossano S, Waychunas GA, Solomon EI, Brown GE (2005) Multi-spectroscopic study of Fe(II) in silicate glasses: Implications for the coordination environment of Fe(II) in silicate melts. Geochim Cosmochim Acta 69:4315-4332. doi: $10.1016 /$ j.gca.2005.01.008

294. Métrich N, Susini J, Foy E, Farges F, Massare D, Sylla L, Lequien S, Bonnin-Mosbah M (2006) Redox state of iron in peralkaline rhyolitic glass/melt: X-ray absorption micro-spectroscopy experiments at high temperature. Chem Geol 231:350-363. doi: 10.1016/j.chemgeo.2006.02.001

295. Wilke M, Farges F, Partzsch GM, Schmidt C, Behrens H (2007) Speciation of Fe in silicate glasses and melts by in-situ XANES spectroscopy. Am Mineral 92:44-56. doi: 10.2138/am.2007.1976

296. Rossano S, Behrens H, Wilke M (2008) Advanced analyses of 57Fe Mössbauer data of aluminosilicate glasses. Phys Chem Miner 35:77-93. doi: 10.1007/s00269-007-0200-8

297. Giuli G, Paris E, Hess K-U, Dingwell DB, Cicconi MR, Eeckhout SG, Fehr KT, Valenti P (2011) XAS determination of the Fe local environment and oxidation state in phonolite glasses. Am Mineral 96:631-636. doi: 10.2138/am.2011.3464

298. Giuli G, Alonso-Mori R, Cicconi MR, Paris E, Glatzel P, Eeckhout SG, Scaillet B (2012) Effect of alkalis on the $\mathrm{Fe}$ oxidation state and local environment in peralkaline rhyolitic glasses. Am Mineral 97:468-475. doi: 10.2138/am.2012.3888

299. Calas G, Petiau J (1983) Coordination of iron in oxide glasses through high-resolution K-edge spectra: information from the pre-edge. Solid State Commun 48:625-629.

300. Waychunas GA, Brown GE, Ponader CW, Jackson WE (1988) Evidence from X-ray absorption for network-forming Fe2+ in molten alkali silicates. Nature 332:251-253. doi: $10.1038 / 332251 \mathrm{a} 0$

301. Keppler HN (1992) Crystal field spectra and geochemistry of transition metal ions in silicate melts and glasses. Am Mineral 77:62-75. 
Le Losq, Cicconi, Greaves, Neuville. Silicate Glasses. In: Springer Handbook of Glass.

302. Jackson WE, Leon JM de, Brown GE, Waychunas GA, Conradson SD, Combes J-M (1993) High-Temperature XAS Study of Fe2SiO4 Liquid: Reduced Coordination of Ferrous Iron. Science 262:229-233. doi: 10.1126/science.262.5131.229

303. Rossano S, Balan E, Morin G, Bauer J-P, Calas G, Brouder C (1999) 57Fe Mössbauer spectroscopy of tektites. Phys Chem Miner 26:530-538. doi: 10.1007/s002690050216

304. Rossano S, Ramos A, Delaye J-M, Creux S, Filipponi A, Brouder C, Calas G (2000) EXAFS and Molecular Dynamics combined study of $\mathrm{CaO}-\mathrm{FeO}-2 \mathrm{SiO} 2$ glass. New insight into site significance in silicate glasses. EPL Europhys Lett 49:597. doi: 10.1209/epl/i2000-00192-1

305. Leonteva A (1940) Measurements of the viscosity of obsidian and of hydrated glasses. Izv Akad Nauk SSSR Ser Geol 2:44-54.

306. Saucier H (1952) Quelques expériences sur la viscosité à haute température de verres ayant la composition d'un granite. Influence de la vapeur d'eau sous pression. Bull Société Fr Minéralogie Cristallogr 75:1-45.

307. Friedman I, Long W, Smith RL (1963) Viscosity and water content of rhyolite glass. J Geophys Res 68:6523-6535.

308. Shaw HR (1963) Obsidian-H2O viscosities at 1000 and 2000 bars in the tempearture range $700^{\text {lcirc\$ }}$ to $900^{\text {lcirc\$ }}$ C. J Geophys Res 68:6337-6343.

309. Dingwell DB, Romano C, Hess K-U (1996) The effect of water on the viscosity of a haplogranitic melt under P-T-X conditions relevant to silicic volcanism. Contrib Mineral Petrol 124:19-28. doi: 10.1007/s004100050170

310. Richet P, Lejeune A-M, Holtz F, Roux J (1996) Water and the viscosity of andesite melts. Chem Geol 128:185-197. doi: 10.1016/0009-2541(95)00172-7

311. Richet P, Polian A (1998) Water as a Dense Icelike Component in Silicate Glasses. Science 281:396-398. doi: 10.1126/science.281.5375.396

312. Ochs FA, Lange RA (1999) The Density of Hydrous Magmatic Liquids. Science 283:13141317. doi: 10.1126/science.283.5406.1314

313. Richet P, Whittington A, Holtz F, Behrens H, Ohlhorst S, Wilke M (2000) Water and the density of silicate glasses. Contrib Mineral Petrol 138:337-347.

314. Malfait WJ, Seifert R, Petitgirard S, Mezouar M, Sanchez-Valle C (2014) The density of andesitic melts and the compressibility of dissolved water in silicate melts at crustal and upper mantle conditions. Earth Planet Sci Lett 393:31-38. doi: 10.1016/j.epsl.2014.02.042

315. Malfait WJ, Seifert R, Petitgirard S, Perrillat J-P, Mezouar M, Ota T, Nakamura E, Lerch P, Sanchez-Valle C (2014) Supervolcano eruptions driven by melt buoyancy in large silicic magma chambers. Nat Geosci 7:122-125. doi: 10.1038/ngeo2042

316. Andújar J, Scaillet B (2012) Relationships between pre-eruptive conditions and eruptive styles of phonolite-trachyte magmas. Lithos 152:122-131. doi: 10.1016/j.lithos.2012.05.009 
Le Losq, Cicconi, Greaves, Neuville. Silicate Glasses. In: Springer Handbook of Glass.

317. Le Losq C, Neuville DR, Moretti R, Kyle PR, Oppenheimer C (2015) Rheology of phonolitic magmas - the case of the Erebus lava lake. Earth Planet Sci Lett 411:53-61. doi:

10.1016/j.epsl.2014.11.042

318. Luongo G, Perrotta A, Scarpati C (2003) Impact of the AD 79 explosive eruption on Pompeii, I. Relations amongst the depositional mechanisms of the pyroclastic products, the framework of the buildings and the associated destructive events. J Volcanol Geotherm Res 126:201-223. doi: 10.1016/S0377-0273(03)00146-X

319. Luongo G, Perrotta A, Scarpati C, De Carolis E, Patricelli G, Ciarallo A (2003) Impact of the AD 79 explosive eruption on Pompeii, II. Causes of death of the inhabitants inferred by stratigraphic analysis and areal distribution of the human casualties. J Volcanol Geotherm Res 126:169-200. doi: 10.1016/S0377-0273(03)00147-1

320. Balcone-Boissard H, Boudon G, Villemant B (2011) Textural and geochemical constraints on eruptive style of the 79 AD eruption at Vesuvius. Bull Volcanol 73:279-294.

321. Shea T, Hellebrand E, Gurioli L, Tuffen H (2014) Conduit- to Localized-scale Degassing during Plinian Eruptions: Insights from Major Element and Volatile $(\mathrm{Cl}$ and $\mathrm{H} 2 \mathrm{O})$ Analyses within Vesuvius ad 79 Pumice. J Petrol 55:315-344. doi: 10.1093/petrology/egt069

322. Dingwell DB (1996) Volcanic Dilemma - Flow or Blow? Science 273:1054-1055. doi: 10.1126/science. 273.5278 .1054

323. Papale P (1999) Strain-induced magma fragmentation in explosive eruptions. Nature 397:425428. doi: $10.1038 / 17109$

324. Zhang Y (1999) A criterion for the fragmentation of bubbly magma based on brittle failure theory. Nature 402:648-650. doi: 10.1038/45210

325. Scholze H (1960) Zur Frage der unterscheidung zwischen H20-Molekeln und OH-gruppen in gläsern und mineralen. Naturwissenschaften 47:226-227.

326. Moulson AJ (1958) Entry of Water into Silica Glass. Nature 182:200-201.

327. Moulson AJ, Roberts JP (1961) Water in silica glass. Trans Faraday Soc 57:1208-1216.

328. Bartholomew RF, Butler BL, Hoover HL, Wu CK (1980) Infrared Spectra of a WaterContaining Glass. J Am Ceram Soc 63:481-485. doi: 10.1111/j.1151-2916.1980.tb10748.x

329. Mysen BO, Virgo D, Harrison WJ, Scarfe CM (1980) Solubility mechanisms of $\mathrm{H}_{2} \mathrm{O}$ in silicate melts at high pressures and temperatures: a Raman spectroscopy study. Am Mineral 65:900-914.

330. Stolper A (1982) Water in silicate glasses: An infrared spectroscopic study. Contrib Mineral Petrol 81:1-17.

331. Mysen BO, Virgo D (1986) Volatiles in silicate melts at high pressure and temperature 1. Interaction between $\mathrm{OH}$ groups and $\mathrm{Si}^{4+\$}, \mathrm{Al}^{3+\$}, \mathrm{Ca}^{2+\$}, \mathrm{Na}^{+}$and $\mathrm{H}^{+}$. Chem Geol 57:303-331.

332. McMillan P, Remmele RLJ (1986) Hydroxylsites in $\mathrm{SiO}_{2}$ glass: A note on infrared and Raman spectra. Am Mineral 71:772-778. 
Le Losq, Cicconi, Greaves, Neuville. Silicate Glasses. In: Springer Handbook of Glass.

333. Mysen BO, Virgo D (1986) Volatiles in silicate melts at high pressure and temperature 2. Water in melts alon the join $\mathrm{NaAlO}_{2}-\mathrm{SiO}_{2}$ and a comparison of solubility mechanisms of water and fluorine. Chem Geol 57:333-358.

334. Kohn SC, Dupree R, Smith ME (1989) Proton environments and hydrogen-bonding in hydrous silicate glasses from proton NMR. Nature 337:539-541.

335. Kohn SC, Dupree R, Smith ME (1989) A multinuclear magnetic resonance study of the structure of hydrous albite glass. Geochim Cosmochim Acta 53:2925-2935.

336. Davis KM, Tomozawa M (1996) An infrared spectroscopic study of water-related species in silica glasses. J Non-Cryst Solids 201:177-198.

337. Schmidt BC, Behrens H, Riemer T, Kappes R, Dupree R (2001) Quantitative determination of water speciation in aluminosilicate glasses: a comparative NMR and IR spectroscopic study. Chem Geol 174:195-208.

338. Cody GD, Mysen BO, Lee SK (2005) Structure vs. composition: A solid-state ${ }^{29 \$} \mathrm{Si}$ NMR study of quenched glasses along the $\mathrm{Na}_{2} \mathrm{O}-\mathrm{SiO}_{2}-\mathrm{H}_{2} \mathrm{O}$ join. Geochim Cosmochim Acta 69:2373-2384.

339. Mysen $\mathrm{BO}$ (2007) The solution behavior of $\mathrm{H}_{2} \mathrm{O}$ in peralkaline aluminosilicate melts at high pressure with implications for properties of hydrous melts. Geochim Cosmochim Acta 71:18201834. doi: 10.1016/j.gca.2007.01.007

340. Malfait WJ, Xue X (2010) The nature of hydroxyl groups in aluminosilicate glasses: Quantifying $\mathrm{Si}-\mathrm{OH}$ and $\mathrm{Al}-\mathrm{OH}$ abundances along the $\mathrm{SiO}^{27 \$} \mathrm{Al}-{ }^{29 \$} \mathrm{Si}-\$ \wedge 1 \$ \mathrm{H}$ NMR spectroscopy. Geochim Cosmochim Acta 74:719-737.

341. Le Losq C, Cody GD, Mysen BO (2015) Alkali influence on the water speciation and the environment of protons in silicate glasses revealed by $1 \mathrm{H}$ MAS NMR spectroscopy. Am Mineral 100:466-473. doi: 10.2138/am-2015-5004

342. Nowak M, Behrens H (1995) The speciation of water in haplogranitic glasses and melts determined by in situ near-infrared spectroscopy. Geochim Cosmochim Acta 59:3445-3450.

343. Sowerby JR, Keppler H (1999) Water speciation in rhyolitic melt determined by in-situ infrared spectroscopy. Am Mineral 84:1843-1849.

344. Behrens H, Yamashita S (2008) Water speciation in hydrous sodium tetrasilicate and hexasilicate melts: Constraint from high temperature NIR spectroscopy. Chem Geol 256:306-315.

345. Chertkova N, Yamashita S (2015) In situ spectroscopic study of water speciation in the depolymerized Na2Si2O5 melt. Chem Geol 409:149-156. doi: 10.1016/j.chemgeo.2015.05.012

346. Silver LA, Ihinger PD, Stolper E (1990) The influence of bulk composition on the speciation of water in silicate glasses. Contrib Mineral Petrol 104:142-162. doi: 10.1007/BF00306439

347. Ohlhorst S, Behrens H, Holtz F (2001) Compositional dependence of molar absorptivities of near-infrared $\mathrm{OH}-$ and $\mathrm{H} 2 \mathrm{O}$ bands in rhyolitic to basalitic glasses. Chem Geol 174:5-20. 
Le Losq, Cicconi, Greaves, Neuville. Silicate Glasses. In: Springer Handbook of Glass.

348. Le Losq C, Moretti R, Neuville DR (2013) On the speciation and amphoteric behavior of water in aluminosilicate melts and glasses: High-Temperature Raman spectroscopy and reaction equilibria. Eur J Mineral 25:777-790. doi: http://dx.doi.org/10.1127/0935-1221/2013/0025-2322

349. Deubener J, Müller R, Behrens H, Heide G (2003) Water and the glass transition temperature of silicate melts. J Non-Cryst Solids 330:268-273.

350. Xue X, Kanzaki M (2004) Dissolution mechanisms of water in depolymerized silicate melts: Constraints from ${ }^{29} \mathrm{Si}$ NMR spectroscopy and ab initio calculations. Geochim Cosmochim Acta 68:5027-5057.

351. Xue X, Kanzaki M (2006) Depolymerization effect of water in aluminosilicate glasses: Direct evidence from ${ }^{27 \$} \mathrm{Al}$ heteronuclear correlation NMR. Am Mineral 91:1922-1926.

352. Xue X, Kanzaki M (2008) Structure of hydrous aluminosilicate glasses along the diopsideanorthite join: A comprehensive one- and two-dimensional 1H and 27Al NMR study. Geochim Cosmochim Acta 72:2331-2348. doi: 10.1016/j.gca.2008.01.022

353. Mysen $\mathrm{BO}$, Cody $\mathrm{G}$ (2005) Solution mechanisms of $\mathrm{H}_{2} \mathrm{O}$ in depolymerozed peralkaline melts. Geochim Cosmochim Acta 69:5557-5566.

354. Mookherjee M, Stixrude L, Karki B (2008) Hydrous silicate melt at high pressure. Nature 452:983-986. doi: 10.1038/nature06918

355. Kohn SC, Dupree R, Mortuza MG (1992) The interaction between water and aluminosilicate magmas. Chem Geol 96:399-409.

356. Kohn SC, Smith ME, Dirken PJ, Van Eck ERH, Kentgens APM, Dupree R (1998) Sodium environment in dry and hydrous albite glasses: Improved ${ }^{23 \$} \mathrm{Na}$ solid state NMR data and their implications for water dissolution mechanisms. Geochim Cosmochim Acta 62:79-87.

357. Whittington AG, Bouhifd MA, Richet $\mathrm{P}$ (2009) The viscosity of hydrous $\mathrm{NaAlSi}_{3} \mathrm{O}_{8}$ and granitic melts: Configurational entropy models. Am Mineral 94:1-16.

358. Xue X (2009) Water speciation in hydrous silicate and aluminosilicate glasses: Direct evidence from ${ }^{29 \$} \mathrm{Si}^{27 \$} \mathrm{Al}-\$ \wedge 1 \$ \mathrm{H}$ double-resonance NMR. Am Mineral 94:395-398.

359. Malfait WJ, Xue X (2014) Hydroxyl speciation in felsic magmas. Geochim Cosmochim Acta 140:606-620. doi: 10.1016/j.gca.2014.05.017

360. Bouhifd MA, Whittington AG, Richet P (2015) Densities and volumes of hydrous silicate melts: New measurements and predictions. Chem Geol 418:40-50. doi:

10.1016/j.chemgeo.2015.01.012

361. Mercier M, Muro AD, Métrich N, Giordano D, Belhadj O, Mandeville CW (2010) Spectroscopic analysis (FTIR, Raman) of water in mafic and intermediate glasses and glass inclusions.

Geochim Cosmochim Acta 74:5641-5656. doi: 10.1016/j.gca.2010.06.020 
Le Losq, Cicconi, Greaves, Neuville. Silicate Glasses. In: Springer Handbook of Glass.

362. Le Losq C, Neuville DR, Moretti R, Roux J (2012) Determination of water content in silicate glasses using Raman spectrometry: Implications for the study of explosive volcanism. Am Mineral 97:779-790. doi: 10.2138/am.2012.3831

363. Bouhifd MA, Whittington A, Roux J, Richet P (2006) Effect of water on the heat capacity of polymerized aluminosilicate glasses and melts. Geochim Cosmochim Acta 70:711-722. doi: 10.1016/j.gca.2005.09.012

364. Bouhifd MA, Whittington AG, Withers AC, Richet P (2013) Heat capacities of hydrous silicate glasses and liquids. Chem Geol 346:125-134. doi: 10.1016/j.chemgeo.2012.10.026

365. Papale P, Moretti R, Barbato D (2006) The compositional dependence of the saturation surface of $\mathrm{H}_{2} \mathrm{O}+\mathrm{CO}_{2}$ fluids in silicate melts. Chem Geol 229:78-95.

366. Ni H, Keppler H (2013) Carbon in Silicate Melts. Rev Mineral Geochem 75:251-287. doi: 10.2138/rmg.2013.75.9

367. Guillot B, Sator N (2011) Carbone dioxide in silicate melts: a molecular dynamics simulation study. Geochim Cosmochim Acta 75:1829-1857.

368. Pedeche S, Simon P, Matzen G, Moulin B, Blanchard K, Querel G (2003) Probing gas bubbles inside industrial glasses by Raman scattering. J Raman Spectrosc 34:248-252. doi: $10.1002 /$ jrs. 984

369. Morizet Y, Brooker RA, Iacono-Marziano G, Kjarsgaard BA (2013) Quantification of dissolved CO2 in silicate glasses using micro-Raman spectroscopy. Am Mineral 98:1788-1802. doi: $10.2138 / \mathrm{am} .2013 .4516$

370. Mysen BO, Virgo D (1980) The solubility behavior of CO2 in melts on the join NaAlSi3O8CaA12Si2O8-CO2 at high pressures and temperatures: a Raman spectroscopic study. Am Mineral 65:1166-1175.

371. Dasgupta R, Mallik A, Tsuno K, Withers AC, Hirth G, Hirschmann MM (2013) Carbon-dioxiderich silicate melt in the Earth/'s upper mantle. Nature 493:211-215. doi: 10.1038/nature11731

372. Brooker RA, Kohn SC, Holloway JR, McMillan PF, Carroll MR (1999) Solubility, speciation and dissolution mechanisms for $\mathrm{CO} 2$ in melts on the $\mathrm{NaAlO} 2-\mathrm{SiO} 2$ join. Geochim Cosmochim Acta 63:3549-3565. doi: 10.1016/S0016-7037(99)00196-9

373. Verweij H, Van Den Boom H, Breemer RE (1977) Raman scattering of carbonate ions dissolved in potassium silicate glasses. J Am Ceram Soc 60:529-534.

374. Sharma SK (1979) Structure and solubility of carbon dioxide in silicate glasses of diopside and sodium melilite compositions at high pressures from Raman spectroscopic data. Carnegie Inst Wash Year b 78:532-537.

375. Mysen BO, Virgo D (1980) Solubility mechanisms of carbon dioxide in silicate melts: a Raman spectroscopic study. Am Mineral 65:885-899. 
Le Losq, Cicconi, Greaves, Neuville. Silicate Glasses. In: Springer Handbook of Glass.

376. Rai CS, Sharma SK, Muenow DW, Matson DW, Byers CD (1983) Temperature dependence of $\mathrm{CO} 2$ solubility in high pressure quenched glasses of diopside composition. Geochim Cosmochim Acta 47:953-958.

377. Burke EAJ, Lustenhouwer WJ (1987) The application of a multichannel laser Raman microprobe (Microdil-28®) to the analysis of fluid inclusions. Chem Geol 61:11-17.

378. Nakano S, Moritoki M, Ohgaki K (1998) High-Pressure Phase Equilibrium and Raman Microprobe Spectroscopic Studies on the CO2 Hydrate System. J Chem Eng Data 43:807-810. doi: $10.1021 /$ je9800555

379. Brooker RA, Kohn SC, Holloway JR, McMillan PF (2001) Structural controls on the solubility of CO2 in silicate melts: Part II: IR characteristics of carbonate groups in silicate glasses. Chem Geol 174:241-254. doi: 10.1016/S0009-2541(00)00318-1

380. Konschak A, Keppler H (2014) The speciation of carbon dioxide in silicate melts. Contrib Mineral Petrol 167:998. doi: 10.1007/s00410-014-0998-2

381. Bourgue E, Richet P (2001) The effects of dissolved CO2 on the density and viscosity of silicate melts: a preliminary study. Earth Planet Sci Lett 193:57-68. doi: 10.1016/S0012$821 \mathrm{X}(01) 00491-5$

382. Ghosh S, Ohtani E, Litasov K, Suzuki A, Sakamaki T (2007) Stability of carbonated magmas at the base of the Earth's upper mantle. Geophys Res Lett 34:L22312. doi: 10.1029/2007GL031349

383. Liu Q, Lange RA (2003) New density measurements on carbonate liquids and the partial molar volume of the $\mathrm{CaCO} 3$ component. Contrib Mineral Petrol 146:370-381. doi: 10.1007/s00410003-0505-7

384. Kot WK, Gan H, Pegg IL Sulfur incorporation in waste glass melts of various compositions. In: Environ. Issues Waste Manag. Technol. pp 441-449

385. Métrich N, Mandeville CW (2010) Sulfur in Magmas. Elements 6:81-86. doi: 10.2113/gselements.6.2.81

386. Paris E, Giuli G, Carroll MR (2001) paris-CM-01-39-331.pdf. Can Mineral 39:331-339.

387. Bonnin-Mosbah M, Métrich N, Susini J, Salome M, Massare D, Menez B (2002) Micro X-ray absorption near edge structure at the sulfur and iron K-edges in natural silicate glasses. Spectrochim Acta Part B At Spectrosc 57:711-725.

388. McKeown D., Muller I., Gan H, Pegg I., Stolte W. (2004) Determination of sulfur environments in borosilicate waste glasses using X-ray absorption near-edge spectroscopy. J Non-Cryst Solids 333:74-84. doi: 10.1016/j.jnoncrysol.2003.09.035

389. Fleet ME (2005) XANES SPECTROSCOPY OF SULFUR IN EARTH MATERIALS. Can Mineral 43:1811-1838.

390. Wilke M, Jugo PJ, Klimm K, Susini J, Botcharnikov R, Kohn SC, Janousch M (2008) The origin of S4+ detected in silicate glasses by XANES. Am Mineral 93:235-240. doi:

10.2138/am.2008.2765 
Le Losq, Cicconi, Greaves, Neuville. Silicate Glasses. In: Springer Handbook of Glass.

391. McKeown DA, Muller IS, Gan H, Pegg IL, Kendziora CA (2001) Raman studies of sulfur in borosilicate waste glasses: sulfate environments. J Non-Cryst Solids 288:191-199.

392. Manara D, Grandjean A, Pinet O, Dussossoy JL, Neuville DR (2007) Sulfur behavior in silicate glasses and melts: Implications for sulfate incorporation in nuclear waste glasses as a function of alkali cation and V2O5 content. J Non-Cryst Solids 353:12-23. doi:

10.1016/j.jnoncrysol.2006.09.041

393. Lenoir M, Grandjean A, Poissonnet S, Neuville DR (2009) Quantitation of sulfate solubility in borosilicate glasses using Raman spectroscopy. J Non-Cryst Solids 355:1468-1473. doi:

10.1016/j.jnoncrysol.2009.05.015

394. Klimm K, Botcharnikov RE (2015) The determination of sulfate and sulfide species in hydrous silicate glasses using Raman spectroscopy. Am Mineral 95:1574-1579. doi: 10.2138/am.2010.3590

395. Klimm K, Kohn SC, O’Dell LA, Botcharnikov RE, Smith ME (2012) The dissolution mechanism of sulphur in hydrous silicate melts. I: Assessment of analytical techniques in determining the sulphur speciation in iron-free to iron-poor glasses. Chem Geol 322-323:237249. doi: 10.1016/j.chemgeo.2012.04.027

396. Baker DR, Moretti R (2011) Modeling the Solubility of Sulfur in Magmas: A 50-Year Old Geochemical Challenge. Rev Mineral Geochem 73:167-213. doi: 10.2138/rmg.2011.73.7

397. O’Neill HSC, Mavrogenes JA (2002) The Sulfide Capacity and the Sulfur Content at Sulfide Saturation of Silicate Melts at $1400^{\circ} \mathrm{C}$ and 1 bar. J Petrol 43:1049-1087. doi: 10.1093/petrology/43.6.1049

398. Liu Y, Samaha N-T, Baker DR (2007) Sulfur concentration at sulfide saturation (SCSS) in magmatic silicate melts. Geochim Cosmochim Acta 71:1783-1799. doi:

10.1016/j.gca.2007.01.004

399. Wykes JL, O'Neill HSC, Mavrogenes JA (2015) The Effect of FeO on the Sulfur Content at Sulfide Saturation (SCSS) and the Selenium Content at Selenide Saturation of Silicate Melts. J Petrol 56:1407-1424. doi: 10.1093/petrology/egv041

400. Moretti R, Papale P, Ottonello G (2003) A model for the saturation of C-O-H-S fluids in silicate melts. Geol Soc Lond Spec Publ 213:81-101. doi: 10.1144/GSL.SP.2003.213.01.06

401. Moretti R, Ottonello G (2005) Solubility and speciation of sulfur in silicate melts: The Conjugated Toop-Samis-Flood-Grjotheim (CTSFG) model. Geochim Cosmochim Acta 69:801823. doi: 10.1016/j.gca.2004.09.006

402. Aiuppa A, Baker DR, Webster JD (2009) Halogens in volcanic systems. Chem Geol 263:1-18. doi: 10.1016/j.chemgeo.2008.10.005

403. Butov OV, Golant KM, Tomashuk AL, van Stralen MJN, Breuls AHE (2002) Refractive index dispersion of doped silica for fiber optics. Opt Commun 213:301-308. doi: 10.1016/S00304018(02)02087-4 
Le Losq, Cicconi, Greaves, Neuville. Silicate Glasses. In: Springer Handbook of Glass.

404. Kakiuchida H, Sekiya EH, Shimodaira N, Saito K, Ikushima AJ (2007) Refractive index and density changes in silica glass by halogen doping. J Non-Cryst Solids 353:568-572. doi: 10.1016/j.jnoncrysol.2006.10.025

405. Zeng Q, Stebbins JF (2000) Fluoride sites in aluminosilicate glasses: High-resolution 19F NMR results. Am Mineral 85:863-867.

406. Mysen BO, Cody GD, Smith A (2004) Solubility mechanisms of fluorine in peralkaline and meta-aluminous silicate glasses and in melts to magmatic temperatures1. Geochim Cosmochim Acta 68:2745-2769. doi: 10.1016/j.gca.2003.12.015

407. Kiczenski TJ, Du L-S, Stebbins JF (2004) F-19 NMR study of the ordering of high field strength cations at fluoride sites in silicate and aluminosilicate glasses. J Non-Cryst Solids 337:142-149. doi: $10.1016 /$ j.jnoncrysol.2004.03.123

408. Kiczenski TJ, Stebbins JF (2006) The Effect of Fictive Temperature on the Structural Environment of Fluorine in Silicate and Aluminosilicate Glasses. J Am Ceram Soc 89:57-64. doi: 10.1111/j.1551-2916.2005.00677.x

409. Baasner A, Schmidt BC, Dupree R, Webb SL (2014) Fluorine speciation as a function of composition in peralkaline and peraluminous $\mathrm{Na} 2 \mathrm{O}-\mathrm{CaO}-\mathrm{A} 12 \mathrm{O} 3-\mathrm{SiO} 2$ glasses: A multinuclear NMR study. Geochim Cosmochim Acta 132:151-169. doi: 10.1016/j.gca.2014.01.041

410. Dalou C, Le Losq C, Mysen BO, Cody GD (2015) Solubility and solution mechanisms of chlorine and fluorine in aluminosilicate melts at high pressure and high temperature. Am Mineral 100:2272-2283. doi: 10.2138/am-2015-5201

411. Baasner A, Schmidt BC, Webb SL (2013) Compositional dependence of the rheology of halogen $(\mathrm{F}, \mathrm{Cl})$ bearing aluminosilicate melts. Chem Geol 346:172-183. doi:

10.1016/j.chemgeo.2012.09.020

412. Stebbins JF, Du L-S (2002) Letters. Chloride ion sites in silicate and aluminosilicate glasses: A preliminary study by 35Cl solid-state NMR. Am Mineral 87:359-363.

413. Sandland TO, Du L-S, Stebbins JF, Webster JD (2004) Structure of Cl-containing silicate and aluminosilicate glasses: A 35Cl MAS-NMR study. Geochim Cosmochim Acta 68:5059-5069. doi: $10.1016 /$ j.gca.2004.07.017

414. Zimova M (2006) The effect of chlorine on the viscosity of Na2O-Fe2O3-A12O3-SiO2 melts. Am Mineral 91:344-352. doi: 10.2138/am.2006.1799

415. Evans KA, Mavrogenes JA, O’Neill HS, Keller NS, Jang L-Y (2008) A preliminary investigation of chlorine XANES in silicate glasses. Geochem Geophys Geosystems 9:Q10003. doi: $10.1029 / 2008 \mathrm{GC} 002157$

416. Baasner A, Hung I, Kemp TF, Dupree R, Schmidt BC, Webb SL (2014) Constraints on the incorporation mechanism of chlorine in peralkaline and peraluminous $\mathrm{Na} 2 \mathrm{O}-\mathrm{CaO}-\mathrm{A} 12 \mathrm{O} 3-\mathrm{SiO} 2$ glasses. Am Mineral 99:1713-1723. doi: 10.2138/am.2014.4717 
Le Losq, Cicconi, Greaves, Neuville. Silicate Glasses. In: Springer Handbook of Glass. 